The construction industry has a bad image. There seems a lack of quality in construction works at the time of delivery, and estimates of time and costs seem to be exceeded structurally, especially in public projects. Partially, this has to do with the increased complexity of construction projects. Therefore, procuring agencies and contractors feel the need to discuss all aspects of the project before closing a contract. Changes In pre-contractual negotiations were to decrease post-contractual renegotiations and to improve mutual commitment. With the Competitive Dialogue procedure, a public procurement method that was introduced in 2004, this need was met. Yet, the procedure is not proven effective.

This dissertation addresses the question how inter-organisational negotiations and commitments are interrelated, and what the effect is of using the competitive dialogue procedure. Based on a survey, a multiple-case study and an in-depth single case study, the author shows that understanding is the most important determinant for the development of negotiations and commitments in inter-organisational projects. Investment in creation of mutual understanding in early stages of project negotiations is likely to prevent renegotiations in later stages. The competitive dialogue could have a positive influence on the creation of mutual understanding, yet the research shows how several mechanisms of the procedure are currently counterproductive in realising that. The author proposes several measures to realise a more effective use of the competitive dialogue procedure.

\section{THE COMPETITIVE DIALOGUE PROCEDURE:}

NEGOTIATIONS AND COMMITMENT IN INTER-ORGANISATIONAL CONSTRUCTION PROJECTS

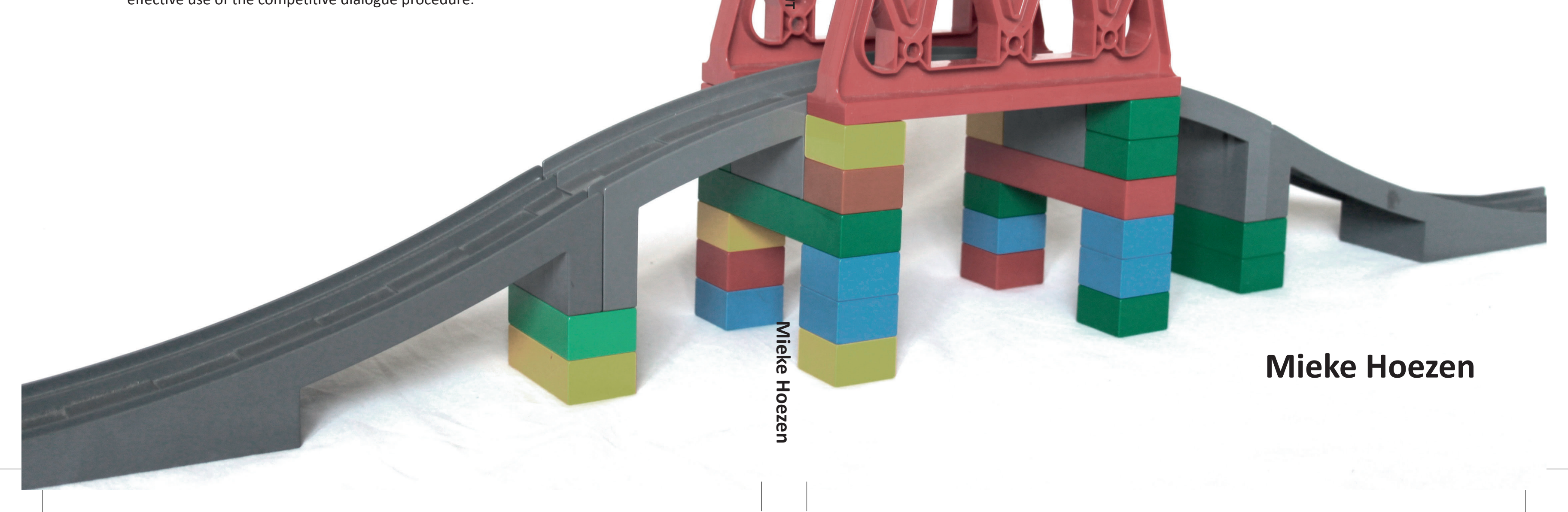


THE COMPETITIVE DIALOGUE PROCEDURE:

NEGOTIATIONS AND COMMITMENT

IN INTER-ORGANISATIONAL CONSTRUCTION PROJECTS 


\section{Graduation committee}

Chairman:

Prof. dr. ir. F. Eising

Prof. dr. ir. F. Eising

Prof. dr. G.P.M.R. Dewulf

Assistant promotor: Dr. J.T. Voordijk

Members:
Prof. dr. E.J.M.M. Arts

Prof. mr. C.E.C. Jansen

Dr. A. Kadefors

Prof. dr. ir. A.G. Dorée

Dr. M.J. van Riemsdijk
University of Twente

University of Twente

University of Twente

University of Twente

University of Groningen

VU University Amsterdam

Chalmers University

University of Twente

University of Twente 


\title{
THE COMPETITIVE DIALOGUE PROCEDURE: NEGOTIATIONS AND COMMITMENT IN INTER-ORGANISATIONAL CONSTRUCTION PROJECTS
}

\author{
DISSERTATION
}

to obtain

the degree of doctor at the University of Twente,

on the authority of the rector magnificus, prof. dr. H. Brinksma, on account of the decision of the graduation committee, to be publicly defended

on Friday the $22^{\text {nd }}$ of June 2012 at 14.45 hrs

by

Maria Elisabeth Louisa Hoezen

born on the $17^{\text {th }}$ of November 1980

in Eindhoven, the Netherlands 
This dissertation has been approved by:

Prof. dr. G.P.R.M. Dewulf

Dr. J.T. Voordijk
Promotor

Assistant promotor

ISBN: 978-90-365-3365-2

(C) Mieke Hoezen, Nijmegen, 2012

All rights reserved. No part of this publication may be reproduced or transmitted in any form or by any means, electronic or mechanical, including photocopying, recording or by any information storage and retrieval system, without prior written permission of the author.

English correction by Giles Stacey, Englishworks

Printed by Gildeprint Drukkerijen

Illustrations by Arjen Besselink, Jip Besselink and Tes Besselink

Design by Monique Burggraaf 


\section{Table of Contents}

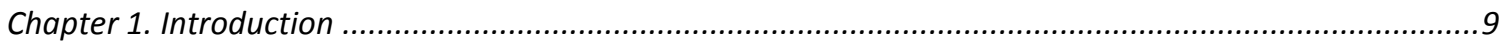

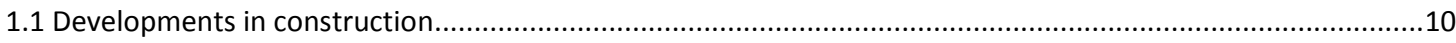

1.2 Response to developments: changes both in negotiations and in commitments .......................................11

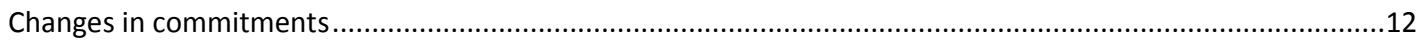

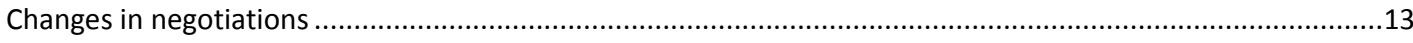

A new procurement procedure

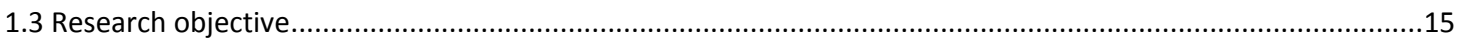

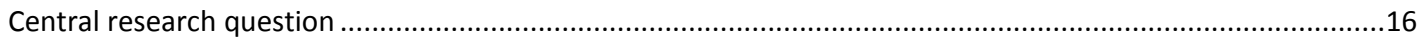

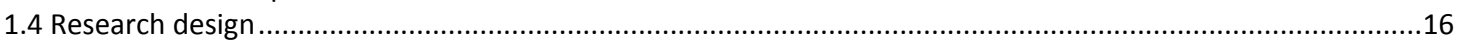

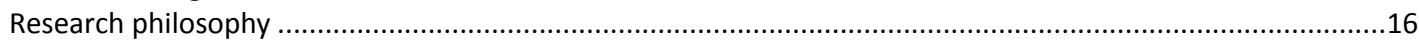

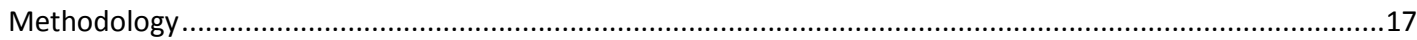

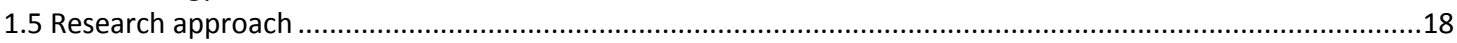

A. How are which components of negotiations and commitments playing a role

in inter-organisational projects? .....................................................................................................19

B. What is the influence of the CD procedure on negotiations and commitments? ..................................19

C. How do negotiations and commitments develop over time in a CD-procured construction project? ......21

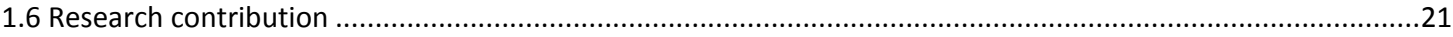

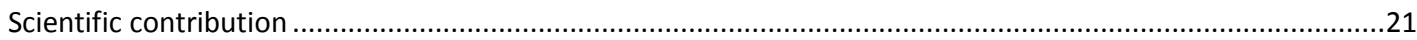

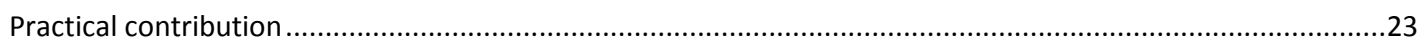

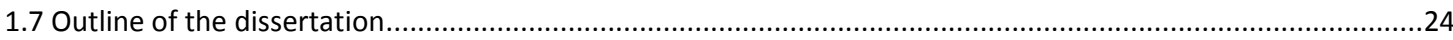

Chapter 2. Formal and informal negotiation and commitment in inter-organisational projects:

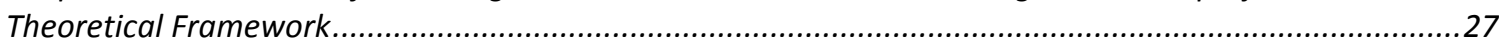

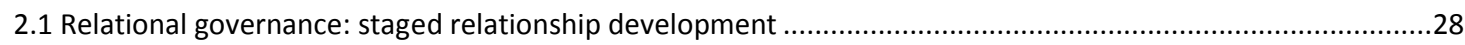

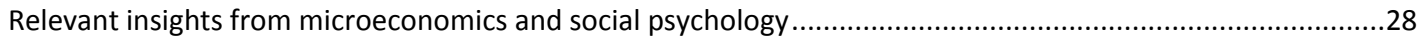

Ring and Van de Ven's process model of inter-organisational relationship development.................................29

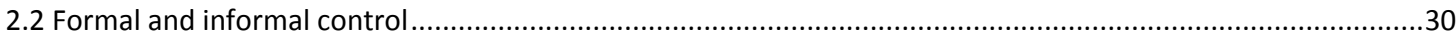

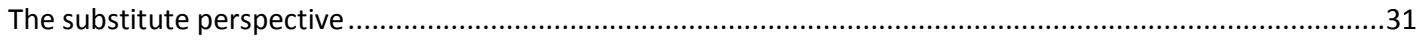

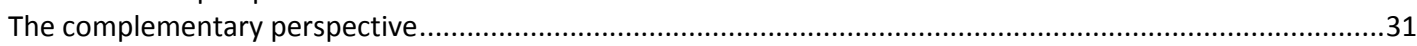

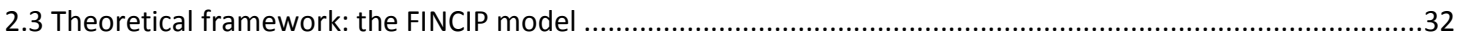

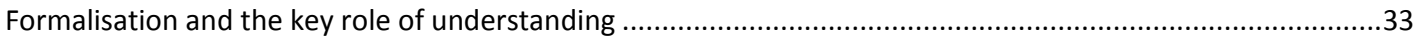

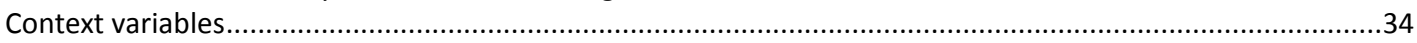

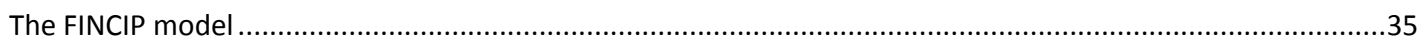

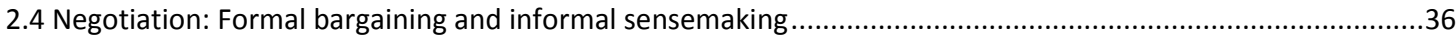

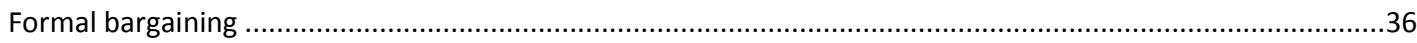

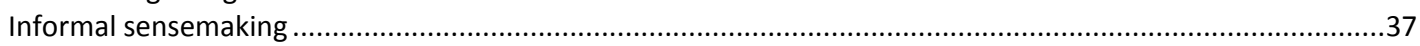

2.5 Commitment: Informal psychological contract and formal legal contract ....................................................38

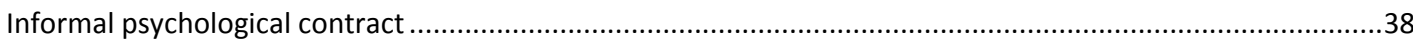

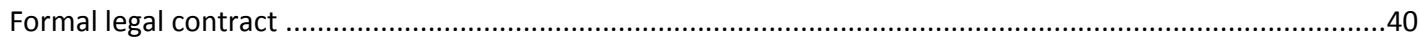

2.6 Understanding: link between negotiation and commitment .................................................................41

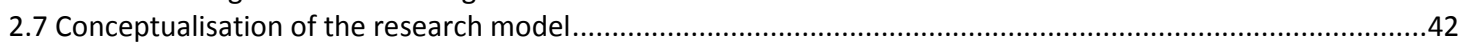

2.8 Propositions about the interrelatedness of negotiations and commitments ...............................................44

Chapter 3. Perceived influence of the CD procedure on negotiations and commitments .........................47

3.1 Design of the CD procedure: the European Commission's intended objectives ...............................................48

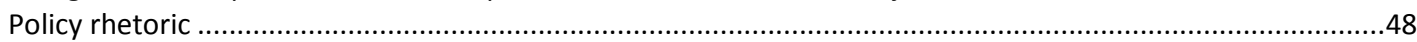

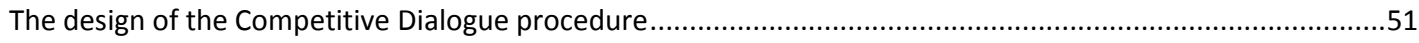

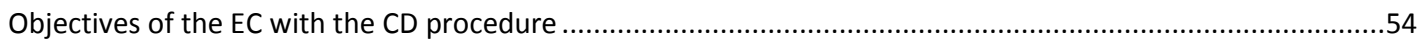

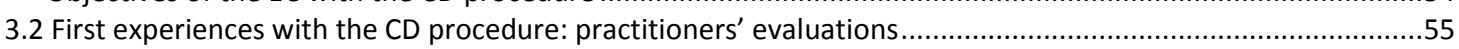

Ex ante evaluation of the CD procedure: Expert interview method ............................................................55

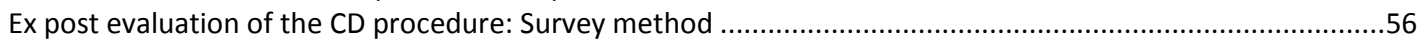

3.3 Perceived working of the CD procedure: twelve mechanisms and their effects ..........................................60

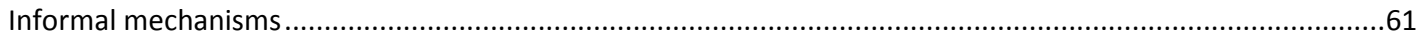

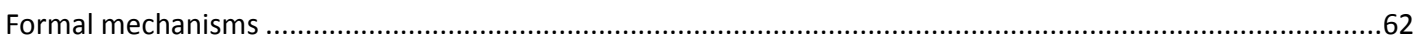

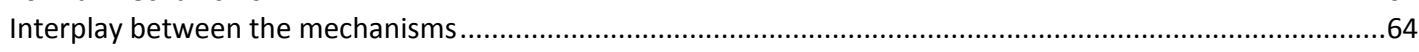

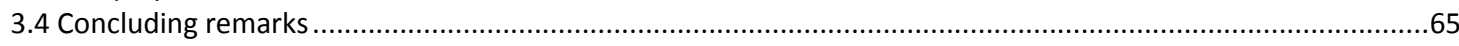

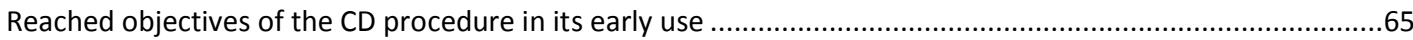

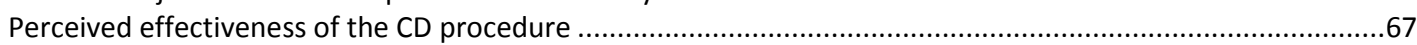


Chapter 4. Differences in negotiation and commitment between projects with and without the CD procedure: A multiple-case study

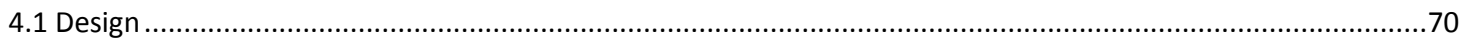

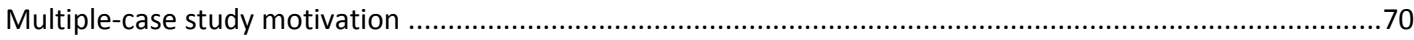

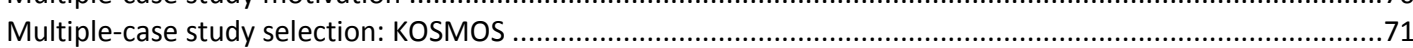

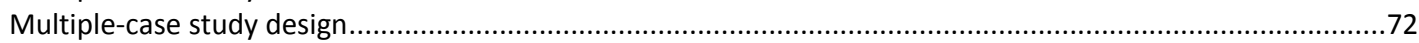

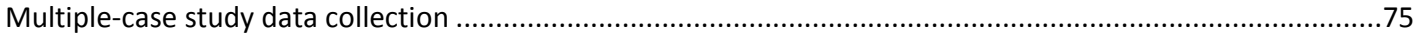

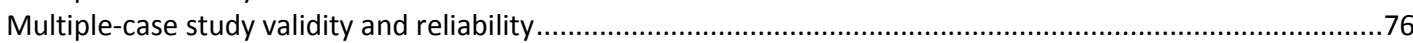

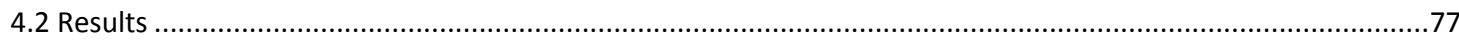

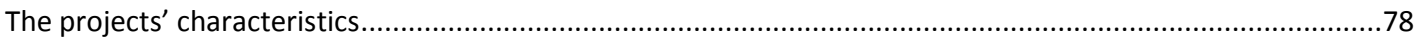

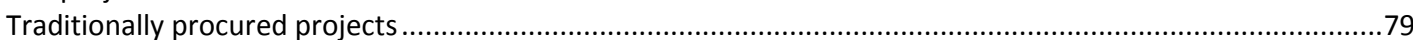

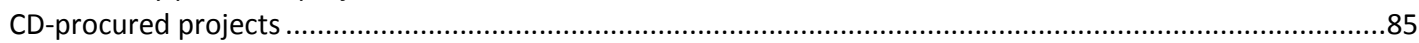

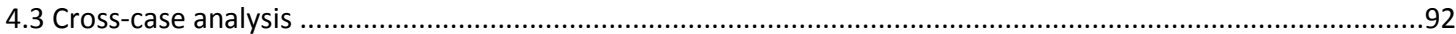

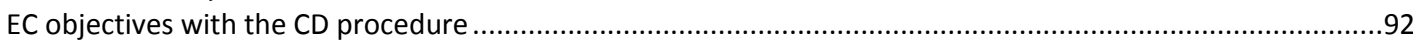

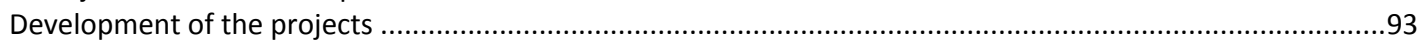

Differences in case development explained by the informants ..........................................................95

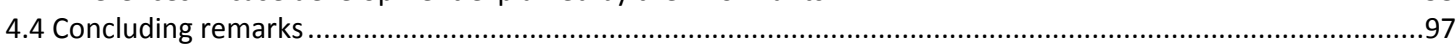

Finding further evidence for the propositions

concerning the influence of the CD procedure on the $\mathrm{EC}^{\prime}$ s objectives ..................................................97

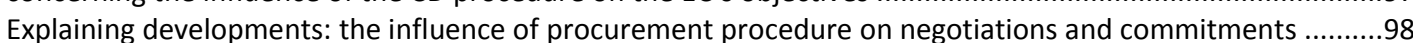

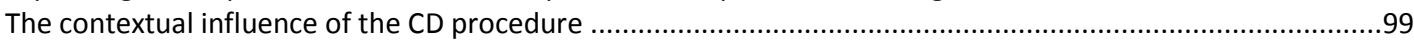

\section{Chapter 5. Development of negotiation and commitment in a CD procured project:}

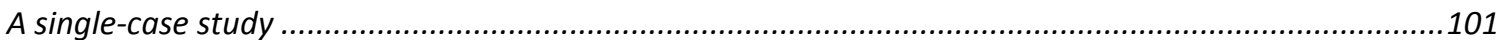

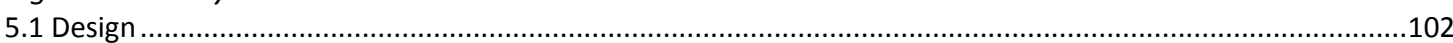

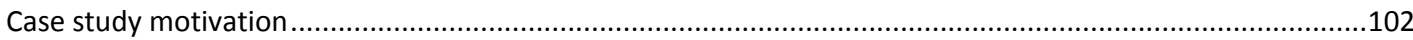

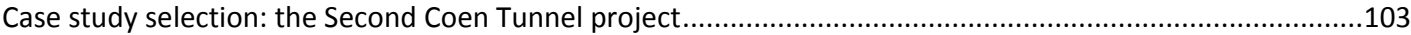

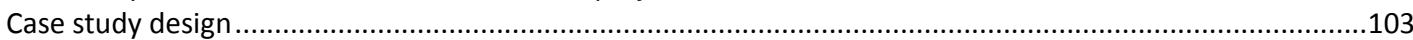

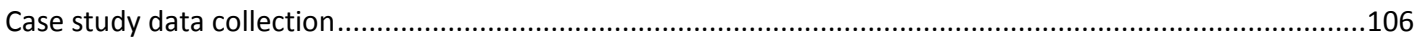

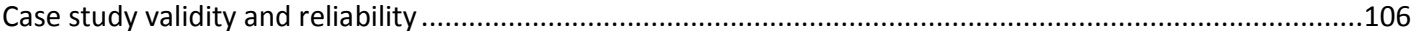

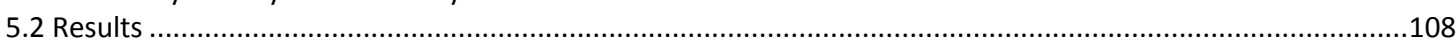

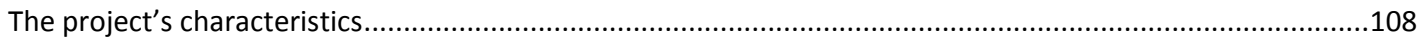

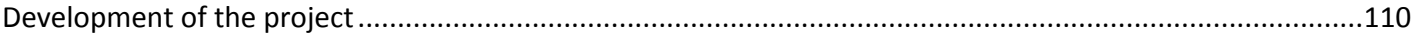

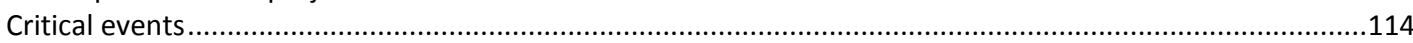

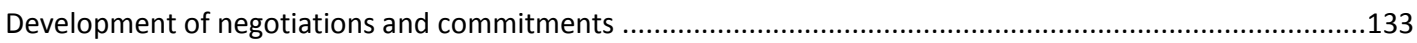

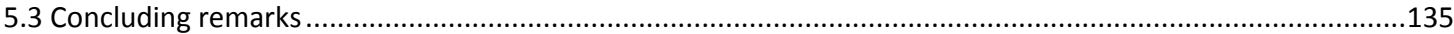

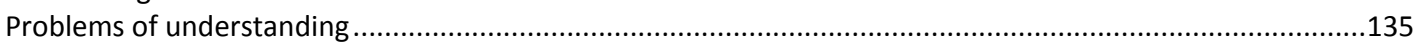

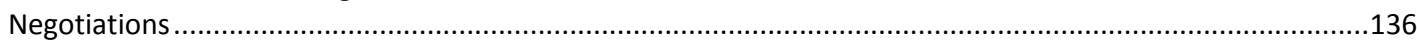

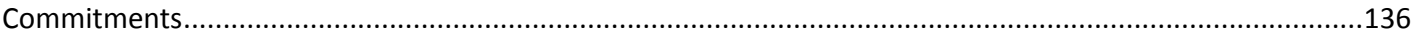

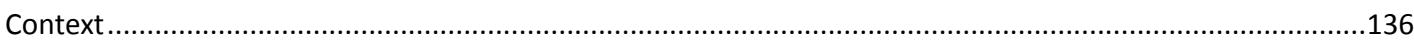

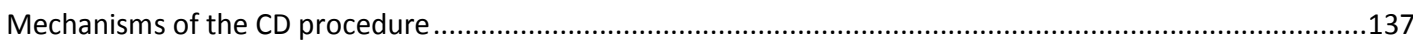

Chapter 6. Conclusion:

the CD procedure's impact on negotiations and commitments could be increased................................139

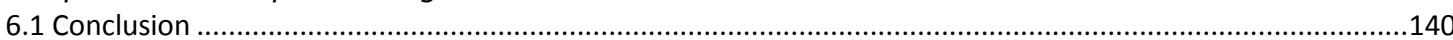

A. Components and development of negotiations and commitments conform the FINCIP model ............140

B. The influence of the $C D$ procedure on negotiations and commitments: mainly through sensemaking processes

C. Development of negotiations and commitments in a CD procured construction project:

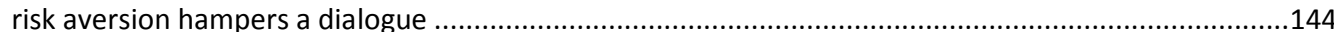

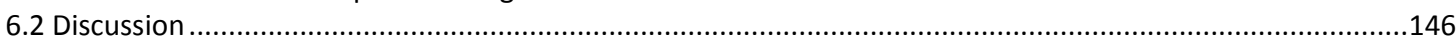

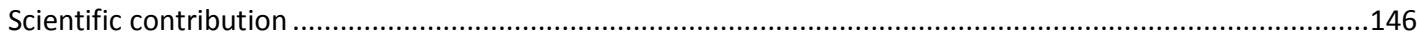

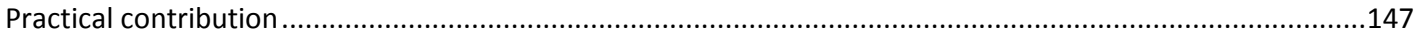

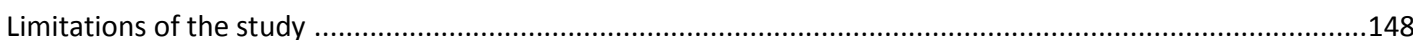

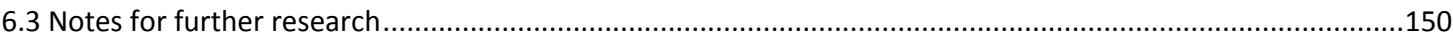


References

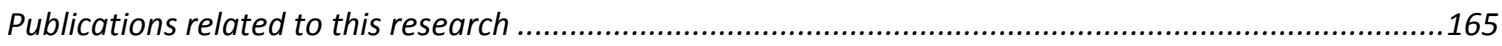

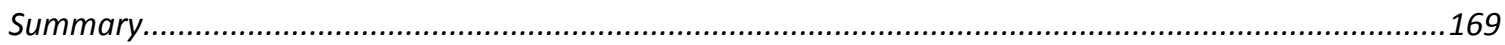

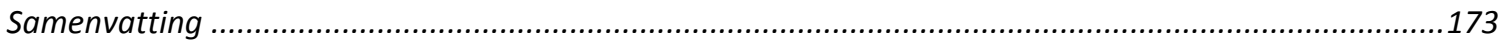

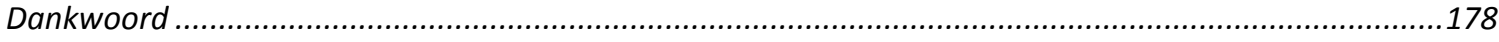

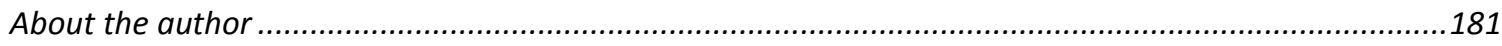

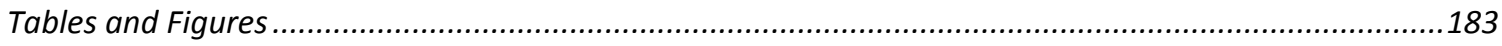

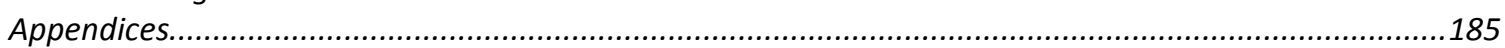

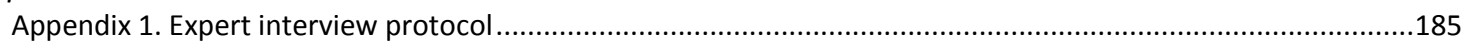

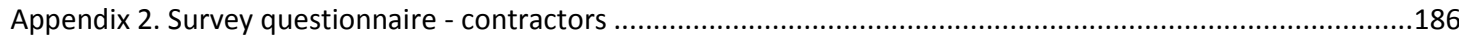

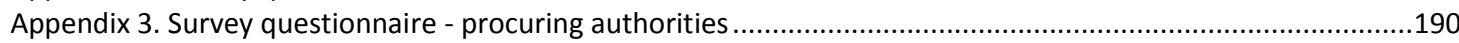

Appendix 4. Case study protocol KOSMOS projects with CD procedure ..........................................................194

Appendix 5. Case study protocol traditionally procured KOSMOS projects .......................................................196

Appendix 6. Case study protocol Dutch Highways and Waterways Agency .......................................................198

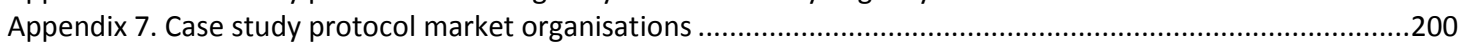

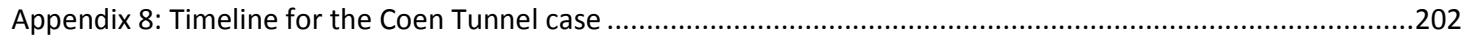




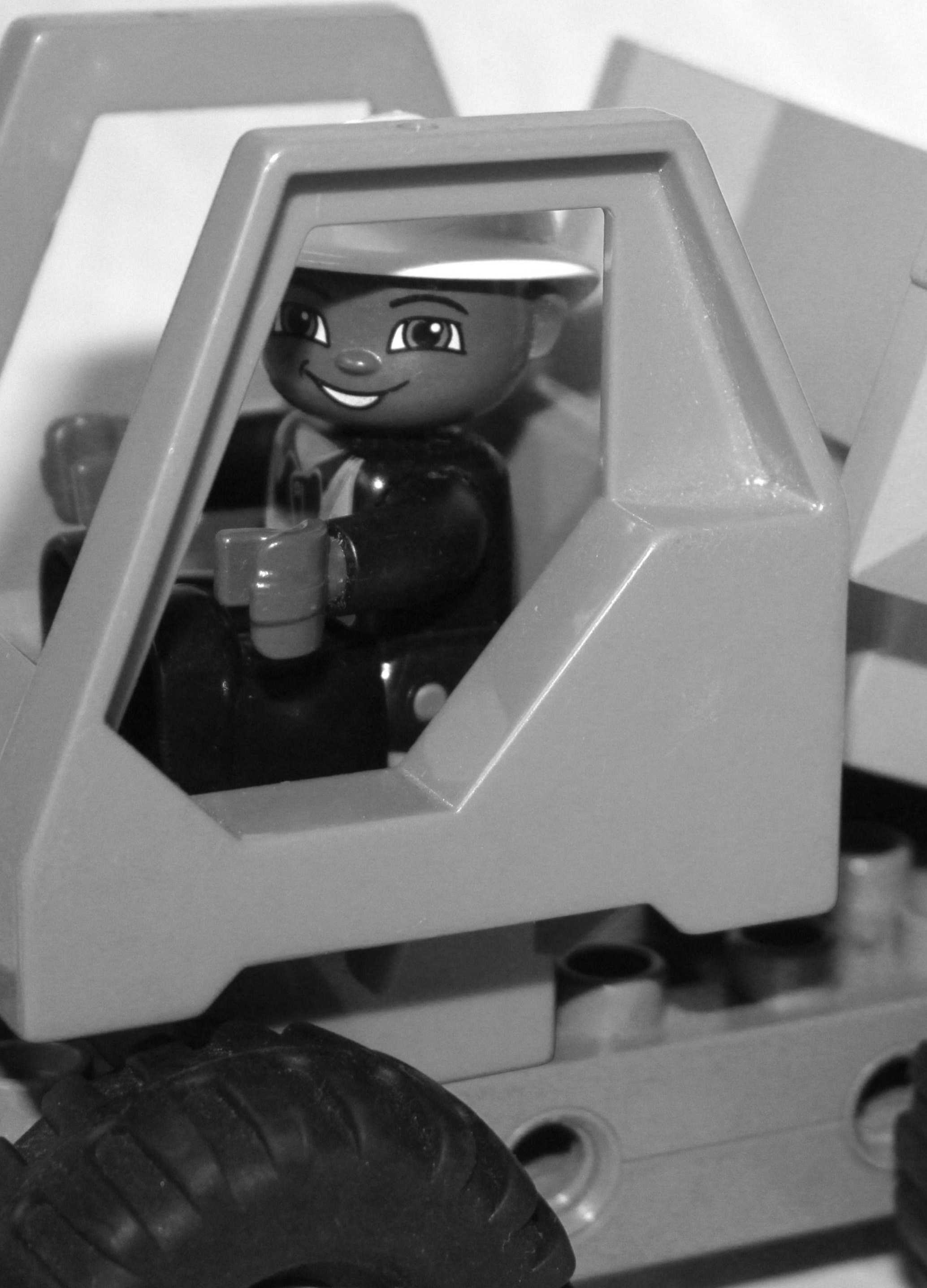




\section{Chapter 1. Introduction}

In the construction industry, several developments are driving changes. These developments include the increasing project complexity (Baccarini, 1996; Laufer, Denker \& Shanhar, 1996; Alderman, Ivory, McLoughlin \& Vaughan, 2005; Walker, 2007), changing government roles (Blanken, 2008) and the construction sector's poor professional functioning (Egan, 1998; National Audit Office, 2001). One of the responses to these developments was the introduction of the Competitive Dialogue (CD) procedure for the procurement of complex construction works.

The research described in this dissertation aims to provide insight in how interorganisational negotiations and commitments develop in the context of procurement by the $\mathrm{CD}$ procedure. As an introduction to the research, the current chapter gives the background of the research in a short overview of the relevant developments in the construction industry (Section 1.1) and the responses to these developments, including the introduction of the CD procedure (Section 1.2). Based on this, it is explained in Section 1.3 why research into inter-organisational negotiations and commitments within the CD procedure is needed. In the Sections 1.4 and 1.5 the design and approach to the research are described. After that, the scientific and practical contribution of this research are discussed (Section 1.6). The chapter concludes with an outline of the dissertation in Section 1.7. 


\subsection{Developments in construction}

Recent discussions indicate that construction projects have become progressively more complex, which has even led to linking the field of construction project management with chaos and complexity theories (Walker, 2007, p.51). Therefore, complexity has become an issue for the construction industry (Baccarini, 1996). From an historical context, Laufer et al. (1996) show that the 1960s were mainly about scheduling simple, definitive projects, the 1970 s about teamwork and integration, the 1980s about reducing uncertainty by flexibility in complex, uncertain projects, and the 1990s about simultaneity for complex, uncertain and quick projects. Although proper definitions of complexity are still lacking, academics do agree that construction projects are becoming larger; qualitative demands are increasing (for example in sustainability and architecture); time pressures are growing; the demands to restrict congestion and nuisance are getting louder; public expenses are watched more closely and, due to new developments, it is increasingly difficult to foresee all possible solutions to a problem (Alderman et al., 2005; Williamson, 1999).

Since complexity made it hard to determine the best technical solutions or to foresee contingencies, it became useful for public principals to involve contractors earlier in the construction process. Thus, contractors could become responsible for more tasks like the design or stakeholder communication. In the 1980s the organisation of the market also changed due to liberalisation, privatisation, autonomisation and deregulation. In those years, budget deficits increased and unemployment rates rose. The efficiency and effectiveness of governments were discussed, and it became an objective not to let the share of the public sector in the economy grow any further (Blanken, 2008). Moreover, it was an increasingly common opinion that government should leave those activities which could just as well, or even better, be carried out by the market (Dhonte, 1997; Linder, 1999; Ter Bogt, 1997). In this context, the increasing role of European procedures should be noted. Knill and Lenschow (2005) show how the rules of the European Commission that were meant to encourage strong competition in parts of the public sector, resulted in the transfer of tasks from the public sector to private organisations.

Yet, in the recent decades dissatisfaction with the functioning of the construction industry increased. Worldwide the construction sector has been characterised as fragmented, lacking client-orientation, non-innovative, unproductive, conflict-seeking and lacking transparency (Dorée, 2001; Egan, 1998; Emmerson, 1962; Latham, 1994; National Audit Office, 2001; NEDO, 1975). This negative image worsened further when some large scandals emerged. For example, in the Netherlands, large irregularities were discovered at the beginning of this millennium in the procurement of, mainly publicly procured, construction projects. Contractors divided projects out among themselves, and the contractor to whom the project was "awarded" paid for the tendering costs of the other candidates. In some cases, public servants were bribed (PEC, 2002). These irregularities could be viewed as symptoms of an overly-strong contractor competition (Dorée, 2001). Since public authorities awarded their contracts to the contractor offering the lowest bid, contractors felt forced to make pricing agreements in order to survive. Nevertheless, they still felt the need to compensate for their unrealistically low bids by renegotiating signed contracts during the construction stage. This clawing back of margins after contract closure added to the construction sector's bad image. 


\subsection{Response to developments: changes both in negotiations and in commitments}

The combination of increased project complexity, changing government roles and the construction sector's poor professional functioning have changed the tasks and roles of the market and of government (Baccarini, 1996; Laufer, Denker and Shanhar, 1996; Alderman, Ivory, McLoughlin \& Vaughan, 2005; Walker, 2007; Blanken, 2008; Egan, 1998; National Audit Office, 2001). Public principals have less influence on the contents of works, and are striving for "professional commissioning" with increasing outsourcing to market organisations. The public principal confines itself to monitoring and checking the public's interest more and more. Conversely, market organisations, alongside with the executives, gain more substantive tasks in realising construction works. Increased contractor responsibility during execution of the project, however, involves less certainty for the public principal during the procurement stage. When contingencies have to be solved after contract close, this might lead to renegotiations of agreed upon terms. Costs might increase, project deliveries might be delayed, and quality standards might be lowered. As a response to the experienced low commitment and many renegotiations during construction, both commitments and negotiations during procurement changed.

Commitment refers to the state of being bound to a course of action or to another party, and stems from both natural motivators as feelings of empathy or shared values, and from artificial motivators as contract clauses and reward mechanisms. Commitment to the project by both public principal and his contractor is reflected in agreements and the signing of a contract (Kamminga, 2008). Construction contracts reflect the need to anticipate to contingencies in the construction stage by the applied reward system (from fixed price in regular projects to cost plus in case of complexity, in several variations), the allocation of risks (from allocating risks to the party that can take them best to shared risks for contingencies, in several variations), and willingness to rely on trust (complete contracts exist next to incomplete contingency claims contracts). The introduction of alliance contracts with a shared risk fund (Turner, 2004) reflects how commitments at the end of the procurement stage are made sustainable to contingencies during execution of the project, and so are the upcoming partnering contracts (Black, Akintoye \& Fitzgerald, 2000; Bresnen \& Marshall, 2000b).

Negotiation refers to the bargaining (give and take) process between two parties (each with its own aims, needs and viewpoints) seeking to discover a common ground and reach an agreement to settle a matter of mutual concern or resolve a conflict. It are processes of interactive communications in which both sides make decisions (Kamminga, 2008). Procurement processes reflect the need to reduce renegotiations in the executions stage by the usage of procurement procedures (from bidding to prescribed conditions in case of regular projects to the use of interactive procedures in case of complexity) and award methods (quality-based selection gains interest as opposed to price-based selection). The dominance of contractor expertise and focus on selecting the best contractor by the procuring principal in Best Value Procurement (Kashiwagi, 2004) reflects how negotiations during the procurement stage are expanded, just as the competitive dialogue procedure that is used for complex projects (Beuter, 2005). Below, both the changes in commitments and in negotiations during the procurement stage will be further explained. 


\section{Changes in commitments}

Complex projects need cooperation in order to handle risks and contingencies (Laan, 2009). As such, governments are developing from an authoritarian customer into a cooperative partner (Raganelli \& Fidone, 2007). Given the absence of in-house knowledge due to reform in the eighties, governments have to delegate the complex tasks to market organisations. A vacuum arises because governments are retreating, but market organisations are not yet sure whether and how to use this new reality (Huque, 2005). Moreover, given their existing distrust in contractors, governments are not sure whether and how to transfer tasks and responsibilities to them. This leads to governments seeking the possibility to carry out certain activities together with market organisations, for example in the form of PPPs (BultSpiering \& Dewulf, 2006). In such joint projects, both public and private interests have to be secured. This is achieved by a new allocation of tasks, responsibilities and risks, and reflected in the new, innovative contract forms that are being developed since the late-1980s. Integrated contract forms, in which responsibilities for not just construction but also for design and financing are transferred to the market, have become a common tool for both governments and the market.

However, the distrust between public principals and private contractors, resulting from the poor image and the culture of fighting over margins, has not been conducive to the handing over of responsibilities from government to market organisations (Blanken, 2006). The search for new arrangements, that suit both public and private interests better, continues. Governments are becoming less involved in the contents of the work and more concerned with procurement, controlling the public interest, and monitoring the contractors' activities. Rather than prescribing the input wanted from the contractors, the principal prescribes the output needed (product-led contract) or even the outcome needed (service-led contract) (Alderman et al., 2005). Technical knowledge is no longer the business of the public sector. Rather, the procurement and management of contracts with market organisations, and directing those organisations, has become the focus (Bult-Spiering \& Dewulf, 2006).

The shift from input to outcome implies a need for a different incentive structure for the contract because of changes in the specifications, duration of the contract, and allocation of responsibilities (Hoezen et al., 2010). Each contract type results in different contractor behaviours, simply because their specifications, scope, and decision freedom are different. Table 1.1 displays the characteristics of the main three contract types used in construction. It shows that with the shift from input to outcome specifications, the scope of the project, the decision freedom, the natural incentive for the contractor and thus its behaviour, and the selection criteria and monitoring by the principal are changing. 
Table 1.1. Characteristics of three contract types (Hoezen et al., 2010)

\begin{tabular}{|c|c|c|c|}
\hline & Traditional & DB & DBFM \\
\hline Specifications & Input: design-led & Output: product-led & Outcome: service-led \\
\hline Scope & Construct & Design and Construct & $\begin{array}{l}\text { Design, Construct, } \\
\text { Finance, Maintain }\end{array}$ \\
\hline $\begin{array}{l}\text { Decision freedom for } \\
\text { contractor }\end{array}$ & $\begin{array}{l}\text { None: has to follow the } \\
\text { specifications }\end{array}$ & $\begin{array}{l}\text { Little: can have some } \\
\text { influence on the design }\end{array}$ & $\begin{array}{l}\text { Much: can make } \\
\text { decisions as long as } \\
\text { remaining within the } \\
\text { scope }\end{array}$ \\
\hline Selection criterion & Price & $\begin{array}{l}\text { Design creativity, } \\
\text { constructability and } \\
\text { price }\end{array}$ & $\begin{array}{l}\text { Overall quality and } \\
\text { price }\end{array}$ \\
\hline Natural incentive & $\begin{array}{l}\text { Low bid, with } \\
\text { compensation through } \\
\text { extra work }\end{array}$ & $\begin{array}{l}\text { Low bid by design } \\
\text { efficiencies }\end{array}$ & $\begin{array}{l}\text { Low bidding and cost } \\
\text { reduction by design and } \\
\text { process efficiencies }\end{array}$ \\
\hline $\begin{array}{l}\text { Effect on the } \\
\text { contractor's behaviour } \\
\text { after contract closure }\end{array}$ & $\begin{array}{l}\text { Opportunistic, mistake- } \\
\text { hiding, quality-shirking, } \\
\text { extra work-claiming }\end{array}$ & $\begin{array}{l}\text { Opportunistic, mistake- } \\
\text { hiding, quality-shirking }\end{array}$ & $\begin{array}{l}\text { Opportunistic, mistake- } \\
\text { hiding }\end{array}$ \\
\hline Monitoring & $\begin{array}{l}\text { Ongoing, by the } \\
\text { principal }\end{array}$ & $\begin{array}{l}\text { Ongoing, by } \\
\text { engineering firms }\end{array}$ & $\begin{array}{l}\text { Ongoing, by contractor } \\
\text { and by his financers. } \\
\text { Occasional, by the } \\
\text { principal }\end{array}$ \\
\hline
\end{tabular}

\section{Changes in negotiations}

In the 1990s, the European procedures for the award of public service contracts, public supply contracts and public works contracts were coordinated by three separate directives: the Council Directive 92/50/EEC of 18 June 1992; the Council Directive 93/36/EEC of 14 June 1993; and the Council Directive 93/37/EEC of 14 June 1993. At that time, negotiations over construction projects were guided in the EU by three main types of public procurement procedures: 1) the open procedure, 2) the restricted procedure and 3) the negotiated procedure. The open procedure was characterised by the publication of a tender call. In reply to this call, all interested suppliers could submit a bid based on the technical specifications provided by the procuring authority. The restricted procedure differed from the open procedure in that only those suppliers invited by the procuring authority could bid. In an initial step, all interested suppliers could ask to participate in response to a call for tenders. In the second step, only a limited number of selected suppliers would be asked to make a firm bid. In negotiated procedures, the procuring authority was free to select appropriate candidates, and to consult and negotiate with potential suppliers to adapt received tenders to better meet the specified needs.

Within these three procedures, two awarding methods could be employed: lowest price (of all the bids) and MEAT: the most economically advantageous tender. In the MEAT method the published criteria, their priorities and the minimum thresholds needed to be achieved. 
With the shift from design-led towards product- and service-led contracts, it became difficult to review bids on basis of just their price. Qualitative aspects like design creativity and constructability became more important to the procuring agencies. Hence, the use of MEAT criteria increased. Furthermore, as a reflection of the more complex tasks involved, the negotiations during procurement had to become more comprehensive. Besides, due to the changed roles and tasks, soft qualities like cooperation skills became more important to perform well in the changed inter-organisational relationship. Procuring agencies were looking for manners to incorporate this in the procurement of their projects, when the negotiations about the project took place (Zaghoul \& Hartman, 2003).

Of the available procurement procedures, the open procedure was used most commonly (Heijboer \& Telgen, 2002). The restricted procedure was used when the procuring authority wanted to be assured of the contractor's suitability, particularly with technically complicated contracts. The negotiated procedure was only applicable in special cases, such as urgent or confidential projects, or when the other procedures had not produced an acceptable tender (Pijnacker Hordijk, Van der Bend, \& Van Nouhuys, 2009). Of the awarding methods the lowest price method was mostly used with low complexity projects with a well-defined design and a certain degree of trust in the constructor. In general, the MEAT approach was especially common in design-build (DB) contracts, and also in cases where there was organisational or technical complexity (see Table 1.2).

Table 1.2. Usage of procurement procedures and award methods before 2004 (based on Heijboer \& Telgen, 2002)

\begin{tabular}{l|ll} 
& Lowest price & MEAT \\
\hline Open procedure & Most common, simple cases & Simple DB cases \\
Restricted procedure & $\begin{array}{l}\text { Assurance of contractor's suitability } \\
\text { needed, in cases with a well-defined } \\
\text { design } \\
\text { Special cases, but trust in contractor }\end{array}$ & More complex DB cases \\
Negotiated procedure & Special, complex cases
\end{tabular}

Given the developments described earlier, it is not surprising that the negotiated procedure gained popularity towards the end of the 1990s. Increasing complexity and changing government roles had stimulated early contractor involvement. As a consequence, the contracts to govern construction projects had to be signed earlier in the process, when the chances to unforeseeable contingencies were great. Renegotiations during the execution stage of projects therefore occurred on a regular basis (Dorée, 2001).

As a response to the experienced low commitment and many renegotiations during construction, both commitments and negotiations during procurement changed. To come to an understanding about project details, the allocation of responsibilities and risks and the terms for cooperation, both procuring authorities and contractors felt the need to have conversations before a contract was signed (Dorée, 2001; PEC, 2002; PSIBouw \& Regieraad Bouw, 2007; Reniers, 2007). Except for the negotiated procedure, direct one-to-one communication was simply not allowed for in the existing procurement procedures. The open and the restricted procedures included a system of "notes of information". Those notes were questions, sent in writing from the contractors to the procuring authority. The answers to those notes were also in written form, with the disadvantage that much 
interpretation of questions and answers took place, often leading to misunderstandings. The negotiated procedure had the advantage of direct communication: procuring authorities could consult contractors of their choice and negotiate contractual terms with one or more of them.

\section{A new procurement procedure}

Given the developments described above, it is not surprising that the negotiated procedure gained popularity towards the end of the 1990s. None of the existing other procedures provided the opportunity of direct communication during the procurement. Only in the negotiated procedure procuring authorities were able to consult contractors of their choice and negotiate contractual terms with one or several of them. The European Commission (EC), well aware of the desire for a procurement method that left room for extensive dialogue during the negotiations, noticed that the negotiated procedure was often used improperly (COM(96) 583 final). The EC did not want this procedure to be used too often though, because it left no room for other competitors during the negotiations stage. To overcome this problem without denying procuring agencies a procurement procedure with room for dialogue, the EC introduced a new procedure in 2004: the Competitive Dialogue (CD) procedure.

The CD procedure is a procurement method that consists of several rounds of discussion between the principal and potential contractors, during which all aspects of the tender are open for discussion. The CD procedure aims at aligning the complex demands of principals with possible solutions that contractors have to offer (Hebly and Lorenzo van Rooij, 2006). It regulates the negotiation process during the procurement stage, thus expectedly affecting the commitment and possible renegotiations between principal and contractor. Main expectations with concern to the procurement stage as a result of using the CD procedure were stronger contractor competition than possible with the negotiated procedure, and improved dialogue between procuring agency and potential contractors than possible with traditional procedures. Thus, complexity and renegotiations during the execution stage of the project were expected to decrease.

\subsection{Research objective}

Several academics conclude that the actual design of the CD procedure could work against its objectives because competition and dialogue seem two conflicting objectives (Arrowsmith, 2006; Raganelli \& Fidone, 2007; Ramsey, 2006). Early experiences with the CD procedure in the Netherlands support this. Studies indicate that the effectiveness of the $C D$ procedure in terms of obtaining the European Commission's objectives is low (Floor \& Kolkman, 2008; Hoezen \& Dorée, 2008). The parties involved in the CD procedure balance between open information sharing for an effective dialogue and keeping information to themselves because of competition. This raises the question whether the realised dialogue negotiations during procurement could actually result in a limitation of renegotiations during the construction stage of projects when commitment in the procurement stage is low as a result of inter-candidate competition. It is difficult to assess the effectiveness of the CD procedure in regulating negotiations during procurement so that renegotiations after 
contract close are limited. For such an assessment it should be clear how negotiations and commitments are interrelated. The objective of this research is therefore formulated as follows:

The objective of this research is to explain the perceived ineffectiveness of the $C D$ procedure, based on gained insights in the interrelatedness of inter-organisational negotiations and commitments during procurement and during construction.

Many authors have discussed the complex relation between negotiations and the final commitment (Laan, 2009; Ring \& Rands, 1989; Ring \& Van de Ven, 1994; Vlaar et al., 2006). During negotiations, client and contractors are negotiating the terms of their agreements. These negotiations have impact on the agreement itself and on further commitment of both parties to the transaction. Despite the many mechanisms in inter-organisational relationships that already have been studied and described (Boddy, Macbeth \& Wagner, 2000; Donaldson \& O'Toole, 2001; Dwyer, Schurr \& Oh, 1987; Ford, 1998; Ford, Hakansson \& Johanson, 1985; Pascale \& Sanders, 1997; Ring \& Van de Ven, 1994; Thompson \& Sanders, 1998; Vlaar, Van den Bosch \& Volberda, 2006; Walker \& Hampson, 2003; Wilson, 1995), it is still unclear how the interrelatedness of negotiations and commitments is influenced by procurement procedures like the CD procedure. Further research will therefore be required.

\section{Central research question}

Due to developments in the inter-organisational relationship between public principals and their private contractors, changes are taking place in both their negotiations and the commitments between them. The Competitive Dialogue procedure is a method that regulates negotiations during procurement with the expectation to result in limited renegotiations during construction. Early experiences with this procedure indicate that its effectiveness is low. When one would like to explain this, insights in the interrelatedness of inter-organisational negotiations and commitments is needed. The central research question of this research is therefore formulated as follows:

How are inter-organisational negotiations and commitments interrelated in the context of procurement by the Competitive Dialogue procedure?

\subsection{Research design}

\section{Research philosophy}

The central research question concerns the interrelatedness of inter-organisational negotiations and commitments in the context of procurement by the CD procedure. The question is of explanatory order since we do not know which factors will have a decisive influence on the development of negotiations and commitments. To understand the development of negotiations and commitments in the specific context of the Competitive Dialogue procedure, in-depth studies are preferred. It is doubted whether questionnaires could sufficiently reflect the extensiveness of the real-life situation to understand the true motives of the actors involved, and the aspects that are involved in the development of negotiations and commitments (Swanborn, 1987; Swanson \& Holton, 2005). 
This last remark reflects certain reservations of the researcher. Unlike those who believe that there is only one objective reality, and that this can be uncovered through good approximations to the truth (the positivist view) (Swanborn, 1987; Swanson \& Holton, 2005), the researcher is more attracted to the constructivist view: that reality is a subjective phenomenon constructed uniquely by each person (Swanborn, 1987; Swanson \& Holton, 2005). The theoretical model used to guide this study into the development of negotiations and commitments starts from this same research philosophy: the conviction that people base their actions on what they believe others mean by their acts (Swanborn, 1987; Swanson \& Holton, 2005). Therefore, in collecting data within this study the focus is on the subjective views of policymakers, procuring authorities and contractors. From their views on how interorganisational negotiations and commitments are interrelated, and how this is affected by characteristics of the CD procedure, the picture of the development of inter-organisational negotiations and commitments will be painted. In this research, an interpretive philosophy has largely been adhered to. By combining understanding and interpretation of the manner in which the development of inter-organisational negotiations and commitments is explained by those involved, the aim is to come to an understanding of how the two are interrelated.

\section{Methodology}

Explanatory questions as the main question in this research is, are defined by Yin (2009) as "how/why" questions. The nature of this type of question is that they deal with "operational links, needing to be traced over time, rather than mere frequencies or incidence" (Yin, 2009, p.9). Unlike exploratory "what" questions, which could be answered using almost any type of research, answering explanatory questions is likely to require the use of case studies, experiments or histories. Choosing one from these three, or perhaps a combination thereof, will be determined by the events which are being researched. Yin (2009) shows that the extent of control over and access to the events are the two major determining factors. When the researcher has neither control over nor access to the events under study, formulating a history is the preferred approach. A case study is preferred when examining contemporary events, in a situation where the researcher is unable to manipulate relevant behaviours. When the relevant behaviours can be manipulated directly, precisely and systematically, experiments are likely to be a better option.

Considering access and control aspects of the current research question, the problem as outlined in Section 1.3 satisfies the conditions set by Yin (2009) for case study research. The procurement process is a contemporary event, but one that cannot be influenced by the researcher. Case study research would therefore seem to be the best method to answer the research question. Yin $(2009$, p.18) defines case study research as "an empirical inquiry that investigates a contemporary phenomenon in depth and within its real-life context, especially when the boundaries between phenomenon and context are not clearly evident". In addition to this definition of the subject of case study research, Yin (2009, p. 18) also provides an indication of the appropriate data collection method: "the case study inquiry copes with the technically distinctive situation in which there will be many more variables of interest than data points, and [...] relies on multiple sources of evidence, with data needing to converge in a triangulating fashion, and [...] benefits from the prior development of theoretical propositions to guide data collection and analysis". 
Despite the many variations in case study research, a general approach to designing case studies is described in literature (Swanborn, 1987; Swanson \& Holton, 2005; Yin, 2009). The steps of the design are:

\section{The study's question}

The central question in this research is: How are inter-organisational negotiations and commitments interrelated in the context of procurement by the $C D$ procedure? Literature is used to narrow the interest of the research to a few key topics, to look for new questions or loose ends for future research and to provide support for potential questions or ways of sharpening them. In the current chapter, the major question is divided into four subquestions. The key topics (being inter-organisational negotiations and commitments, and the working of the CD procedure) are explored further in Chapter 2 and Chapter 3.

\section{The study's propositions}

Propositions about the outcome of the study are important. In this research, four propositions are defined to reflect theoretical issues and to provide a starting point for relevant evidence. The propositions for this research, and the theoretical background to them, are provided in Chapter 2.

\section{The study's unit(s) of analysis}

Since different units of analysis, and their related questions and propositions, would call for different research designs and data collection strategies, it is important to select the appropriate unit of analysis. In Chapters 4 and 5, the two case studies undertaken are described, each with a different unit of analysis. At the beginning of each of these chapters, one section will reflect on the appropriate study design for the issue at hand.

4. The logic linking the data to the propositions

Steps 4 and 5 foreshadow the data analysis of case study research. Data analysis requires combinations of the case study data as a direct reflection of the initial study propositions. Both Chapters 4 and 5 contain sections in which the data analysis approach is described.

\section{The criteria for interpreting the findings}

As a means to demonstrate that the observed facts are significant, one could consider, in advance, rival explanations for the findings. With these rival explanations in mind, the data are collected to prove them wrong and so strengthen the cases for the claimed findings. Chapter 6 contains an overview of rival explanations considered in this research.

\subsection{Research approach}

The five steps in case study design have guided the definition of three main research questions that contribute to answering the central research question: How are interorganisational negotiations and commitments interrelated in the context of procurement by the Competitive Dialogue procedure? 


\section{A. How are which components of negotiations and commitments playing a role in inter-organisational projects?}

The recent developments in the construction industry have led to both additional and changing negotiations and commitments between procuring agencies and contractors. Expectations of the European Commission that changes in negotiations during procurement (introduction of the CD procedure) would lead to sustainable commitment and limited renegotiations during construction (agreements to manage the execution of complex projects) are supported by scientific studies. Academics have not, however, fully untangled the relationship between negotiations and commitments. The combination of several academic insights concerning components of negotiations and commitments that play a role in procurement will provide a framework for studying the manner in which interorganisational negotiations and commitments are interrelated in the context of procurement by the $\mathrm{CD}$ procedure.

The first stage of this research consists of the development of a conceptual model that can be used to analyse how negotiations and commitments develop in CD procured construction projects. First, the literature on inter-organisational relationships is studied. The insights gained on the roles of negotiations and commitments in the development of interorganisational relationships are reviewed. Secondly, based on existing inter-organisational relationship models (Ring \& Van de Ven, 1994; Ring \& Van de Ven, 2000; Vlaar, Van den Bosch \& Volberda, 2006), a theoretical framework is constructed that helps explaining the development of negotiations and commitments. This framework consists of a model that covers both formal and informal commitments, and formal and informal negotiations. These are interrelated through understanding as a key concept. Since the model describes the development of negotiations and commitments, the theoretical framework in Chapter 2 of this dissertation contributes to answering the central research question. It will guide the empirical search for insights into the interrelatedness of inter-organisational negotiations and commitments in the context of procurement by the CD procedure.

\section{B. What is the influence of the CD procedure on negotiations and commitments?}

With the review of literature on the interrelatedness of negotiations and commitments, a theoretical frame will be built. Knowledge about the influence of the CD procedure, however, is scarce. Therefore, the second main research question is what the influence is of the $C D$ procedure on negotiations and commitments. The question is divided in two subquestions. The first focuses on the characteristics of the $C D$ procedure that determine its influence. The second focuses on the impact of the $C D$ procedure, by comparing the development of negotiations and commitments in CD-procured projects with development of negotiations and commitment in comparable, but traditionally procured projects. 
B1. Which characteristics of the CD procedure are perceived to be of main influence to negotiations and commitments?

The CD procedure is a clear example of how inter-organisational negotiations in the European construction industry were tried to be regulated in order to influence the commitments and any renegotiations resulting from it. Notwithstanding the limited knowledge about how procurement procedures affect negotiations and commitments, the European Commission had assumptions about the working of the CD procedure when designing it. Analysis of the intended and unintended mechanisms within the CD procedure and how these are perceived to affect negotiations and/or commitments could help guiding the data collection in the case studies. Knowledge of perceived important mechanisms within the $C D$ procedure help painting a picture of the contextual influence of the $C D$ procedure in the development of negotiations and commitments.

The first part of the second stage of this research consists of a document study analysing the policy rhetoric of the European Commission when designing the CD procedure. This reconstruction of the intended working of the $C D$ procedure is to provide more insight in how negotiations were assumed to affect the intended objectives of the CD procedure. Therefore the document study was followed by a discussion of the policy rhetoric with experts from relevant fields in science and practice. The thus derived expected working of the $C D$ procedure was then confronted with the practice of some early $C D$ procured construction projects. At the end of Chapter 3 twelve main mechanisms and their perceived effects on the intended purposes of the $C D$ procedure are listed as a first step to finding the contextual influence of the $C D$ procedure to the development of negotiations and commitments.

\section{B2. How do negotiations and commitments differ between $C D$-procured projects and projects that are traditionally procured?}

There is only limited knowledge about how procurement procedures affect negotiations and commitments. Therefore, the research described in this dissertation contains a study in which negotiations and commitments of similar projects, but procured with use of different procurement methods, are compared. Finding differences in negotiation and commitment patterns in different projects provide indicators of the manner in which the procurement method affects negotiations and commitments. These indicators can then be used as inputs in a continuation study that researches the development of negotiations and commitments in more detail. Answering this research question helps to untangle the relationship between negotiations and commitments under influence of different procurement methods, thus guiding the next step of the research.

During the second part of the second stage of the research four comparable construction projects are identified, two of which are procured by the CD procedure and two by another procurement procedure. It is ensured that project characteristics of the four projects are identical. Using a case study protocol, based on the theoretical framework developed in the first research stage, both the negotiations and commitments in all four projects are examined and compared. 
The results of these examinations and comparisons are reflected in Chapter 4. Thus, not just differences and similarities are sought for, but also reasons for these differences and similarities. Those reasons provide indicators for the influence of procurement method characteristics for the development of inter-organisational commitments and negotiations.

\section{How do negotiations and commitments develop over time in a CD- procured construction project?}

As stated earlier, research into the relationship between negotiations and commitments is topical, given the developments in the construction industry. In the light of these developments, the $C D$ procedure was introduced to influence negotiations and commitments both during procurement and during construction of inter-organizational projects.

To find out in detail how negotiations and commitments develop under influence of CD procurement, an in-depth case study was performed. Thus, empirical data were collected to support theoretical ideas about the interrelationship of negotiations and commitments. Current academic contributions are generally lacking empirical data, especially when it comes to the procurement stage of projects (Bijlsma-Frankema \& Costa, 2005). Furthermore, the study will provide insights in the current practice of application of the CD procedure.

The third stage of this research therefore consists of a single, longitudinal case study, again guided by the theoretical framework constructed during the second stage. First, a construction project was selected in which the construction stage had already started, but where the procurement stage would be still fresh in the memory of those involved. Further, it was ensured that the complexity and size would be representative of the Dutch situation. The second Coen Tunnel project matched these criteria and had the additional advantage of being well-documented and accessible for research purposes. Secondly, through retrospective interviews, based on an analysis of critical events during the procurement process and on evaluations conducted at the request of the project organisation, developments in the Second Coen Tunnel project were reconstructed. Central in this reconstruction were the elements of the theoretical framework, a focus reflected in the used interview protocols. Third, the collected data were analysed. By putting interview passages and document quotes with similar labels together, patterns in the development over time of negotiations and commitments were identified. In this way, the longitudinal case study - the subject of the fifth chapter of this dissertation - contributes to answering the question how negotiations and commitments develop over time in a CD-procured construction project.

\subsection{Research contribution}

\section{Scientific contribution}

Empirical evidence to explain the interrelatedness of inter-organisational negotiations and commitments is scarce, especially when it comes to the procurement stage of projects (Klein Woolthuis, Hillebrand, \& Nooteboom, 2005; Laan, 2009). Greater insight in the case of the construction industry could help bring the scientific debate to a higher level, feeding it with 
actual, empirical evidence. Three scientific contributions are made. The first contribution lies in the insight in the interrelatedness between negotiations and commitments. The second contribution focuses on the interrelatedness between the formal and informal components of negotiations and commitments. Finally, insight is provided in the the influence of procurement method on the development of negotiations and commitments. The contributions are briefly described below.

A first contribution is providing insights into the interrelatedness of negotiations and commitments. Increased understanding of the development of negotiations and commitments and their interrelatedness contributes to the academic field of relational governance. Several academics in this discipline have performed research into this interrelationship. Yet, studies focus either on the procurement stage of projects (Pascale \& Sanders, 1997; Walker \& Hampson, 2003) or on the execution stage (Boddy, Macbeth \& Wagner, 2000; Dwyer, Schurr \& Oh, 1987; Thompson \& Sanders, 1998) and when the total relationship is incorporated, the level of abstraction is high and/or empirical evidence is lacking (Donaldson \& O'Toole, 2001; Ford, Hakansson \& Johanson, 1985; Ford, 1998; Ring \& Van de Ven, 1994; Vlaar, Van den Bosch \& Volberda, 2006; Wilson, 1995).

By combining several studies concerning the interrelatedness of negotiations and commitments, a theoretical model will be created and empirically tested. Thus, the interrelatedness of negotiations and commitments, both during procurement and during execution of the project is combined into one model. Next to contributing to the knowledge in relational governance studies, this might especially help academics who intend to study bargaining processes in relation to contract structures. Given the increased attention that is being paid to the effects of several distinct negotiations characteristics on the final agreement (Ahola, Laitinen, Kujala, \& Wilkström, 2008; Cox \& Thompson, 1997; Elfving, Tommelein, \& Ballard, 2005; Eriksson \& Laan, 2007; Love, Skitmore, \& Earl, 1998), insights in the relations between negotiations and commitments could help other academics to understand how pre-contractual negotiation characteristics might influence the contract that eventually is signed, and how characteristics of the contract induce renegotiations during execution of the contract.

Secondly, insights will be provided in the interrelatedness of formal and informal components of negotiations and commitments. It is assumed that negotiations and commitments have a formal and an informal component (Ring and Van de Ven, 1994). Especially in the field of trust research, academics dispute the way in which the formal and the informal forms of control interact. The debate has gained broad attention in the last decade (Levitt, Henisz, Scott \& Settel, 2010; Macneil, 1978; Scott, 2001; Williamson, 1979). Input has not only been given by pure trust researchers. Academics who conduct studies in the construction industry have also made contributions (e.g. Kadefors ,2005; Kamminga, 2008; Klein Woolthuis, Hillebrand \& Nooteboom ,2005; Laan ,2009; Welling ,2006). For now, academics generally state that formal and informal control are dynamically interrelated and that empirical evidence is needed to help the discussion further (Klein Woolthuis, Hillebrand \& Nooteboom, 2005; Laan, 2009). This research contributes to the debate by providing data and by further sharpening existing models. 
Finally, insight is provided in the influence of procurement method on the development of negotiations and commitments. This is important, since academics are currently very interested in the impact of formal procurement characteristics on all kinds of informal topics related to procurement. Examples of studies that address these kinds of issues are research about the impact of procurement design on competition and cooperation (Eriksson \& Westerberg, 2011); communication (Pietroforte, 1997); fairness (Kadefors, 2005); human behaviour (Cheung, Ng, Wong, \& Suen, 2003); motivation and commitment (Bresnen \& Marshall, 2000a); and the use of expertise (Bajari, McMillan \& Tadelis, 2002). This research could provide a frame into which these studies may fit.

\section{Practical contribution}

The objective of this research is to explain the perceived ineffectiveness of the CD procedure, based on gained insights in the interrelatedness of inter-organisational negotiations and commitments in the context of CD procurement. For practice, this research makes two contributions. Firstly, the insight in the effects of personal acts on the development of negotiations and commitments might help practitioners in their daily work to respond effectively to project situations. Secondly, insight in the influence of using the CD procedure to the development of negotiations and commitments will help to decide when and how the use of the CD procedure could be useful. Insight in the causes for experienced low effectiveness of the CD procedure will help to improve its use and prevent renegotiations after contract close. The contributions are briefly described below.

Firstly, since the interrelatedness between inter-organisational negotiations and commitments and their formal and informal components is studied in this research, greater insight will be gained into the practical implications of this interrelatedness for interorganisational relationships. By description of critical events, the influence of actions on the development of the inter-organisational project can be determined. From this, managers of both procuring authorities and contractors, will have access to more information and suggestions on the possible effects of their acts both during procurement and during construction of inter-organisational projects. This will help them to respond to project situations in a manner that suits their situation best.

Secondly, insight is provided in the influence of using the CD procedure to the development of negotiations and commitments. Given the existing lack of a structured, thorough evaluation of the $C D$ procedure, this study will add to the practical knowledge on the effectiveness of the CD procedure in its current use, in terms of some of the goals set by the European Commission. With the gained insight in the cause for experienced low effectiveness of the CD procedure, suggestions will be made with regard to when and how the use of the $C D$ procedure is useful for inter-organisational projects. Thus, the effectiveness of using the $C D$ procedure could be improved, and renegotiations during construction decreased. 


\subsection{Outline of the dissertation}

The research is performed in three stages that reflect the main questions described above. In Figure 1.1, the links between the research questions and the subsequent chapters of the dissertation are illustrated.

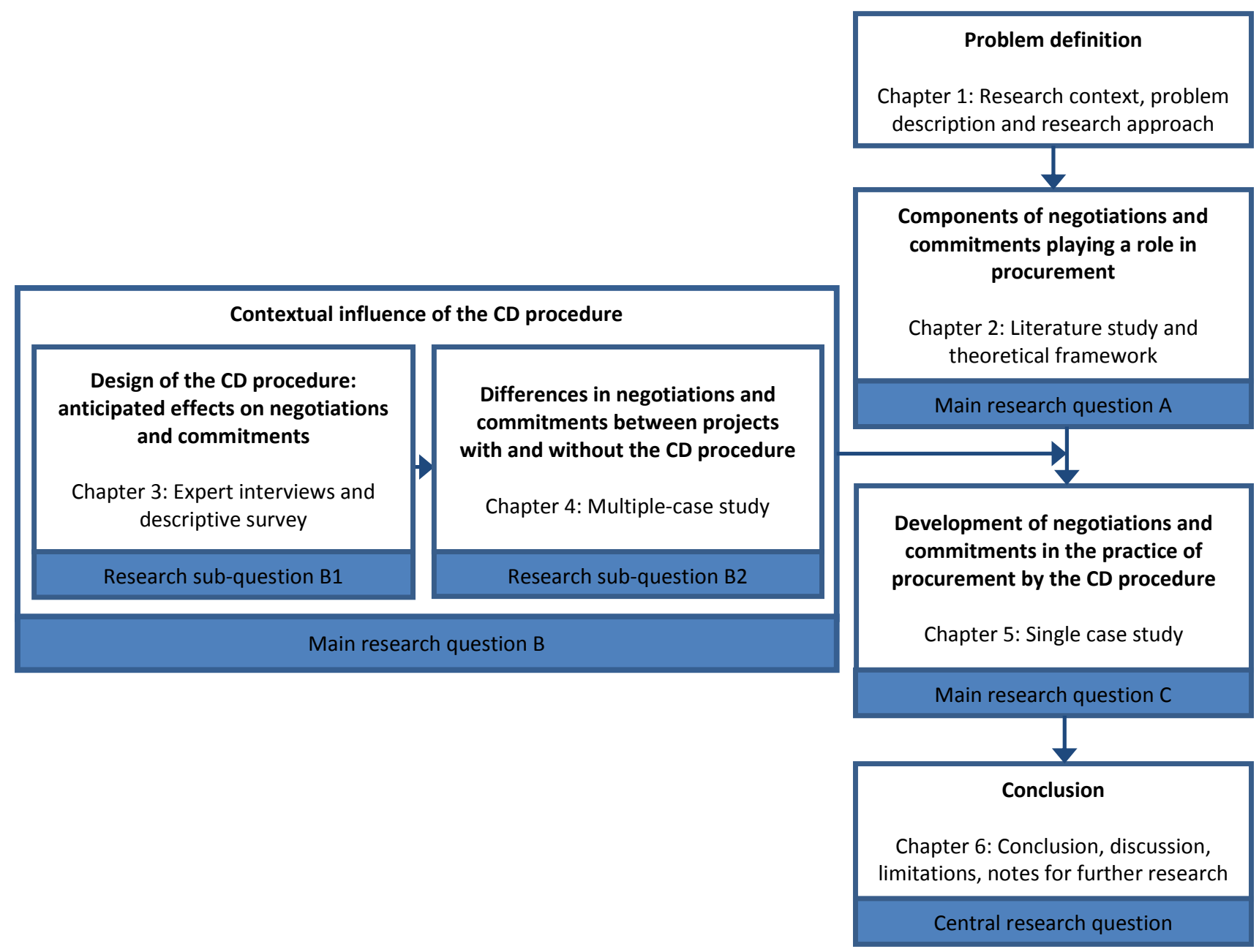

Figure 1.1. Structure of the research

In Chapter 2, insights from various disciplines on both negotiations and commitments are combined to provide a framework for studying their interrelationship in practice. Chapter 3 and Chapter 4 together provide an overview of the contextual influence of the $C D$ procedure. Chapter 3 combines the objectives of the $C D$ procedure with expert expectations of the $C D$ procedure, and puts those against early experiences with usage of the $C D$ procedure. In Chapter 4, a multiple-case study is used to compare traditional and CDprocured construction projects to reflect on the effect of using the CD procedure on both negotiations and commitments. In Chapter 5 in an in-depth single case study, the interrelationship of negotiations and commitments during procurement and the first year of construction is investigated and described for a large Dutch construction project, procured with the $C D$ procedure. In Chapter 6 the answers to the three main research questions together answer the central research question: How are inter-organisational negotiations and commitments interrelated in the context of procurement by the Competitive Dialogue procedure? 


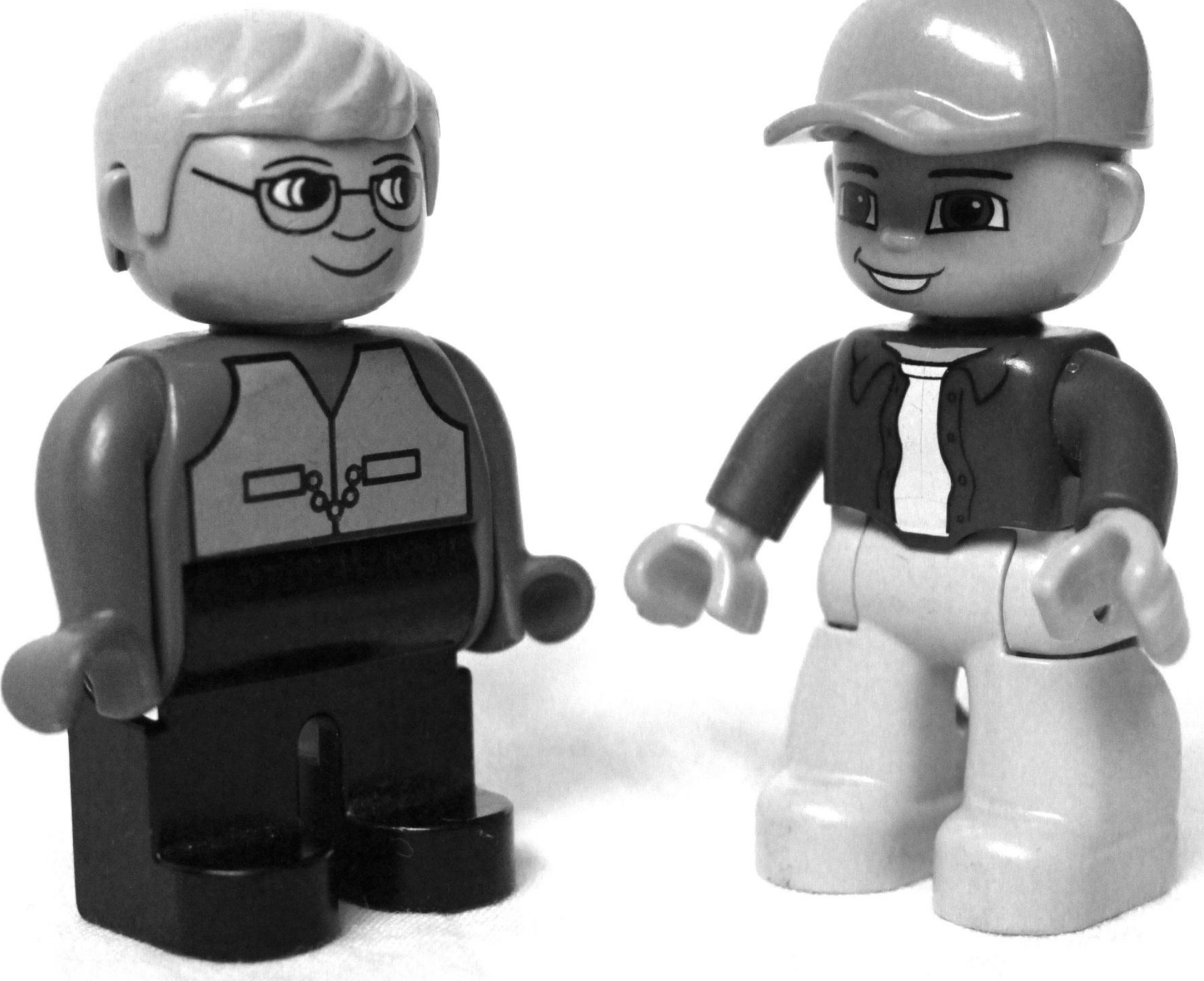




\section{Chapter 2. Formal and informal negotiation and commitment in inter- organisational projects: Theoretical Framework}

Part of this Chapter is published in:

Hoezen, M., Voordijk, H. \& Dewulf, G. (2011). Formal and informal contracting with the competitive dialogue procedure. In Wamelink, J.W.F, Geraerdts, R.P. \& Volker, L. (Eds) Proceedings of the CIB International Conference Management and Innovation for a Sustainable Built Environment - MISBE2011 20-23 June 2011, Amsterdam, The Netherlands. Amsterdam, The Netherlands: TUDelft.

The recent developments in the construction industry as described in Chapter 1 have led to changes both in negotiations and in commitments. The introduction of the CD procedure matches these developments by regulating the negotiation process during procurement, thus expectedly affecting the commitment and possible renegotiations during construction. Academics have not, however, fully untangled the relationship between negotiations and commitments. Therefore, in the current chapter an answer is sought to the main research question how which components of negotiations and commitments are playing a role in inter-organisational projects. Particular attention is given to formal and informal forms of control, subject in the field of relational governance.

Within relational governance, insights from microeconomics are combined with ones from social psychology. Therefore, in Section 2.1 the basic principles of both microeconomics and social psychology are described, followed by an important relational governance process model concerning the development of cooperative inter-organisational relationships (of Ring and Van de Ven (1994)). In this model both negotiations and commitments contain components from formal as well as from informal control. Therefore, Section 2.2 describes the academic debate concerning the interrelatedness of formal and informal control. In Section 2.3 the construction of the FINCIP model, the theoretical framework for this thesis' research, is described. Formal and informal negotiations in the FINCIP model are explained in Section 2.4, after which Section 2.5 addresses the formal and informal commitments. Linking concept between negotiations and commitments, understanding, is explained in Section 2.6. A conceptualisation of the theoretical framework for studying negotiations and commitments in the context of procurement by the CD procedure is given in Section 2.7. The chapter concludes in Section 2.8 with the propositions for this research. 


\subsection{Relational governance: staged relationship development}

\section{Relevant insights from microeconomics and social psychology}

Procurement has been widely studied (see Hughes, Hillebrandt, Greenwood \& Kwawu, 2006), but primarily from two distinct disciplines: microeconomics and social psychology. Microeconomists consider procurement as formal bargaining to reach Pareto-efficient contracts that guide the inter-organisational transaction (Kamminga, 2008). The outcome of this bargaining is influenced by several aspects. The main aspects are bounded rationality (people intend to act rationally, yet do so only to a limited extent), informational asymmetry (related to the fact that transacting parties have potentially unequal access to information), transaction costs (the various costs of market transactions as outlined by Coase (1937)), and enforceability problems (difficulties due to monitoring problems, costs or other causes to enforce the terms agreed in the contract) (Williamson, 1975).

Next to the aspects above, Williamson (1975) alludes to another aspect: atmosphere. Atmosphere refers to the beliefs, perceptions and attitudinal considerations of both contracting parties. To microeconomists this is but one aspect, and viewed as only of minor importance to the transaction (which is the focus of that research field). However, atmosphere has a much more prominent position in the field of social psychology, where rather than the transaction, the relationship between parties is the subject of study. In this research field, procurement is considered as a process to come to a shared understanding of the transaction, the context of the transaction and the value of it to the other party and to oneself. Being defined as the study of how people's thoughts, feelings and behaviours are influenced by the actual, imagined or implied presence of others (Allport, 1985), social psychology assumes that both intra- and inter- personal phenomena influence the outcome of these processes. The most important aspects are attitudes (learned, global evaluations of persons, objects, places or issues that influence thought and action (Perloff, 2008)); social cognition (the manner in which people perceive, think about and remember information about others); attribution (explanations people give for behaviour, either their own or of others); and social influence (the way people affect the thoughts, feelings and behaviours of others) (Levine, Rodrigues \& Zelezny, 2008).

Despite the different focus of the two disciplines (one on the transaction and the other on the relationship between the parties involved in the transaction), insights gained from microeconomics are not necessarily contrary to insights drawn from social psychology. Nevertheless, due to the differing foci the two research fields provide different explanations for human actions. The focus of microeconomists is on the formal transaction, whereas social psychologists focus on the informal relationship between the parties involved. Both scientific disciplines provide insights into the structures and processes involved in procurement, and the two views are similar on several points. For example, both see procurement as a sequence of events, developing through vicious cycles. Previous acts (and interpretations thereof) will influence successive acts (and interpretations thereof) in positive or negative senses. Negative acts will be answered by negative acts, and positive acts by positive ones (Axelrod, 1984; Macaulay, 1963). The same is true with interpretations: once one thinks negatively about another, future acts will also be interpreted negatively (Weick, 1995). 
However, alongside the past, the future also affects procurement (Weick, 1993). Without an expectation of a shared future, there is little urge to make sense of the shared present, and the shadow of the future is viewed as important in microeconomics since the possibility of being punished at a later date for deficiencies will prevent parties from acting opportunistically. Finally, understanding plays an important role in both microeconomics and in social psychology: understanding how the other is acting during negotiations, helps to determine one's own negotiation strategy. Further, collective action is made possible by coming to a shared understanding of the environment.

Given these commonalities it is not surprising that, since the 1980 s, academics have started combining microeconomic and socio-psychological views in an attempt to bring together both the formal and the informal components that are involved in relationship development. The most important contributions in terms of this research come from relational governance studies, which is founded in organisation science. Relational governance research examines the dynamics between two individuals, or entities, and their influence on people's behaviour in the relationship (Lewicki, Barry \& Saunders, 2007), and has been widely studied by academics such as Boddy, Macbeth and Wagner (2000), Donaldson and O'Toole (2001), Dwyer, Schurr and Oh (1987), Ford (1998), Ford, Hakansson and Johanson (1985), Pascale and Sanders (1997), Ring and Van de Ven (1994), Thompson and Sanders (1998), Walker and Hampson (2003) and Wilson (1995).

\section{Ring and Van de Ven's process model of inter-organisational relationship development}

An important, often cited contribution to the field of relational governance is the publication of Ring and Van de Ven (1994): "Developmental processes of cooperative interorganizational relationships". In this article Ring and Van de Ven consider inter-organisational relationships as socially contrived mechanisms for collective action, and ones that are continually shaped and restructured by actions and symbolic interpretations of the parties involved (p. 96). Ring and Van de Ven combine legal and economic frameworks, used to understand the institutional governance and structural safeguards for transactions, with psychological and social frameworks for understanding the interpersonal dynamics of transactions. Based on these frameworks, Ring and Van de Ven (ibid., p.96) explain the development of relationships as "consisting of a repetitive sequence of negotiation, commitment and execution stages, each of which is assessed in terms of efficiency and equity" (see Figure 2.1).

In the negotiation stage, the focus is on formal bargaining and informal sensemaking. Here, parties will develop joint expectations about their motivations, possible investments and perceived uncertainties. To a certain extent they also get to know and understand each other. In the commitment stage, parties will reach an agreement on the obligations and rules for action in their relationship. A governance structure is established and codified in a formal contract and "informally understood in a psychological contract between the parties" (ibid, p. 98). Finally, in the execution stage, these commitments and rules of action are put into practice "[t]hrough series of role interactions, parties may become more familiar with one another as persons, and they may increasingly begin to rely on interpersonal, as opposed to inter-role relationships" (ibid, p. 98). 
Over time, misunderstandings and changing expectations are inevitable, so parties may have to renegotiate in order to reach supplementary agreements over contested issues.

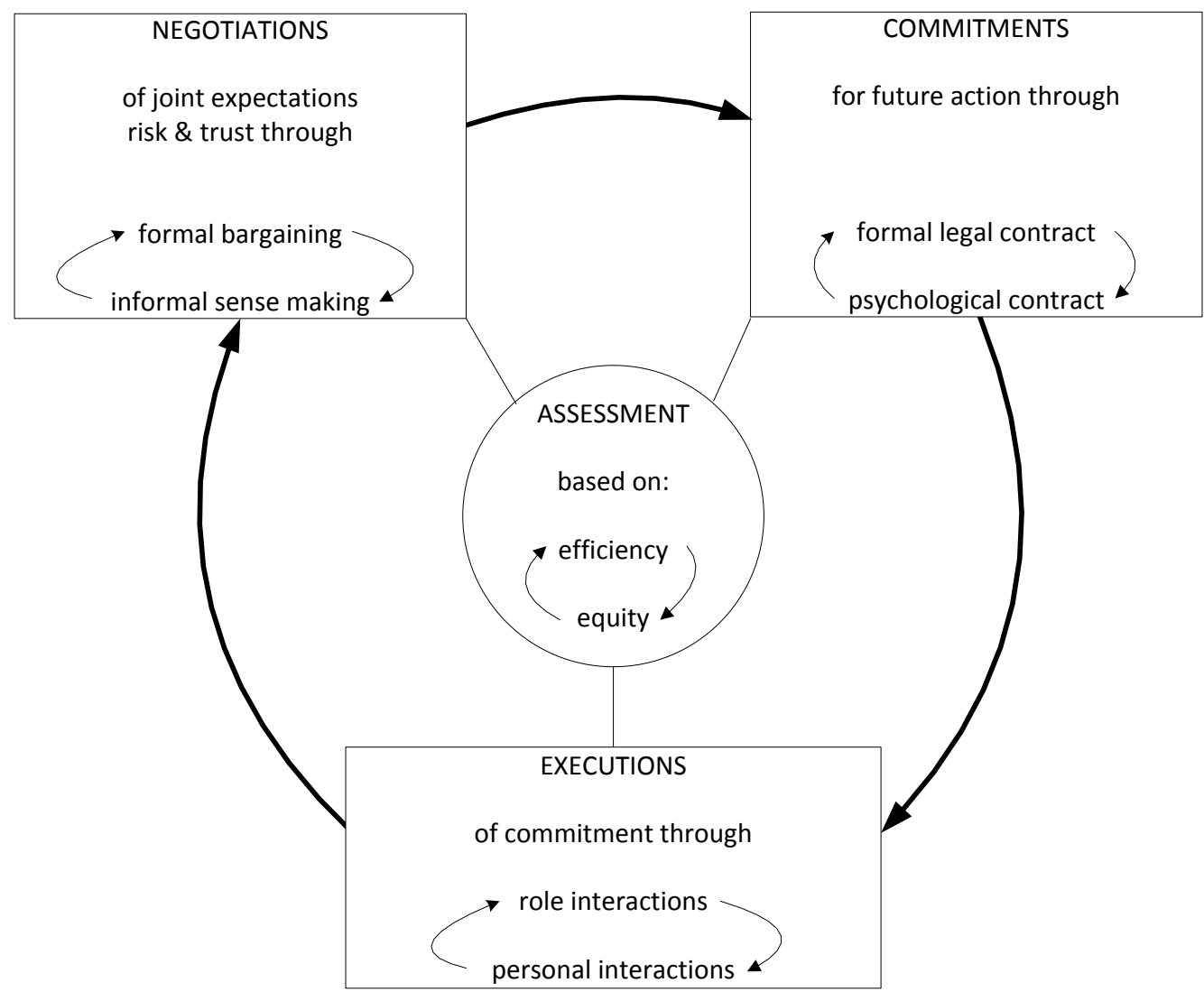

Figure 2.1. Process Framework of the Development of Cooperative IORs (Ring \& Van de Ven, 1994)

\subsection{Formal and informal control}

Ring and Van de Ven (1994) distinguish between formal and informal components in each of the stages they identified. Basic concept underpinning their model is the assumption that formal and informal control can serve as substitutes for each other. Meanwhile they also state (p.106) that "when the temporal duration of inter-organisational relationships is expected to exceed the tenure of agents, informal understandings and commitments will be formalized". This remark reflects the discussion between relational governance academics about the interrelatedness of formal and informal control. In general, relational governance theorists argue that informal agreements between the parties involved, prevent opportunistic behaviour arising, even when the formal legal contract is incomplete (Levitt, Henisz, Scott \& Settel, 2010; Macneil, 1978; Scott, 2001; Williamson, 1979).

However, academics dispute the way in which the formal and the informal contracts interact. It is generally assumed that the informal contract supports informal (verbal) arrangements, and that the incentives and penalties of formal contracts are there to enforce formal (written) agreements. There are, however, different opinions about the manner in which formal and informal forms of control are interrelated. Generally, two views exist: one seeing formal and informal contacts as substitutes for one another, and the other viewing them as complementary. 


\section{The substitute perspective}

Given that the informal contract supports informal arrangements, the substitute perspective sees the introduction of a formal contract as making the informal contract superfluous, and vice versa. In other words: informal contracts, consisting of relational norms and trust, can serve as substitutes for extensive, formal contracts or vertical integration (Adler, 2001; Bernheim \& Whinston, 1998; Bradach \& Eccles, 1989; Dyer \& Singh, 1998; Granovetter, 1985; Gulati, 1995; Larson, 1992; Macaulay, 1963; Uzzi, 1997). Dyer and Singh (1998) argue that informal self-enforcing agreements, which rely on trust and reputation, "often supplant" the formal controls that are characteristic of formal contracts. Uzzi (1997) states that the embeddedness of exchanges within social structures circumvents, and thus economises on, the time otherwise spent in costly contractual renegotiations. Similarly, Larson (1992) shows how informal social controls push formal contracts into the background, making formal contracts somewhat unimportant in the exchange agreements she examined. A common idea behind the substitution perspective is that informal contracts will lower transaction costs and facilitate easier adaptation between organisations.

An even stronger idea is that formal regulations disrupt the effectiveness of the informal contract. In particular, the norm of reciprocity is ruined by formal contracts: the use of incentives and punishments indicating that reciprocity is not expected. Thus, the relationship is put into a purely economic context, replacing the social context of the informal arrangement. As Sitkin and Roth (1993: p. 376) put it: "legalistic remedies can erode the interpersonal foundations of a relationship they are intended to bolster because they replace reliance on an individual's "good will" with objective, formal requirements".

Ghoshal and Moran (1996, p.24) describe how the use of surveillance, monitoring and authority can actually make authorities distrust their employees, so that they increasingly feel the need for even more surveillance and control. Macauly $(1963$, p.64) states that next to the question as to whether contracts and contract law are always needed, one should also consider the negative effects they might deliver: "Detailed negotiated contracts can get in the way of creating good exchange relationships between business units". Finally, Bernheim and Whinston (1998) show how particularly explicit contracts can stimulate those forms of opportunism that are not catchable in contractual terms.

To summarise, academics who hold the view that formal and informal contracts serve as substitutes for each other justify this based on the following two lines of reasoning: either the formal contract undermines the need for the informal contract (or vice versa), or formal contracts stand in the way of establishing an informal contract.

\section{The complementary perspective}

In opposition to the substitute perspective, the complementary perspective departs from the idea that formal and informal contracts are mutual supportive. In uncertain environments, it is argued, governing a transaction through a combination of formal and informal contracts may be more efficient and may result in a better outcome than either alone. From the complementary perspective, formal contracts help enforce informal arrangements because despite the existence of the informal contract, informal arrangements are not self-enforcing. Or, in the words of Poppo and Zenger (2002, p. 712): 
"The presence of clearly articulated contractual terms, remedies, and processes of dispute resolution as well as relational norms of flexibility, solidarity, bilateralism, and continuance may inspire confidence to cooperate in inter-organisational exchanges". Academics who adopt the complementary perspective on formal and informal contract interaction, believe that formal contracts have a regulating influence on the informal processes that lead parties to cooperate or defect. Since informal agreements would only be stable when the long-term profits exceed the gains to be made by short-term agreement-breaking, the value of living up to the informal agreements could be increased by reducing the gains to be made from short-term agreement breaking (Poppo and Zenger, 2002).

The complementary view argues that incentives and punishments in the formal contract can achieve this. Academics who take the complementary perspective on formal and informal contract interaction, argue that formal contracts have three functions in this mechanism. They spell out the parties' long-term commitment to exchange and, by specifying punishments for defection, they also limit the potential gains to be made from opportunism. Additionally, the fact that a formal contract is written down, leads the parties to expect each other to cooperate, which decreases the incentives for defection (Baker, Gibbons \& Murphy, 1994). The empirical work by Larson (1992) supports this view, suggesting that success between partners in the past will yield even greater success in the present. Poppo and Zenger (2002, p. 713) add that, in themselves, contracting processes may promote expectations of cooperation since activities relating to creating complex contracts result in parties determining and committing themselves to methods for handling contingencies, monitoring solutions and penalties. Thus, exchange hazards are not just tackled by formal specification of limits and expectations, but also by the mutual expectations and social relationships developed during procurement. This is supported by Blomqvist, Hurmellina and Seppänen (2005, p. 497) who state that "the contracting process may be used purposefully to increase mutual understanding".

The debate concerning formal and informal forms of control, conducted especially in the research on trust, has gained broad attention in the last decade (Levitt, Henisz, Scott \& Settel, 2010; Macneil, 1978; Scott, 2001; Williamson, 1979). Input has not only been given by pure trust researchers. Academics who conduct studies in the construction industry have also made contributions (e.g. Kadefors, 2005; Kamminga, 2008; Klein Woolthuis, Hillebrand \& Nooteboom, 2005; Laan, 2009; Welling, 2006). For now, academics generally state that formal and informal control are dynamically interrelated and that empirical evidence is needed to help the discussion further (Klein Woolthuis, Hillebrand \& Nooteboom, 2005; Laan, 2009).

\subsection{Theoretical framework: the FINCIP model}

To guide the study into how negotiations and commitments are interrelated in the context of $\mathrm{CD}$ procured construction projects, a model is constructed in which the development of negotiations and commitments in inter-organisational projects is reflected. Of the academics studying inter-organisational relationships, Ring and Van de Ven (1994) provide a 
comprehensive reflection of the dynamics of formal and informal negotiations and commitments involved (See Section 2.1). Their process framework "that focuses on formal legal, and informal psychological processes by which organisational parties jointly negotiate, commit to, and execute their relationship in ways that achieve efficient and equitable outcomes and internal solutions to conflicts when they arise" (Ring \& Van de Ven, 1994, p. 90 ) is used as a starting point. It gives an overview of the components that are involved in relationship development, and negotiations and commitments are part of it.

The model of Ring and Van de Ven (1994) is used, especially because their model reflects upon the development of the inter-organisational relationship as a whole, not limited to just the stage of procurement (unlike Pascale and Sanders (1997); Walker and Hampson (2003)) or just the stage of execution of the contract (unlike Boddy, Macbeth and Wagner (2000); Dwyer, Schurr and Oh (1987); Thompson and Sanders (1998)). Ring and Van de Ven (1994) do not, however, go into detail about the manner in which negotiations and commitments are interrelated. Furthermore, the influence of contextual aspects such as the procedure by which the project is procured, are not incorporated. Therefore, to make the model of Ring and Van de Ven (1994) useful for this study into how negotiations and commitments develop in the context of procurement by the CD procedure, the model is expanded with the model of Vlaar et al. (2006) and with the framework later suggested by Ring and Van de Ven (2000). The added value of these models is described below.

\section{Formalisation and the key role of understanding}

Although in their model Ring and Van de Ven (1994) depict negotiations and commitments as interrelated, they do not explain the interrelatedness of the concepts they use. A detailed description of the formalization process (including both negotiations and commitments) is given by Vlaar et al. (2006). In their model reflecting "Relationships between Formalization, Mechanisms, Sensemaking, and Understanding in an Interorganizational Context", Vlaar et al. (2006) state that both negotiations and commitment are intricately related to problems of understanding (p. 1618). They "believe that formalisation accomplishes part of its purpose not just with the words agreed upon, but also by means of the process through which parties arrive at these words, and through the words discussed and ultimately rejected" (ibid., p.1619).

Vlaar et al. (2006) are convinced that formalisation helps in making sense of the interorganisational relationship and to its context, through four mechanisms: 1). Focusing attention, 2). Forcing articulation, deliberation and reflection, 3). Instigating and maintaining interaction, and 4). Reducing judgemental errors and individual biases, and diminishing the incompleteness and inconsistency of cognitive representations. According to Vlaar et al. (ibid.) "problems of understanding propel the need for formalisation, which subsequently influences sensemaking through four mechanisms, eventually enabling participants in interorganizational relationships to achieve more congruent understandings". Opposed to Ring and Van de Ven (1994) who go from commitments back to (re)negotiations via the execution of a contract, Vlaar et al. (2006) close the loop from commitments to (re)negotiations directly via the solving of problems of understanding. 


\section{Context variables}

The central research question in this thesis is about the interrelatedness of negotiations and commitments in the context of procurement by the CD procedure. The contextual influence of procurement procedures is, however, not incorporated in either one of the models of Ring and Van de Ven (1994) or Vlaar et al. (2006). In 2000, however, Ring and Van de Ven explored a part of their earlier process framework in greater detail. When doing so, they developed a model that describes the "Relationships among Transaction Context, Structure, and Process". This model (Ring \& Van de Ven, 2000; p. 173) looks into the influence of context on negotiation processes and on the structure of the formal legal contract. The stage after contract close was not taken into account. However, with their statements that the structure of governance and safeguards (transaction structure) "establishes a context for inter-party action", and that "prior processes construct and embody future transaction structures"(Ring \& Van de Ven, 2000, p.174), they acknowledge that context variables which are important during procurement, work through during execution of the transaction as well.

According to Ring and Van de Ven (2000), context influences both transaction structures and processes. Structures depend on the risk of the deal (stemming from uncertainty, asset specificity, size of the deal, complexity, longevity, interdependence, bounded rationality, opportunism and information asymmetry), whilst processes depend on trust among parties (stemming from similarity - compatibility, power balance, information asymmetry - , and prior transactions - amount / degree, stability, performance, small numbers -).

Besides risk and trust, Ring and van de Ven (ibid) state that how people behave in formal and informal processes is influenced by their roles in the transaction. In their model of 1994, role and personal interactions were only incorporated in the executions stage. The model of 2000 acknowledges that these interactions are already of influence during the procurement stage of the project. Ring and Van de Ven (2000) show how both individuals in a transaction relationship enact "inherently contradictory roles" since, alongside their own personal interests, each of them also represents an organisation that has an interest in the transaction. Furthermore, they argue that not just the transaction, but also the outcomes of negotiations are assessed by all parties in terms of efficiency and equity, measured against their outcome expectations. The extent to which transactions are assessed both efficient and equitable influences the development of the relationship.

Finally, Ring and Van de Ven (2000) acknowledge that the environment of the transaction may expose constraints to the development of the relationship which are not predictable at forehand.

Summarized, the context variables distinguished by Ring and Van de Ven $(1994,2000)$ are: perceived risk of the deal, trust in parties, role relationships, outcome expectations, and environmental constraints. These variables are expectedly of influence both during procurement and during execution of the inter-organisational project. 


\section{The FINCIP model}

In this research, answers are sought to the question how negotiations and commitments are interrelated in the context of procurement by the CD procured construction projects. To develop a theoretical frame to guide the research, three relational governance models have been combined. Ring and Van de Ven's Process Framework of the Development of Cooperative IORs (1994) forms the basis, added with information concerning the interrelatedness of Negotiations and Commitments and concerning context variables from Vlaar et al.'s model of Relationships between Formalisation, Mechanisms, Sensemaking, and Understanding in an Inter-organisational Context (2006), and Ring and Van de Ven's model on the relationships among Transaction Context, Structure and Process (2000). The thus created model (See Figure 2.2) is called FINCIP: a process model describing Formal and Informal Negotiations and Commitments in Inter-organisational Projects.

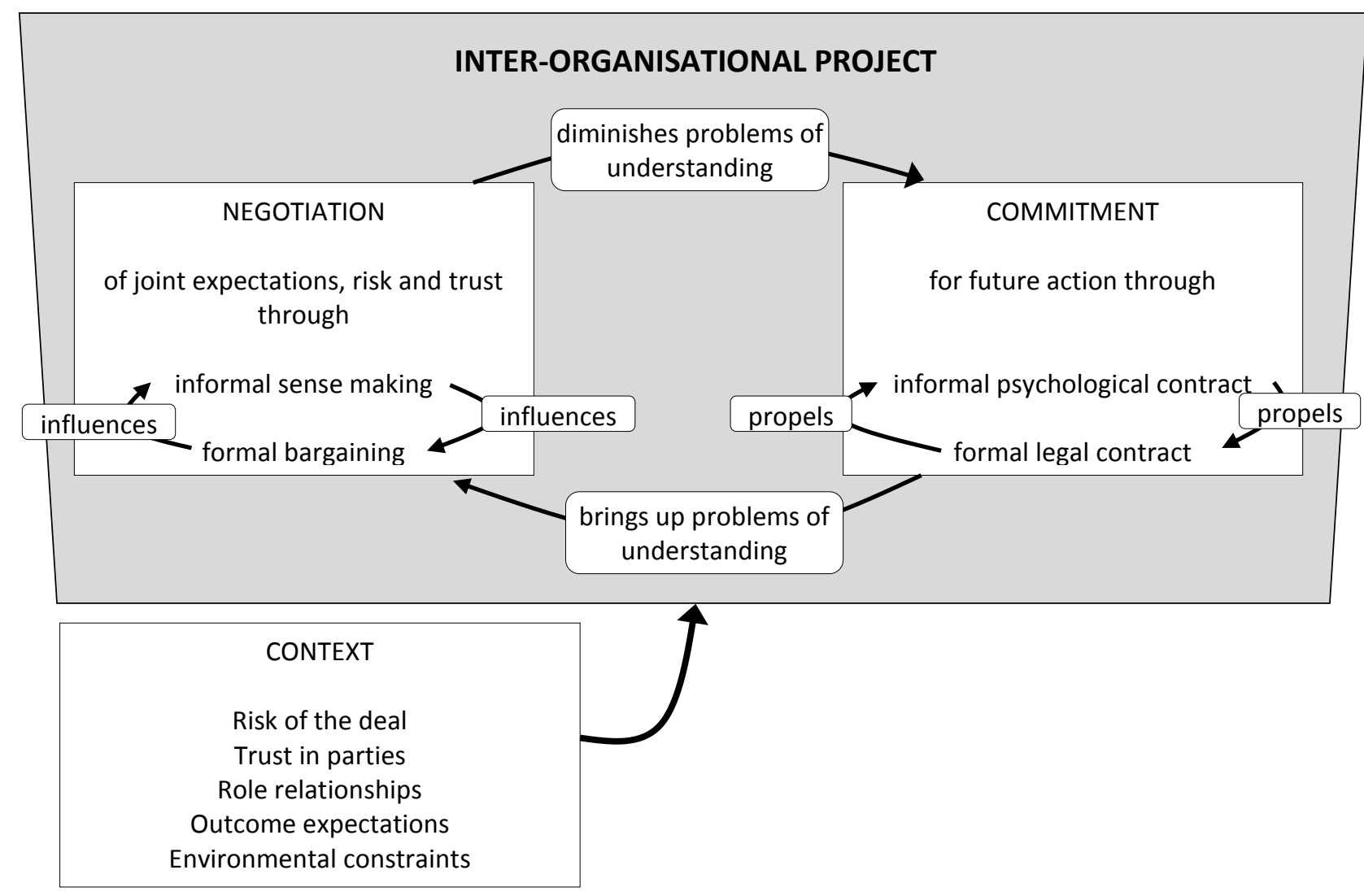

Figure 2.2. The FINCIP model describing Formal and Informal Negotiations and Commitments, involved in Inter-organisational Projects.

The FINCIP model shows how inter-organisational projects encompass both negotiations and commitments, and that these develop within a complex context. Both the negotiation frame and the commitment frame consist of a formal part (formal bargaining / formal legal contract) and an informal part (informal sensemaking / informal psychological contract), and these develop as problems of understanding are identified or resolved. This model will be further elaborated upon in Sections 2.4, 2.5 and 2.6. 


\subsection{Negotiation: Formal bargaining and informal sensemaking}

In the previous section, in Figure 2.2, the FINCIP model was presented that will guide the research concerning the development of formal and informal negotiations and commitments in $\mathrm{CD}$ procured construction projects. The main parts of the framework are negotiations and commitments. In this section, those framework elements that form negotiations are explained. First, formal bargaining is elaborated upon, followed by informal sensemaking processes.

\section{Formal bargaining}

Within the field of microeconomics, bargaining is seen as a process of interactive communication aimed at coming to an agreement in a situation where the parties involved have somewhat conflicting interests (Kamminga, 2008). Usually, both before and after contract close, the terms of the agreement are the subject of the bargaining. In their attempt to come to a consensus about these terms, several mechanisms occur. Relational governance academics (See Vlaar et al., 2006 for an overview) have identified four mechanisms that occur during bargaining: focusing attention; forcing articulation, deliberation and reflection; interacting; and reducing biases, judgement errors, incompleteness and inconsistency. Vlaar et al. (2006) explain these four mechanisms as follows:

- Focusing Attention: in the negotiation stage of contracting, parties co-orient on the formal bargaining processes, and so formal bargaining amounts to a focusing device. Formal bargaining provides focal points for different streams of on-going activities, giving them meaning and direction. Vlaar et al. (2006) show how formal processes focus attention by highlighting the order and the content of decisions which have to be made; by drawing lines as to what is allowed, expected and possible, and what is not; and by guiding the parties towards the important primary issues, and thus dissuading them from distractions. Thus, the perceived complexity will decrease since the information and cues on which participants focus their attention become limited.

- Forcing Articulation, Deliberation and Reflection: while bargaining over possible terms and conditions, parties are forced to make their individual and mutual goals explicit. This helps parties make knowledge and assumptions - which were, up to then, only abstract or tacit - explicit, simple, ordered and relevant to the situation in hand. Vlaar et al. (2006) show how the need to articulate the knowledge and assumptions forces people to reflect, cogitate and think deeper. Through articulation, deliberation and reflection, tacit knowledge is turned into words and schemas.

- Interacting: formal bargaining involves parties exchanging ideas about future tasks and outcomes through conversations and dialogues. The bargaining processes of arguing, listening and working to harmonise differences, enable individuals to express their ideas, confront their own beliefs and opinions with those of others and challenge each other's points of view. As such, parties come to share and fuse knowledge, assumptions and mental models. 
- Reducing biases, judgement errors, incompleteness and inconsistency: the fact that, in inter-organisational bargaining processes, several people are usually involved compensates for deficiencies in individual thought processes. Vlaar et al. (2006) argue that these bargaining processes are therefore likely to result in more nuanced, consummate and consistent pictures of reality, and that this increases the likelihood of a reliable and predictable decision-making process. Further, it makes it more likely that the considered information is relevant; that it is treated properly; and that inconsistencies are uncovered and eliminated.

The identified outputs of the bargaining process (information confinement and cues on which participants focus their attention; tacit knowledge turned into words and schemas; shared and fused knowledge, assumptions and mental models; and reduced impact of biases and judgement errors / increased consistency and completeness of cognitive representations) form conditions for the second part of negotiations: informal sensemaking. Vlaar et al. (2006, p.1622) argue that formalisation (formal bargaining) "enables, or even forces collaborating parties to engage in sensemaking, helping them to create common ground and achieve mutual understanding". So, bargaining influences informal sensemaking.

\section{Informal sensemaking}

Sensemaking is a social process during which members of an organisation interpret their environment in and through interactions with others, thus constructing observations that allow them to comprehend the world and to act collectively (Isabella, 1990; Sackman, 1991;Sandelands \& Stablein, 1987; Starbuck \& Milliken, 1988; Weick \& Roberts, 1993). In inter-organisational projects, two parties with different patterns of beliefs and assumptions have to create coherent understandings in order to come to collective action (Maitlis, 2005; Weick, 1993). Whereas, in microeconomics the emphasis is on the differences in interests between the parties, social psychologists tend to emphasise the risk for misinterpretations and miscommunication when the two parties involved have different backgrounds, work in different cultures and have dissimilar belief systems (Sutcliffe \& Huber, 1998). Yet, since the two parties intend to work together, they will strive for congruent views on the purpose and expectations of the relationship. Sensemaking processes are therefore assumed to play a central role in the procurement of a project. These processes form "the primary site where meanings materialise that inform and constrain [action]" (Mills, 2003, p.35; Weick, Sutcliffe \& Obstfeld, 2005, p. 409).

Weick earlier (1995, p.30) described the sensemaking process as one of enactment: parties produce part of the environment they face. According to Weick (1995), people take whatever is clear to them, and link it to what is less clear. This could easily refer to beliefs and actions: "beliefs can affect themselves through the mediation of action, and [...] actions can affect themselves through the mediation of beliefs" (pp.155-156). Weick distinguishes various ways in which people impose frames on on-going flows (growing meaning: beliefdriven sensemaking) and the ways in which people link frames with cues in the interest of enhancing meaning (creating meaning: action-driven sensemaking). On-going flows and cues can be either internal (one's own beliefs and actions) or external (someone else's beliefs and actions). Belief-driven sensemaking principles cover arguing and expecting, and actiondriven principles involve committing and manipulating (See Table 2.1). 
Table 2.1. Weick's (1995) four sensemaking principles

\begin{tabular}{l|ll} 
& $\begin{array}{l}\text {...belief } \\
\text { (on-going flows) }\end{array}$ & $\begin{array}{l}\text {...action } \\
\text { (cues) }\end{array}$ \\
\hline $\begin{array}{l}\text { Internal... } \\
\text { (one's own) }\end{array}$ & $\begin{array}{l}\text { Arguing } \\
\text { Growing meaning by discussing non- } \\
\text { congruent (or even contradictory) beliefs }\end{array}$ & $\begin{array}{l}\text { Manipulating } \\
\text { Creating meaning to justify actions high in } \\
\text { choice, visibility and irrevocability, by focussing } \\
\text { on congruent beliefs }\end{array}$ \\
$\begin{array}{l}\text { External... } \\
\text { (someone } \\
\text { else's) }\end{array}$ & $\begin{array}{l}\text { Expecting } \\
\text { Growing meaning by noticing what is }\end{array}$ & $\begin{array}{l}\text { Committing } \\
\text { Creating meaning to explain actions taken to } \\
\text { make the "right" things happen, by focussing }\end{array}$ \\
& & $\begin{array}{l}\text { on congruent beliefs } \\
\text { on }\end{array}$
\end{tabular}

The result of the sensemaking process is an understanding of the transaction, the context of the transaction and the value of it to the other party and to oneself. Shared understandings between the two parties are reflected in mutual beliefs, norms, values and routines. These form the basics of the first part of Commitments: the informal psychological contract. Ring and Van de Ven (1994, p.100) describe this as follows: "Psychological contracts [...] consist of unwritten and largely nonverbalised sets of congruent expectations and assumptions held by transacting parties about each other's prerogatives and obligations". So, sensemaking ultimately results in informal psychological contracts.

\subsection{Commitment: Informal psychological contract and formal legal contract}

In this section, the commitment part of the FINCIP model will be elaborated upon. First, the informal psychological contract is described, after which the formal legal contract is explained.

\section{Informal psychological contract}

Contemporary literature has seen a plethora of attempts to define the elusive construct of a psychological contract (Argyris, 1960; Dunahee \& Wrangler, 1974; Herriot \& Pemberton, 1995; Kotter, 1973; Levinson, Price, Munden, Mandl \& Solley, 1962; McLean Parks, Kidder \& Gallagher, 1998; Morgan, 1986; Neale \& Northcraft, 1991; Portwood \& Miller, 1976; Rousseau, 1989, 1990, 1998; Rousseau \& Tijoriwala, 1998; Schein, 1965). In most of these, the definition of the psychological contract is narrowed to the relationship between employer and employee, either at the bilateral level between individual and organisation or at a unilateral level between two individuals, one of whom represents an organisation.

Following the literature review of Van Den Brande, Sels, Janssens and Overlaet (2002), four aspects of these psychological contracts between an employer and an employee seem key and are considered: subjectivity, reciprocity, implicitness and obligation. These "elements of quasi-moral involvement among parties" are much more common among members of an internal organisation, but also can and do appear in an inter-organisational context (Williamson, 1975, p. 38). In other words, the construct of a psychological contract between an employer and an employee does not have to differ from the construct of a psychological contract between a principal and a contractor. Nevertheless, the term psychological contract is widely used to explicitly refer to the employer-employee relationship. Therefore, we would emphasise that, in this research, we apply the construct to a different form of 
exchange relationship than is common. To further reinforce this point, in this research the term informal psychological contract is used to highlight the distinction from a formal legal contract.

Further, the term informal psychological contract is related to the term informal control as used by relational governance academics. Combining the three-way distinctions made in control forms by Williamson (1975) and by Nooteboom (1996), a two-way distinction was developed between formal control - based on measures - and informal control - based on values - (Eisenhardt, 1985; Kadefors \& Laan, 2010). Table 2.2 shows how the two terms informal psychological contract and formal legal contract of the FINCIP model compare to the two terms informal control and formal control (Eisenhardt, 1985; Kadefors \& Laan, 2010); to the three terms benevolence, incentive control and opportunity control (Nooteboom (1996), and to the three terms social ordering, private ordering and legal ordering of Nooteboom (1994). Private ordering and incentive control could both be divided into a formal and an informal component. Using the definitions of Nooteboom (2002), Kadefors and Laan (2010) state that "Informal control is about purposefully establishing norms, values and routines, to reduce discrepancies in goal preferences and inclinations towards opportunism. Consequentially, informal control reduces risk through the establishment of shared values. A shared understanding encourages parties to establish reasonable and achievable goals, which as well reduces risk (Das \& Teng, 2001)". This is unlike in formal control which is, according to Kadefors and Laan (2010), "about establishing and utilising contracts, formal procedures and monitoring policies. It is aimed at limiting risk, by mitigating opportunities and incentives for opportunism (by contracts) in order to acquire evidence of intentions".

Table 2.2. The relationships between formal / informal contracts and three control-ordering principles

\begin{tabular}{|c|c|c|c|}
\hline FINCIP model & $\begin{array}{l}\text { Classification of } \\
\text { Williamson (1975) and } \\
\text { Nooteboom (1994) } \\
\end{array}$ & $\begin{array}{l}\text { Classification of } \\
\text { Nooteboom (1996) }\end{array}$ & $\begin{array}{l}\text { Classification of } \\
\text { Eisenhardt (1985) and } \\
\text { Kadefors and Laan (2010) }\end{array}$ \\
\hline \multirow[t]{2}{*}{$\begin{array}{l}\text { Informal } \\
\text { psychological } \\
\text { contract }\end{array}$} & $\begin{array}{l}\text { Social ordering } \\
\text { (complemented by } \\
\text { Nooteboom, 1994): } \\
\text { Decreasing propensity for } \\
\text { opportunism by using } \\
\text { norms, values and loyalty }\end{array}$ & $\begin{array}{l}\text { Benevolence } \\
\text { Limitation on inclination } \\
\text { towards opportunism based } \\
\text { on established, socially } \\
\text { inculcated norms and values; } \\
\text { and also on empathy, } \\
\text { identification, affect and } \\
\text { routines developed in specific } \\
\text { relationships }\end{array}$ & \multirow[t]{2}{*}{$\begin{array}{l}\text { Informal control } \\
\text { Purposefully establishing } \\
\text { norms, values and routines to } \\
\text { reduce discrepancies in goal } \\
\text { preferences and inclinations } \\
\text { towards opportunism }\end{array}$} \\
\hline & \multirow{2}{*}{$\begin{array}{l}\text { Private ordering } \\
\text { Incentives such as shared } \\
\text { ownership of specific } \\
\text { investment, and } \\
\text { reputation mechanisms or } \\
\text { posting of hostages }\end{array}$} & \multirow{2}{*}{$\begin{array}{l}\text { Incentive control } \\
\text { Limitation on material } \\
\text { incentives to utilise } \\
\text { opportunities for opportunism }\end{array}$} & \\
\hline \multirow[t]{2}{*}{$\begin{array}{l}\text { Formal legal } \\
\text { contract }\end{array}$} & & & \multirow{2}{*}{$\begin{array}{l}\text { Formal control } \\
\text { Establishing and utilising } \\
\text { contracts, formal procedures } \\
\text { and monitoring policies }\end{array}$} \\
\hline & $\begin{array}{l}\text { Legal ordering } \\
\text { Means to constrain } \\
\text { opportunism including } \\
\text { contracts and monitoring }\end{array}$ & $\begin{array}{l}\text { Opportunity control } \\
\text { Limitation on the } \\
\text { opportunities for opportunism }\end{array}$ & \\
\hline
\end{tabular}


The elements within both forms of control are reflected in either formal legal or informal psychological contracts. In legal jargon, the term informal contract explicitly refers to a contract that is not signed under seal. This is explicitly not what is meant here. Here, an informal (psychological) contract refers to the implicit set of expectations between the principal and the contractor which further, unlike in a written contract, are subject to continual change. As such, it is a highly flexible and undefined set of terms that are interpreted by the individuals involved. Although it is only implicit, it can be a significant determinant of behaviour within transactions, and any perceived violations can have lasting effects.

Ring and Van de Ven (1994) describe how the informal contract becomes formally codified. Given that individuals act as agents for their organisations, these organisations will require formal documentation and standardisation. Thus, the informal commitments made by interacting individuals will be put into writing for their organisations and for other individuals also acting as agents for these organisations. Furthermore, informal commitments become institutionalised over time due to the repetitive execution of acts by the individuals involved. Berger and Luckmann (1966, p. 57) describe this as follows: "Man is capable of producing a world that he then experiences as something other than a human product."

\section{Formal legal contract}

When a formal legal contract is perceived to reflect formal control, it contains both limitations on the opportunities for opportunism and limitations on the material incentives to utilise these opportunities. There are several mechanisms with which contracting parties could address this form of control. These mechanisms, that are derived from transaction cost economics, are: a shift in rights/powers of decision; reward systems; monitoring; and bonding (Douma \& Schreuder, 2008; Kamminga, 2008).

- A shift in rights/powers of decision: When a contract captures a shift in the rights or powers to make decisions, it amounts to the principal delegating (part of) its rights or decision-making power to the agent such that the agent can make decisions on behalf of the principal. Such delegations of power will be put in writing in the body of the formal legal contract.

- Reward systems: There are various reward systems, and these are designed to align the agent's interests with those of the principal. Rewards can be based on either output or input measurements. Output measurement contains more risk for the agent (environmental aspects play a role in the ability to meet output goals), and so the agent will seek compensation in the form of a higher reward. If the principal wants to avoid this by rewarding based on input, then they will draw on one or both of the mechanisms outlined below: monitoring and bonding.

- Monitoring: Monitoring is a mechanism that can be used to check on an agent's actual efforts. This will involve transaction costs (the monitoring costs) on the principal's account.

- Bonding: When using a bonding mechanism, agents themselves have to prove which efforts they have made in performing their tasks. This mechanism also involves transaction costs (bonding costs), but these are on the accounts of the agent. 
Vlaar et al. (2006) argue that there are several disadvantages in formalising informal understandings. They come to the conclusion that formalisation may have negative effects on sensemaking, causing new problems in understanding. The risk is that it may make events appear more comprehensible and controllable than they really are. It may lead to formalism, resulting in increased rigidity, a loss of creativity and flexibility, and diminished trust. Further, the preparation of formal legal contracts may involve large efforts and huge transaction costs, and it could hamper the conversation when the benefits of the contract are unclear to the parties. Furthermore, although standardised formal contracts guide the agents of organisations, Ring and Van de Ven (1994) argue that "new agents may employ these blueprints without fully understanding the initial and changing intentions of a relationship. As this drift between appreciation of the formal and informal contracts develops over time, we would expect conflicts to erupt among the parties." Ring and Van de Ven (1994) suggest that these conflicts (problems of understanding) can either terminate the relationship or initiate another cycle of negotiations (bargaining / sensemaking).

\subsection{Understanding: link between negotiation and commitment}

Earlier in this chapter, in Sections 2.4 and 2.5, the cycle of negotiations - commitments negotiations was elaborated upon. A key concept in this cycle is understanding. Having made sense of a new situation, people wish to enact their inputs to the sensemaking processes back into their world, in order to reorder it (Weick, 1995). This might be in the form of having confirmed a better understanding of, for example, the other parties' cultures, capabilities, management systems and weaknesses, and about the context in which the relationship is embedded (Vlaar et al., 2006). Enactment of sensemaking processes could also occur in the form of making new formal agreements or contracts. Parties may create "a solid understanding of the business, share a common fact base, and agree on important assumptions" (Kaplan \& Beinhocker, 2003, p. 72). Vlaar et al. (2006) add that understandings could also involve the nature and size of the outcome of the relationship; the processes that are important in reaching this outcome; and each other's intentions, actions and behaviour. The resulting collective consciousness, common reality or shared understanding provides a common basis for action. For those points on which this collective consciousness, common reality or shared understanding is reached, parties have progressed to commitment (Ring \& Van de Ven, 1994).

However, processes of informal sensemaking also propel new formal bargaining processes. These might, for example, relate to the details of contractual arrangements or to the agenda for the next meeting. These new bargaining processes further facilitate new sensemaking processes that, in turn, could improve understanding. However, parties do not need to completely understand each other or share a point of view. Differences in prior experiences, and distinct interests and objectives, will result in differing interpretations and understandings persisting (Vlaar et al., 2006).

Ring and Van de Ven (1994) indicate that formal and informal processes interact during each stage of the development process. It is not just that formal bargaining leads to a formal legal contract, and informal sensemaking to an informal psychological contract. As Ring and Van de Ven (2000, p. 172) describe it: "the two (...) are interdependent; transaction structure and process are like opposite sides of a coin. (...) [U]nderstanding transaction structures and 
processes requires an appreciation of both formal and informal processes. Formal legal requirements impose constraints on transaction structure and process, yet transaction negotiation and execution involves informal, interpersonal interactions. These, in turn, affect formal processes". However, whereas Ring and Van de Ven (1994) assume that formal and informal contracts are substitutes for each other (that is, the existence of an informal contract diminishes the need to establish a formal contract), the insights of Vlaar et al. (2006) suggest that formal and informal contracts serve rather as complements to one another. Developments in the informal contract lead to developments in the formal contract, and vice versa.

The basic premise in this research is that principles of understanding form the main force in these developments. This is reflected in the theoretical framework, which is elaborated in Section 2.7 below.

\subsection{Conceptualisation of the research model}

The main concepts in this research are formal and informal negotiation (formal bargaining and informal sensemaking) and formal and informal commitment (formal legal contract and informal psychological contract). The literature review has not provided clear operationalisations for these concepts and, therefore, they will be treated as sensitising concepts. Following Blumer (1969, p. 148) sensitising concepts are defined as followed: "[A sensitizing concept] gives the user a general sense of reference and guidance in approaching empirical instances. Whereas definitive concepts provide prescriptions of what to see, sensitizing concepts merely suggest directions along which to look. The hundreds of our concepts - like culture, institutions, social structure, mores, and personality - are not definitive concepts but are sensitizing in nature." Table 2.3 reflects on the sensitising concepts with reference to their sources. The aspects in which each of the concepts in this research are reflected are detailed in the third column. In this way, the theoretical framework guides this research. 

to an agreement in a situation where the parties involved have somewhat

\section{Sensitising concepts: theoretical definition}

Formal bargaining: a process of interactive communication aimed at coming conflicting interests (Kamminga, 2008).
Concretised in the following dimensions and sub-dimensions

Focusing Attention: decreasing complexity by limiting the information and cues on which participants focus their attention (Vlaar et al., 2006).

Articulation, Deliberation and Reflection: turning tacit knowledge into

Interaction: sharing and fusing knowledge, assumptions and mental models (Kotabe et al., 2003).

Reducing biases, judgemental errors, incompleteness and inconsistency: compensating for deficiencies in individual thought processes by confronting them with several others (Vlaar et al., 2006).

Belief-driven sensemaking: growing meaning of ongoing flows by arguing or expecting (Weick, 1979).

fiformal sensemaking: a social process during which members of an others, thus constructing observations that allow them to comprehend the world and to act collectively (Isabella, 1990; Sackman, 1991; Sandelands \& Stablein, 1987; Starbuck \& Milliken, 1988; Weick \& Roberts, 1993). Informal psychological contract: the informal set of expectations between parties, including norms, values and routines (Nooteboom, 2002)
Action-driven sensemaking: giving meaning to cues by commitment or manipulation (Weick, 1979). established, socially inculcated norms and values, and on empathy, words and schemas (Weick et al., 2005).

In this research, reflected in:

Focal points in protocols and agendas

Individual and mutual goals, knowledge and assumptions

Exchange of ideas, conversations, dialogue

Revision/nuancing of points of views, uncovering and elimination of inconsistencies

\section{Arguments}

Expectations

\section{Justifications}

Focus on limited number of beliefs

Benevolence: limitation on inclinations towards opportunism, based on Mutual understanding

identification, affect and routines developed in specific relationships

Norms/values

Empathy/affection

Nooteboom, 2006).

Informal incentive control: limitation on non-material incentives to utilise opportunities for opportunism due to dependence on the relationship [...] or reputation effects (Nooteboom, 2006).

Formal legal contract: contract, formal procedures and monitoring policies (Nooteboom, 2002)

Problems of understanding: the uncertainty and ambiguity that parties in inter-organisational relationships experience in early stages of collaboration, Formal incentive control: limitation on material incentives to utilise opportunities for opportunism due to [...] hostages [...] (Nooteboom, 2006).

Opportunity control: limiting opportunities for opportunism by restricting the range of a partner's action through contract or hierarchical supervision (Nooteboom, 2006).

Discontinuities in structures, contexts, routines, expectations and perceptual frameworks (Vlaar et al., 2006)

due to differences between the parties in terms of culture, experience, structure and industry. (Vlaar et al., 2006)

Context: situational opportunities and constraints that affect the occurrence and meaning of organizational behavior as well as functional relationships between variables (Johns, 2006)
Specific situational variables of task context, social context and physical context that influence behavior directly or moderate relationships between variables (Hattrup \& Jackson, 1996; Mowday \& Sutton, 1993).

\section{Routines}

Importance of the on-going relationship Importance of reputation

Reward system

Allocation of risks

Contract clauses

Output specifications

Monitoring system

Discussions

Irritations

Expressed inabilities to make sense of the partner, the relationship or the context.

Especially perceived risk of the deal; trust in parties; role relationships; outcome expectations; environmental constraints (Ring \& Van de Ven, 2000) 


\subsection{Propositions about the interrelatedness of negotiations and commitments}

In Chapter 1, five steps for case study research were summarised, and the first step was made by describing the research's question, main questions and sub-questions. In the preceding sections of this chapter, a start has been made on step 2: developing the study's propositions. By describing the relevant constructs and the theories related to the main questions and sub-questions of the research, it has been clarified what is already known and what kind of theories have already been developed. The newly developed FINCIP model, depicting how which components of negotiations and commitments play a role in interorganisational projects, provides an indication of the dynamics in both the formal and informal components of negotiations and commitments involved in inter-organisational projects. Procurement methods like the $C D$ procedure set the rules for negotiations during the procurement of a project. These are incorporated in the model as a context variable. The results of step 2 in the research are reflected in four propositions, that are described below.

The $C D$ procedure was intended for procurement activities in complex projects, for which technical, legal and/or financial solutions were not objectively specifiable by the procuring authority. Complex projects can be characterised by high levels of risk and insecurity about what to expect. Following Ring and Van de Ven (2000), we assume that the important context variables are risk, initial trust levels, outcome expectations and environmental constraints. This leads to the first proposition:

Proposition A: inter-organisational projects are influenced by context variables including perceived risk, initial trust levels, role relationships, outcome expectations and environmental constraints.

The CD procedure is a relatively new approach to procurement, and is expected to influence the execution of a project through influencing negotiations during procurement. One could argue that procurement equates to negotiations as identified in the FINCIP model, whilst project construction starts in the commitment part. This might seem logical if one considers the contract that is signed at the end of the procurement process to be the formal legal contract. However, this is not in line with the premise in the FINCIP model that understanding, and problems of understanding, determine whether negotiations start or commitments are developed. Given this view, contract closure cannot be seen as the demarcation point between negotiations and commitments. The contract that is signed will still be renegotiated in new series of formal bargaining and informal sensemaking. Nevertheless, the contract that is signed at the end of the tendering process is meant to be a formalisation of the understandings reached during the tender negotiations, and parties do intend to commit to the agreements reflected within. Based on the motivation for designing the $\mathrm{CD}$ procedure as described in Chapter 1 , we come to the following proposition:

Proposition B: by facilitating sensemaking processes in the negotiations during procurement, the $C D$ procedure prevents extensive renegotiations to be necessary in the execution stage of inter-organisational projects. 
This is closely related to the concept of understanding, that has a key role in the FINCIP model. The parties involved might well understand each other on some aspects of the project, and face problems with understanding on others, during any stage of the project. However, since it is not possible to simultaneously both understand and have problems in understanding a specific aspect, the parties are expected to be either involved in negotiations or in commitments for each individual aspect at any point in time. This means that negotiations and commitments can be seen as substitutes for each other (in the sense that one of them, but never both, is applicable at any point time) and led to proposition C:

Proposition C: during all phases of a project, from initiation through to delivery, negotiations and commitments are substitutes for each other: the parties involved go back and forth between negotiations and commitments, depending on whether there is understanding or not.

During interaction, both formal and informal processes take place. Formal bargaining and informal sensemaking are both meant to decrease problems linked to understanding. Once understanding has been achieved, contracts will contain both formal and informal components. The formal legal contract and the informal psychological contract both reflect the understanding that has been reached. The premise in the FINCIP model, that formal and informal components interact within stages, implies that formal bargaining and informal sensemaking are complementary, as are the formal legal contract and the informal psychological contract.

Proposition D: formal and informal components of negotiations and commitments are complements of one another.

These propositions form the starting point from where we examine the practice of procuring inter-organisational projects by use of the CD procedure. 


\title{
Chapter 3. Perceived influence of the CD procedure on negotiations and commitments
}

\author{
Parts of this Chapter have been presented in: \\ Hoezen, M.E.L. (2009). \\ Efficiëntie en effectiviteit van de Europese Commissie: \\ ontwerp en invoering van de concurrentiegerichte dialoog als voorbeeld. \\ Berg en Dal, the Netherlands, 8ste Nederlands-Belgisch PoliticologenEtmaal 29 May 2009.
}

Parts of this Chapter are/will be published in:

Hoezen, M., Voordijk, H. \& Dewulf, G. (in press) Procuring complex projects using the competitive dialogue procedure: Expected effects International Journal of Project Organisation and Management

Hoezen, M.E.L. \& Dorée, A.G. (2008) First Dutch competitive dialogue projects: a procurement route caught between competition and collaboration In A. Dainty (Ed.), Proceedings 24th ARCOM conference, 1-3 September 2008, Cardiff, UK (pp. 535-543). Reading, UK: Arcom

Hoezen, M. \& Hillig, J. B. (2008) The competitive dialogue procedure: advantages, disadvantages, and its implementation into english and dutch law In J. Adriaanse, P. Kennedy, J. Adshead \& M. Brand (Eds.), Proceedings of COBRA 2008, 4-5 September 2008, Dublin, Ireland (pp. 1-16). London, United Kingdom: RICS

In the introduction to this research several developments in the construction industry were described that led to the design of the Competitive Dialogue (CD) procedure. Notwithstanding the limited knowledge about how procurement procedures affect negotiations and commitments, the European Commission had assumptions about the working of this new procedure. It was assumed to regulate negotiations in order to influence the commitments and any renegotiations resulting from it. In the current chapter mechanisms with perceived importance to the working of the CD procedure are mapped. This helps identifying the contextual influence of the CD procedure in the development of negotiation and commitment.

First, it is explained why the European Commission (EC) introduced the CD procedure and which processes and intended objectives determined its design (Section 3.1). These objectives are compared to the early experiences with the CD procedure in the Netherlands (Section 3.2). Based on the practitioners' perceptions of the working of the CD procedure, in Section 3.3 an overview is derived of the perceived mechanisms to the working of the CD procedure. These mechanisms are used as a guide for the further research into how the inter-organisational negotiations and commitments are interrelated in the context of procurement by the Competitive Dialogue procedure. 


\subsection{Design of the CD procedure: the European Commission's intended objectives}

The combination of increased project complexity (Baccarini, 1996; Laufer et al., 1996; Alderman et al., 2005; Walker, 2007), changing government roles (Blanken, 2008) and the construction sector's poor professional functioning (Egan, 1998; National Audit Office, 2001) have changed the tasks and roles of the market and of government. Public principals remain more distant to construction projects, sourcing out more and more of the work. Stemming from these changing tasks and roles, both commitments and negotiations between public principals and contractors have been changing and are continuously developing (Bajari \& Tadelis, 2001; Cox \& Thompson, 1997; Zaghoul \& Hartman, 2003).

Given these developments, it is not surprising that the negotiated procedure gained popularity towards the end of the 1990s. Except for this procedure, none of the existing other European procedures provided the opportunity of direct one-to-one communication during the negotiation stage. According to the Council Directive 93/37/EEC Public Works Contracts (article 7), the negotiated procedure was originally only intended to be used in the following cases:

- when procurement by the open or the restricted procedures had failed;

- when the works involved were carried out purely for the purpose of research, experiment or development;

- when the works could only be carried out by a particular contractor;

- in cases of extreme urgency;

- when unforeseen additional works were needed to already awarded contracts;

- when new works were procured that replicated similar works awarded in an earlier contact;

- in exceptional cases when the nature of the works or the risks attached did not permit prior overall pricing.

Nevertheless, given the perceived need for interaction between the procuring agency and candidate contractors, more and more contracts were awarded by using the negotiated procedure. The European Commission doubted whether in all of these cases the projects which were procured, did meet the criteria for procurement by the negotiated procedure. If the EC wanted to stop the excessive use of the negotiated procedure, it would have to intervene. The EC was well aware of the desire for a procurement method that left room for extensive dialogue during the negotiations, yet the negotiated procedure had one major disadvantage: it left no room for other competitors during the negotiations stage. In the new procurement procedure Competitive Dialogue, both features of dialogue and competition came together. In this section, the developments leading towards the final design of this procedure are described.

\section{Policy rhetoric}

\section{Green Paper}

In a Green Paper (COM(96) 583 final), adopted by the European Commission on 27 November 1996, it was pointed out that the three directives for public service contracts, public supply contracts and public works contracts (Council Directive 92/50/EEC; Council Directive 93/36/EEC; and Council Directive 93/37/EEC) had to be simplified and modernised. 
In addition, in their contribution to the Green Paper, Trans-European Networks identified three principal concerns regarding facilitating, and not obstructing, private sector involvement in projects (COM(96) 583 final, pp. 34-36):

- Private sector organisations needed assurance that they would not be excluded from the tendering procedures if engaged in pre-tender discussions or studies, without threatening the principle of equal treatment.

- The possibility of consortia bidding for concessions should remain, and for them to be able to award contracts to their associates within the consortium. This would enable the private sector to participate on a risk basis in the building and operation of infrastructural projects in partnership with the public sector.

- Complex works and services contracts could, in some cases, justify the use of the negotiated procedure. The Utilities Directive gave procuring entities a free choice between procedures, yet only under certain well-defined circumstances the traditional sectors could insist on the negotiated procedure.

The EC noted that, due to the increased complexity of works, procuring authorities sought new contract forms (e.g. PPP and PFI - Private Finance initiative -) and made use of more flexible procurement procedures and awarding methods (Raganelli \& Fidone, 2007). At the time the Green Paper was written, the European Commission believed that the European Community public procurement rules could facilitate private sector participation in public projects without any need, at that stage, to amend the existing legal framework (COM(96) 583 final, p.34). However, an analysis of responses to the Green Paper (in total almost 300, coming from various economic sectors, the Member States and institutions) indicated that there was a need to simplify the legal framework and adapt it to the new electronic age while maintaining the stability of its basic structure. The Commission accepted the need to simplify the existing legal framework by clarifying provisions which were obscure or complex, and by amending legislation when the problems to be addressed could not be solved through re-interpretation of the provisions. In addition, the Commission announced it would consolidate the three "classic Directives" and merge them into a single text (COM(98) 143 final).

\section{Proposal for a Directive}

To meet these objectives the Commission published a Proposal for a Directive on the coordination of procedures for the award of public supply contracts, public service contracts and public works contracts in 2000 (COM(2000) 275 final). The Proposal served a threefold objective: simplification, modernisation and flexibility.

- Simplification - to lighten rules which were sometimes too detailed and complex;

- Modernisation - to take account of new technologies and changes in the economic environment;

- Flexibility - to respond better to the criticism of procedures which were seen as excessively rigid and not meeting the needs of public purchasers.

In Part One of the Proposal, the existing Directives are restructured and clarified, and more amendments are delineated. In Part Two of the Proposal, containing the main substantive amendments, the Commission lived up to the Green Paper ideals and tackled the other issues addressed by the parties concerning the need to ensure that partnerships between 
the public and private sectors were in no way inhibited (COM(96) 583 final, p.34). In reaction to the responses to the Green Paper, the Commission noted that specific attention needed to be paid to particularly complex contracts (COM(98) 143 final). It recorded that, with such contracts, purchasers "are well aware of their needs but do not know in advance what is the best technical solution for satisfying those needs. Discussion of the contract and dialogue between purchasers and suppliers is therefore necessary in such cases. But the standard procedures laid down by the public sector Directives [...] leave very little scope for discussion during the award of contracts and are therefore regarded as lacking in flexibility in situations of this type" (COM(98) 143 final).

Consequently, the Commission sought ways to broaden the scope of the discussion. To make procedures more flexible and to allow dialogue in the course of such procedures, and not just in exceptional circumstances, the Commission intended to "propose a new standard procedure, the "competitive dialogue', which would operate alongside open and restricted procedures and would replace the existing negotiated procedure with prior publication of a notice. The conditions and the rules under which procuring authorities would be allowed to use this new procedure and the details of the procedure itself will have to be spelt out and will be based inter alia on the principles of transparency and equal treatment" (COM(98) 143 final). The possibility of applying this new, flexible procedure was meant to be less exceptional than using the negotiated procedure was at that time, involving prior publication of a notice. The only exceptional procedure left would be the negotiated procedure without prior contract notice (COM(98) 143 final, par. 2.1.2.2) (For an extensive description see Jansen, 2001, pp. 76-78).

However, the Commission dropped this idea after further consideration and consultations. Following these, "it was felt that it would be more appropriate not to introduce an entirely new procedure: the choice made was to extend the applicability of the negotiated procedure with prior publication to include these cases" (COM(2000) 275 final/2, p.8). Thus, having a multiplicity of procedures was avoided. In the Proposed Directive, the Commission therefore looked for "the introduction of a new case for the use of the negotiated procedure, which for particularly complex contracts - permits a "dialogue" between the procuring authority and the different candidates, while ensuring that there is competition and compliance with the principle of equality of treatment" (COM(2000) 275 final/2, p. 4).

\section{From Proposal to Directive}

This last remark concerning extending the case for use of the negotiated procedure seemed sensible at the time. The negotiated procedure had gained popularity because it enabled procuring authorities to procure projects for which they were unable to define the technical specifications and price level in advance. However, there were some downsides to this procedure. For example, project complexity meant that bidders were unable to submit unconditional final bids. As a consequence, within the negotiated procedure, exclusive negotiations followed selection of the preferred bidder before a deal could be signed (National Audit Office, 2007).

This part of the process led to less advantageous terms since negotiating with a single bidder lacked the competitive element. Further, during these negotiations, the scope of the 
projects often underwent major changes, which led to a distorted competition. Moreover, the negotiations with a preferred bidder often took almost as long as the competitive stage that had preceded them, making procurement a lengthy process (National Audit Office, 2007).

Broadening the scope of the negotiated procedure was not regarded as a solution that would overcome its disadvantages. Adding a competitive dialogue to the existing negotiated procedure would not decrease, but rather increase, the use of the negotiated procedure. Therefore, after intensive discussions, the Commission decided to develop the competitive dialogue into a fully-fledged procedure (Directive 2004/18/EC, Article 29: Competitive Dialogue), and to make the negotiated procedure only applicable in exceptional cases, such as when other procurement procedures failed to lead to a contract being awarded (Directive 2004/18/EC, Articles 30 and 31 regarding the use of negotiated procedures with and without prior publication of a contract notice).

\section{The design of the Competitive Dialogue procedure}

The Competitive Dialogue was defined as a procedure in which any economic operator could ask to participate. In April 2004, the EU Public Sector Procurement Directive (Directive 2004/18/EC), which incorporates the Competitive Dialogue procedure, was published in the Official Journal of the European Union (OJEU). Since then, it has been described in several handbooks for public authorities (e.g. Arrowsmith, 2009; Essers, 2006; Pijnacker Hordijk,et al., 2009; Trepte, 2007).

In the first stage of the CD procedure, the procuring authority selects potential operators which meet the selection criteria as set beforehand. Then it conducts a dialogue with the economic operators admitted to the procedure. The aim of the dialogue is to develop one or more appropriate solutions that are capable of meeting the procuring authority's requirements. Once the appropriate solutions are sufficiently clear to the procuring authority, the (remaining) economic operators are invited to tender. In this procedure, the contract is always awarded on the basis of criteria, reflecting the most economically advantageous tender (MEAT-criteria).

The main objective of the CD procedure was to provide for "a flexible procedure, preserving not only competition between economic operators but also the need for the procuring authorities to discuss all aspects of the contract with each candidate". Although the Competitive Dialogue provides flexibility for bidders and the procuring authority to discuss how the output specification will be met, there is only limited scope to make changes to a project once the preferred bidder has been selected. Once the best and final offers have been submitted, bidders may only be asked to "fine tune, specify and clarify their bids". No substantial modifications which might result in distortion of competition can be made.

However, minor clarifications to the definition of the scope and other small modifications are allowed during the period in which the preferred bidder is identified. This should also reduce the duration and costs of this stage. The risk, however, is that the overall tendering costs for both the public and the private sectors increase due to the tendency of negotiating many minor elements of the potential deal - that are of no consequential interest to the contract close as such - with a number of economic operators prior to selecting the preferred bidder. 


\section{When to use}

To ensure transparency and fair competition, the EU Public Sector Procurement Directive contains some general clauses on the Competitive Dialogue procedure. Article 11 of the Directive 2004/18/EC distinguishes between five procurement procedures: an open procedure; restricted procedure; competitive dialogue; negotiated procedure; and design contest. Here, the legislation makes clear that the Competitive Dialogue option is only to be used in cases of "particularly complex" public contracts. Public contracts are considered to be complex when the procuring authorities (1) are not objectively able to define the technical means capable of satisfying their needs or objectives; and/or (2) are not objectively able to specify the legal and/or financial composition of a project. Section 2 of the Explanatory Notes (CC/2005/04_rev1) states that the provisions about complexity should be read in the light of the first part of recital 31 of the Directive: "Procuring authorities which carry out particularly complex projects may, without this being due to any fault on their part, find it objectively impossible to define the means of satisfying their needs or of assessing what the market can offer in the way of technical solutions and/or financial/legal solutions. This situation may arise in particular with the implementation of important integrated transport infrastructure projects, large computer networks or projects involving complex and structured financing the financial and legal make-up of which cannot be defined in advance".

The Explanatory Notes (CC/2005/04_rev1) point out that whether the use of the Competitive Dialogue procedure is justified should be checked on a case-by-case basis. For example, a simple statement that the project will be procured through a PPP is not sufficient justification for using the Competitive Dialogue procedure. The complexity of the project has to be explained in detail. The procuring authority has an obligation of diligence - if it is in a position to define the technical resources necessary, and establish the legal and financial framework, use of the Competitive Dialogue is not possible.

\section{How to use}

Following the statements on the complexity issue and about the obligation to use MEAT in awarding the contract, Article 29 of the Directive continues with brief explanations about the Dialogue itself. Firstly, procuring authorities have to publish a contract notice in which they set out their needs and requirements, defined in that notice and/or in a descriptive document.

Secondly, having selected candidates, procuring authorities should open a dialogue to identify and define the means best suited to satisfying their needs. During this dialogue, the Directive states, one is free to discuss all aspects of the contract with the chosen candidates. The dialogue may therefore relate not only to "technical" aspects, but also to economic aspects (prices, costs, revenues etc.) and legal aspects (distribution and limitation of risks, guarantees, possible creation of special purpose vehicles etc.). The starting point is that the dialogue should be individually carried out with each of the participants on the basis of the ideas and solutions of the economic operator concerned. It is emphasised that all candidates must be treated equally, and that commercial confidentiality must be maintained unless the candidate agrees that information may be passed to others. 
Thirdly, provided that it is declared in the contract notice, the procuring authorities are free to conduct the dialogue in successive stages. They may reduce the number of solutions by applying the award criteria mentioned in the contract notice and/or the descriptive document. As long as there remains enough competition, the procuring authority may start with more candidates (at least three) and then exclude some of them during the dialogue stage as a result of rejecting solutions on the basis of the award criteria.

Fourthly, the dialogue can continue until the procuring authority is convinced of the suitability of a solution or solutions. Once the dialogue is closed, the participants will be asked to submit their final tenders based on the solution(s) presented during the dialogue. In assessing final tenders, procuring authorities may ask candidates to clarify, specify and finetune their bids, as long as this does not involve changes to the basic features of the tender which might distort the competition or have a discriminatory effect.

Fifthly, all tenders received have to be assessed based on the award criteria as laid down in the contract notice or the descriptive document, and the most economically advantageous tender has then to be chosen. The preferred candidate may be asked to clarify aspects of the tender, or confirm commitments contained in the tender. However, its clarifications or confirmations may not affect or modify substantial aspects of the tender / the call for tender; and may not distort competition or result in discrimination.

In concluding, the Directive notes the possibility for procuring authorities to specify prices or payments to participants in the dialogue.

\section{Implementation of the Directive into the law of member states}

EC directives need to be implemented through the national laws of member states. That is, they are not directly applicable except in exceptional cases (such as when a member state fails to implement the directive within time). If procuring authorities have to, or choose to, apply the procedure, they need to apply it in the form of the national legislation which implemented the Directive. This is a crucial difference from EC regulations which apply directly, that is without having to be implemented (see Article 249 of the EC Treaty in: European Union, 1997). Although the text of Directive 2004/18/EC is not directly applicable, it is important because the courts of the member states will turn to this source if questions of interpretation arise.

Normally directives set out minimum standards, which the member states have to implement through their laws, while being free regarding the form and method of implementation. However, there is no such obligation to implement this Directive's content regarding the $C D$ procedure because the $C D$ is an "optional procedure" (Trepte, 2007: par 7.188): the member states may provide a CD procedure in their national legislation but are free to refrain from so doing. The text of Article 29(1) of the Directive makes clear this optional character ("Member States may provide ...").

In the Netherlands, the Directive, including the CD procedure, was implemented with effect from 1 December 2005 by the Besluit Aanbestedingsregels voor Overheidsopdrachten (BAO) (which can be translated as "Regulation for Procurement Rules for Public Contracts"). 


\section{Objectives of the EC with the CD procedure}

Officially, the objective of the Competitive Dialogue is to provide "a flexible procedure [...] which preserves not only competition between economic operators but also the need for the procuring authorities to discuss all aspects of the contract with each candidate" (Directive 2004/18/EC, recital 31). This objective is twofold in that it [a] puts the focus on preserving competition, and [b] underlines optimisation through interaction. During the legislative process, several objectives were discussed but not all made it into the final wording of the formal objective. In October 2001, the Committee for Economic and Monetary affairs advised the European Parliament that "the content and limits of the negotiated procedure should be made transparent for both procuring authorities and contenders and, in the interests of both parties, should provide the basis for collaboration based on trust" (A5-0378/2001, p.100). Other suggested objectives of the procedure are: (1) "Giving the procuring authority the opportunity to [...] create competition between [participants]" (CES0515/2001, par. 4.4.2); and (2) stimulating innovation ("The procuring authorities may also want to allow innovative solutions" (COM(2000)0275, p.7), and "giving the procuring authority the opportunity to appropriate the results of participants" inventiveness and innovation" (CES0515/2001, par. 4.4.2)). The ideas on "collaboration based on trust", the "innovation stimulus" and "appropriation" did not make it into the final, formal objective of the CD. These items did and do however play an important role in the rhetoric and justification of the competitive dialogue and in its rolling out in practice.

In conclusion, the $C D$ procedure was expected to stimulate more dialogue during the negotiations in comparison to traditional procurement procedures like the open and restricted procedure. Furthermore, it expected the $C D$ procedure to lead to stronger competition compared to the negotiated procedure. In comparison to the existing procurement procedures the EC expected the $C D$ procedure to lead to more innovative solutions and to more trust between the public client and its contractor. So, the direct objectives of the $C D$ procedure were more dialogue, stronger competition, stimulating innovation, and a relationship based on more trust in the procurement stage of projects.

Indirectly, the CD procedure was meant to be an answer to increased project complexity, changing government roles and the construction sector's poor professional functioning. The dialogue, being the main element of the $C D$ procedure, was envisioned to reduce project complexity, to come to a proper allocation of tasks and risks between the procuring agency and the contractor, and to affect aspects of project control like increased project quality, and decreased overruns in time and costs. So, the indirect objects are reducing complexity, a proper allocation of tasks and risks, increased project quality, and decreased overruns in time and costs in the construction stage of projects. 


\subsection{First experiences with the CD procedure: practitioners' evaluations}

As we have seen in Section 3.1, the European Commission was convinced that the design of the $C D$ procedure would change procurement (more dialogue, competition, innovation and trust), thus expectedly affecting construction (reduced project complexity, proper allocation of tasks and risks, and increased quality without overruns in time and costs). In the first years after its introduction, however, several academics concluded that the actual design of the CD procedure could work against its objective, due to counteractive mechanisms (Arrowsmith, 2006; Raganelli \& Fidone, 2007; Ramsey, 2006). The mechanisms that are likely to determine the working of the CD procedure, are identified in this section. Given the little experience with the $C D$ procedure thus far, firstly an ex ante evaluation was performed to identify expectations about the working of the $C D$ procedure, through interviews with experts in construction procurement. The second step was to explore to what extent the intended objectives of the CD procedure are reached when applying this procedure. For this purpose, an ex post evaluation was performed to reveal the actual experienced working of the procedure through a survey. At the end of this section the main results of these studies are described in a list of twelve mechanisms that are perceived to determine the working of the CD procedure.

\section{Ex ante evaluation of the CD procedure: Expert interview method}

Experts were interviewed from several fields: i.e. academic and legal experts, procuring agents, contractors and advisors. Seven to ten prominent individuals from each of the four key expert groups were selected and invited to participate in the study. Of the 35 selected experts, only two (a lawyer and an advisor) declined to take part. Table 3.1 gives an overview of the groups and number of interviews.

Table 3.1. Expert groups for the expert interviews

\begin{tabular}{llc}
\hline & Main group & Number of interviews \\
\hline A. & Law / science & 6 \\
B. & Procuring agencies & 9 \\
C. & Industry (contractors) & 10 \\
D. & Advisers & 8
\end{tabular}

The semi-structured interviews consisted of three main parts (See Appendix 1 for the interview protocol). Part A served to assess the general opinion of the experts about the $C D$ procedure, compared to other procurement procedures. Part B considered the elements of the $C D$ procedure as it was (planned to be) used, and the expected impact of these elements on the EC's objectives. Part C was included to determine how the experts envisaged the effects of the $C D$ procedure in terms of the objectives of the CD procedure as formulated by the European Commission. In each part, an open question was first asked to allow participants to express their basic ideas. The next step was to narrow the question so as to acquire results that would be easier to compare. 
The qualitative data analysis software QSR Nvivo was used in the analysis of the transcribed interviews. After transcription, codes (called 'nodes' in NVivo) were assigned to text fragments using a 'top-down' approach for Parts $A$ and $C$ of the interviews, and a 'bottomup' approach for Part B. The top-down approach is based on an a priori coding scheme with tree nodes (see Table 3.2), whereas the bottom-up approach starts without any such strong prior assumptions.

Table 3.2. Coding scheme for Parts $A$ and $C$ of the interviews

\begin{tabular}{llll} 
Part & $\begin{array}{l}\text { Tree nodes } \\
\text { Family node }\end{array}$ & Parent node & Child node \\
\hline A & ADDED VALUE & FOR CONTRACTOR \\
& FOR PROCURING AUTHORITY & \\
& & FOR OTHERS & \\
C & EXPECTATIONS & DIRECT EC-OBJECTIVES & DIALOGUE \\
& & COMPETITION \\
& & INNOVATION \\
& & TRUST \\
& INDIRECT EC-OBJECTIVES & COMPLEXITY \\
& & RISK / TASK ALLOCATION \\
& & QUALITY \\
& PROJECT CONTROL & TIME \\
& & COSTS
\end{tabular}

\section{Ex post evaluation of the CD procedure: Survey method}

After the interviews, that revealed the experts' expectations about the effects of the CD procedure, a survey was prepared to find the perceived effects of procurement by the $C D$ procedure in practice. In the Netherlands, the Directive, and along with it the Competitive Dialogue procedure, was implemented in Dutch legislation with effect from December 1st 2005. Since the CD procedure is still a relatively new procurement method, the number of Dutch construction projects using it was relatively small at the time of the survey. These projects vary in terms of both their scope and size (see Table 3.3).

Table 3.3. Early CD-procured construction projects in the Netherlands

Second Coentunnel Tunnel

A2 Hooggelegen Traffic junction, several transport functions

A2 Maastricht Traffic junction, unlocking of a city

A4 Burgerveen - Leiden Broadening of a highway with aqueducts

Belastingkantoor Doetinchem Tax office

Detentiecentrum Zestienhoven Detention centre

Combiplan Nijverdal Broadening connecting road and parallel

railroad

KOSMOS Six large-scale infrastructural maintenance projects

Kromhoutkazerne Military base

Kempkensberg Office towers

Renovatie Haringvliet Sluice renovation

\begin{tabular}{ll} 
Contract type & $\begin{array}{l}\text { Estimated cost } \\
\text { (€ million) }\end{array}$ \\
\hline DBFM*(30 years) & 1300 \\
Alliance & 130 \\
DBM** $^{*}$ & 639 \\
D\&C** & 700 \\
DBFMO *** (15 years) & 27 \\
DBFMO (25 years) & 89,5 \\
D\&C & 195 \\
& \\
D\&C & $13.8-62.4$ \\
DBFMO (25 years) & 250 \\
DBFMO (20 years) & 183 \\
D\&C + M (10 - 15 years) & 60
\end{tabular}

* DFBM $=$ Design, Build, Finance and Maintain

** DBM = Design, Build and Maintain
*** D\&C = Design and Construct

**** DBFMO = Design, Build, Finance, Maintain and Operate 
The explorative survey, meant for contractors and procuring authorities who were or had been involved in a Dutch CD-procured construction project, consisted of a number of statements reflecting the elements that were mentioned in the interviews as expected to have positive and negative impact on the EC-objectives with the CD procedure. Further, statements were included related to the expectations with regard to the objectives of the European Commission. The expert interviews had shown such a variety in interpretations of competition, complexity and task/risk allocation, that it was decided not to include statements regarding these constructs. Instead, for these expectations, the possibility to call the respondents for further questions was used to retrieve more reliable answers than the survey statements probably would. Table 3.4 shows the relationship between the conclusions drawn from the expert interviews and the statements included in the survey (See Appendices 2 and 3 for the survey protocols).

The responses to the statements were in the form of a six-point scale, with the following options: 1 . strongly agree, 2. agree, 3 . slightly agree, 4. slightly disagree, 5 . disagree, 6. strongly disagree. Using this format allows the scale to be treated not just as ordinal values, but also as intervals (Carifio and Perla, 2007), and this makes it easier to run statistical analyses between groups.

In autumn 2007, the survey was distributed to all procuring authorities and contractors involved in Dutch construction projects that had so far been procured using the CD procedure. Projects where the dialogue had yet to be concluded were deliberately included, to increase the number of projects and to incorporate the most recent experiences. For each project, one questionnaire was sent to the procuring authority, and one to each of the (potential) contractors, with the request to let it be completed by the contract-, tender- or project manager, or by the project director. The response rate to the questionnaire was $43.8 \%$ for the procuring authorities (7 out of 16 ) and $63.9 \%$ for the contractors (46 out of 72), with 15 of the sixteen identified projects eliciting at least one response. Only the Renovatie Haringvliet project failed to produce a response. In Table 3.5, the contractor responses are broken down across the projects included in the survey. 


\section{Table 3.4. Expectations from expert interviews and corresponding survey statements}

Expert/stakeholder expectations

Survey questions/statements

\section{Part A}

\section{Added value}

Structured, officially allowed conversation

Better fit between problems and solutions

Reduced complexity

Proper allocation of tasks and risks

\section{Part B}

Elements, positively affecting objectives

Security of the contractors' interests

The $C D$ procedure has potential.

It is clear to procuring authorities when it is allowed to use the $C D$ procedure.

Use of the CD procedure leads to bids that better match the wishes and needs of procuring authorities.

The project complexity that I experienced was reduced after the conducted dialogues.

Use of the CD procedure helped aligning tasks and risks between principal and contractor.

Flexibility in demand specifications

Focus on content instead of on price

Fear that certain information will become public is a reason for contractors to be restrained in contributing to the dialogue.

The procuring authority carefully handled the information that the contractors provided during the dialogue.

Contractors were given the opportunity to influence the demands.

Use of the CD procedure has led to better demand specifications.

In the project considered, emphasis was more on bid price than on quality.

In the project considered, qualitative aspects should have received greater emphasis.

The demand specifications gave contractors sufficient opportunities to distinguish

themselves from other potential contractors.

In the project considered, the demand was specified in functional terms (open solution).

Elements, negatively affecting objectives High transaction costs

There were too many dialogue conversations.

The same result could have been accomplished with fewer conversations.

The number of dialogue products which had to be delivered was excessive.

During the design stage, the contractors detailed their designs more than we asked for.

The time spent on the dialogue compares well with its result.

Level playing field

Contractors were given the opportunity to influence the demands.

Use of the $C D$ procedure stimulated contractors to propose innovative solutions.

Fear that certain information will become public is a reason for contractors to be restrained in contributing to the dialogue.

\section{Part C}

EC Objectives

Dialogue

The issues that came up during the dialogue were well discussed

The interactions improved as the process developed.

The procuring authority provided answers that were useful to the contractor.

Contractors asked appropriate questions.

There was sufficient time during the dialogue to discuss issues.

Competition

Use of the $C D$ procedure increases the competition between tendering firms

I was more aware that I had to compete with other firms for this contract than usually

Use of the CD procedure leads to more innovative solutions.

Use of the $C D$ procedure stimulated contractors to propose innovative solutions.

Trust-based relationship

There was mutual trust between the procuring authority and the contractor.

The interactions improved as the process developed.

Quality increase

Time and cost overrun decrease*

* Since the contracts for the projects covered by this survey had not yet or had only just been awarded, in most cases the construction stage still had to start. The respondents were therefore not able to comment on time and cost overruns.

Analysis of the responses shows that the best response rates were achieved with projects for which the contracts had already been awarded at the time of the survey. The response rate was much lower where the contract had yet to be awarded. Interestingly, in those projects, the questionnaires which were returned came mostly from contractors who had not been selected to take part in the on-going final dialogue stages (see Table 3.6). 
Table 3.5. Survey response for contractors

\begin{tabular}{llc} 
& Sent out & Returned \\
\hline Second Coentunnel Tunnel & 5 & 4 \\
A2 Hooggelegen Traffic junction, several transport functions & 5 & 2 \\
A2 Maastricht Traffic junction, unlocking of a city & 5 & 2 \\
A4 Burgerveen - Leiden Broadening of a highway with aqueducts & 4 & 2 \\
Belastingkantoor Doetinchem Tax office & 5 & 2 \\
Detentiecentrum Zestienhoven Detention centre & 4 & 4 \\
Combiplan Nijverdal Broadening connecting road and parallel railroad & 5 & 3 \\
KOSMOS Six large-scale infrastructure maintenance projects & 5 & 4 \\
NH & 5 & 4 \\
U-ZH-Z & 5 & 4 \\
ZHZ-Z & 4 & 3 \\
L L-NB & 4 & 4 \\
Kromhoutkazerne Military base & 4 & 1 \\
Kempkensberg Office towers & 6 & 2 \\
Renovatie Haringvliet Sluice renovation & 5 \\
\hline Total & 1 & 0
\end{tabular}

Table 3.6. Contractor response characteristics

\begin{tabular}{lll} 
& Sent out & Returned \\
\hline Contract was awarded to the contractor & 12 & 8 \\
Contract was awarded, contractor did not win the contract, but was a candidate until & 28 & 25 \\
the final bid round & 13 & 5 \\
Contract was awarded, contractor was not selected to make a final bid & 12 & 3 \\
Contract not yet awarded, contractor is still a candidate & 7 & 5 \\
Contract not yet awarded, but contractor already excluded from the dialogue & 72 & 46
\end{tabular}

There were 33 contractors who returned completed questionnaires. Due to the fact that some of them participated in the tender of more than one CD-procured project, these 33 contractors together completed the 46 questionnaires. Some of the contractors who were involved in more than one project only completed one questionnaire. This was particularly the case with many of the KOSMOS subprojects since, according to the contractors, the results of the KOSMOS subprojects were similar. In the analyses, multi-project respondents who did not fill out more than a single questionnaire, have only been counted once. Although the number of KOSMOS respondents is relatively large compared with other projects, the results of the KOSMOS respondents did not differ significantly from the other responses suggesting this is not due to a special factor in this project. When significant differences did occur between responses, this could be related to the project type: renovation or construction. Where there were significant differences, these are mentioned in the text. For the analysis of the completed questionnaires, data were entered into SPSS 16.0 for Windows. To test whether the means of the two groups differed, t-test statistics with a $5 \%$ significance level were used. 


\subsection{Perceived working of the CD procedure: twelve mechanisms and their effects}

Experts indicated that with the $C D$ procedure, the European Commission designed a procedure that was in theory suitable to meet the objectives set (dialogue, competition, innovation, trust, reduced complexity, proper task and risk allocation, and increased project control - quality, time, costs -). However, the survey results indicate that the CD procedure, as it was used in the first sixteen Dutch construction projects that were procured with this procedure, worked out different than expected. In the sixteen projects in the survey, practitioners experienced unexpected counteractive side-effects of CD procedure's elements. These (mostly unintended) mechanisms determine to what extent the intended objectives are reached. Through these mechanisms, the CD procedure in its early use leads to less dialogue than intended, to more competition, to less trust and hardly any improvement on complexity or task/risk allocation. Only the actual level of innovation and the price-quality ratio meet the expectations.

The identified mechanisms are conversation; focus on content; risk aversion; opportunistic behaviour; lack of openness; protection of contractors' interests; flexibility in demand specifications; a minimum of three candidates to the dialogue; design fee; level playing field; transaction costs; and a lack of clarity over when to use the procedure. These mechanisms can roughly be divided in two groups: one group of mechanisms that refer to norms, values and routines (informal mechanisms), and one group of mechanisms that refer to contracts, formal procedures and monitoring policies (formal mechanisms).

Table 3.7. Effects of the mechanisms within the CD procedure on the EC's objectives

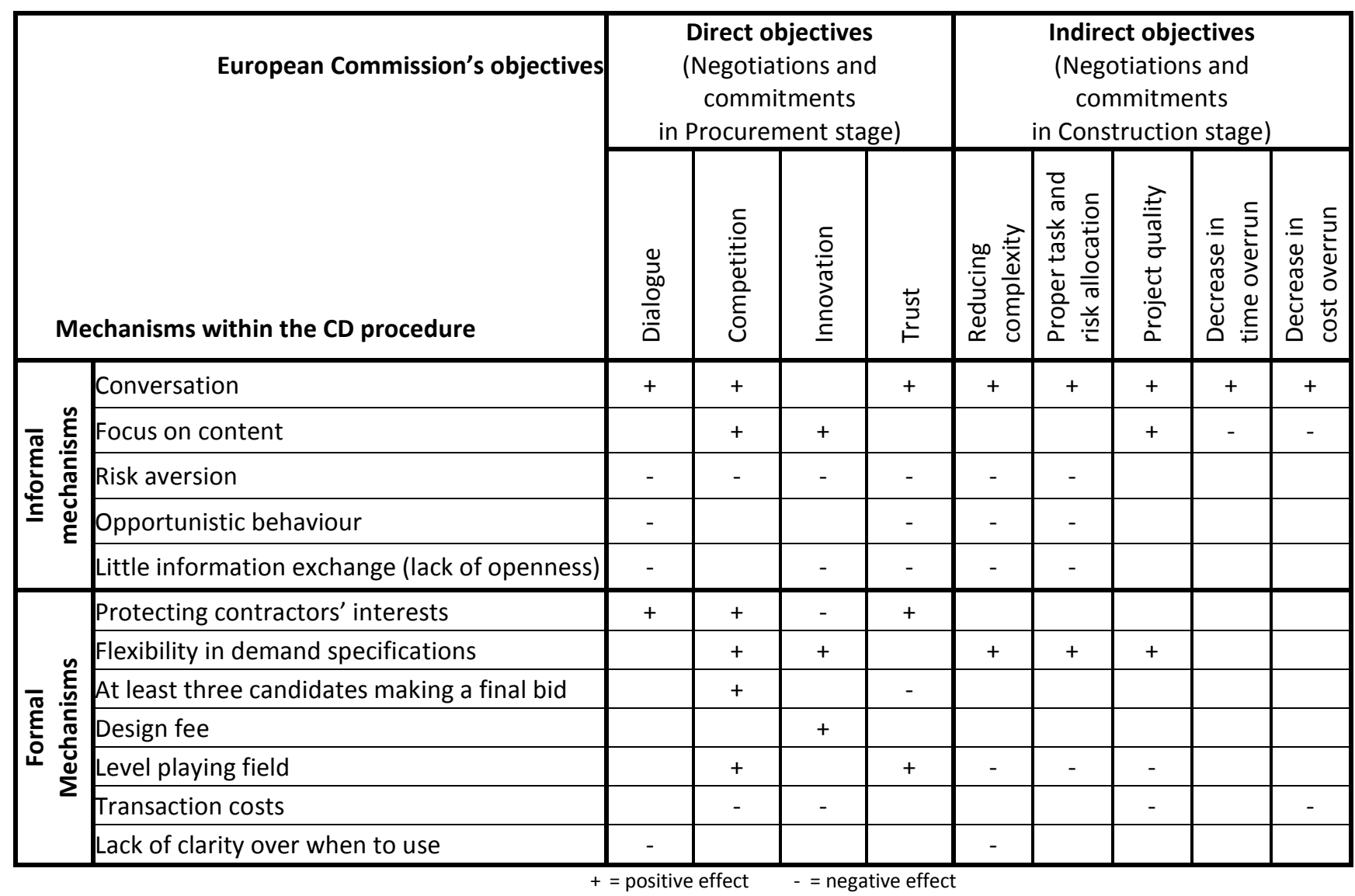


Table 3.7 summarises the results found in the CD-procured projects. In this table, the mechanisms are put alongside the objectives of the European Commission. The plus signs in the table means that the mechanism is indicated to have a positive effect on the objective at the top of the table. The minus signs in the table means that the mechanism is indicated to have a negative effect on the objective at the top of the table. An empty box means that there is no indication of any effect. Below, first the effects of the informal mechanisms are described, then of the formal mechanisms, and finally the interplay between the mechanisms is explained.

\section{Informal mechanisms}

\section{Conversation}

The conversation allowed during the procurement process has several effects. In the conversation, a structured dialogue between principal and contractor is possible. Problems and solutions can be aligned, thus reducing complexity and stimulating quality. Alongside this, it helps to create mutual understanding, which is a stimulus for trust. Talking about tasks and risks also makes it possible to allocate the two in a proper and sensible manner between procuring authority and contractor. Besides, it helps in making realistic estimations of time and costs, which is said to lead to less overruns in the construction stage. Furthermore, through dialogues contracting agencies are able to avoid contractors making invalid bids, which means that more candidates make valid bids, so that the competition between contractors increases.

\section{Focus on content}

In the procurement stage of a CD procured project the parties are supposed to focus on content instead of on price, because of the obligation to use MEAT criteria and because price is only brought in at the end of the procurement stage. This has several effects. Firstly, it stimulates contractors to come up with innovative ideas because the proposed solutions are judged as part of the reward criteria making it more attractive for contractors to be innovative. Since evaluation is no longer limited to price, this element also has the effect of broadening competition between candidates and stimulate quality. Finally, the survey results seem to suggest that a focus on the content of the project rather than the price might reduce the inclination of contractors to over-detail their bids. However, without such detail, it is likely that the accuracy of estimated time and costs decreases, which make overruns more likely.

\section{Risk aversion}

The risk aversion of both procuring authorities and contractors has, both directly and indirectly, negative influence on many of the desired effects of the CD procedure. Due to the felt need of diminishing risks, procuring authorities in practice offer less flexibility in terms of demand specifications than is possible, and still focus on price over content. This is not conducive to the objectives of the dialogue especially since the risk aversion of the other stakeholders leads to a cautious approach which has a negative influence on openness. Combined, the effects of this risk aversion are negative on all direct objectives, and it does not reduce complexity nor not just the objective of boosting competition. 


\section{Opportunistic behaviour}

Given that little attention is paid to opportunistic behaviour in the design of the CD procedure, it is remarkable that the opportunistic behaviour during the dialogue both of procuring authorities and of contractors was mentioned several times as a negative side effect of some of the CD procedure's elements. The enforced competition between at least three contractors, the high transaction costs, and risk aversion were mentioned as reasons for this kind of behaviour. This opportunism is said to lead to little or no information exchange, resulting in a less effective dialogue and so a failure to reduce complexity, to allocate risks and tasks properly or to stimulate trust.

\section{Little information exchange (lack of openness)}

The lack of openness is mentioned as a factor that is damaging to the success of the CD procedure since it diminishes the dialogue which was its purpose in the first place. When conversation partners are open, this stimulates the solving of complex issues, innovative ideas and a proper allocation of tasks and risks. Furthermore, information exchange is seen as important in developing mutual trust. The most important reason for little information exchange seems to be the risk aversion of both procuring authority and contractors. However, information exchange was shown to improve over time, as those around the dialogue table became familiar with each other and with the CD procedure, and when mutual trust evolved.

\section{Formal mechanisms}

\section{Protecting contractors' interests}

The fact that contractors' interests are secured by explicitly forbidding cherry picking, and by stating that confidential information may not be shared with others than the contractor concerned, could help the dialogue process by making contractors feel comfortable about being open. The objectives of stimulating dialogue, competition, and trust are served by this element. However, the objective of resolving the lack of innovation and striving for more innovativeness could be hampered by it since the procuring authorities are not allowed to combine the best ideas from all the candidates. As such, the final accepted bid is likely to be less than optimal.

\section{Flexibility in demand specifications}

The fact that demand specifications may be changed when good ideas and solutions suggested by contractors do not fit the initial specifications has several effects. This is one way of aligning problems and solutions more effectively, thus reducing project complexity and stimulating project quality. Further, it can stimulate innovative ideas since the specifications do not place limits on the solution space. Furthermore, it enhances competition because it offers contractors greater possibilities to distinguish themselves from their competitors. Finally, this flexibility stimulates the seeking of the most efficient allocation of tasks and risks between the procuring authorities and the contractors. 


\section{At least three candidates invited to the dialogue}

To stimulate competition, one of the elements in the CD procedure is that at least three candidates should initially be invited to the dialogue. This is to provide the procuring authority with a reasonable choice, and not to be locked-in to a situation with only one candidate as was the case in the negotiated procedure. Despite this positive effect on the competition objective, this element also has negative effects. Being in a competition with other candidates does not encourage contractors to invest that much in the relationship with the procuring authority because they still face the likelihood of not being selected as most economically advantageous tender. This makes that trust does not develop easily.

\section{Design fee}

The element of paying a design fee to the contractors is mentioned by the experts as a positive element since it stimulates contractors to work out their dialogue products in some detail, and so innovative ideas are more likely to be included. The fee offers some compensation for the potential contractors' R\&D costs. However, this increases the procuring authority's transaction costs, and it makes a big difference if three contractors have to be paid a fee rather than just one.

\section{Level playing field}

The maintenance of a level playing field is built into the procedure to assure a fair competition. All contractors should have equal opportunities, and so the procurement terms should not be changed too much during the process. If changed, any new terms should apply to all candidates. This means that when changes in the specifications are necessary to make possible the solution of one of the contractors, the specifications should change for all of them. This could conflict with the "security of candidates' interests" element since one has to potentially change the terms to allow an innovative idea, while not allowing competitors to work out what that idea is from the new specifications. Contractors may fear this is impractical and so be hesitant to come up with innovative ideas. This view, expressed in the expert interviews, was, however, not supported in the survey: there has been no indication that the level playing field affects innovation at all. Another view from the experts was that the level playing field condition might make procuring authorities reluctant to change specifications and conditions, thus reducing the effectiveness of the "flexibility in demand specifications" element.

There are indications that the level playing field thus affects solving complexity, the allocation of tasks and risks and the project quality in negative ways. In terms of the trust building objective, the level playing field element requirement could work out positive: contractors could rely on the procuring authority since it had to keep the playing field level. This is only partly supported by the survey results, which show that still the fear of valuable information becoming public is a reason for contractors to be restrained in sharing information. Combined with the survey's found correlation between openness and trust, one could conclude that when contractors are confident that the procuring authority keeps the level playing field, this might stimulate trust building. 


\section{Transaction costs}

Although the large transaction costs of the CD procedure is more a side effect than an element of the procedure itself, this effect was mentioned several times as a negative aspect of the dialogue process that influences whether or not objectives are met. Due to the high transaction costs, the number of contractors willing and able to compete will be low. This will have a negative influence on the objectives of competition (only a few competitors) and of innovation (developing new solutions costs even more). Further, it may well change the manner in which contractors act: the high transaction costs will involve potential contractors in large investments and so their stake in being awarded the contract will increase, and this might lead to an increase in opportunistic behaviour, both during the dialogue and during construction of the project. The contractor that gets the contract might, for example, search for ways to make up for their investments during construction. This is, according to the respondents, likely to result in a decrease of project quality or in cost overruns.

\section{Lack of clarity over when to use}

To procuring agencies, it is unclear when to use the CD procedure. This might lead to its usage in projects which are less complex than it was aimed at, or to it not being used in appropriately complex projects. This might have a negative outcome on meeting the objective of solving complexity. The experts feared that misuse of the CD procedure might lead to further restrictions being imposed and, as such, that the procedure might destroy itself. Naturally, this would have a negative effect on all of the objectives, especially the most unique objective of stimulating dialogue between contracting agencies and contractors.

\section{Interplay between the mechanisms}

In the previous sections, the effect of twelve of the CD procedure's mechanisms on its intended objectives was described. Some of the mechanisms, however, increase the occurrence of other mechanisms.

\section{Transaction costs}

Although the large transaction costs of the CD procedure is more a side effect than an element of the procedure itself, this effect was mentioned several times as a negative aspect of the dialogue process that influences whether or not objectives are met. Having a conversation for example, takes much more time than exchanging questions and answers on paper. In addition, the procuring authority has to invest much more time and effort in answering contractors' questions. Furthermore, when several potential contractors have to estimate a project in some detail, this will raise the transaction costs, and not just for these contractors but also for the procuring authority who has to assess their products. Finally, the flexibility in demand specifications makes that candidates cannot simply calculate the costs of a given specification. They have to come up with designs, based on lengthy conversations, and then calculate costs. The design fee makes up for the transaction costs of procuring agencies as well, and it makes a big difference if three contractors have to be paid a fee rather than just one. 
The transaction costs might be lowered though, due to an even stronger mechanism: risk aversion. Due to risk averse behaviour of procuring authorities, the offered flexibility in demand specifications is lower than intended (the less procuring authorities know upfront, the bigger is the risk they experience). An example of risk averse behaviour at the side of contractors is over-detailing their bids. By elaborating their designs, they lower the risk they experience since risks, time and costs can be better calculated. This does, however, have an increasing effect on transaction costs.

\section{Openness}

Concluding, the high transaction costs and the risk aversion both parties experience, were mentioned several times as reasons for opportunistic behaviour. The high pressure to get the contract awarded, combined with the presence of other candidates make them to put effort into reverse tactics (such as withholding information) in order to confuse competing candidates, which might hamper the dialogue. At the side of the procuring agency, risk aversion in combination with keeping the level playing field make that less information is shared than intended. It turned out that procuring authorities found it difficult to assess what information to treat confidentially, and what to share with all candidates. One of their risk averse tactics showed not to share anything with any of the candidates.

\subsection{Concluding remarks}

In the first sections of this chapter, the European Commission's objectives with the CD procedure were reconstructed, after which the actual working of the CD procedure in the first sixteen Dutch CD procured construction projects was explained. The outcomes of the survey indicated an interplay between the CD procedure's elements that were identified by the interviewed experts. Twelve main mechanisms determine the working of the CD procedure in its current use in the Netherlands. In this section, the impact of the CD procedure in its early use is explained by confronting the intended effects of the EC with those twelve mechanisms.

\section{Reached objectives of the CD procedure in its early use}

Direct objectives, regarding negotiations and commitments during procurement

The design of the $C D$ procedure intended foremost to facilitate a dialogue between procuring authorities and contractors during the procurement stage of a construction project. The survey results show that although technically a dialogue takes place, in practice this still lacks a "real" interaction: there is less dialogue than intended by the EC. Unfamiliarity with the procedure, a fear of disrupting the level playing field, a felt need to control the outcome of the dialogue and opportunistic considerations linked to competing with others, are the main reasons for the two parties at the table to be reluctant to share some information. 
With the CD procedure, the EC intended to create more competition than was the case in the negotiated procedure. From the survey results it can be concluded that the early use of the $C D$ procedure resulted in even more competition in practice than initially intended. Respondents to the survey frequently state that the competitive element of the $C D$ procedure results in an unexpected side-effect: opportunistic behaviour of candidates to the procedure. Due to this opportunism, not only dialogue is curbed, is also causes that there is less trust than intended.

The EC's objective to create a procedure which would provide the basis for collaboration based on trust, was expected to be met by the experts and stakeholders. However, the survey indicated that the competitive element of the CD procedure, combined with inherent risk aversion and opportunistic behaviour, led to little openness during the dialogue, which could hamper the development of trust, despite the trust promoting elements built into the procedure. Although the results of the survey indicate that innovativeness could be further increased, one concludes that innovation is stimulated by the CD procedure as was the EC's objective. Since cherry picking is explicitly forbidden, a potential contractor's good innovative idea is unlikely to be executed if they are not the successful bidder, though, and this hampers innovation to some extent. A reduction of the transaction costs of the CD procedure, lowering risk aversion and stimulating information sharing would also help to increase innovations.

Indirect objectives, regarding negotiations and commitments during construction

Notwithstanding the somewhat disappointing results for the explicit objectives, participants to the survey are positive about the CD procedure. Using the procedure has been perceived as beneficial in the first sixteen Dutch construction projects. Unfortunately, the projects in the survey had only just been awarded or were still in the negotiations stage. Therefore there is little to say about effects on the construction stage of projects. The project quality, time and costs were yet to be determined. Still, the price-quality ratio of the projects is positively assessed, and both procuring authorities and contractors are positive about the conducted dialogues. The conversations are said to contribute to solving complexity and a proper task- and risk allocation between the principals and the contractors. This is even more stimulated by the possible flexibility in demand specifications. However, risk aversion makes that the procuring agencies refrain from using the possible flexibility in the specifications, and causes a lack of openness both by agencies and contractors during procurement. There would be much to gain in stimulating openness and flexibility in specifications. Furthermore, the strong competition and the level playing field clause make contractors opportunistic in that they are reluctant to share information. Altogether, these side-effects of the CD procedure's design make that the conducted dialogue is less effective on the construction of the project than expected: complexity is hardly reduced and the task and risk allocation is far from efficient yet. 


\section{Perceived effectiveness of the CD procedure}

From the study, described in this chapter, two conclusions can be drawn. First, it can be concluded that the $C D$ procedure as it was used in the first $16 \mathrm{CD}$ procured Dutch construction projects did not quite match the objectives of the European Commission. In practice there was less dialogue, more competition and less trust than intended. Only innovation was stimulated, as expected. Furthermore, complexity was hardly reduced by use of the CD procedure, and the allocation of tasks and risks far from efficient yet. The pricequality ratio of the projects was positively assessed, but due to the fact that projects had not been delivered at the time of the research, the reduction of renegotiations during construction could not been assessed.

Secondly, it can be concluded that formal and informal mechanisms in the negotiations stage are affecting negotiations and commitments, both in the procurement stage of the project and during construction. It is, however, neither said that these mechanisms are unique to the $C D$ procedure, nor whether or not the reaching of objectives is effectively caused by the CD procedure. Therefore, in the next chapter differences in negotiations and commitments will be compared between projects with and without the CD procedure. These differences indicate the contextual influence of the $C D$ procedure in the development of negotiation and commitment during procurement as well as construction of the project. 


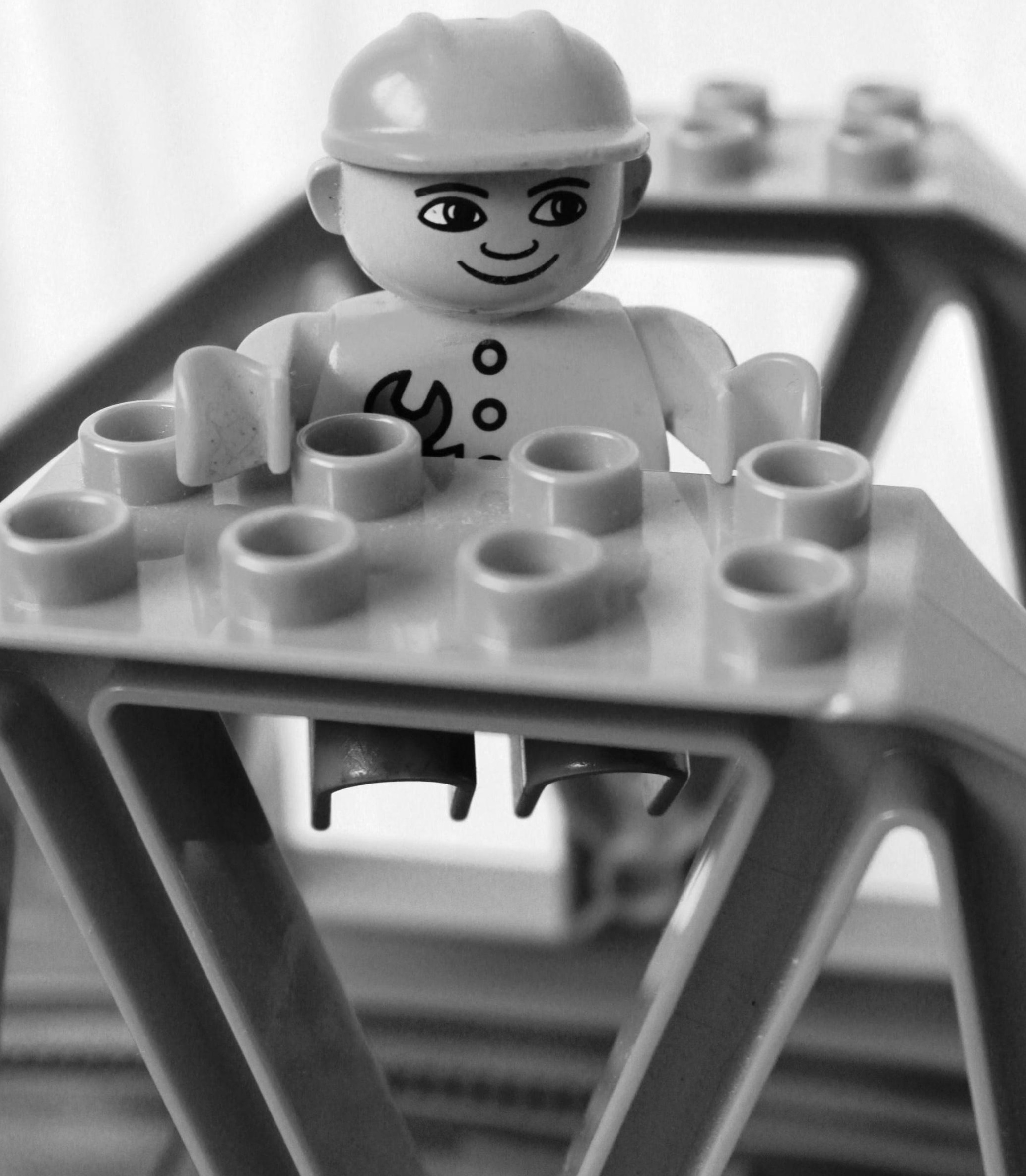




\title{
Chapter 4. Differences in negotiation and commitment between projects with and without the $C D$ procedure: $A$ multiple-case study
}

\author{
Part of this Chapter is published in: \\ Hoezen, M.E.L., Voordijk, J.T \& Dewulf, G.P.M.R. (in press) \\ Formal and informal contracting processes in the competitive dialogue procedure: a multiple-case study \\ Engineering Project Organization Journal \\ Hoezen, M., Voordijk, J.T. \& Dewulf, G.P.M.R. (2011) \\ Sense making and bargaining in the Competitive Dialogue procedure. \\ In F. Rozemeijer, M. Wetzels \& L. Quintens (Eds) Conference proceedings $20^{\text {th }}$ IPSERA conference, \\ Vision 20/20 - Preparing today for tomorrow's challenges \\ 10-13 April, Maastricht, The Netherlands: IPSERA
}

When designing the $C D$ procedure, the European Commissions expected it to induce stronger contractor competition than possible with the negotiated procedure, and improved dialogue between procuring agency and potential contractors than possible with traditional procedures. Thus, by influencing the procurement of the project, the complexity and renegotiations during construction of the project were expected to decrease. The results of Chapter 3 indicate that the CD procedure does not meet what was expected. From the perceptions of participants to early $C D$ procured projects it was concluded that the $C D$ procedure might be less effective than expected upfront. Several mechanisms and the interplay between them have been identified, together affecting negotiations and commitment, both during procurement and during construction. In this chapter, first it is tested whether the $C D$ causes the identified effects or that traditionally procured projects develop likewise. Secondly, the effect of the CD procedure on negotiations and commitments is explained by comparing developments in $C D$ procured projects with projects that are traditionally procured. This contributes to knowledge about the influence of procurement procedures on negotiations and commitments, the current chapter answers the question how negotiations and commitments differ between CD procured projects and projects that are traditionally procured.

Firstly, the design of a case study is addressed (see Section 4.1). Secondly, the results for both traditionally procured and CD-procured projects are described, focusing both on the EC's objectives with the CD procedure and on the development of negotiations and commitments (Section 4.2). Thirdly, a cross-case analysis is performed (in Section 4.3). The chapter ends with the conclusions of the study (Section 4.4), depicting differences in negotiations and commitments and the influence thereon of procurement procedure. 


\subsection{Design}

\section{Multiple-case study motivation}

Academics in the construction research are performing studies into the impact of procurement on several aspects of inter-organisational projects like on project performance (Bresnen, 2007:371; Bresnen \& Marshall, 2000a; Davis, 1999; Eriksson \& Westerberg, 2011; Rahman \& Kumaraswamy, 2002), on communication (Pietroforte, 1997), on fairness (Kadefors, 2005), on human behaviour (Cheung, Ng, Wong, \& Suen, 2003), and on motivation and commitment (Bresnen \& Marshall, 2000a). The results of these studies indicate that procurement methods affect project cooperation and the development of federative mechanisms such as informal roles and rules. However, besides the notions that perceptions of fairness influence the interaction process, that joint action influences the development of the inter-organisational relationship, and that cognitive and social dimensions (sometimes contrary to intentions) affect the impact of contractual incentives, there is only limited knowledge about the effect of procurement procedures on negotiations and commitment. There is a lack of empirical studies that compare different forms of procurement and their effect on the development of the inter-organisational project and on its result (Bresnen, 2007; Laan, 2009).

In studying differences in project development, context is important (Bijlsma-Frankema \& Costa, 2005), especially since, as Weick (1995) describes, situations are open to interpretation and framing. This is why it is important to make people's interpretations explicit. Their perceptions are crucial in understanding why and how negotiations and commitments develop in different situations and circumstances. When one is interested in acquiring an in-depth understanding of the process characteristics of a phenomenon, case studies form a useful research method (Swanson \& Holton, 2005). Given that the focus of this part of the research is on differences in negotiation and commitment development under the influence of different procurement methods, case study research is seen as the most appropriate research strategy to answer the questions how negotiations and commitments differ between CD-procured projects and projects that are traditionally procured. As Yin $(2009$, p.2) argues: case study research "allows investigators to retain holistic and meaningful characteristics of real-life events". He further states that this strategy is desirable if one wants to study contemporary phenomena within their real-life context, especially when the boundaries between the phenomena and their context are not clear (ibid., p.13). As such, choosing case study research to explain how negotiations and commitments differ between CD-procured projects and projects that are traditionally procured, should provide a rich, contextualised understanding (Miles \& Huberman, 1994; Yin, 2009; Swanson \& Holton, 2005).

To confirm that a cause-effect relationship exists when it comes to policy effectiveness, Vedung (2000, p.50) argues for comparing situations in which a policy is implemented with similar situations in which the policy is not implemented. This research aims to compare projects in which the $C D$ procedure is used with similar projects in which the CD procedure is not used. Combined with the rationale for conducting case study research, it was decided to conduct a multiple-case study. From the prior hypothesis that projects, procured by 
traditional procurement procedures would result in different formal and informal contracts than projects, procured by the CD procedure, an embedded, multiple-case study was designed (Yin, 2009, p.59). The steps of case study selection, design and data collection, as well as the measures taken for validity and reliability, are described below.

\section{Multiple-case study selection: KOSMOS}

To study the differences in negotiation and commitment development between projects procured by the $\mathrm{CD}$ procedure and projects procured by other procurement procedures, it is important that the selected cases are indeed comparable. An embedded multiple-case study in this situation will require at least four comparable projects: two projects procured by the $C D$ procedure, and two projects that are traditionally procured. Within these projects, the negotiations and the commitments would have to be analysed, both during procurement and during execution of the project.

In April 2006, the Minister for the Dutch Highways and the Waterways Agency (Rijkswaterstaat) decided to use the CD procedure to procure the major maintenance of construction works in the KOSMOS project. KOSMOS is the abbreviation for the Dutch name given to this work: "Kunstwerken Onderhoud in Samenwerking met de Markt onder Systeemgerichte contractbeheersing". Effectively, this was a maintenance programme to cover a backlog of highway maintenance including flyovers, overpasses and other related objects in cooperation with private parties. Within KOSMOS, construction objects that needed major maintenance were bundled in nine similar work packages, eight of which were contracted out to the market in Engineering and Construct (E\&C) contracts. When the decision was made to procure the KOSMOS projects using the $C D$ procedure, two of the work packages had already started the procurement process in a traditional manner, using the restricted procedure. It was therefore decided to procure only the other six work packages using the $\mathrm{CD}$ procedure.

This situation provides a perfect sample of projects for the embedded multiple-case study: eight work packages, consisting of multiple construction works requiring overdue maintenance, two of which were procured by the restricted procedure, and six by the CD procedure. The two work packages procured by the restricted procedure were automatically selected, and two CD-procured work packages had to be selected to form a sample for the embedded multiple-case study. To satisfy the replication design, the selected CD-procured work packages had to be similar to those procured by the restricted procedure (Yin, 2009, p.91). Two of the six CD-procured work packages contained only "wet" construction works, such as sluices and bridges, and one work package contained only "dry" construction works (such as viaducts and tunnels). These three packages were therefore excluded because the selected work packages should, to match the two traditionally procured work packages, contain a mixture of "wet" and "dry" construction works.

The number of construction works, the number of special works and the available information per project were also seen as important criteria since these aspects have an influence on a project's risks, which is one of the main subjects in the dialogue conversations of the $C D$ procedure. Of the two traditionally procured work packages, one contained many 
special works (waterworks, enclosing dykes etc.) and one no such works. Therefore, it was decided to select one CD-procured work package with many special works, and one with as few as possible. Usefully, these work packages contained comparable numbers of construction works and were similarly documented - creating four comparable packages for the multiple-case study.

\section{Multiple-case study design}

The multiple-case study is designed to answer the question how negotiations and commitments differ between CD-procured projects and comparable, but traditionally procured, projects. It serves two goals: 1 ) testing whether the CD causes the identified effects or that traditionally procured projects develop likewise, and 2) explaining this effect by comparing developments in $C D$ procured projects with projects that are traditionally procured. Both purposes are reflected in the case study protocols (see Appendices 4 and 5).

Finding further evidence for the propositions concerning the influence of the $C D$ procedure on the EC objectives

As we have read in Chapter 3 , the EC added the $C D$ procedure to existing procurement procedures to provide a procedure that would create more dialogue, a greater basis for a trust-based relationship, more innovation, little experienced complexity a more balanced allocation of tasks and risks, a better project quality, and less overruns in time and costs than was the case with existing procedures. Only the level of competition between the candidates to gain the contract would need to be comparable.

Further in Chapter 3, however, it was concluded that the objectives with regard to competition, trust, experienced complexity and the allocation of tasks and risks were not met by the CD procedure. Dialogues take place, albeit less than intended, and for the objectives regarding project control (quality, time, costs) no strong conclusions could be drawn. If the results of the multiple-case study agree with the early experiences as described in Chapter 3, then this will confirm the following propositions:

1. Competition within the CD-procured projects is stronger than in the traditionally procured projects.

2. There is more dialogue in the CD-procured projects than in the traditionally procured ones.

3. The basis for trust in the $C D$-procured projects is comparable to the basis for trust in the traditionally procured ones.

4. There is more innovation in the CD-procured projects than in the traditionally procured ones.

5. The experienced complexity in the CD-procured projects is comparable to the experienced complexity in the traditionally procured ones.

6. The allocation of tasks and risks in the CD-procured projects is comparable to the allocation of tasks and risks in the traditionally procured ones.

The case study results can confirm these propositions (thus confirming the conclusions in Chapter 3 about the perceived low effectiveness of the CD procedure), or add weight to the $\mathrm{EU}$ policy rhetoric, meaning either that the $\mathrm{CD}$ procedure is more effective than experienced 
at first, or that perceived effects are not caused by the CD procedure. To find evidence for these propositions, questions were included in the case study protocols to investigate the facilitation of dialogue, the level of competition, the level of innovation and the basis provided for trust just as the perceived complexity, the allocation of tasks and risks and the effect on aspects of project control like quality, time and costs in the parts of the case study protocol that handled negotiations and commitments both before and after contract closure (see Appendices 4 and 5).

Table 4.1. The case study's testing constructs and aspects, and their sources in the multiple-case study

\begin{tabular}{|lllll|}
\hline \multicolumn{2}{|l}{ Testing constructs } & Aspects & Sources \\
\hline Objectives of & Direct & Dialogue & Discussions, interactions & Interviews, \\
the European & objectives & Competition & Role of other contenders & complemented with \\
Commission & & Innovation & Brand new solutions & document study \\
with the design & & Trust & Interpersonal confidence & \\
\cline { 2 - 5 } of the CD & Indirect & Complexity & Experienced project complexity & Interviews, \\
procedure & objectives & Risk and task allocation & Alignment of tasks and risks & complemented with \\
& & Project quality & Overall project quality & document study \\
& & Time overrun & Delay & \\
& Cost overrun & Budget overruns & \\
\hline
\end{tabular}

\section{Explaining differences in developments: the influence of procurement on negotiations and commitments}

The analysis of how negotiations and commitments develop in the KOSMOS cases is based on the theoretical framework as derived in Chapter 2 (Section 2.7). The conceptualisation of commitments and negotiations is described in Table 4.2, and reflected in the case study protocols (see Appendices 4 and 5).

The protocols start with questions concerning the project's characteristics and its context. These were included so that the comparability of the projects could be checked and the context variables that were identified in Chapter 2 could be related to the effects of the CD procedure by the people involved. Moreover, especially in case study research, it is the context that matters (Yin, 2009, p.18). This first question was followed by three further questions, two concerning the negotiations and commitments in the procurement stage, and one concerning the negotiations and commitments in the construction stage of the project, considered as starting at contract closure. This breakpoint between procurement and construction was made because the rationale behind the CD procedure was to indirectly influence and improve the construction of a project by changing the procurement. Furthermore, there was a practical advantage in making this division and having two procurement-related questions and one concerning the construction stage. Test interviews had shown that interviews went more smoothly when following a sequential time line. Therefore, first, questions were asked about the negotiations and commitments during procurement, and then the questions turned to the same aspects during construction of the inter-organisational projects. 
Table 4.2. The case study's explanative constructs and aspects, and their sources in the multiple-case study

\begin{tabular}{|c|c|c|c|c|}
\hline \multicolumn{3}{|c|}{ Explanative constructs } & \multirow[b]{2}{*}{$\begin{array}{l}\text { Aspects } \\
\text { Focal points in protocols and agendas } \\
\text { Individual and mutual goals, } \\
\text { knowledge and assumptions } \\
\text { Exchange of ideas, conversations, } \\
\text { dialogue } \\
\text { Revision/nuancing points of views, } \\
\text { uncovering and elimination of } \\
\text { inconsistencies }\end{array}$} & \multirow[b]{2}{*}{$\begin{array}{l}\text { Sources } \\
\text { Interviews, } \\
\text { complemented } \\
\text { with document } \\
\text { study }\end{array}$} \\
\hline Negotiations & $\begin{array}{l}\text { Formal } \\
\text { bargaining }\end{array}$ & $\begin{array}{l}\text { Focusing Attention } \\
\text { Articulation, Deliberation, } \\
\text { and Reflection } \\
\text { Interaction } \\
\text { Reducing bias, judgement } \\
\text { errors, incompleteness } \\
\text { and inconsistency }\end{array}$ & & \\
\hline & $\begin{array}{l}\text { Informal sense } \\
\text { making }\end{array}$ & $\begin{array}{l}\text { Belief-driven } \\
\text { Action-driven }\end{array}$ & $\begin{array}{l}\text { Arguments } \\
\text { Expectations } \\
\text { Justifications } \\
\text { Focus on few beliefs }\end{array}$ & Interviews \\
\hline \multirow[t]{2}{*}{ Commitments } & $\begin{array}{l}\text { Informal } \\
\text { psychological } \\
\text { contract }\end{array}$ & Informal incentive control & $\begin{array}{l}\text { Understanding } \\
\text { Norms / values } \\
\text { Empathy / affection } \\
\text { Routines } \\
\text { Importance of the (future) relationship } \\
\text { Importance of reputation }\end{array}$ & Interviews \\
\hline & $\begin{array}{l}\text { Formal legal } \\
\text { contract }\end{array}$ & $\begin{array}{l}\text { Formal incentive control } \\
\text { Opportunity control }\end{array}$ & $\begin{array}{l}\text { Reward system } \\
\text { Allocation of risks } \\
\text { Contract clauses } \\
\text { Output specifications } \\
\text { Monitoring system }\end{array}$ & $\begin{array}{l}\text { Document study, } \\
\text { complemented } \\
\text { with interviews }\end{array}$ \\
\hline \multirow[t]{2}{*}{ Understanding } & $\begin{array}{l}\text { Problems of } \\
\text { understanding }\end{array}$ & $\begin{array}{l}\text { Discontinuities in } \\
\text { structures, contexts, } \\
\text { routines, expectations and } \\
\text { perceptual frameworks }\end{array}$ & $\begin{array}{l}\text { Discussions } \\
\text { Irritations } \\
\text { Expressed inabilities to make sense of } \\
\text { the partner, the relationship or the } \\
\text { context }\end{array}$ & $\begin{array}{l}\text { Interviews, } \\
\text { complemented } \\
\text { with document } \\
\text { study }\end{array}$ \\
\hline & $\begin{array}{l}\text { Reached } \\
\text { understanding }\end{array}$ & $\begin{array}{l}\text { Sustained structures, } \\
\text { contexts, routines, } \\
\text { expectations and } \\
\text { perceptual frameworks }\end{array}$ & Stable and quiet working atmosphere & \\
\hline
\end{tabular}

The final part of the interview protocol asked the informants to compare projects (for example, they might give explanations for observed differences or note commonalities outside the research frame) and whether there were other aspects they would like to comment upon and so add to the interview. Before reflecting on the procurement process of the four projects with participants, first documents were studied covering all the projects once they were finished. The first interviews were then conducted in 2008, with informants from both procuring agencies and the contractors for the then completed KOSMOS projects.

Problems of understanding were labelled as key to the development of negotiations and commitments in Chapter 2. Together with the twelve mechanisms, identified in Chapter 3, these serve as guides for the researcher to discover patterns during the data analysis. 


\section{Multiple-case study data collection}

The empirical component of the project was conducted in 2008 and 2009. Data were collected through a series of twelve in-depth face-to-face interviews: two interviews (with a contractor and with a principal) for each project plus four additional interviews with informants who could add more about the KOSMOS projects in general. Three were from the principal organisation; these were the procurement manager, the legal counsel and the contract manager of KOSMOS as a whole (that is, all eight work packages). The extra interviewee from the contractor side was involved in the tender of two KOSMOS projects that were procured by the $C D$ procedure and one that was traditionally procured. Of these three tenders, only one was successful - a CD-procured contract, but not one of those included in the multiple-case study. An overview of the interviews, differentiated by role and participation level of the informants, is provided in Table 4.3.

Table 4.3. Number of interviews, differentiated by participation level and role

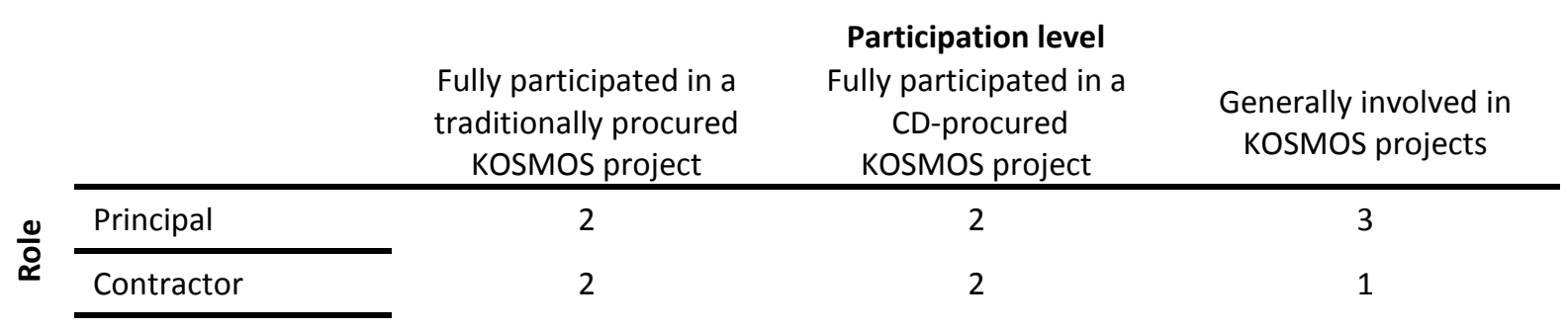

Each interview took between 60 and 90 minutes, and was guided by the case study protocols included in Appendices 4 and 5. The protocols were used in a flexible manner, thus guiding the interview but not constraining the conversation. Informants were asked to speak freely in response to the researcher's questions, and the researcher ensured that, by the end, all aspects of the protocol had been covered. Thus, informants were able to talk about the manner in which negotiations and commitments developed over time, both during procurement and construction. The interviews were recorded and then transcribed for systematic analysis, and complemented with information from an earlier evaluation report (Schrijvers, Buijs, Robben, Vis, Volwerk, van Es \& van Amstel, 2007), the procurement documents themselves, contractual documents and requests to change contractual terms after contract closure. In total, the empirical data collection process generated 95 pages of interview text; the evaluation report; two procurement protocols (one for the traditionally procured projects and one for the CD-procured projects); four procurement process reports; four contracts and four series of requests on changing contractual terms. This was all loaded into the data analysis program 'QSR NVivo', which was used to attach labels from the theoretical framework to the gathered empirical information. Using the program, text fragments with identical labels can be easily compared, patterns discovered and, from that, conclusions drawn. Information is sought out that relates to the propositions, patterns in negotiations and commitments, and especially similarities and differences in project development between the traditionally and the CD-procured projects. 


\section{Multiple-case study validity and reliability}

Having selected a multiple-case study approach as appropriate for answering the question of how negotiations and commitments differ between CD-procured projects and comparable, but traditionally procured, projects, the quality of the case study undertaken needed to be assured. There are four tests that are common to all social science methods that are used to establish the quality of empirical social research. These are tests for construct validity, internal validity, external validity and reliability (see Kidder \& Judd, 1986; Swanborn, 1987; Swanson \& Holton, 2005; Yin, 2009). Below, the incorporation of these four items is addressed.

Construct validity, which concerns identification of the correct operational measures for the concepts being studied, can be enhanced in various ways, and triangulation is a common approach. Several measures to enhance construct validity are adopted, starting with the use of two data collection methods (i.e. methodological triangulation): in this study, interviews with key informants and studying relevant project documents both provided insights into the same topics but used different research methods. The combination of micro-economic and social psychological theories within the theoretical framework, using predefined construct definitions used by other, well-known researchers for the case study protocols assured theoretical triangulation. Having the data collected by two researchers, investigator triangulation was achieved: the design of both the case study protocols and the data collection methodology, as well as the interpretation of the findings, were the result of an iterative process between theory and data that was based on strong inter-researcher agreement. Finally, by having interviews with several different project participants about similar topics, data triangulation was also achieved. As a final step, a draft of the case study report was discussed with participants in the study, and with independent researchers, in order to further increase the construct validity of the study (Swanson \& Holton, 2005: Yin, 2009).

A further very important aspect in quasi-experimental research is internal validity: the extent to which the research actually answers the questions it claims to answer using the data that were gathered. In quasi-experimental case studies such as this, internal validity refers to the validity of causal interpretation (Swanborn, 1987). Yin (2009) argues that developing an analytical strategy is the first step in achieving case study internal validity. By keeping to a predetermined strategy, the likelihood of answering the question the research claims to answer is increased. To assist in developing analytical strategies, Yin (2009) determines five analytical techniques. Successful case studies can be achieved by working modestly, thoroughly and introspectively towards developing compelling case study analyses. The strategies used in this research are pattern matching, explanation building and cross-case synthesis. By considering all the evidence that was available related to the propositions that were defined in advance, it was tried not to rule out alternative interpretations based on evidence that otherwise might have been ignored. When there were rival interpretations, advanced by other researchers or respondents, these were included in the case study or recorded as a loose end to be investigated in future research. The most significant aspects of the case study are, however, used as explanations, and this prevents interesting but minor 
aspects being given too much attention. To summarise, by being aware of prior knowledge and developing a focus before analysing the data, it was ensured that the researchers remained also open to rival explanations.

External validity refers to the ability to generalise a study's findings to other populations or settings (Swanborn, 1987; Swanson \& Holton, 2005; Yin, 2009). By making use of multiple cases (two cases procured by the CD procedure and two procured by the traditional, restricted procedure), literal replication is achieved. By seeking explanations that are found in both cases within each sub-group (either CD-procured or traditionally procured), the external validity of the results is enhanced: conclusions that are common to both projects within a sub-group can be generalised to the larger group of similarly procured projects. This generalisation was further reinforced by discussing the results of the study in two panel discussions. One panel consisted of project managers working for the procuring agency, and the other of members of the tender teams working for the contractors. Both panels recognised the findings of the cases included in this study as also occurring in other construction projects they had worked on.

Finally, turning to the fourth validity test, the reliability of the case study process is considered. Essentially, reliability means that the same results would be achieved when the operations of the study were repeated by another researcher. Following Yin (2009), a case study protocol is used, and a case study database is developed in which the case study notes, documents and interview transcriptions are documented, thus improving the reliability of the study and allowing it to be repeated.

\subsection{Results}

In 2004, the backlog of maintenance work on highway and waterway infrastructure was becoming a hot political issue. Some maintenance work had been neglected for thirty years, resulting in both recurring maintenance problems and problems expected in the short term. The Dutch parliament decided in 2005 that these issues should be resolved within two years, in order to keep the infrastructure up and running. In this period, the non-utility of the infrastructure and the expanding traffic jams were becoming of greater concern for several reasons. One issue was that the then current maintenance programmes were not synchronised with each other, or merged when appropriate. Individual objects were subject to just-in-time maintenance, resulting in several uncoordinated closures or obstructions of highways and waterways. Contemporary public opinion was demanding a more user-friendly approach taking the whole infrastructural network into account, so that closures and obstructions could be adjusted and brought in line. Given this situation, the Ministry decided to develop a more corporate approach to object maintenance. All the existing technical problems related to flyovers, overpasses, bridges and similar infrastructure built on or in the Dutch highway and waterway infrastructure network were merged into one programme: KOSMOS (Mousset \& Vis, 2008). In this section, a general description of the programme and the various projects investigated within the programme is given, followed by a description of the formal and informal contracts involved. 


\section{The projects' characteristics}

Within the KOSMOS programme, the typical contract size was increased by bundling objects. The regional offices of the Dutch Highways and Waterways Agency decided which objects were to be included in the KOSMOS maintenance programme, while the central procurement and engineering department decided upon the actual make-up of the contracts to be procured. This latter decision was made after consulting the private sector. This resulted in the eight projects mentioned earlier. The four cases selected for this study were four Engineering and Construct $(E \& C)$ contracts with an interdisciplinary content (both road and water, that is "dry" and "wet" works), regionally spread, and each containing between 100 and 200 objects and 300-500 problems.

To achieve both end-user satisfaction and market satisfaction, and after consultation with the market, a corporate (i.e. national) procurement strategy was established. This strategy aimed at integrating all the necessary disciplines in one E\&C contract; providing maximum transparency in terms of information for all interested parties; and standardising processes and procedures. A specific demand from the industry raised during the market consultation was that not only the large construction companies should be able to take part in the tender. In response, the pre-selection requirements were kept rather abstract so that smaller contractors, or a combination of smaller companies, would also be able to tender. For the Dutch Highways and Waterways Agency, this proved to be advantageous in providing competition, support and success by increasing the number of entities able to participate in the various tenders. Further, the benefits of learning from the KOSMOS Programme would not be restricted to the "big six contractors" (Mousset \& Vis, 2008).

The suggestion to procure six of the projects using the $C D$ procedure was made in September 2005 (Agency's internal memoranda and notes). At that time, this procedure was one of four options: open procedure, restricted procedure, CD procedure and negotiated procedure. The first two options did not provide any opportunity to have a conversation with market parties, which was an aim of the Agency. Further, several risks were identified concerning indistinctness in controlling and allocating risks; claims for extra work; whether the contractors would understand the need for integrated approaches; and possible claims from non-selected candidates at the end of the work because of the differences between the tender details and the actual work done. The remaining two procedures were considered to offer the possibility of preventing these undesirable risks because they allowed extensive conversations during the tendering process, so that everything could be made clear to all the candidates. The negotiated procedure was judged as being too intensive since the workload for the Agency would become too large. Therefore, procurement by use of the $C D$ procedure seemed the advisable approach.

However, the question arose as to whether the KOSMOS projects were sufficiently complex to justify the use of this procedure. Several internal memos were written, giving either positive or negative advice, based on consideration of the possible consequences should the EC decide that this was an illegitimate use of the CD procedure. Nevertheless, in April 2006, the Minister decided to use the $C D$ procedure for these six projects. The complexity of the 
projects was in the fact that the risks and solutions were not open to objectification, so that "objectively defining the technical means, capable of satisfying the Agency's needs or objectives" was not possible (See Subsection 3.1 "When to use" for an explanation of technical complexity).

Table 4.4. Timeline of the procurement decisions for the KOSMOS work packages

\begin{tabular}{llllllll} 
Sept. & Dec. & Feb. & April & April - May & May & Jan. & Jun - July \\
$\mathbf{2 0 0 5}$ & $\mathbf{2 0 0 5}$ & $\mathbf{2 0 0 6}$ & $\mathbf{2 0 0 6}$ & $\mathbf{2 0 0 6}$ & $\mathbf{2 0 0 6}$ & $\mathbf{2 0 0 7}$ & $\mathbf{2 0 0 7}$ \\
\hline Suggestion & Start of & Contract & Decision: CD & Publication & Contract & Contract & Contract \\
to procure & traditional & awarded for & procedure & of decision & awarded for & awarded & awarded for \\
KOSMOS & procurement & first & appropriate & to procure & second & for first & the five \\
projects by & for two & traditionally & for procuring & six projects & traditionally & CD- & remaining \\
the CD & KOSMOS & procured & the KOSMOS & by the CD & procured & procured CD-procured \\
procedure & projects & project with & projects & procedure & project & project & projects \\
& & & & & & &
\end{tabular}

When this decision was made, the procurement of two other work packages had already taken place. The responsible authorities were not willing to await a decision concerning the CD procedure, and procured using the restricted procedure (See Table 4.4).

In the upcoming sections, attention is given to the traditionally procured projects and the CD-procured KOSMOS projects respectively, based on the interview results and document study. After a short description of the development of the projects, in which attention is given to the development of negotiations and commitments during procurement and execution of the project, the meeting of the objectives for the CD procedure (i.e. dialogue, competition, innovation, trust, reducing complexity, proper allocation of tasks and risks, and aspects of project control - quality, time and costs -) is assessed for the KOSMOS projects. These overviews are based on finding congruent statements by at least two informants working in different projects. When statements come from only one informant, or from two informants within a single project, or when the informants all work for either the Agency or the contractor, or when there are contradictory statements, this is explicitly noted in the text.

\section{Traditionally procured projects}

\section{Developments during procurement}

The contractors that were invited to bid in the KOSMOS projects procured by the restricted procedure were selected from the group of interested contractors on the basis of relatively simple criteria such as ISO certification, experience/expertise in maintenance and/or reconstruction of similar objects and of highways and/or waterways. Alongside this, their experience/expertise in managing a design and construct contract, including a proven lifecycle approach, was judged, along with their expertise in the field of interdisciplinary management and their experience in realising a constructional contract combined with traffic management (working while maintaining traffic flow). The selection phase led to five potential bidders being selected for each of the two projects. 
Selection in both of the traditionally procured packages was based on MEAT criteria (most economically advantageous tender). Additional assessments of the objects included in the contract were made by an engineering firm hired by the Dutch Highways and Waterways Agency. The results of this study were expressed in condition assessments, based on which the contractors made their bids.

The contract amounted to a small overall contract with an underlying uniform document structure and hierarchy, a uniform set of general terms and the scope of the work. Given that this was an Engineer and Construct contract, the Agency did not prescribe the manner in which the maintenance should be carried out. Participants were free to judge the data in the assessments and to decide which maintenance approaches would be employed. In all the situations, participants were provided with strict maintenance time-slots based on the traffic situation and the influence of non-utility of the infrastructure. Furthermore, traffic hindrance was discouraged through financial incentives in the contract.

Based on their own calculations, the bidders had to produce an action plan which formed part of the MEAT documents that participants had to deliver along with a monitoring plan. The Dutch Highways and Waterways Agency asked participants to guarantee the quality of the delivered product. The process to be applied to monitor this quality was then assessed by the Agency. This monitoring system was new to both the Agency and the contractors. The contractor who overall best met the Agency's demands qualitatively (least traffic hindrance, quickest delivery, best planning and management) and quantitatively (lowest bid) was awarded the contract. Table 4.5 illustrates this schematically.

Table 4.5. Procurement developments within traditionally procured KOSMOS projects

Procurement by restricted procedure

Bid and Contract award

Candidates selected on the basis of
An external agency produces assessments reflecting the state of the objects within the contract scope

Potential bidders
determine
maintenance activities
based on the provided
assessments, and
develop an action
plan

Potential bidders certification and experience / expertise in maintenance, contract management, interdisciplinarity and traffic management.

\section{Bids, containing a} price, an action plan and a monitoring plan, submitted and judged on the basis of MEAT criteria

An intention expressed by the Dutch Highways and Waterways Agency was to coach the contractor on its tasks since both the Agency and the contractor were in a learning phase. Functional specification and system-based monitoring were rather new to both sides, so the idea was to jointly learn from the KOSMOS processes.

\section{Developments during construction}

\section{Problems of understanding}

When the construction of the projects started, immediately after contract closure, the Agency and the successful contractors had, so far, only little contact. Except for the public inquiries during the procurement stage, no information exchange had taken place. Therefore, the mutual understanding about the meaning of the contract, its scope and the 
plans that were made by the contractor had to grow during the construction stage. In practice, there were several situations that led to problems of understanding in the early stages of the construction.

The first problems of understanding arose from different interpretations of tasks and duties. This had mainly to do with the fact that neither the Agency nor the contractors had experience in procuring contracts with a design component under a system-based monitoring approach. On the one hand, the contractors thought it was odd that the Agency had not drawn conclusions from the condition assessments (did the whole bridge have to be replaced or would it be sufficient to reconstruct parts of it?). On the other hand, there was the Agency feeling that it was the contractors' responsibility to make that decision and then put a price on it:

Principal 1- Well, all realisation-related risks were for the contractor - are for the contractor. And all the risks concerning the demarcation of the contract scope are ours. I feel that this is good and balanced. The further research was our job, but the development, the solution, that was theirs. That was very clear to all of us.

One of the Agency's employees who worked on the traditionally procured projects acknowledged that, with hindsight, the contractors were given too little time to get to know the ins and outs of the condition assessments. However, neither he nor his counterpart in the other traditionally procured project were aware of this when the contracts were signed. This informal assessment of an imbalance in mutual expectations did not, however, come to the surface until the construction stage.

When the contractors started the work, they were confronted with objects and roads which turned out to be in a different condition to that described in the condition assessments. This caused problems of understanding. In the contracts, it was agreed that, in the event of incomplete or insufficient data or when the actual state of objects and roads was worse than one might reasonably expect from the condition assessment, that the extra work would be on the account of the Dutch Highways and Waterways Agency. Contractual clauses protected against contractors claiming for nonexistent or unnecessary extra work by stating that when differences were discovered, the Agency had to first be contacted. Extra work should only be carried out after the Agency had consented. In practice, this was not as straightforward as one might have expected. For example:

Contractor 1- Well, the condition assessment said that the problem existed for about 10 metres. Yet, in practice, it turned out to be 20 metres. However, if you find out about this in the middle of the night, when the road is closed for maintenance, the project manager has to decide on the spot whether to replace 20 metres or 10. Of course, you cannot reach anyone at that hour from the principal, that is the Agency. So, our project manager decides to replace 20 metres, thinking on his feet you know, since otherwise the road would have to be closed for another night later on. However, the next day, the principal complains: we did not act as agreed upon in the contract. 
The contractor's plans which were assessed using the MEAT criteria, to win the contract, were only outlines of the working and monitoring plans. These had to be specified in more detail after contract closure, and agreed by the Agency. System-based monitoring was new to both the Agency and the contractors, which meant that, in both projects, the contractors found it difficult to find the right level of abstraction (resulting in large amounts of paperwork in improving their efforts), and the Agency took its time in checking the plans, and rejected them several times. The Agency somewhat hovered between wanting to monitor the process from a distance and checking upon the details of the product itself. However, there was not the time to keep checking and re-checking modified plans since the closure of the roads involved was already scheduled, and the dates were approaching. This put pressure on the development of the working and monitoring plans. Table 4.6 illustrates the problems of understanding during construction of the traditionally procured KOSMOS projects.

Table 4.6. Problems of understanding during construction of traditionally procured KOSMOS projects

\section{Construction}

Problems of understanding due to different interpretations of tasks and duties

Increased problems of
understanding due to differences
between the actual state of
objects and the data in the
condition assessments

Increased problems of between the actual state of condition assessments

\author{
Acceptance of working and \\ monitoring plans took \\ considerable time, while deadlines \\ for the work were approaching
}

Summarising, the early construction months of the traditionally procured projects were not contributing to the development of positively assessed relationships between the Agency and the contracted organisations. At contract closure, there were minor problems in understanding the working roles that each party should fill. When the actual state of objects and roads turned out not to match the description provided in the condition assessments, these small problems of understanding grew larger. The lengthy period and the extra versions required before the working and monitoring plans were accepted, and the discussions over extra work that had been performed without first consulting the Agency, contributed to the mutual feelings of misinterpretations in the working roles:

Contractor 1- Whilst in my opinion the idea was, and still is, that "the Agency has a problem: certain objects have to be patched up. We would solve this for them, and we will do that within a certain time span. We will make sure that the traffic is not obstructed too much, and that the project gets finished" This we have done, but the Agency regressed to a paper version of the project. They no longer went outside to the project. In the end, all that counted was rightfulness, the accountant and I don't know what other issues, instead of whether or not the car drivers were standing still while the object was maintained. I felt as if the Agency was not focusing on the essence of the contract.

Negotiations and commitments

From the above, it is clear that especially the understanding of what was written in the formal legal contract differed between the Agency and the contractors. This caused the relationships in both projects to deteriorate in negative vicious cycles. Nevertheless, both 
the Agency and the contractors involved in the projects remained committed to their informal psychological contract. They were willing to cooperate for the benefit of the project:

Contractor 2- Road closures were sacred. They are the Agency's responsibility, and officially should be fixed at least six months in advance. The Agency has to work for months in organising a weekend closure, to come to agreements with the various stakeholders, so it cannot be changed at short notice. The Agency knew that, and so did we, so we agreed to do the work in the agreed weekend. To do this, we had to work in a different way than we had agreed. While we worked, the Agency looked over our shoulders. This was the only way to get this work done then.

Besides these bargaining processes to develop practical solutions with regard to working on the objects and highways without having agreed working and monitoring plans at the closure dates, also the working relationships became looser:

Contractor 1- Their people, in themselves, were all right; but the process the Agency asks its people to follow, I felt it was a straitjacket for them. Naturally, they cannot be held responsible for that, of course.

In both projects, a project restart was organised, and this helped in the sensemaking process of both parties involved. After these renegotiations, the parties reached a better mutual understanding of the job to be done, and the roles of both parties in this. This helped in finishing the last parts of the projects, by changing the working routines and establishing a better working atmosphere than was the case during the earlier repairs.

Principal 1- At first, we all acted by following the wording in the contract whilst, later, the ideas behind the contract were acted upon. It became more cooperative. [...] At first, we all held opposing ideas about the work that had to be done; about what their tasks were and what we were responsible for. [...] Well, we were expecting the contractor to solve at least half or even the whole problem with an object. That was what we were reading into the contract. But, actually, one could read the contract in two ways, and it the end we came to a solution which was acceptable to both parties. [...] They did not have to complete the whole object, but limit the work to certain parts of the object.

Principal 2- Before this renegotiation, the relationship was purely business. That was a pity, since it makes one tend towards writing letters and e-mails instead of simply calling. It went against us in the end. I noticed that my own behaviour was working against me. Yes, you will have to respond to letters, but these cost much time and energy. A phone call is just as fine for many such things.

Contractor 1- We only got to know each other after the renegotiations, you know. In June 2006 we signed the contract, and we were supposed to enter the highway during a fixed closure period in August. We absolutely needed this closure to do our job. No doubt that we had to use this closure period. Yet, before we could enter the highway, 
several plans had to be handed in, and weeks in advance. We lived up to that agreement, but then our plans were not approved by the Agency. So, we already had our first argument. Further, because the highway closure had already been fixed, this put huge pressure on the early months. Actually, the whole project became frustrated by this. The principal did not get the chance to get to know us, and we were not able to get to know the principal. It was just talking business, from the first meeting on. [...] Only after the restart in March 2007 did we clarify what the goals were for both parties. Where the two of us were going, and how we were going to get there together. After that, it went much better.

Contractor 2- It is kind of interplay: once one of the two becomes a little rigid, the other becomes more rigid too, and the two grow further and further apart. [...] The project restart helped a lot. Then, every time we were discussing a subject, we made plans: how are we going to do it? What extras do you want in our plans to make it acceptable to you? Well, in very many cases, we could live with their ideas; we didn't have any problems at all. And, if there were things that we argued about and could not reach agreement during the meeting, we referred them to a higher level. While the issue lay with the big bosses, we moved on to the next subject. We managed to avoid creating an atmosphere of "them and us". It was just a feeling of making the project a success together. The restart helped a lot in this.

To summarise, whereas, at the start of the construction stage of these traditionally procured KOSMOS projects, the parties involved had no strong expectations, their attitudes towards each other became somewhat negative during the first few construction months. However, pragmatism and official restarts created renewed mutual understanding such that the last months of the construction stage went much more cooperatively and smoothly. See Table 4.7 for a timeline of negotiations and commitments during construction of the traditionally procured KOSMOS projects.

Table 4.7. Construction developments within traditionally procured KOSMOS projects

Construction

The work started, even though working plans were not formally accepted, for the benefit of the project.
Working plans were accepted.

Project restarts were organised, during which mutual understanding was achieved about the job and the roles of both parties.

\section{EC objectives with the $C D$ procedure}

Considering the direct objectives set by the EC for the CD procedure, the first, enabling dialogue, was not part of the procurement process in these restricted procedures. Competition was only mentioned in relation to incorporating learning costs. Since E\&C contracting and working with system-based monitoring was new to all the contractors involved, transaction costs were high. However, incorporating these costs in the bid price might put a contractor far behind its competitors. Further, competition was not an issue to either of the interviewed contractors. Innovation was not achieved according to the respondents. The trust level after the procurement phase of the project was assessed as 
neutral by three of the respondents and as negative by the fourth. However, in his examples, this respondent (Contractor 1 ) is referring more to benevolence than to trust:

Contractor 1- Before the renegotiations, it was not that easy: the distrust, which was there from the beginning, grew each day. So, if we asked things from each other at that time, it ended up at the bottom of the pile with further questions. After the restart, we were thinking differently: "I'll do this quickly for you, so that we can both move on".

Summarising, projects that were traditionally procured did not lead to dialogue, competition, innovation or trust. Given that these objectives were justifications for introducing the CD procedure, and that this procedure was not used for those two KOSMOS projects, this result matches the theoretical pattern.

With regard to the indirect objectives, the conclusion can be drawn that respondents did not experience much complexity. The allocation of tasks and risks could have been better: in the traditionally procured projects did it lead to problems of understanding. This matches the theoretical pattern as well.

\section{CD-procured projects}

\section{Developments during procurement}

The selection criteria for successful bidders in the CD-procured KOSMOS projects were similar to the criteria used in the traditionally procured projects. Besides ISO certification, candidates had to demonstrate their experience/expertise in maintenance and/or reconstruction of objects and of highways and/or waterways. Further, their experience/expertise in managing a design and construct contract including a proven lifecycle approach was judged, as were their expertise in the field of interdisciplinary management and experience in realising a construction contract combined with traffic management (working while maintaining traffic flows). Again, five contractors were selected to participate in the tender process.

In the CD-procured projects, dialogue started early on. In the first stage of the dialogue, the preselected candidates were given responsibility for determining the actual problems with the infrastructure during the procurement procedure. Together, they had to determine what additional research (condition assessments) had to be undertaken on the objects covered by the contract. The Dutch Highways and Waterways Agency then commissioned an engineering firm to carry out the assessment work, and the data were provided to all the candidates. Based on this information, the individual contractors could make their calculations, determine risks and costs, and ask questions during later stages of the dialogue.

After this dialogue, the contract offers could be finalised: the procedural and technical gaps were filled; and each pre-selected potential contractor had discussed individual risk distributions. This made it possible for the Dutch Highways and Waterways Agency to start the competitive dialogue for a situation in which the technical solutions would be developed by the contractors, whilst taking into account services related to consumer demands: traffic management, road safety, traffic-related information and communication. The candidates 
were thus given the opportunity to provide solutions to problems defined by the Agency. An associated issue was that asset management was only starting to be developed at the Dutch Highways and Waterways Agency. Information gaps related to the assets had prevented some problems being solved. The Agency wanted to fill their information and technical gaps through dialogue with the bidders. Another reason for starting the dialogue was that the Agency wanted to achieve full cooperation over innovations in order to improve their realisation methods related to the users of the infrastructure. Therefore, parts of the contracts were custom-made for each candidate, depending on their offered solutions and risk distributions.

During the dialogue, the scope of the CD-procured KOSMOS projects was determined separately for each candidate. The contract and the reward system were not included in the dialogue, nor were the contract philosophy or the monitoring system. The conversations focused mainly on the actual state of the objects and the roads within the projects' scopes. Although there was considerable available knowledge on the state of the objects and roads, there was also some possibly important knowledge that was not available, and which might be needed to make a proper risk assessment. The construction elements for which adequate knowledge was available were labelled $X$, and the construction elements with knowledge gaps were labelled $\mathrm{Y}$.

For the $\mathrm{X}$ elements, the minimum and maximum risks had already been assessed, and, in their bids, the candidates had to put a price on each individual $X$ (comparable to how the traditionally procured projects were treated). For the $Y$ elements, the minimum risk was assessed, and the candidates could commission assessment work by an engineering firm to help them also assess the maximum risk. In their bids, the candidates had to estimate the risk for each $Y$ element, and to put a price on it. If the risks were assessed as excessive, candidates could choose to leave the elements concerned out of their bid. This would create a virtual increase in their bid price since, in the MEAT criteria for non-solved elements, a certain hostage sum was added for each excluded element. With this approach, the Dutch Highways and Waterways Agency expected candidates to include many elements at a low bid price. Further, in cases where all the contractors assessed the risk as being too high, the Agency would at least have received efficient condition assessments for each $Y$ element since the five candidates would together have decided which information was needed.

At the end of the dialogue, for each project, five different scopes and monitoring systems were presented, complete with five different bid prices. The contractual clauses of all the contractors were the same within each project, although small differences existed between the projects. Although the contract had not been part of the dialogue, in some cases the wording of the specifications had been changed to make solutions possible for individual contractors. Candidates were offered strict maintenance time-slots according to actual traffic requirements and the influence of non-utility of the infrastructure. Further, traffic hindrance was minimised by offering financial incentives in the contract. After contract closure, the Dutch Highways and Waterways Agency intended to coach the selected contractors, as the work progressed, in system-based quality control, since both parties were in a learning phase. Competitive Dialogue, contracting by functional specification and system-based monitoring were all new to both the Agency and the contractors, and the 
Agency did not want this to harm the projects. Table 4.8 illustrates this in a timeline of negotiations and commitments during procurement of the CD procured KOSMOS projects.

Table 4.8. Procurement developments within the CD-procured KOSMOS projects

Pre-selection

Candidates selected

on the basis of

certification and

experience /

expertise in

maintenance,

contract

management,

interdisciplinarity

and traffic

management.
Procurement by the CD procedure

Bid and Contract

award

Candidates define
their requirements
to an external
agency, which will
then make a single
condition
assessment of the
identified objects
for all the
candidates.

candidates.

Dialogue

conversations

about the state of

the objects and the

allocation of $X$ and

$Y$ risks. (The

contract philosophy

and the reward

system were not

part of this

dialogue).
Submitting bids

containing a price,

an action plan, a

monitoring plan,

the contract scope

and a risk

allocation. These

were then judged

on the basis of

MEAT criteria.

\section{Developments during construction}

Problems of understanding

Already during the dialogue stage, problems of understanding were arising. The first issue was the time required to go through all the Agency's available information. Candidates felt they could not assess

how complete or qualitative this information was, such that it was difficult to determine what the assignment to the engineering firm should include. The available information was both too much in quantity and too poor in quality. Further, the engineering firm's allocated assessment time (15 minutes per element) was judged as insufficient. Furthermore, candidates felt that there was insufficient time between the condition assessments being delivered and the bids having to be submitted for them to evaluate the work required. However, they did not make a big deal of this with the Agency, resulting in it not being discussed while it clearly was an issue.

Principal 1- In my opinion the candidates should have said "Dear principal, now you ask the impossible, we are opting out of the tender". However, it still seems difficult for candidates to say "I quit, because this does not suit me". No, their craving for work is just too strong.

Contractor 1 - These are the sort of things we have to deal with. For if we say: "Well, due to all this vague information and answers it is too risky for us", we will never respond to a tender. That's how it is. But, it should be improved, the Agency should give a plain and clear answer when asked something. And yes, maybe things would then become clear which the Agency would rather leave implicit. [...] The answer "no, that risk is ours", will never ever be given. No, they always produce a nice piece of paper, the longer the text the better... and the closer we will have to read it. 
The second cause for problems linked to understanding was in assigning work to the engineering firm. The Agency's intention was that candidates would jointly be responsible for drawing up the engineering firm's assignment. However, the fact that this firm was appointed and paid for by the Agency gave a different signal to the candidates. Further, the contractors did not feel responsible for the contents of the condition assessments, and the given situation encouraged them to behave opportunistically. Respondents from both the Agency and the contractors stated that the drawing up of the assignment for the engineering firm ended up being more of a game between the candidates than a proper attempt to get the needed information. All five Agency respondents and two of the three from the contractors' side agreed that the contractors were more active in trying to confuse each other than with getting the right information included in the condition assessments. It was as if discouraging competitors was more beneficial in eventually winning the bid than cooperating to get a clear understanding of the risks in the project. This caused friction on the Agency's side about the candidates' interpretation of tasks and duties. Furthermore, contractors were of the opinion that they would not have to check the situation with the objects and roads themselves, since all the necessary knowledge had been delivered on paper. The Agency, however, was somewhat surprised that they did not go and look for themselves:

Principal 1 - Well, there are certain things which you could easily observe if you went and checked the situation yourself [...]. When the specs say that you will have to solve a problem, then you should consider the situation in your solution: [...] These kinds of issues have, in my opinion, not been taken into account at all. They did nothing about it at all. Well then I think, as a professional contractor, you have made a gaff. You shouldn't expect the Agency, in this form of contract, to prescribe everything for you.

These problems of understanding were, however, not expressed during the dialogue. So, although all the successful parties came out of the dialogue process thinking they had signed contracts on which there was mutual understanding, the execution of the projects showed that the understanding of these contracts was not shared at all. The Agency and the contractors adopted different positions when the actual state of objects and roads did not appear to match their expectations, based on the condition assessments. In short, there were two situations. Firstly, there would be a problem with an element of type $Y$, but it was not clear whether this problem concerned a scenario in which it was the contractor's responsibility or the Agency's. Secondly, during the condition assessment, something had been overlooked and later it turned out that more work was required than expected. The Agency felt that the candidates should have checked this, and since they had not, the Agency held them responsible to pay the extra costs. Contractors held a different opinion, and put the claims on the Agency.

Third, whilst the Agency employees were unanimous in their opinion that contractors did not feel sufficiently responsible, and were not truly committed to the project; the contractors complained about the Agency taking the contract too literally, not thinking in terms of the project's interests, but only from the Agency's perspective. This was especially reflected in issues concerning the system-based monitoring. Both contractors and the Agency's employees felt that the system was excessive for the minor tasks that maintenance 
actually is. However, with the two parties holding to different working routines, and with claims being advanced, and with a monitoring system which was new to all parties involved, negative vicious cycles were developing. An outcome for the contractors was that small shortcomings could result in large payments being withheld awaiting the resolution of the shortcoming.

Contractor 2 - ... contract managers tried hard not to pay. We kept being confronted with defects and shortcomings and we, as contractors, just had to accept it. The inconvenience for us was that payments were withheld; and that was happening everywhere. In 2007, all the sums were paid in one go by the principal at the end of the financial year, with a statement that they were being accommodating! And, in 2008, it started all over again: in total there were arrears of $€ 100$ million on KOSMOS. And that was seen as OK, but (a) it was never the idea of KOSMOS not to pay as work was completed, and (b) contractors cannot bear this level of pre-financing.

Table 4.9. Problems of understanding in the CD-procured KOSMOS projects

Procurement by the $\mathrm{CD}$ procedure

Problems of understanding arose since candidates felt that the time to interpret available information was too short, as was the time for the engineering firm to make the condition assessments.
Different interpretations of responsibilities towards the engineering firm.

Opportunistic behaviour by the candidates towards each other.
Construction

$\begin{array}{ll}\text { Differences between } & \text { Differences } \\ \text { the actual state of } & \text { in } \\ \text { objects and the } & \text { expectations } \\ \text { contractor's } & \text { about the } \\ \text { expectations from the } & \text { contract and } \\ \text { data in the condition } & \text { monitoring } \\ \text { assessments. } & \text { philosophy. }\end{array}$

To summarise, problems of understanding that occurred during the procurement stage of the CD-procured KOSMOS projects increased throughout the construction stage due to differences in interpretations and expectations. During the dialogue conversations, most of these issues were not raised and therefore not discussed or resolved.

Negotiations and commitments

Just as in the traditionally procured KOSMOS projects, the CD-procured projects also developed through negative vicious cycles. From the above, it can be seen that especially the informal understanding of what was written in the formal legal contract differed between the Agency and the contractors. In attempts to make sense of the situation, both parties in each project sought to provide explanations. These were found mostly in doubting the other party's professionalism.

Principal 2 - Maybe we were expecting too much of the contractors. Unfortunately, thinking in terms of risk management has not become as common in contracting firms as we believe is necessary.

Contractor 2 - When, in 2007, a new auditor became involved, one who was experienced, also in ISO 9001 and so on, he knew much better when something was a defect, when it was a shortcoming, when a claim was just and when not, what was a 
strong measure and what not. As such, he was much better in evaluating how bad the failures were. [...] After this change, on our side, we could agree with points made by the Agency. We much quicker came to the view "no, they are right, done".

The parties continued to fight over their differences about the actual state of works and roads, so these could only be solved by tough bargaining. The first of the identified situations (defining to which scenario the problem applied) was looked at for each occasion by the Agency. For the second situation (things being overlooked during the condition assessments), the Agency and the contractors would attempt to renegotiate, and sometimes even go to court. If a verdict was given in favour of the contractors, the Agency and the contractor concerned would enter a mediation process leading to a settlement. This settlement was then reflected in all the other KOSMOS projects resulting in new agreements about responsibilities for the condition assessments.

Along with the settlement over responsibility for condition assessments, an arrangement was also made over the shortcomings. Contract managers no longer had to decide for themselves whether or not something amounted to a shortcoming or a defect; their bosses at the Agency in Utrecht would take care of this from then on. According to the informants, this helped to alignment of the informal contracts - but it did not deliver empathy.

Contractor 2- At a certain moment the working situation improved - once there were clear guidelines from Utrecht [the headquarters of the Agency, red.]. I noticed things went smoother but, by then, the mutual understandings were pretty much on the rocks already.

Principal 1- The relationships became disturbed: rigidity arose. And everywhere in KOSMOS, not just in our project, the mediators have tried to help and to steer, but it all came far too late.

To summarise, due to problems of understanding remaining unspoken, the negative attitudes of both parties towards each other influenced the manner in which both made sense of new cues. Problems of understanding increased during the construction stage due to using internal sensemaking, resulting in negative vicious circles, rather than openly expressing problems of understanding to each other. Tough negotiations, and even lawsuits in the worst cases, led to solutions, but these could not repair the relationship between Agency and contractor. See Table 4.10 for the timeline of negotiations and commitments during construction of the CD procured KOSMOS projects.

Table 4.10. Construction developments within the CD-procured KOSMOS projects

\section{Construction}

Problems of understanding were explained by internal sensemaking activities, such as

Tough renegotiations over solving problems due to differences between the actual state of objects and the questioning the other party's professionalism contractor's expectations from the data in the condition assessments, sometimes even resulting in going to court 


\section{EC objectives with the $C D$ procedure}

With respect to the first direct objective of the EC in introducing the CD procedure, realising a dialogue, the participants agreed that, within the KOSMOS situation, demands and solutions did not come closer. Although parties embraced the possibility of exchanging ideas, neither the contractors nor the Agency's employees were positive about the actual dialogue in the CD-procured KOSMOS projects. Parties did not open up to each other (for example about the possibility of bearing risks), so that the expected benefits of the dialogue did not arise.

Principal 1- I think we did not get out of the dialogue what is possible. You might well wonder whether a dialogue in this form offers added value to this kind of project. Especially when compared with the effort and capacity it takes. [...] the CD procedure could offer added value, because it provides an opportunity to explore project possibilities outside the framework of the contract. What the principal has designed does not need to remain sacred at all. We are also just human beings, and I know how contracts are thrown together sometimes. There are several possible improvements, and one should sometimes look beyond borders. In my opinion, the CD procedure offers exactly these possibilities. But, if you look at how the CD procedure was designed here, [...] I think it was very limited.

Competition, on the other hand, was very strong. As described above, the drawing up of assignments for the engineering firm resulted in opportunism on the side of the contractors. This competition did harm the process, rather than help it, according to both the Agency and the contractors.

Despite one or two success stories in all the KOSMOS projects, innovative solutions were largely absent. This might have something to do with the risk averseness of the Agency's employees. Two of the three contractors who were interviewed stated that it was difficult to get innovative solutions approved:

Contractor 1 - Such a solution did fit with an idea of a dialogue [...] But it still took over two months before the Agency accepted the plan for this innovation. It had to be revised five times, and after endless negotiations [...] it had to be signed by someone from the Agency, but no one dared to do so.

With respect to creating trust between the Agency and the contractor, all parties agreed that the CD-procured KOSMOS projects added to the feeling that all the ins and outs of the contract were discussed. Both principals and contractors had the impression that the other party was willing to make the project work. However, the discussions about responsibilities and risks after contract closure saw them all agree that the CD procedure had clearly failed to provide a stable basis for trust.

For the indirect objectives the conclusions of the $C D$ procured projects match the projects that were traditionally procured. The experienced complexity was little, yet the allocation of tasks and risks was far from balanced and led to several discussions after contract closure. 
Summarising, with regard to meeting the objectives of the European Commission with the $\mathrm{CD}$ procedure, the conclusion is that, in the CD-procured projects, the possibilities introduced by having a dialogue were not optimally used. Competition, on the other hand, was very strong, and innovations were stimulated although realised to only a limited degree. A basis for trust did seem to be created, but turned out to be less strong than thought following contract closure. Complexity was not decreased, due to the inexistence of complex issues and the allocation of tasks and risks was not as balanced as aimed for.

\subsection{Cross-case analysis}

In Section 4.2, overviews were given of developments in the traditional and the CD-procured KOSMOS projects. Attention was paid to problems of understanding, negotiations, commitments and to the actual meeting of the CD procedure's objectives. In this section, the results of both the previous subsections are compared and reflected upon. First an analysis of the objectives of the European Commission (i.e. improving dialogue, competition, innovation and trust) is described; followed by an analysis of the negotiations and commitments in both types of KOSMOS project. The cross-case analysis ends with an overall evaluation of the KOSMOS program by the informants: what are, in their opinion, the reasons for similarities and differences between the traditionally procured KOSMOS projects and the CD-procured ones?

\section{EC objectives with the CD procedure}

When comparing the traditionally procured projects with the CD-procured ones in terms of the $C D$ procedure's objectives, the general conclusion is that, when considering all four points (dialogue, competition, innovation and trust), the CD-procured projects have done slightly better overall than the traditionally procured projects. Whereas informants stated that the dialogue within the CD-procured projects was not sufficiently comprehensive and open, the fact that conversations were held before contract closure, rather than only afterwards, was positively evaluated. The competition between candidates was probably no less in the traditionally procured instances than in the CD-procured ones. Further, given the competitive elements in the KOSMOS dialogue, candidates were aware of the competition, and reacted by trying to eliminate each other and refusing to cooperate (demonstrating opportunistic behaviour). The CD-procured KOSMOS projects showed that innovation could indeed be stimulated by the dialogue, although the final outcome somewhat disappointed the Agency. Contractors did come up with some process innovations, whereas none were observed in the traditionally procured projects. This was linked to the possibility of altering the specifications of the CD-procured projects, whereas the specifications were fixed within the traditionally procured projects. The basis for trust seemed to be stronger within the CDprocured projects than in the traditionally procured projects, given that the parties had already gained insights into what was driving each other. However, when looking at the manner in which the Agency and contractors handled conflicts in the execution stage of the project, one could say that there was not too much trust left by the end of the projects. While the foundations for a trust-based relationship may have been laid during the dialogue, these foundations proved to be insufficiently strong to build upon. In the traditionally procured projects, the parties ended up trusting each other more than in the CD-procured projects. 
Complexity was not an issue in either type of the projects. Concluding, the allocation of risks and tasks was assessed in both the traditionally procured projects and in the CD procured projects as poor.

\section{Development of the projects}

\section{Negotiations and commitments}

The problems and issues concerning the formal legal contract were very similar in both traditionally and CD-procured projects. These included: errors in the condition assessments and in the database; inexperience with system-based monitoring in an Engineering and Construct contract; and deficiencies in pre-financing by contractors. Up to the point of closing contracts, there were no major differences between traditionally and CD-procured projects. However, due to greater lack of clarity in risk allocations in the CD-procured projects compared to the traditionally procured projects, major problems of understanding arose in the CD-procured projects.

The case-comparison shows just how influential the role of problems of understanding is. In traditionally procured projects, the contract is extensively renegotiated shortly after contract closure. Given that an objective of the EU with the CD procedure is for procuring authorities to discuss all aspects of a contract with each candidate during the negotiations, one would expect similar post-closure renegotiations to be unnecessary in CD-procured projects. However, reality turned out to be very different. As a contract manager of a KOSMOS project puts it:

Principal 1- Looking at the number of misunderstandings, discussions and disputes, I have the strong impression that the $C D$ procedure leads to more nonsense than the restricted procedure. [...] the objective of using CD within KOSMOS was to reach a tailor-made risk allocation (including tailor-made descriptions of the risks), but I don't think the CD procedure has led to a more balanced allocation of risks at all.

\section{Problems of understanding}

When problems of understanding arose due to differing ideas about risk allocation, the starting situation at contract closure was different in the CD-procured projects than in the traditionally procured projects. In the traditionally procured projects, both parties entered the construction stage rather open and uninformed: the principal and the contractor were only starting to get an idea of who the other party was, and what was important to them. Conversely, in the CD-procured projects, both parties had already formed an image of the other (sense was made) when the construction stage started. In the CD-procured projects, bargaining processes to renegotiate aspects of the project seemed only to emphasise existing differences in norms, values and working routines, and inabilities to empathise, causing problems of understanding to worsen. The contrary happened in the traditionally procured projects, where the bargaining led to understanding, empathy/affection and mutually satisfactory working routines, even though the norms and values of the parties involved did not correspond in all spheres (See Table 4.11 for an overview of the comparison between the development of traditionally procured KOSMOS projects and CD-procured KOSMOS projects). 
Table 4.11. Timeline for development of the KOSMOS projects

Traditionally procured KOSMOS projects

Candidates selected on the basis of

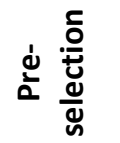

certification and experience/expertise in

maintenance, contract management,

interdisciplinarity and traffic

management.

An external agency assessed the state of the objects within the contract scope.

Determining, and committing to paper, action plans for the maintenance activities, based on the condition assessments.

Submitted bids, containing a price, an

action plan and a monitoring plan were

judged on the basis of MEAT criteria.
CD-procured KOSMOS projects

Candidates selected on the basis of certification and

experience/expertise in maintenance, contract

management, interdisciplinarity and traffic

management.

Problems of understanding since candidates felt that the time to interpret available information was too short, as was the time for the engineering firm to make the condition assessments.

Candidates define the assignment to an external agency, which will deliver a single assessment of the objects" state for all of the candidates. Different interpretations of responsibilities towards the engineering firm, and opportunistic behaviour by the candidates towards each other, arose.

Dialogue conversations about the state of objects and the allocation of $X$ and $Y$ risks (the contract philosophy and the reward system were not a part of the dialogue). Determining, and committing to paper, action plans for the maintenance activities, based on the condition assessments and dialogue conversations.

Submitted bids, containing a price, an action plan, a monitoring plan, the contract scope and a risk allocation, were judged on the basis of MEAT criteria.
Problems of understanding due to different interpretations of tasks and duties.

Increased problems of understanding due to differences between the actual state of objects and the data in the condition assessments.

Acceptance of working and monitoring plans took much time, whilst meanwhile the project had to be carried out The work started, although working plans were not formally accepted, to benefit the project.

Working plans were accepted.

Project restarts were organised, during which mutual understanding was achieved about the job and the roles of both parties.
Differences between the actual state of objects and the contractor's expectations from the data in the condition assessments.

Differences in expectations about the contract and monitoring philosophy.

Problems of understanding were explained by internal sensemaking activities, such as questioning the other party's professionalism.

Tough renegotiations to resolve problems due to differences between the actual state of objects and the contractor's expectations from the data in the condition assessments, sometimes even going to court.

To summarise, when the problems of understanding concerning risk allocation had been discussed during the dialogues, it seems likely that what happened in the traditionally procured projects would also have happened in the CD-procured projects. That is, the 
parties would have started to make sense of the situation without having preconceived ideas about the other party. However, since such conversations did not take place during the dialogues, the implementation stage of the CD procedure turned out to be less effective than expected. Both parties falsely believed that the dialogue conversations had led to proper understandings on both sides of the table. Consequently, they believed that renegotiations would only be necessary if the other party failed to act as agreed. Given that the parties were unaware of the differences in understanding between them, negative cycles began to develop: observed shortcomings by the Agency were followed by proposed amendments by the contractors, followed by the rejection of the amendments and putting payments on hold by the Agency. At this point there was only one way out of the negativity to make the projects succeed: a conciliation board. However, after this settlement step, the parties in the CD-procured projects did not begin to work well together, like in the traditionally procured projects. Instead, the working routines remained distant and stiff due to the fact that, despite the open trust-building CD conversations, the relationship was damaged by both parties' responses to disagreements about risk allocations.

\section{Differences in case development explained by the informants}

How could this inconsistency between the expected benefits of CD procurement and the reality in the CD-procured KOSMOS projects be explained? What caused the inconsistency between theoretical and empirical patterns? Why exactly did everything that one feared would happen when using the open or restricted procedure actually occur in the CDprocured projects? An important factor may be that the KOSMOS projects were the first Dutch construction projects to use the CD procedure. Neither the Dutch Highways and Waterways Agency nor the contractors had experience with this procurement method. As such, both the Engineering and Design contract form and the monitoring system were new to the potential contractors. Before this case study started, the view was that it would not matter that the parties were unfamiliar with all of this since the CD procedure was just one element being added to the situation in the first pair of cases. However, given that the parties used to traditionally procured projects experienced handling the new contract form and the new monitoring system as a huge amount of additional work, the added novelty of the $C D$ procedure could easily prove overwhelming. The informants themselves advanced several explanations for why the CD procedure in this project did not bring the expected benefits:

Principal 2- The candidates in the dialogues were too busy getting the jump on each other to make a real dialogue happen.

Principal 3- The dialogue was nothing more than a nice get-together. [...] There were several reasons for that:

- Due to the time pressures, there was far too little time to prepare for the dialogue conversations: if you want a well-conducted dialogue conversation, you simply have to prepare well.

- I think both parties were unfamiliar with the subject matter. From the Agency's side, what was not clear was: "how far can we go? What is allowed by the European Commission?". And, from the contractors" viewpoint, "How far should we go? How responsive should we be?". 
- I also think that the mutual trust should have been further developed. There were still issues along the lines of "Will the principal treat my information confidentially?" and "Could we trust our contractor?".

Principal 4- I think that the type of work was simply not suitable for the CD approach. In my opinion, one should apply the dialogue approach when one has questions for the candidates: problems that you want to discuss. Yet, the work issues also need a certain complexity, so that knowledge from the market is needed to solve them. And that was not the situation with KOSMOS. We had enough knowledge to know how the maintenance of those objects should be performed. You should not ask market organisations to look at the problem for you if you already know all you need.

The final remark above explicitly claims that the situation was the opposite of the reason used to justify using the CD in the first place. It had been claimed KOSMOS was so complex that is was impossible to objectively define the technical means capable of satisfying the Agency's needs and objectives. Employees of the Agency, however, claim that in advance they knew well enough how the maintenance of the objects should be carried out. One can therefore doubt whether the projects were so complex that a dialogue could really make a difference.

Principal 4- With the reference frame I now have, knowing how the dialogue has developed in other projects, I think that the dialogue in KOSMOS was nothing more than a slight upgrade of the information notes we know from the open and restricted procedures. That is, it was not really a dialogue. It was more like pricing a list of $Y$ elements, about which, now and then, a question was asked. So I did not think of it as a real dialogue. [...] The CD procedure was not that suitable for this project but, with hindsight, I think we could have gained more from the dialogue if we had offered more. Although a dialogue can offer freedom, one has to dare to grasp this liberty. [...] We put all the $Y$ elements in a row, and we could have discussed the contractor taking over the whole package of those elements. Instead, reality saw us looking at the contents of those $Y$ elements, without discussing any kind of a strategy. We were focusing on contents instead of on strategy. What I have noticed in other dialogues I have been involved in is that they mainly focus on strategy and not so much on contents. And yes, of course, management and maintenance are not that strategic, but still there are links to consider between problems, methods of project management, and how to apply these in the project. But, for this kind of discussion, the KOSMOS dialogue process offered no room.

Summarising, participants to the KOSMOS dialogues give specific reasons for the inconsistency between the expected outcome of the CD dialogue and the KOSMOS practice. Firstly, because the project might not have been as complex as was argued in advance. Secondly, because the dialogue in this instance was not designed to be as comprehensive as perhaps was necessary. Thirdly, because the potential contractors used it more as a means to eliminate each other than to clarify the essence of the problems. A final specific reason was the limited time that was available for both preparation and risk assessment work by both the contractors and the engineering firm employed to assess individual work objects. 
The informants think that the $C D$ procedure might have been much more effective when applied as it was originally envisaged. The topics in the renegotiations, which were held at the beginning of the projects' construction stages, would then have been covered during the dialogue. However, given that the dialogues were not open for discussion on all aspects of the projects, and that candidates were more committed to eliminating each other than to cooperation, it is unlikely that the dialogue would ever have been as effective as one had hoped. Further, in both the traditionally and the CD- procured projects misunderstandings arose because expectations and interpretations were not expressed.

\subsection{Concluding remarks}

In this chapter, answers have been sought for the question how negotiations and commitments differ between CD-procured projects and comparable, but traditionally procured, projects. Propositions were drawn to verify the conclusions of Chapter 3 concerning the influence of the CD procedure on reaching the EC's objectives. Furthermore, developments in negotiations and commitments during procurement and construction in both traditionally and CD-procured projects were described to explain the influence of the $\mathrm{CD}$ procedure on developments in the inter-organizational project. The results are described below.

\section{Finding further evidence for the propositions concerning the influence of the CD procedure on the EC's objectives}

In Chapter 3, it was concluded that the CD procedure in its early use did not meet the intended objectives of the European Commission. The CD procedure leads to less dialogue than intended, to more competition, to less trust and hardly any improvement on complexity or task/risk allocation. Only the actual level of innovation and the price-quality ratio meet the expectations. Twelve mechanisms were derived that were experienced to determine to what extent the intended objectives are reached. The identified mechanisms are conversation; focus on content; risk aversion; opportunistic behaviour; lack of openness; protection of contractors' interests; flexibility in demand specifications; a minimum of three candidates to the dialogue; design fee; level playing field; transaction costs; and a lack of clarity over when to use the procedure.

The results of the KOSMOS case studies reveal that CD procurement does indeed lead to the direct objectives of dialogue (although less than intended in these instances); competition (stronger than intended); innovation (although less than intended) and trust (although less effective than intended). With regard to the indirect objectives, participants from neither type of projects faced complexity; and the allocation of tasks and risks was poor. These findings are consistent with the conclusions drawn from the survey in Chapter 3 . These outcomes were due to time pressures (transaction costs); the probable inappropriate use of the procedure (due to lack of clarity as to when the procedure could be used); the risk aversion of both parties; opportunistic behaviour by the contractors; and a lack of openness.

When compared to the CD-procured KOSMOS projects, the traditionally procured projects faced comparable time pressures, there were no issues over the use of the procedure, risk aversion was comparable, the contractors demonstrated less opportunistic behaviour and there seemed to be greater openness. 
In relative terms, the CD-procured projects had;

1. stronger competition;

2. more dialogue;

3. higher levels of trust, at least at the time of signing the contracts;

4. more innovation;

5. comparable experienced complexity; and

6. comparable allocations of tasks and risks

Thus, the KOSMOS cases confirm the influence of the CD procedure on negotiations and commitments as concluded in Chapter 3 and as reflected in the six propositions in Section 4.1. There is less dialogue than intended, more competition and less trust. Only innovation is stimulated. Complexity is hardly reduced, and the allocation of tasks and risks far from efficient, yet.

\section{Explaining developments: the influence of procurement procedure on negotiations and commitments}

At the end of Chapter 3 it was concluded that formal and informal mechanisms in the negotiations stage of projects are affecting negotiations and commitments, both during procurement and construction. By comparing the developments in negotiations and commitments during procurement and construction both in traditionally and in CD procured projects, the influence of the CD procedure on these developments is sought for. Differences between the two types of cases indicate the contextual influence of the CD procedure in the development of negotiation and commitment during procurement as well as construction of the project.

Within KOSMOS, the actual formal legal contracts did not differ that much between the CDprocured and the traditionally procured projects. However, the informal psychological contracts and the processes for solving problems of understanding in the construction stage of the project did differ when comparing CD-procured projects with traditionally procured ones. It has been shown that problems of understanding were key in the development of both types of contracts and that this was catalysed by sensemaking processes during procurement. This explains why the renegotiations over risk allocation differed between the CD-procured KOSMOS projects and the traditionally procured ones: the CD procedure is mainly affecting processes of sensemaking.

In the CD procedure, parties get to know each other already during the procurement stage. In traditionally procured projects, the get-to-know-process only starts after awarding the contract. Because of this, sensemaking processes at contract closure in CD procured projects differ from sensemaking processes in traditionally procured projects. The intensive interactions between principals and contractors during procurement make that formal legal contract and informal psychological contract develop at the same time. One would expect, if the informal psychological contract contains mutual understandings by both contracting parties, that there would be fewer problems of understanding during the construction phase of a project. However, in the KOSMOS projects, problems of understanding grew more in the CD-procured projects than in the traditionally procured ones. 
This counter-intuitive outcome is explained by stressing that the dialogue conversation failed to uncover existing differences in informal psychological contracts between the parties, causing unilateral instead of mutual understandings to persist. Although formal legal contract and informal psychological contract developed simultaneously, these did not develop along parallel lines, rather, the two grew further apart.

\section{The contextual influence of the CD procedure}

The research results of this chapter indicate that the $C D$ procedure influences negotiations and commitments both during procurement and during construction by starting processes of sensemaking during the procurement of a project. When these sensemaking processes develop in positive cycles, this would probably indeed diminish post contractual renegotiations, in line with proposition B as formulated in Chapter 2. The formal legal contract would then reflect the mutual informal psychological contracts of both parties, so that problems of understanding during construction could be minimised. Within the $C D$ procured KOSMOS cases, however, negative cycles induced the formal legal contract and the informal psychological contract to grow apart, causing huge problems of understanding during construction, leading to even more renegotiations than in the traditionally procured KOSMOS cases.

Furthermore, the outcomes indicate negotiations and commitments are indeed interrelated through problems of understanding, and, as such, conform with the ideas in the FINCIP model from Chapter 2. The results of this multiple-case study do not conflict with the propositions, formulated at the end of Chapter 2, that inter-organisational projects are influenced by context variables (proposition A), or that negotiations and commitments substitute for one another (proposition C), whereas formal and informal components of negotiations and commitments are complementary (proposition D).

A further consideration of the propositions, related to the FINCIP model is made in Chapter 5 , where the development of negotiations and commitments in a CD-procured project will be further described by analysing critical events during the procurement stage and first year of execution. 



\section{Chapter 5. Development of negotiation and commitment in a CD procured project: A single-case study}

Part of this Chapter is published in:

Hoezen, M. E. L., Rutten, J. van, Voordijk, J. T. \& Dewulf, G. P. M. R. (2010) Towards better customized service-led contracts through the competitive dialogue procedure Construction management and economics, 28(11), 1177-1186.

Hoezen, M. E. L., Voordijk, J. T. \& Dewulf, G. P. M. R. (2012)

Contracting dynamics in the competitive dialogue procedure Built Environment Project and Asset Management.

Developments in the construction industry, resulting both in changing commitments and in changing negotiations between procuring authorities and contractors, examples the topicality of the academic debate for practice. In the light of these developments, the Competitive Dialogue procedure was introduced. This procedure was designed to influence negotiations and commitments both during procurement and during construction of interorganizational projects.

To find out in detail how negotiations and commitments develop under influence of CD procurement, an in-depth case study was performed. This will provide the empirical evidence, needed to support theoretical ideas about the interrelationship of negotiations and commitments. Current academic contributions are generally lacking empirical data, especially when it comes to the procurement stage of projects (Bijlsma-Frankema \& Costa, 2005). Furthermore, the study will provide insights in the current practice of application of the CD procedure.

This chapter will indicate how negotiations and commitments develop when procured by the $C D$ procedure. The chapter first addresses the design of the case study to answer main research question C: how do negotiations and commitments develop over time in a CDprocured construction project? (Section 5.1). Secondly, it describes developments in the inter-organisational project during critical events (Section 5.2). The chapter ends by drawing conclusions about the development of negotiations and commitments in this project (Section 5.3). 


\subsection{Design}

\section{Case study motivation}

The academic debate concerning the relationship between negotiation (the bargaining process between two parties seeking to discover a common ground and reach an agreement to settle a matter of mutual concern or resolve a conflict) and commitments (the state of being bound to a course of action or to another party) is on-going, and current. The relationship between the concepts is assumed to develop over time, and is reflected in problems of understanding, occurring as critical events. However, how negotiations and commitments evolve has yet to be researched (Laan, 2009).

When exploring the development of negotiations and commitments in inter-organisational construction projects, the impact of context variables should be taken into account. Combining the importance of context with the research question being a "how" question, identified by Yin (2009) as an explanatory question, means that a case study approach is preferable (Yin, 2009). Data concerning the development of negotiations and commitments was accessible to the researcher, but not controllable, which is why case study research is preferred above histories and experiments. In performing case study research, the aim is to uncover the perceptions of the people involved in those contracts and processes. Their perceptions are crucial in understanding how and why negotiations and commitments develop over time. Weick (1995), for example, stresses how interpretation and framing are key elements in sensemaking processes. Sensemaking is identified in the FINCIP model as important in the development of negotiations and commitments, and identified in Chapter 4 as the component of the model that is mostly influenced by the CD procedure. The usefulness of case studies for acquiring an in-depth understanding of the process characteristics of certain phenomena is also stressed by Swanson and Holton (2005). This is precisely the aim if this study: the objective is to identify how negotiations and commitments develop in a CD-procured construction project.

Given this aim to discover how and why negotiations and commitments develop over time in a CD-procured construction project, a case study approach seemed to be the most appropriate research strategy to answer the questions. A description of how problems of understanding are seemingly playing a key role in the development of negotiations and commitments has been already described. Therefore, when studying the development of negotiations and commitments in a CD-procured construction project, the interest is especially in the understandings of the people involved. Their subjective perceptions are crucial in discovering why problems of understanding arise and/or are solved, and how negotiations and commitments develop over time. Swanson and Holton (2005) argue that case studies are especially useful when researchers are interested in an in-depth understanding of the process characteristics of a certain phenomenon, as is the case when the development of negotiations and commitments is the object of study. Since a case study enables one to conduct in-depth interviews with all the relevant informants, "it allows investigators to retain holistic and meaningful characteristics of real-life events" (Yin, 2009, p.2). It is a desirable strategy for studying a "contemporary phenomenon within its real-life context, especially when the boundaries between phenomenon and context are not clearly evident" (ibid., p. 13). Therefore, conducting a case study for explaining how negotiations 
and commitments develop over time in CD-procured construction projects provides a rich, contextualized understanding of the phenomena (Miles \& Huberman, 1994; Swanson \& Holton, 2005; Yin, 2009).

\section{Case study selection: the Second Coen Tunnel project}

To study a CD-procured construction project from the beginning of the procurement stage through to the signing of the contract or even beyond is difficult for several reasons. Firstly, because procuring a project by the $C D$ procedure takes much time; sometimes more than a year. It asks much of a researcher to invest this amount of time solely in collecting data. Secondly, projects do not wait to start the procurement process for a researcher to be ready. It is more likely a coincidence when a project's planning matches the timetable of a researcher. Third, due to the novelty of the procedure, combined with the emphasis on confidentiality within the procedure's design, procuring agencies are not eager to allow researchers to observe the entire CD procurement process. Despite these difficulties in finding and gaining access to suitable projects, four potential projects were identified that were procured at or around the time that the data collection was planned. It was decided to investigate what seemed the most interesting case out of the four, judged on their size, complexity and accessibility.

It was agreed to start with retrospective interviews as soon as the contract was signed for a one-off CD-procured project: the Second Coen Tunnel project in the Netherlands. This was the first, and still the largest CD-procured, service-led infrastructure project in the Netherlands. It was also the first large project of any form procured using the CD procedure that had well thought out structures and descriptive documents, and in which the CD procedure was actually used to add new insights to the final legal contract. The project is very well-documented, and access was given to its vast dataset, containing all the 2,780 questions that were asked during the dialogue, their answers, and the changes resulting from these discussions in both the design and the contract. The fact that this complete dataset of the project was accessible enabled a detailed reconstruction of its procurement stage. In addition to the analysis of the data, interviews were conducted with employees from both the procuring authority and the contractors who took part in the dialogue.

\section{Case study design}

Given the richness of the available data, and the unique opportunity to reconstruct such an intensive procurement process using accessible and detailed first-hand information, it was decided to conduct a single revelatory case study (Yin, 2009). The case study was intended to provide data with which the FINCIP model (see Chapter 2) could be evaluated. This is a process model describing how negotiations and commitments develop in interorganisational projects. Following Bruner (1991), the research question of this chapter, how do negotiations and commitments develop over time in a CD-procured construction project?, is recognised as a "how" question that requires a process model, or event-driven explanation, of the temporal order and sequence in which a discrete set of events occur based on a story or historical narrative. It was therefore decided to adopt a process approach to the study of how negotiations and commitments had developed over time in the Coen Tunnel project. Process approaches do not focus on entities, but on events (Poole, Van de Ven, Dooley \& Holmes, 2000). Events during the procurement phase of the Coen Tunnel project therefore formed the unit of analysis in this single revelatory case study. 
To answer the research question how negotiations and commitments develop over time in a $C D$-procured construction project, longitudinal data are required. Given the fact that access to the project was not allowed prior to contract signature, a real-time field study of the development process was impossible. The study had to rely on archival data and retrospective interviews to obtain insights into the development process. If one wants to study the development of processes and products in an interplay between two parties, observing the processes is indeed one option. However, when observing, researchers interpret what they see. Further, whilst interviewing parties to discover why certain behaviours and responses are occurring might well help in better understanding those processes and products, it also amounts to interfering in what is going on: by asking questions, the interviewer might influence the development process. If, instead, retrospective interviews are conducted, then participants can explain their behaviour after the event, thus avoiding influencing the development process. However, recalling the details of a lengthy procurement process is difficult. This is the reason why critical events analyses were used in this study into the development of negotiations and commitments in a CDprocured construction project.

The data were numerous and unlimitedly available. The participants were needed to be interviewed as soon as the contract was signed because the longer it would be left, the harder it would be for them to recall the events in a complete procurement process. Furthermore, people change jobs from time to time. When access was given to the project, many of the participants in the dialogue were already working on new projects, some even for new employers. As an aid to reconstruct the dialogue, first the project guides and the evaluation reports were read. From these documents, the most important formal events (the first meeting, invitations to the dialogue, handing in of the first tender documents, etc.) could be identified. Further, some of the informal events could be retrieved (leaving of a key player, innovative suggestions by participants, problems with air quality, etc.). All these events were put in chronological order and placed at the head of the interview protocol that was used in the interviews (see Appendices 6 and 7). The protocols helped the informants to tell the narratives of the procurement process, and helped the interviewer in focusing on those aspects that were part of the theoretical framework. In the protocols, the same conceptualisation of the key concepts was used as in the KOSMOS study in Chapter 4, derived from the theoretical framework in Chapter 2.

The protocols start with introductory questions which are intended to paint a picture of the informant, including context variables and the period in which he/she was involved in the project. The main part of the protocol focuses on the procurement stage of the project. Informants were asked to tell the narrative of the dialogue in chronological order, starting at the moment they entered into the project. They were asked to go into events (including important documents as well as important moments) and describe each of those events, their impact, development and consequences on both the informant and their project partner at the other side of the dialogue table. Once they had described the dialogue in terms of its events, informants were asked for a few general opinions about the dialogue to reflect on their assessment of it. After questions about the dialogue that formed the procurement stage of the Coen Tunnel project, informants were asked about how the project developed after contract closure (in the construction stage). 
Given that the contract for the Second Coen Tunnel project was signed just prior to summer 2008, the document analysis started during the summer holidays. The first interviews were conducted following the holiday period, at the end of 2008 and in early 2009. Table 5.1 provides a summary of the variables addressed in the case study, for which the interviews and the document analysis provided information.

Table 5.1. The case study variables, dimensions and aspects, and their source in the single revelatory case study

$\begin{array}{lll}\text { Variables Dimensions } & \text { Aspects } & \text { Source }\end{array}$

\begin{tabular}{|c|c|c|c|c|}
\hline \multirow[t]{2}{*}{ Negotiations } & $\begin{array}{l}\text { Formal } \\
\text { bargaining }\end{array}$ & $\begin{array}{l}\text { Focusing Attention } \\
\text { Articulation, Deliberation } \\
\text { and Reflection. } \\
\text { Interaction } \\
\text { Reducing biases, } \\
\text { judgement errors, } \\
\text { incompleteness and } \\
\text { inconsistency }\end{array}$ & $\begin{array}{l}\text { Focal points in protocols and } \\
\text { agendas } \\
\text { Individual and mutual goals, } \\
\text { knowledge and assumptions } \\
\text { Exchange of ideas, } \\
\text { conversations, dialogue. } \\
\text { Revision / nuancing points of } \\
\text { views, uncovering and } \\
\text { elimination of inconsistencies }\end{array}$ & $\begin{array}{l}\text { Interviews, } \\
\text { complemented } \\
\text { with document } \\
\text { study }\end{array}$ \\
\hline & $\begin{array}{l}\text { Informal } \\
\text { sensemaking }\end{array}$ & $\begin{array}{l}\text { Belief-driven } \\
\text { Action-driven }\end{array}$ & $\begin{array}{l}\text { Arguments } \\
\text { Expectations } \\
\text { Justifications } \\
\text { Focus on few beliefs. }\end{array}$ & Interviews \\
\hline \multirow[t]{2}{*}{ Commitments } & $\begin{array}{l}\text { Informal } \\
\text { psychological } \\
\text { contract }\end{array}$ & Informal incentive control & $\begin{array}{l}\text { Understanding } \\
\text { Norms / values } \\
\text { Empathy / affection } \\
\text { Routines } \\
\text { Importance of the (future) } \\
\text { relationship } \\
\text { Importance of reputation }\end{array}$ & Interviews \\
\hline & $\begin{array}{l}\text { Formal legal } \\
\text { contract }\end{array}$ & $\begin{array}{l}\text { Formal incentive control } \\
\text { Opportunity control }\end{array}$ & $\begin{array}{l}\text { Reward system } \\
\text { Allocation of risks } \\
\text { Contract clauses } \\
\text { Output specifications } \\
\text { Monitoring system }\end{array}$ & $\begin{array}{l}\text { Document } \\
\text { study, } \\
\text { complemented } \\
\text { with interviews }\end{array}$ \\
\hline \multirow[t]{2}{*}{ Understanding } & $\begin{array}{l}\text { Problems of } \\
\text { understanding }\end{array}$ & $\begin{array}{l}\text { Discontinuities in } \\
\text { structures, contexts, } \\
\text { routines, expectations } \\
\text { and perceptual } \\
\text { frameworks }\end{array}$ & $\begin{array}{l}\text { Discussions } \\
\text { Irritations } \\
\text { Expressed inabilities to make } \\
\text { sense of the partner, the } \\
\text { relationship or the context }\end{array}$ & $\begin{array}{l}\text { Interviews, } \\
\text { complemented } \\
\text { with document } \\
\text { study }\end{array}$ \\
\hline & $\begin{array}{l}\text { Reached } \\
\text { understanding }\end{array}$ & $\begin{array}{l}\text { Sustained structures, } \\
\text { contexts, routines, } \\
\text { expectations and } \\
\text { perceptual frameworks }\end{array}$ & $\begin{array}{l}\text { Stable and quiet working } \\
\text { atmosphere }\end{array}$ & $\begin{array}{l}\text { Interviews, } \\
\text { complemented } \\
\text { with document } \\
\text { study }\end{array}$ \\
\hline Context & & & $\begin{array}{l}\text { Perceived risk of the deal } \\
\text { Trust in other parties } \\
\text { Role relationships } \\
\text { Outcome expectations } \\
\text { Environmental constraints }\end{array}$ & Interviews \\
\hline
\end{tabular}




\section{Case study data collection}

The empirical work for the project was conducted in 2008 and 2009, with some supplementary data collected in 2010. Thirteen in-depth face-to-face interviews with members of the tender teams from both the principal and the contractors provided most of the data. These were supplemented by sixteen shorter interviews with technicians on specialised topics such as the specifications, the contract and considerations with respect to the procurement strategy. The major interviews were held with seven participants from the contracting agency and six from the market organisations, four of whom were held with participants working for winning consortia, and two from unsuccessful bidders. All sixteen supplementary interviews were held with Agency employees (see Table 5.2).

Table 5.2. Number of interviews, differentiated by type of interview and informants' role

\begin{tabular}{|c|c|c|}
\hline & \multicolumn{2}{|c|}{ Type of interview } \\
\hline & $\begin{array}{c}\text { Major } \\
\text { (tender team members) }\end{array}$ & $\begin{array}{l}\text { Supplementary } \\
\text { (technicians) }\end{array}$ \\
\hline Principal & 7 & 16 \\
\hline Winning contractor & 4 & - \\
\hline Losing contractor & 2 & - \\
\hline
\end{tabular}

Each major interview took $1 \frac{1}{2}$ to 2 hours and was guided by the case study protocols in Appendices 6 and 7. The protocols were used flexibly: during the interview, the researcher let the informants tell their narrative of the Coen Tunnel project, interjecting questions supported by the protocol. At the end of each interview, the researcher checked whether all the questions had been addressed, to ensure that no aspects of the protocol had been overlooked. The interviews were tape-recorded and transcribed for systematic analysis. Supplementary documents included evaluation reports (Kooiman, 2008; Theunissen \& Kooiman, 2008), the procurement documents, the database with dialogue questions and answers, and contractual documents. In total, the empirical data collection generated 357 pages of interview text; two evaluation reports; four procurement protocols (a separate protocol was written for each of the stages of the procurement); six versions of the contract (versions $A, B, C, D, 1.0$ and 2.0) and 2780 dialogue questions, draft answers and final answers. All these data were analysed using the data analysis program QSR NVivo. This program was used to attach labels from the theoretical framework to the empirical data, and then to compare those text fragments having identical labels. This process highlights patterns from which conclusions can be drawn. Especially patterns in development of negotiations and commitments were sought for, so that the FINCIP model could be tested.

\section{Case study validity and reliability}

To ensure the quality of the case study, which was designed to answer the question how negotiations and commitments develop over time in a CD-procured project, the issues of validity and reliability were explicitly paid attention to when designing and conducting the study. Below, a description is given of how this study performs in terms of the four tests that are common to all social science methods to establish the quality of social research (construct validity, internal validity, external validity and reliability (see Kidder \& Judd, 1986; Swanborn, 1987; Swanson \& Holton, 2005; Yin, 2009). 
Construct validity, the first test, is about identifying the correct operational measures for the concepts being studied. This validity can be enhanced by several measures, one of which is triangulation. In this research, methodological, theoretical, investigator and data source triangulations were applied. Two research methods, interviewing and document study, were applied to provide insights into the development of the procurement process of the Coen Tunnel project. Theoretical triangulation was achieved by combining microeconomic and socio-psychological theories within the theoretical framework, and by using predefined construct definitions developed by other, well-known, researchers for the case study protocols. By discussing the case study protocols, as well as the data and the analysis of those data, with several researchers, investigator triangulation was achieved. Further, by holding interviews with several project participants about similar topics, data source triangulation was also achieved. As a final step, a draft of the case study report was discussed with participants in the study and with independent researchers in order to further increase the construct validity of the study (Yin, 2009; Swanson \& Holton, 2005).

The second test, internal validity, addresses the extent to which the study actually answers the questions it claims to answer using the data that were gathered. Yin (2009) argues that internal validity is not relevant for descriptive or exploratory studies, since these are not looking for cause and effect relationships. Given that this study has a process approach, describing how independent variables develop during procurement and construction of a CD-procured project, it was not the aim to establish unidirectional cause and effect relationships. As such, internal validity is not an issue in this research.

Thirdly, external validity concerns the ability to generalise a study's findings to other populations or settings (Swanborn, 1987; Swanson \& Holton, 2005; Yin, 2009). Although this study's purpose is to seek an in-depth understanding of how negotiations and commitments develop over time in a CD-procured construction project, the findings are not limited to this case. The model used to study developments in negotiations and commitments is based on accepted theories, and a valid description of the case is ensured through method and data source triangulation. This ensures that the model used is generally applicable. Further, the case study's results were discussed in two panel discussions. One panel consisted of project managers working for the Agency in CD-procured projects, and one of tender team members working for contractors. Both panels recognised the findings of this study in their own experiences with other CD-procured projects. From this, it can be concluded that the results of this case study are generally applicable to CD-procured projects in the construction industry.

Finally, reliability needs to be considered. Reliability means that the same results should be achieved were the operations of the study to be repeated. Following Yin (2009), case study protocols were used, and a case study database was developed in which case study notes, documents and interview transcriptions were all documented, thus improving the reliability of this study. 


\subsection{Results}

The Coen Tunnel, in the northern part of the Dutch Randstad, has long been one of the major bottlenecks in the Dutch infrastructure. Since the beginning of the 1980s, there have been plans to increase the capacity of the tunnel. These plans were not further developed until 2000, partly because of a lack of funds. In 2000, extra money was made available for improving the national infrastructure, enabling the Coen Tunnel's capacity to be expanded (Kooiman, 2008). In this section, a general description of the Coen Tunnel project is given, followed by a detailed description of the formal and informal negotiations and commitments, based on a process approach to analysing the project's procurement.

\section{The project's characteristics}

The Second Coen Tunnel project is both large (estimated value $€ 300$ million NPV) and complex, and involves the maintenance of an existing, forty-year old tunnel plus the construction of a second parallel tunnel alongside the current one. The contract for the Coen Tunnel project was signed in 2008 , and the maintenance of the existing tunnel was also then transferred to the contractor. The construction stage for the new tunnel started in 2009.

This service-led infrastructure project, the first to be procured using the CD procedure in the Netherlands, consists of widening approximately 14 kilometres of highways at the north and south entrances to the existing Coen Tunnel, and expanding the tunnel's capacity from two lanes to three in each direction plus two further reversible lanes, enabling five lanes of traffic in one direction during peak hours (see Figure 5.1). Further, the existing transport infrastructure had to be maintained during the widening activities, and traffic hindrances minimised.

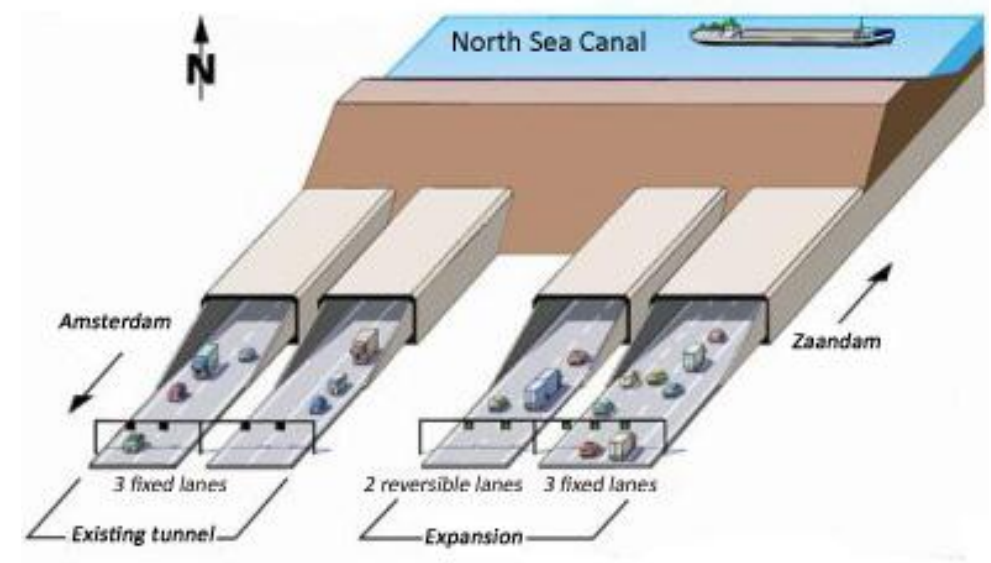

Figure 5.1. Increasing the Coen Tunnel Capacity

An initial decision to procure the project through a DBFM contract was made by the Dutch Minister of Transport in March 2005. Shortly after this, it was decided to apply the CD procedure because of the technical and financial complexities of the project. In June 2005, the market was formally informed about the project and the selected procurement method. The duration of the contract was set at 30 years, from 2008 to 2037, and included the construction and maintenance of the new infrastructure (construction due to be completed in 2013) and the renovation and maintenance of the existing infrastructure (roads and 
original tunnel). The service component in this project consists of making available eight traffic lanes passing under the Noordzee Canal that links Amsterdam to the North Sea.

Five consortia met the qualifications criteria and were therefore invited to participate in the dialogue. The procurement was divided into five stages: Pre-Qualification; Scheme of Action; Consultation; Dialogue; and Tender Submission. The three middle stages together form what amounts to the actual dialogue stage according to the European Directive (see Figure 5.2).

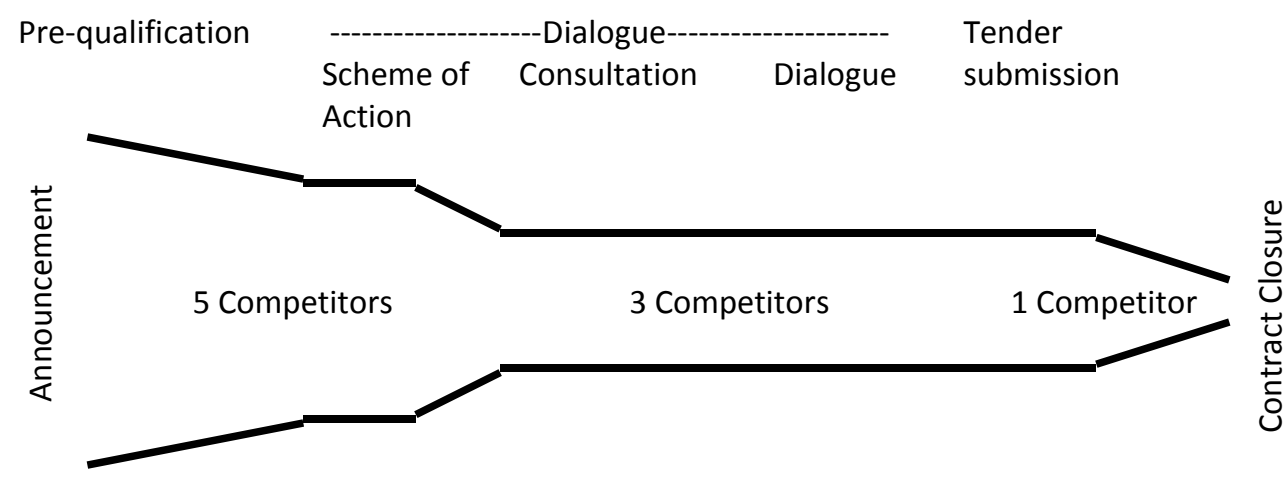

Figure 5.2. Timeline of the procurement of the Coen Tunnel project

Important elements covered in the dialogue were the Scheme of Action, Critical Aspects, Risks and Optional Requirements. At the end of the Scheme of Action stage, the five candidates each had to submit an initial dialogue product (an assignment): namely, their Action Schemes for carrying out the project. Based on evaluations of the action schemes, by both project employees and external judging committees, the five candidates were reduced to a shortlist of three who were invited to move forward to the Consultation stage.

Certain Critical Aspects, as identified by the procuring authority based on risk management (items such as the stability of the existing tunnel, air quality and lane availability during the construction stage), formed the basis for some of the dialogue products which had to be submitted by the candidates at the end of the dialogue stage. These dialogue products had to meet a minimum quality level before the candidates would be invited to bid. Four further Critical Aspects from the Action Scheme, plus the acceptance of Risks and Optional Requirements, were part of the conversation during the Consultation stage. The Optional Requirements set by the procuring authority were additional to the project's scope, and candidates could choose whether or not to meet them. In a similar way, candidates could decide whether to accept Risks, based on a pricing scheme, or leave these in the hands of the contracting agency. Thus, the Dialogue stage resulted in a list of those Optional Requirements that were to be met plus two lists of Risks: risks on the account of the candidate and risks borne by the procuring authority. A notional financial penalty was added to the bid prices at the end of the tender submission stage for each Optional Requirement not met and each Risk not accepted.

After the dialogue, the contract would be awarded to the consortium having best met the principal's requirements both qualitatively and financially (economically most advantageous bid: "EMVI"). The basic contract would be the same for whichever consortium was accepted, but the lists of Optional Requirements and Risks would differ. The documentation would 
contain a small overall contract with an underlying uniform document structure and hierarchy; a uniform set of general terms; and the scope which would be specified in functional terms. In addition, dialogue products, such as plans for auditing and quality control by the contractors, would be made part of the contract. In all cases, participants would be issued strict maintenance time-slots according to actual traffic needs and the influence of non-utility of the infrastructure. Further, traffic hindrance would be discouraged by financial incentives in the contract.

\section{Development of the project}

During the procurement and early construction stages of the project, several events took place. The main ones will be described here in chronological order. Table 5.3 provides the timeline of the various stages, and Table 5.5 the timeline for the critical events.

Table 5.3. Timeline of stages by year and month for the Coen Tunnel project

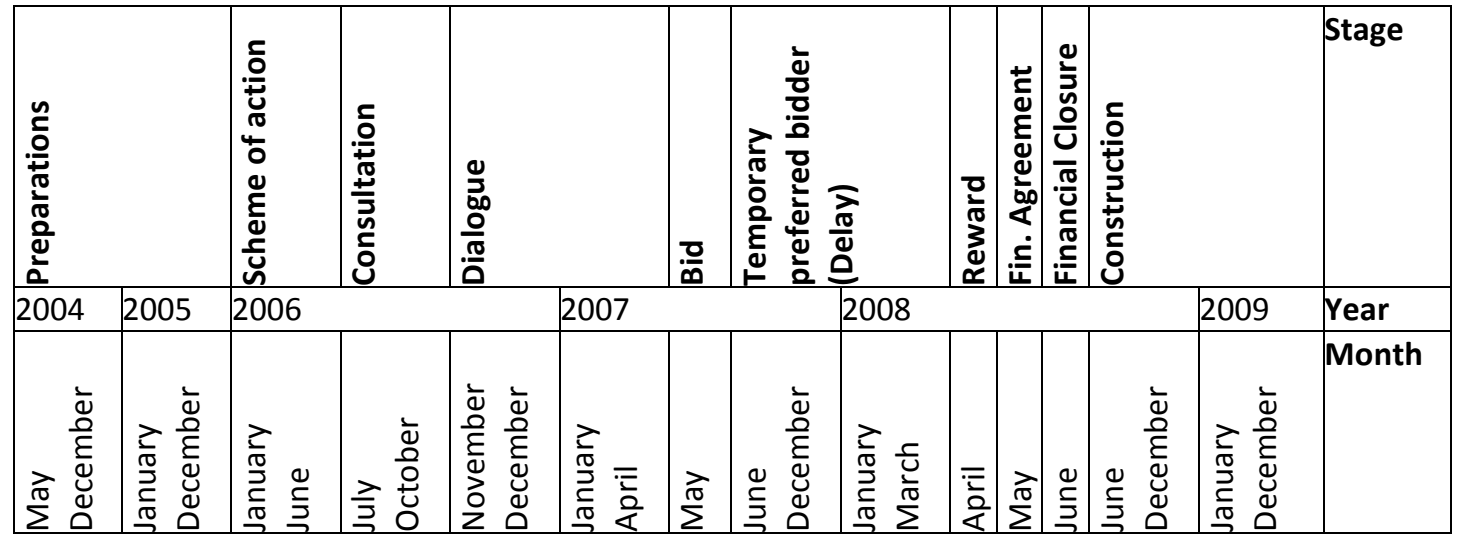

\section{Preparations stage}

The first contact between the procuring authority and market parties took place in June 2005, when a meeting was held at Schiphol Airport where the project's characteristics were presented. Requests to participate had to be submitted by contractors in September, and on October 17th the participants selected to take part in the dialogue were informed. In January 2006, the Scheme of Action stage started, and the Protocol for this stage, plus a very early version $A$ of the Contract, sent to the five participants.

\section{Scheme of Action stage}

In the period between January 2006 and April 2007 the consortia and the procuring authority gained experience with submitting and answering General and Confidential Questions. During this period, several events occurred. One of the Agency's legal advisers left and took up employment in one of the participating contractor's legal offices in March 2006. Subsequently, the procuring authority decided that the legal office concerned could no longer advice the participant in question. In April 2006, the Schemes of Action were submitted based on several Critical Aspects (CAs). CA1 was the Management plan; CA2 concerned Air Quality measures, CA3 measures to assure the integrity and stability of the 
existing Coen Tunnel; CA4 was about merging the technical systems of the existing and new tunnels; and CA5 concerned the availability of lanes and traffic flow.

\section{Consultation stage}

After an assessment of the Schemes of Action in April and May 2006, the best three participants were invited to participate in the Consultation Stage. The remaining two participants were put on hold, and were compensated for their design costs. In May 2006, version $B$ of the contract became available. This would be part of the conversations in the Consultation stage, which would start in July. The participants' Schemes of Actions were further discussed in this stage, and the final scope of the Risks and Optional Requirements fixed. In June and July 2006, it transpired that the "penalties" for not bearing the Risks associated with the existing Coen Tunnel were so large that participants suggested alternative solutions so that the Risk of damage to the existing tunnel would be small. These solutions were like replacing the existing tunnel with a brand new one or like building a new tunnel which was larger than originally designed, so that any damage to the existing tunnel would not be too bad. After extensive considerations, the procuring agency decided not to accept these alternative solutions at the end of the Consultation stage. This was just before the text of contract version C, the final list of Risks, the final list of Optional Requirements and the rating of the Optional Requirements by the Agency were made available.

\section{Dialogue stage}

In November 2006 the Dialogue stage started. In this stage, the i's were dotted and the t's were crossed, and at the end of November the first Dialogue products were submitted (the numbers refer to the list drawn up by the procuring authority and correspond with the position the product would get when attached as an appendix to the final contract):

- $\quad$ 1. Management plan

- 2. Inventory of Risks

- 3. Process plans, resulting from the Management plan

- 5. Sub-plan for a Performance Measurement System (PMS)

- 17. Procedure for recording critical delays

In December of that year, the participants' prices for each Risk were announced at a notary in The Hague, along with the Agency's prices. As such, the risk allocation for each participant became fixed: when the participant put a higher price on bearing a Risk than the Agency did, the Agency would bear it. When the participant could bear it for less than the Agency could, the participant would bear the Risk. Each participant thus got its individual risk allocation, with an individual price ticket attached to it.

In February 2007, the second series of Dialogue products had to be submitted:

- 4. Contractor Specifications

- 6. Sub-plan for a Document Management System (DMS)

- 8. Maintenance Transition System

- 11. Project plan

- 15. Consultative Structure 
These were followed by the final products in March:

- 7. Quality plan for between contract closure and ISO certification

- 9. Safety \& Health Transition System

- $\quad 10$ Five sub-plans for Optional Requirements A to E

- 12. Indexation formula

- 13. Formula for the original Financial Model

- 14. Primary Subcontractors

- 18. Insurances

- 19. Cables and Ducts

In March 2007, contract version D became available. This version of the contract differed for each participant, since it consisted not only of the main text but also of all the Dialogue products, which were unique for each participant. Then, something went wrong: a small part of the contract offered to one participant was accidently made available to another participant. Despite the fact that the mistake was quickly discovered and immediately resolved, extra measures had to be put in place to avoid the procurement process becoming invalid. One had to be sure that the participant to whom the contract had accidently been made available had not been able to acquire data which could distort the competition.

\section{Contents of the dialogue conversations}

The dialogue conversations were broad and general to start and continued by becoming more focused as they detailed the contractual documents. The Scheme of Action stage was mainly used by the candidates to find out more about the procurement process itself (the rules of the game) and about the Agency's main issues. This is reflected in the questions that were asked during this stage: almost 90 per cent of the questions asked during this first stage were about the tender procedure itself and about technical issues such as the specifications (see Table 5.4). The two Critical Aspects most discussed were the condition of the existing tunnel and roads, and the air quality. During the Consultation stage, the focus became more technical. Alongside the Schemes of Action and their ratings, the project scope and the optional requirements were discussed. The most important issues were the condition of the existing tunnel and roads, the suggestions for and rejection of alternative solutions to renovating the existing tunnel and building a new one alongside; and the management plan. In the Dialogue stage, the tender procedure became more important again, and the financial part of the formal contract was more extensively discussed.

Table 5.4. Type and number of questions asked during the various dialogue stages

\begin{tabular}{llllll} 
Subject & $\begin{array}{l}\text { Scheme of Action } \\
\text { stage }\end{array}$ & $\begin{array}{l}\text { Consultation } \\
\text { stage }\end{array}$ & $\begin{array}{l}\text { Dialogue } \\
\text { Stage }\end{array}$ & $\begin{array}{l}\text { Bid } \\
\text { Stage }\end{array}$ & $\begin{array}{l}\text { Complete } \\
\text { dialogue }\end{array}$ \\
\hline Tender procedure & $211(38.5 \%)$ & $160(12.9)$ & $251(25.8)$ & $10(52.6)$ & $632(22.7)$ \\
Technical & $240(43.9)$ & $758(61.1)$ & $466(47.9)$ & $0(0)$ & $1464(52.7)$ \\
Financial & $30(5.5)$ & $49(3.9)$ & $90(9.2)$ & $4(21.1)$ & $173(6.2)$ \\
Legal & $31(5.7)$ & $245(19.8)$ & $123(12.6)$ & $5(26.3)$ & $404(14.5)$ \\
Blank & $35(6.4)$ & $28(2.3)$ & $44(4.5)$ & $0(0)$ & $107(3.9)$ \\
Total & $547(100)$ & $1240(100)$ & $974(100)$ & $19(100)$ & $2780(100)$
\end{tabular}


Bid stage, delay and rewarding of the contract

In May 2007, the final bids were made and assessed using the EMVI criteria. The two losing bidders were notified in June, and a design fee paid to them. Contract version 1.0 was then drawn up and discussed with the remaining participant on 20 July. When, five days later, on 25 July 2007, the Council of the State reversed the Alignment Decision for another project close to the Coen Tunnel due to poor research on air quality and the lack of long-term alternatives if the project would not be executed, the Agency decided not to let the Minister sign the Coen Tunnel contract until they could be sure that the Council of State would not make a similar decision over the Coen Tunnel. The procurement of the Coen Tunnel project was then re-evaluated with all the parties involved. In the meantime, further research was performed on air quality, which led to revisions to the air quality parts of the Alignment Decision. Meanwhile, the contract remained unsigned. Version 2.0 of the contract became available at the end of January 2008 but when, in March, the Alignment Decision for the Coen Tunnel was confirmed, the contract could not be signed because of a dispute between the Agency and the remaining bidder over the costs caused by the delay. In early April, the bidder started proceedings against the Agency to claim its costs for the delay. The proceedings were scheduled for 18 April but the two parties reached an agreement about the delay on April 8.

It was only then that the contract could be awarded to the winning consortium. Contract closure took place on April 22 2008, with financial closure planned for May 22. However, the consortium did not initially meet one of the demands of the banks, delaying the signing of the Financial Agreements, such that financial closure was postponed until June 10. The construction stage of the Coen Tunnel project had been started already by then: at June $1^{\text {st }}$ the contractor started the work.

\section{Construction stage}

During the construction stage of the project, several events took place that are relevant to this study. There were a few project start-up meetings, informal activities for which both the contractor's and the Agency's project team members were invited, and of course also contract meetings. The most critical events were the negative results of the Agency's audits of the contractor's monitoring system. The response of both parties to the audit results were not beneficial for their cooperation. This seemed to improve when the contractor's project manager left in February 2009 (see Table 5.5 for a time-line of critical events). Following this, relations became somewhat more stable and less hostile than before. 
Table 5.5. Timeline of critical events in the Coen Tunnel project

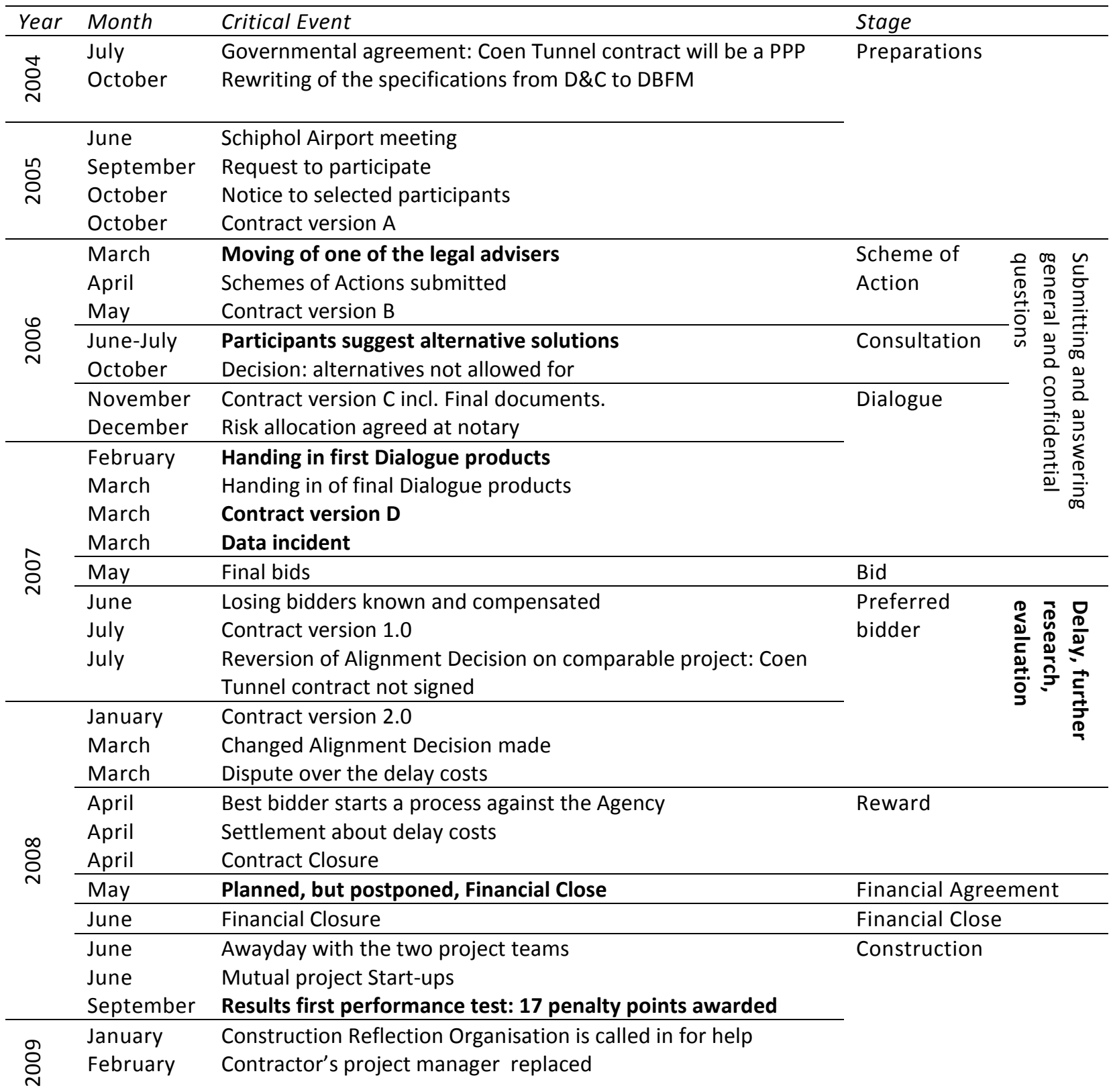

\section{Critical events}

Eight of the events described above were viewed by the respondents as being critical to the development of the Coen Tunnel project:

1. Changed employment of one of the legal advisers

2. Stability of the existing tunnel and the handling of alternative solutions

3. Problems with the management plan (dialogue product)

4. Differences between expected and actual state of the existing tunnel (Contract version D)

5. Data disclosure incident

6. Delays due to needed further research, and costs of the delay

7. Problems with financial closure

8. Disagreement over awarding penalty points 
These critical events are described in more detail below where they are put in chronological order and schematised in accordance with the FINCIP model.

\section{One of the Agency's legal advisers switches employment to one of the candidates' legal offices}

The CD procedure contains a rule that the Agency should not discriminate among the various candidates involved. This means, for instance, that it should inform all candidates equally. The Agency, well aware of the implications of this rule, therefore provided the same documents to all candidates in the same form, and sent the answers to general questions to all candidates. Thus, the Agency became alarmed when, during the Scheme of Action stage, one of its main legal advisers announced that he would start working for an office that had been hired by one of the candidates in the tender. It took initial action by hiring a new legal adviser and immediately sending the former one home.

Problems of understanding arose when the candidates received a letter from the Agency in which they were informed that this particular adviser was no longer working for the Agency. Candidates knew that the adviser would soon start to work for an office hired by one of the candidates, and they wanted to know how this move would be prevented from giving an advantage to the contractor concerned. One of the other candidates asked a formal question during the dialogue conversations: "How will the Agency make sure that the knowledge about the procedure, scoring and other confidential information which are known to this adviser will not be used for the benefit of one specific consortium? Is there an agreement with this adviser and, if so, could the Agency inform us about the contents of this agreement?"

Only then did the Agency realise that taking on another adviser did not solve the problem: the previous adviser still had knowledge and information which might be of use to the candidate that his new office was working for. In an attempt to solve the problem, the Agency started a bargaining process with the candidate involved. The candidate, which was well aware of the implications of this issue, was asked to take appropriate measures. Their response amounted to erecting Chinese walls, built internally around this particular adviser. The adviser would not be working on the Coen Tunnel project; the digital environment of the candidate would not be accessible by the adviser; etc. Following Agency questions, the candidate concerned felt that a satisfactory solution had been found.

However, although the Agency was convinced that the candidate would take appropriate measures, and was not after information from this adviser, it sensed that the risk was still too great. If one of the candidates wanted to disrupt the contracting process, or if the candidate linked to this adviser eventually won the contract, the other candidates could decide to go to court. Given that the Agency did not want to risk a failed tendering process, it forced the candidate concerned to hire a new legal office. This was done by effectively giving the candidate the choice between hiring a new legal office and withdrawing from the tendering process.

In its attempt to make sense of the situation, the candidate involved understood the positions of both the Agency and the other candidates. Even if they never had any contact with the particular adviser, there would always be that suggestion. Nevertheless, the 
candidate felt badly done to by the Agency, which at first had given them the idea that a less severe solution was possible. Nevertheless, the importance of the future relationship, a part of the informal contract, weighed sufficiently heavily for the candidate to change adviser.

Figure 5.3 provides a schematic reflection on Critical Event 1.

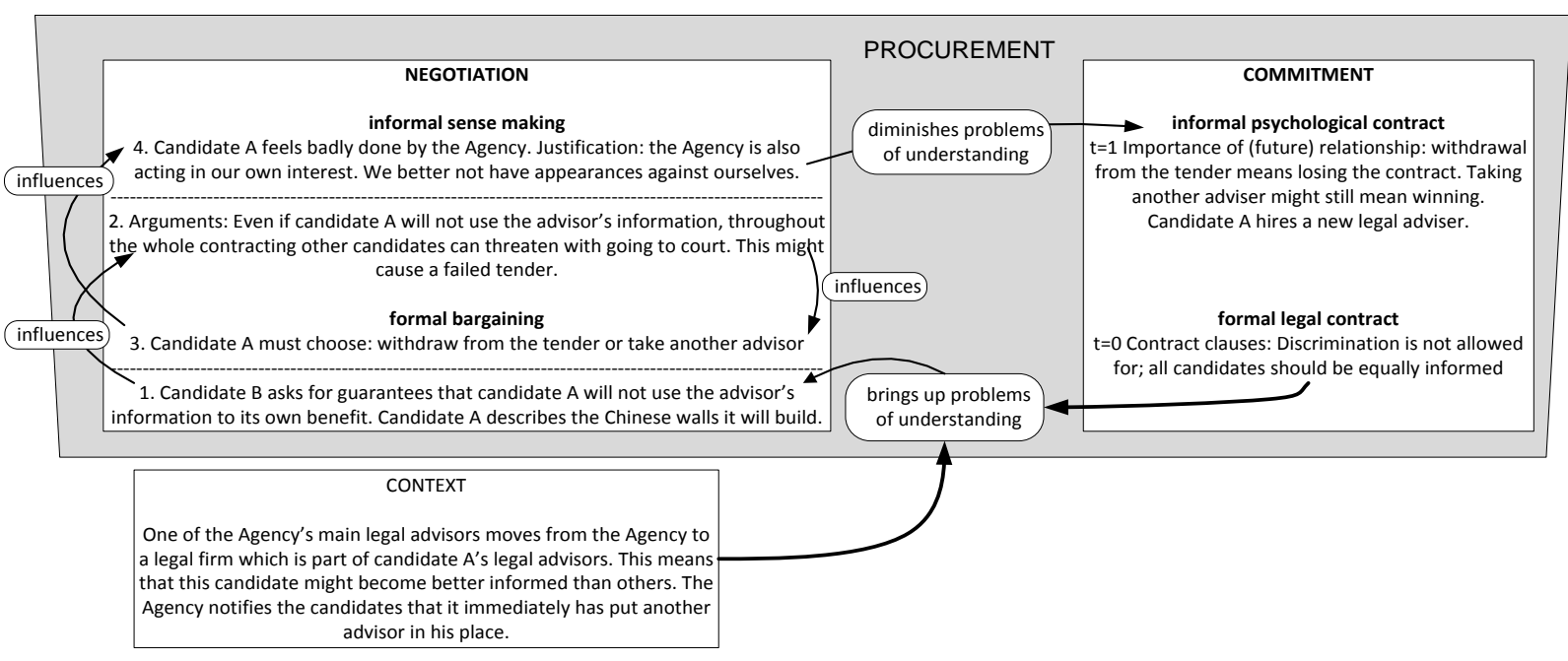

Figure 5.3. The FINCIP model for Critical Event 1 (start at $\mathrm{t}=0$, end at $\mathrm{t}=1$ )

2. The stability of the existing tunnel, and possible alternatives to the primary solution: specifications and risk allocation

One of the largest risks, as identified by the Agency, was the possibility that the existing tunnel would be damaged during the construction of the second tunnel, which was to be located alongside the existing one. The Agency assessed this risk as so high that it preferred not to be responsible for it. However, instead of writing this risk into the formal contract as a risk that was the contractor's responsibility, the Agency decided to make responsibility for the risk negotiable. This option was selected since the Agency did not want the procurement to fail because all the candidates assessed the risk as too high and declined to bid. Candidates were thus given the opportunity to decide whether or not they would take on the risk that the existing tunnel would be damaged. During the procurement stage of the project, candidates were asked to estimate what it would cost them to take on the risk (i.e. to control the risk and to take out insurance). These estimated costs were compared to the Agency's own estimations. The party that would take on the risk at the lowest costs would become responsible for it.

The manner in which the risks were allocated was assessed positively by the candidates. However, the fact that the Agency had also devised a list of surcharges by which the candidate's bid price would be virtually raised if a risk would become the Agency's responsibility was not understood by all the candidates. Nevertheless, none of the candidates asked further questions. This list of surcharges was made available to the candidates in advance, whilst the Agency's estimated costs for accepting the risks remained confidential until the candidates had submitted their estimates. Problems of understanding arose when the list of surcharges was made available. It concerned the candidates that their 
bid price would be raised by a substantial amount if they did not take on the risk of damage to the existing tunnel. If they would not accept responsibility for this risk, their bid price would effectively be increased by more than 20 per cent of the indicated maximum bid (more than hundred million euro), surely causing them to lose the contract. All of the candidates came to the conclusion that the Agency simply did not want to be responsible for this risk. Why then, they wondered, did the Agency put this risk on the negotiable list? Why had it not just written the risk into the contract as a risk to be borne by the contractor?

Candidates started to ask questions like "How did the Agency determine the surcharges?"; "Is there any relation between the surcharges and the Agency's estimate of the costs of bearing the risk?". However, the Agency was not willing to answer such questions. In an attempt to make sense of the situation, all three of the candidates (two of them at much the same time and one later) came to the conclusion that the Agency was willing to pay this substantial amount if the successful candidate would carry the risk of damaging the existing tunnel. Thinking further, each candidate devised means to bargain with the Agency.

"Our tender team thought the surcharge to the risk of damaging the existing tunnel must contain a certain amount as a penalty, and assumed that the penalty cost estimated by the Agency would be between 53 and 55 per cent of their estimate. On this basis, we figured what their estimate would be. For that amount we could solve the problem and control the risk."

For an extra amount above the price of one new Coen Tunnel, all the candidates offered the alternative of also renewing the existing tunnel. Some of them offered to make the second new tunnel a little broader than the existing one; some offered to replace the existing tunnel with a new one as soon as the new tunnel was finished; several ideas came up. And it seemed to be working. The Agency was willing to consider these ideas. However, the candidates were not allowed to change the initial drawings (in other words, the new tunnel would have to be in exactly the same place as the existing one). Furthermore, the candidates would not be compensated for the extra costs. The first condition could be met, but the second presented difficulties for the candidates. If other candidates would take on the risks associated with damaging the tunnel, their bid would be many tens of millions lower without the alternative solution. Further, even if the existing tunnel would be damaged, they could still opt for this solution after all.

When trying to make sense of the high surcharge and the Agency's interest in alternative solutions, while remaining unwilling to compensate the candidates for them, the candidates concluded that there was probably no reasonable cause for the surcharge of over a hundred million euro other than that the Agency did not want to bear the risk. The candidates understood that the Agency was acting strategically: that the surcharge of more than hundred millions of euro's was just a signal. In response to this interpretation, the candidates responded likewise, by providing their own strategic "estimations" of the expected costs. If they did not want to bear the risk, they estimated a ridiculous high amount, and if they were willing to take on the risk, they estimated their costs at zero. That is, informally, the candidates and the Agency agreed upon making strategic estimates to let 
each other know whether or not they were willing to bear the risk. In the formal agreements, however, their estimates of the costs involved in bearing certain risks would be realistic.

Figure 5.4 provides a schematic reflection of Critical Event 2.

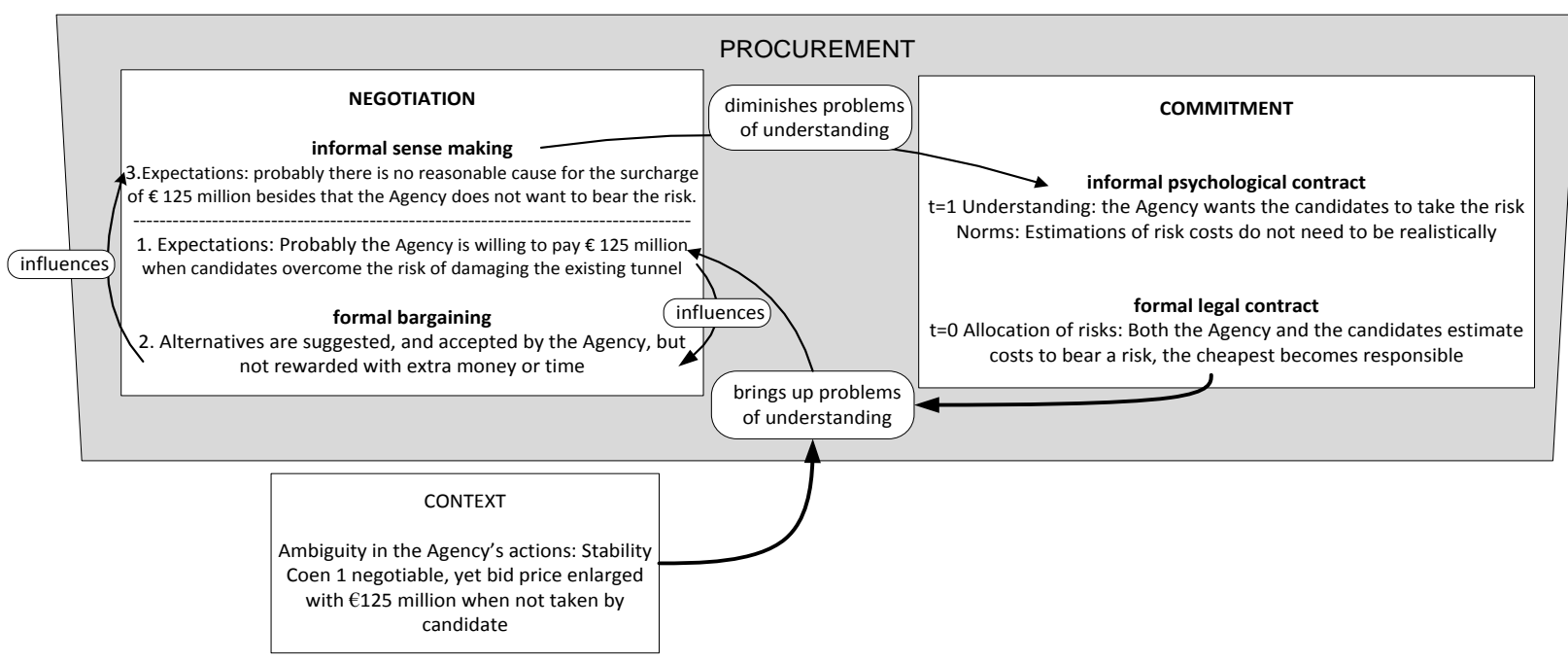

Figure 5.4. The FINCIP model for Critical Event 2 (start at $\mathrm{t}=0$, end at $\mathrm{t}=1$ )

3. Management plan for the construction stage of the project: the monitoring system

In the tender documents for the Second Coen tunnel project, the Agency demanded a "light" management plan which the candidates were asked to deliver as a dialogue product and which would become an appendix to the contract on contract closure. According to the Agency's employees, this dialogue product was meant to give the Agency a confident feeling about the future contractor's management skills, that it would be in control, because the Agency wanted to feel confident about that in order to be able to steer only the highlights. Depending on the risk profile, the Agency would then monitor the project's activities on the system level, the process level or the product level.

The candidates were all convinced that they understood the Agency; however, when they saw the actual specifications for the dialogue product, problems of understanding arose. The specifications asked for much more detail in the management plan than the candidates were expecting. In an attempt to make sense of the situation, candidates concluded that the Agency was asking for details so as to become confident that the candidates would be able to control the project. A bargaining process developed, during which the candidates handed in concept versions of their management plans, containing all sorts of information. This information ranged from descriptions of practical processes to extracts from management handbooks. The Agency, in turn, rejected most of the concept versions, which one of their interviewees described as "many pages of management systems, which of course were gathered from practice, and then stapled together. And that was the management plan. Well, that was not what we were looking for". 
The Agency's sensemaking process led them to explain the situation with the argument that the candidates probably did not understand what was being asked from them. If they wanted them to reach the management level the Agency was aiming for, it would need to help the candidates by intensively discussing their concept management plans. In the following rounds of bargaining, that is exactly what happened. Concept versions of the management plan were broadly discussed, and the Agency intensively guided the rewriting process. Thus, three management plans were created, in which the candidates played along with what they thought the Agency was expecting. The Agency was aware of this, and made sense of its act of helping out with the justification that the candidates lacked management skills. Conversely, the candidates explained this by focusing on the belief that the Agency was using the competition among the three of them to level up the dialogue products.

The formal contract's management plan, over which agreement was finally reached, ended up with many empty slogans; phrases which were written into the plan "because the Agency wanted us, the contractors, to put it like that". On the other hand, the negotiations stage did also influence the informal contract: with the conviction that the management skills of the candidates were inadequate, the Agency developed a routine to check the project management more intensively than it had originally intended. Moreover, the eventually selected contractor understood the management plan as having no practical intention whatsoever. Their norm became that the management plan was a means to convince the Agency that the project was controlled, rather than a means to actually control the project.

In Figure 5.5 a schematic reflection is given of Critical Event 3.

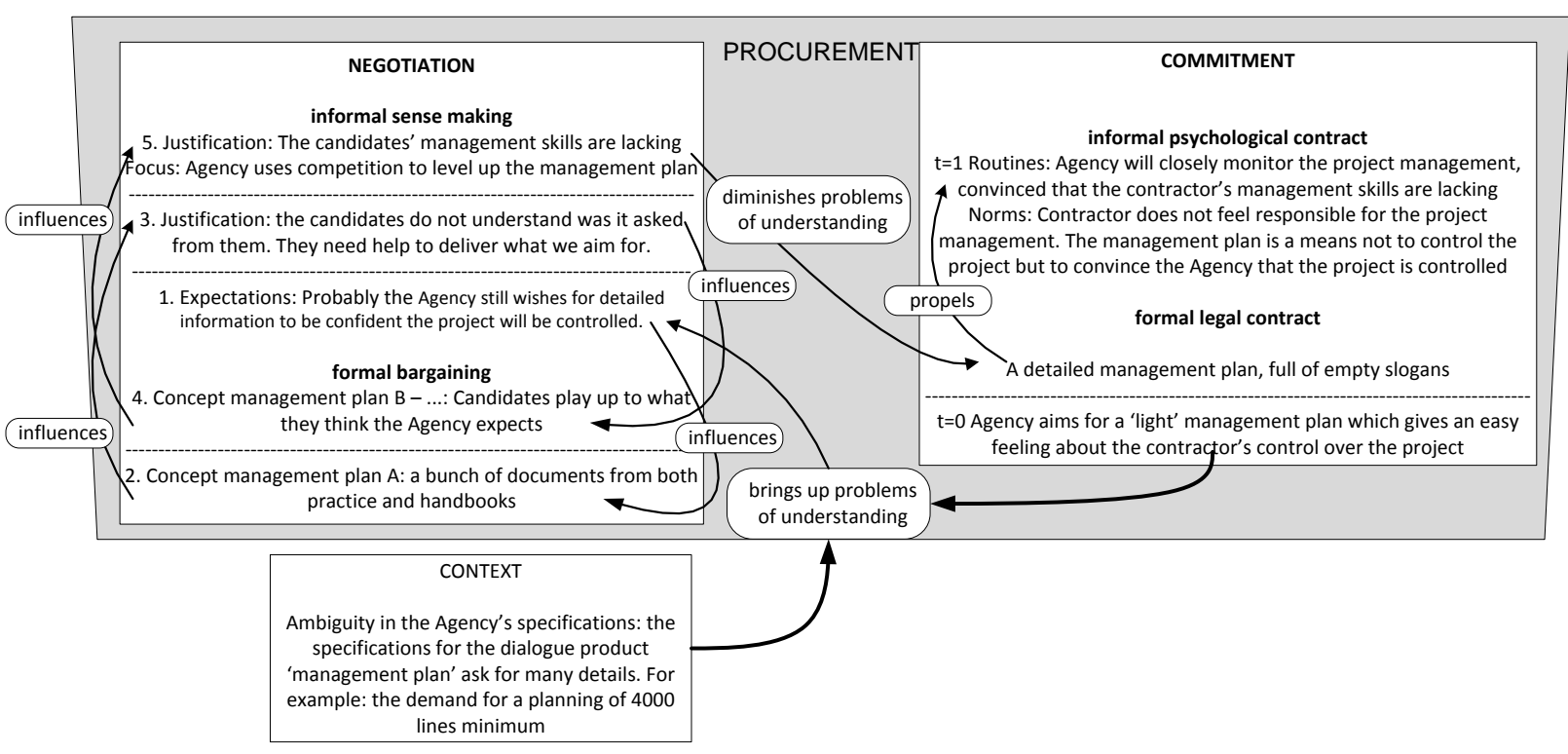

Figure 5.5. The FINCIP model for Critical Event 3 (start at $\mathrm{t}=0$, end at $\mathrm{t}=1$ ) 
4. Actual state of existing tunnel and roads: specifications, reward system and contractual clauses

In the contract for the Second Coen Tunnel project, it was stated that, on the day the contract would be signed, the contractor would become responsible for the state and maintenance of both the existing and the new tunnels and the access roads (the existing and the new system). Specifications were drawn up to ensure that both the new and the existing systems would meet the procurer's aesthetical, functional and safety demands. If the actual systems did not meet these demands, the contractor would be fined.

This rationale was completely clear to the candidates during the procurement of the project. There was a shared understanding of the ideas about being responsible for the state and maintenance of the systems; of being fined when not meeting the demands; and about the demands themselves. To be able to draw up a maintenance plan for the existing system, candidates asked several questions such as "What is the current state of the existing system?"; "What maintenance activities have taken place in the last five years?"; and "When did the Agency last inspect the existing system and could you make the results of these inspections available to the candidates?". The Agency started by stating that all the information required was available in the data supplied. The candidates disagreed, and started to ask more detailed questions from which it became clear that, for several elements, especially in the tunnel, the information lacked the necessary detail. The Agency was not able to answer their questions, and thus one is tempted to conclude that the Agency's document management system was poor and that the Agency had insufficient manpower to dig out all the requested information. The result was that the information provided to the candidates was incomplete. The candidates did not understand why the Agency could not provide the requested information: they were themselves expected to have this kind of data available at any moment if they were to gain the contract. The specifications for their document management systems were very clear about that.

Real problems of understanding arose when the actual state of the existing system in practice, prior to the new contract, also seemed not to be meeting the Agency's own demands. When the Agency arranged for each candidate to be given the opportunity to inspect the existing system, it transpired that the state of the existing system was below the Agency's own specified demands. Both the Agency's document management system and the state of the existing system failed to meet the Agency's own specifications, whilst the future contractor would be penalised if its system did not meet specifications. A bargaining process started, which helped to focus and to reduce mutual biases. During the interactions, the candidates went from being upset about the seemingly unreasonable demands to making sense of the situation: the Agency acknowledged that its asset management was poor and that something had to change in the future. As one of the candidates put it:

"It is very sad that the Agency is unable to answer this kind of basic question. This shows that a DBFM contract is badly needed since the current maintenance of the national highways is dramatically inadequate."

The Agency also gained a new understanding of the situation: why should the contractor have to pay for the Agency's poor asset management? So, in the end, both parties agreed 
that a DBFM was needed, and that it would not be fair if the lack of maintenance to the existing system were to become the contractor's problem. Therefore, both parties agreed that the Agency would do its best to upgrade the level of maintenance of the system before contract closure. As a result of this informal agreement, the contractor was formally given two periods of five working days in which to inspect the state of the existing system when the contract was awarded. The contactor could then apply for lane closures, without being fined, in order to have the existing system meet the Agency's requirements.

Figure 5.6 provides a schematic reflection of Critical Event 4.

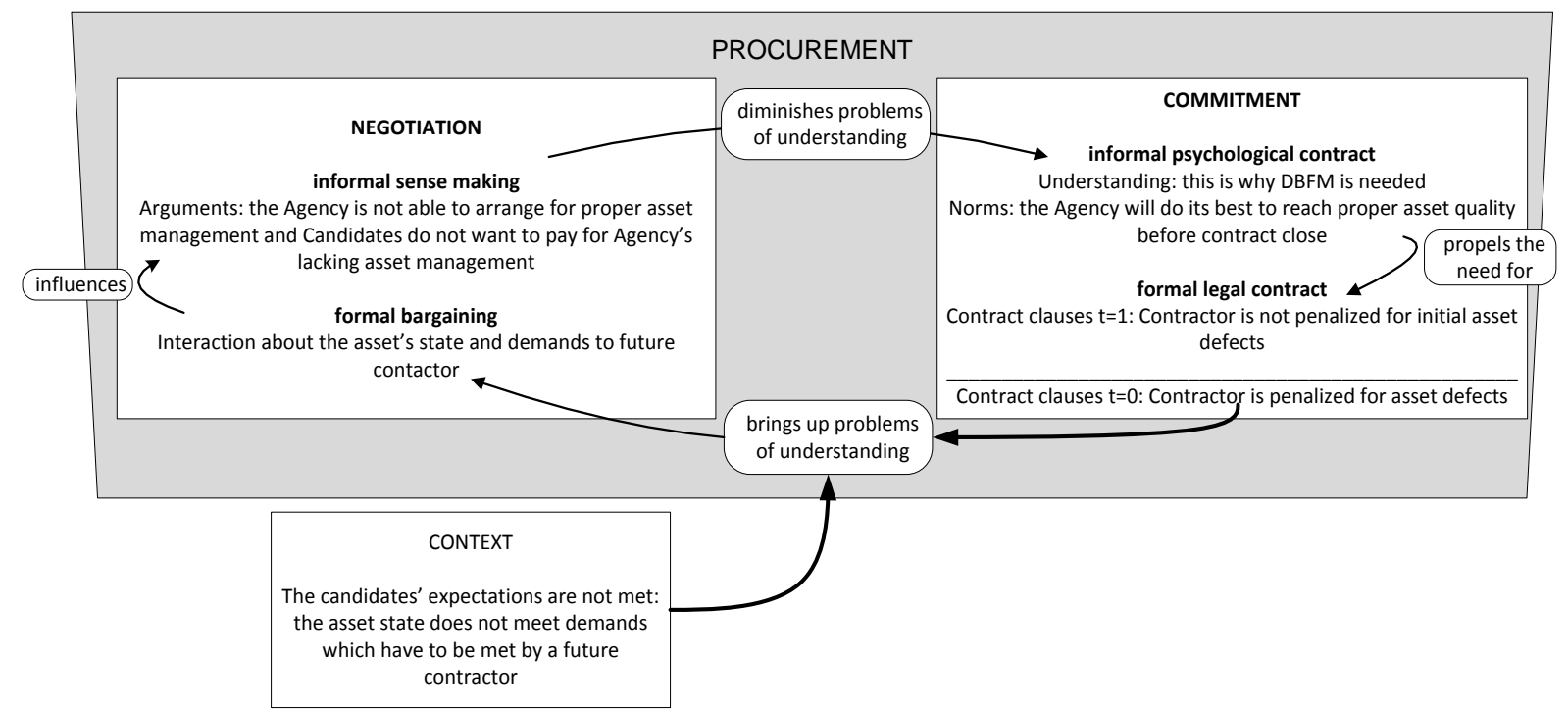

Figure 5.6. The FINCIP model for Critical Event 4 (start at $t=0$, end at $t=1$ )

The necessity of this contractual agreement soon became evident: in the weeks after contract closure an estimated 70,000 square metres of asphalt would have to be replaced before the highway would meet demands. If this had not been agreed, the contractor could formally have faced large penalties immediately on signing the contract. Whether or not this would have actually happened is unknown.

\section{Data incident: Importance of the future relationship}

One of the rules of the $C D$ procedure is that commercially confidential information belonging to one candidate must not be communicated by the contracting Agency to other candidates. This was clearly understood by the Agency, which was fully aware of what kinds of information had to be treated as commercially confidential and what could be discussed.

However, employers of the Agency were involved in putting information in the public data rooms, and human mistakes occur. At the end of the dialogue stage, when the three individual version $\mathrm{D}$ contracts were drawn up and sent to the candidates, an error occurred. Part of the contract for candidate $A$ was put in the data room of candidate $B$, creating a problem of understanding. Candidate $B$, who discovered that they had received the wrong contract, immediately sensed that keeping it might put them in an advantageous position relative to the other candidates. Realising that this might distort competition, and thus harm the contracting process, the candidate deleted the document and contacted the Agency to report the mistake. 
The Agency, in turn, also sensed the risk of a failed contracting process. It took the situation seriously and responded by calling a meeting of all the boards of the large construction firms involved, to consider ways of resolving the situation. This resulted in far-reaching forensic research to discover what information had actually been looked at by candidate B. Alongside this, all of candidate B's employees were asked to swear an oath that they had not looked at the contractual documents inadvertently provided to them.

"Our computer was confiscated. We had to go to the Agency's office, all five of us, to make a statement under oath. And we have done so, just so this tender would not fail. If we had said, "That's your problem, we have not seen anything and that's it", then the other consortium would have responded, "Wait a minute, we don't swallow this" and then they would have gone to court. So we cooperated, in order to prevent the tender process failing."

When the Agency informed candidate A about the mistake, they were furious. However, influenced by the argument that a failed contracting process might mean the end of DBFM in the Netherlands, and that the forensic research had not provided any evidence that candidate $B$ had seen any more than the front page and the table of contents of their contract, candidate $A$ sensed that its commercially confidential information had not actually been shared with another candidate.

All candidates (including the non-involved candidate $\mathrm{C}$ ) agreed that the Agency had resolved the problem professionally. The importance that the candidates attached to the future relationship, which is part of the informal psychological contract, meant that none of them were willing to take any legal action as a result of the mistake made by the Agency.

A schematic reflection of Critical Event 5 is given in Figure 5.7.

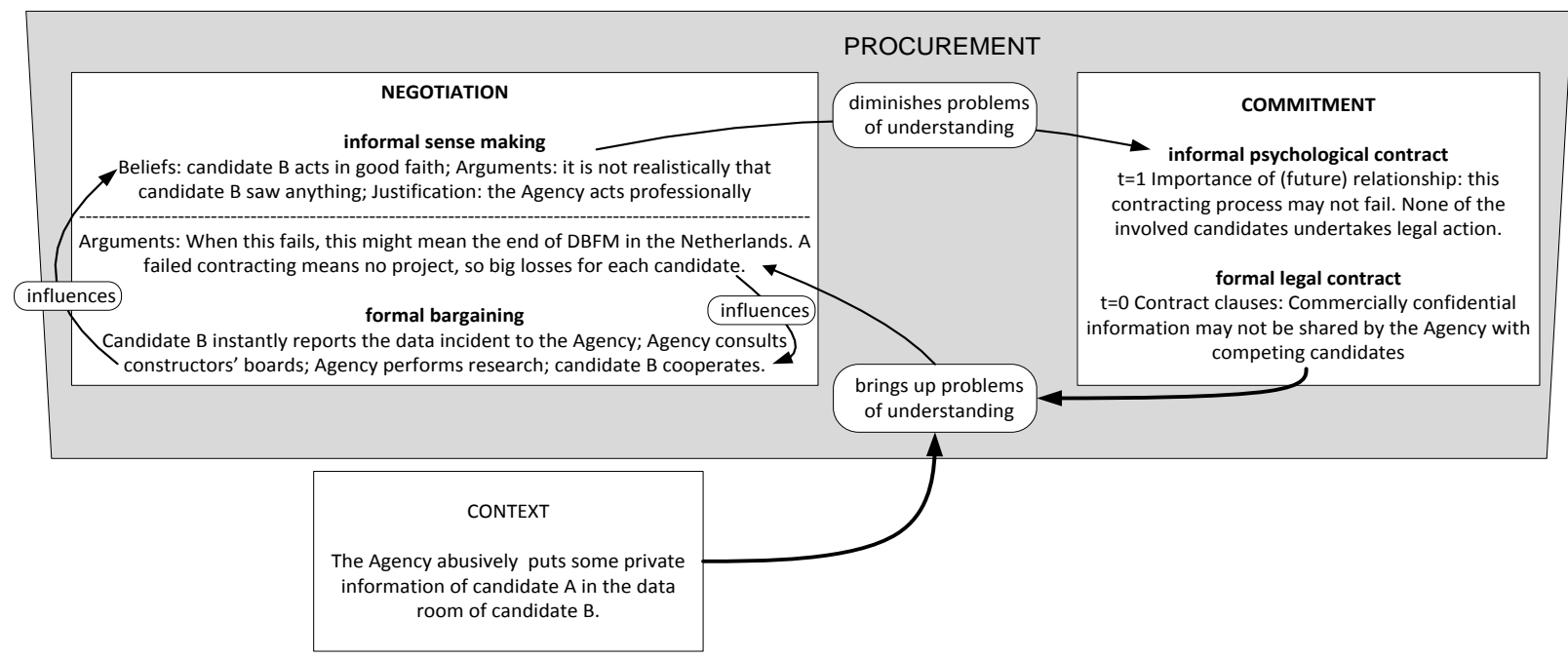

Figure 5.7. The FINCIP model for Critical Event 5 (start at $\mathrm{t}=0$, end at $\mathrm{t}=1$ ) 
6. The risk of delay due to non-acceptance of the definitive Alignment Decision: risk allocation and contract clauses

Another negotiable risk was the possibility that the proposed Alignment Decision would not be accepted on time by the Council of State. If this were the case, the Coen Tunnel project would not be able to start at the expected moment, and thus face delay. The Agency asked the candidates to bear this risk, such that in the event of non-approval of the Alignment Decision, the project would still be finished on the planned date. After some clarifying questions, the consequences attached to non-agreement of the Alignment Decision by the due date were clear to all candidates. When the risks were eventually allocated, one of the three candidates was willing to bear this risk; the other two left the responsibility for it with the Agency. This meant that, if one of these two candidates won the contract, and the Alignment Decision was not accepted, then they would be compensated for any associated financial losses. When the bids were made, it turned out that the most economically advantageous bid was made by one of these two candidates. The difference in bid price between this "contractor-to-be" and the candidate who had made the second best bid, was significant: the second bid was $15 \%$ higher than the winning bid. So, in version 1.00 of the contract between the Agency and this "contractor-to-be", the risks due to delay because of non-acceptance of the Alignment Decision were borne by the Agency.

\section{a. Additional air quality research needed}

Problems of understanding arose when, in a project close to the Coen Tunnel project, the Alignment Decision was rejected due to insufficient data to prove that the project would not excessively pollute the local atmosphere. Here, further research was needed before the Council of State would be willing to consider accepting a new Alignment Decision. In response to this situation, the Agency decided that the Coen Tunnel contract should not be signed because it was unsure whether the data about air pollution in the Coen Tunnel project would be sufficient. Further, if the Minister had to explain to the Lower House that he had ordered further research for one project, while signing a $€ 500$ million formal contract for a project with potentially a similar lack of sufficient air pollution data, it would look bad. The contractor-to-be, on the other hand, assessed it as unfair that the Agency would not sign the contract because it was anticipating a situation in which the Alignment Decision would be rejected.

This problem of understanding led to the contractor-to-be starting a bargaining process to convince the Agency to sign the contract regardless. Although neither of the parties was willing to reconsider their positions, the explanations of respective positions did promote a sensemaking process. The Agency started to understand why the contractor-to-be feared being left empty handed: the two losing bidders had already received compensation, but the "winner" had not even been appointed as the preferred bidder. As a result, the Agency informally promised that compensation for financial losses would be discussed when the continuation of the project could be foreseen. However, the contractor-to-be was not convinced. Their sensemaking process had led to an understanding that not signing the contract was a cheap exit option for the Agency, and so they would rather see the Agency sign a formal contract. 
"Once we had signed the contract, we would have to settle according to the terms of the contract and, if the Agency then wanted to get rid of us, they would have to pay a return on equity. If we did not, the Agency could just say "sorry guys" and we would receive only the tender fee. Well, that could save the Agency a couple of million Euros."

Figure 5.8 provides a schematic reflection of Critical Event 6a.

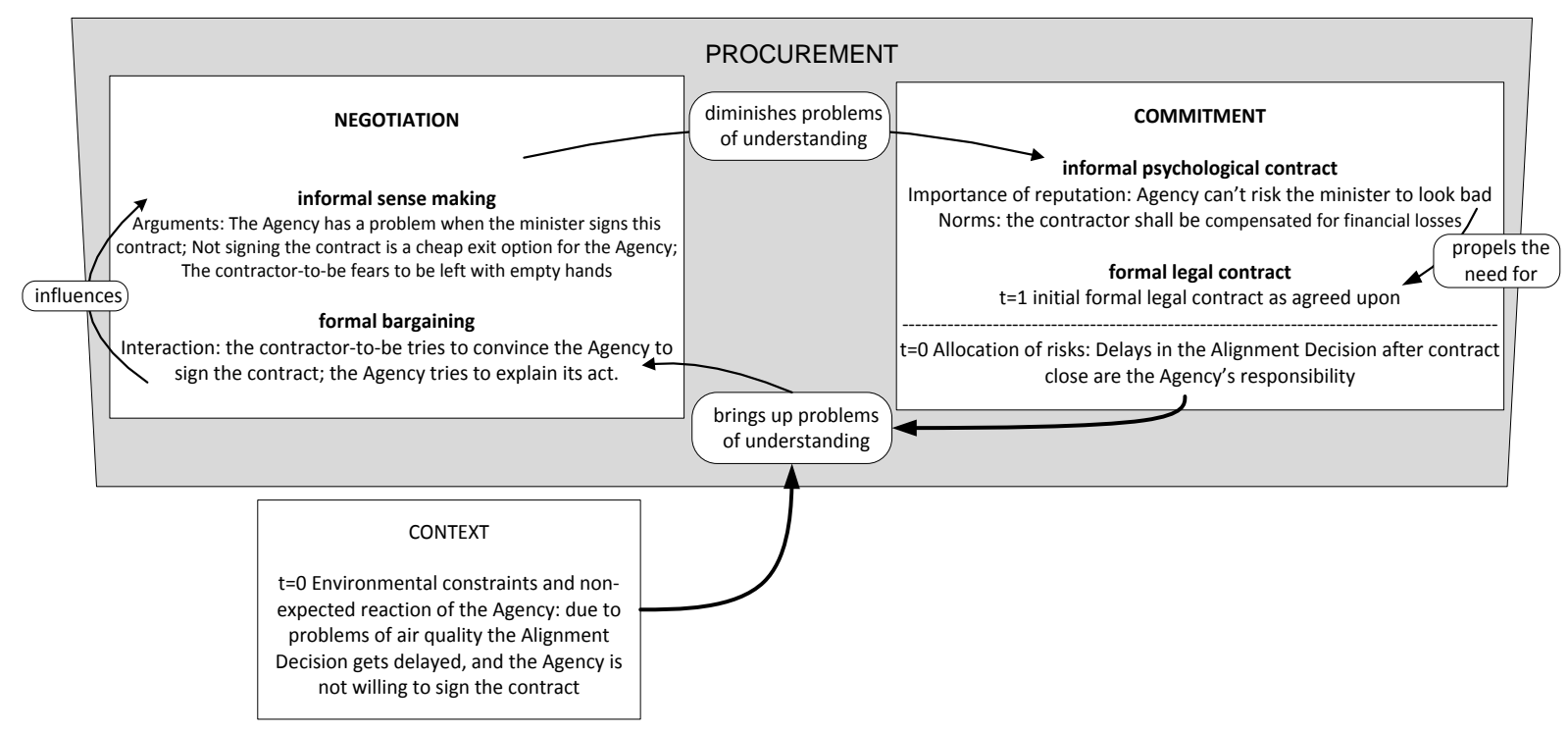

Figure 5.8. The FINCIP model for Critical Event 6a (start at $\mathrm{t}=0$, end at $\mathrm{t}=1$ )

b. Definitive Alignment Decision awaited before signing of the contract Later, when the air quality research had been successfully performed, and the Minister was about to sign new Alignment Decisions for both the projects referred to above, the contractor-to-be restarted bargaining about the signing of the formal contract. Even though this sounded reasonable to several of the Agency's employees, who understood the position of the contractor-to-be and were convinced that signing the contract would not be problematic in the new situation, their bosses told them not to. The reasons for this decision were not very clear to the Agency's employees involved in bargaining with the contractor-tobe and so, instead of helping the sensemaking process by explaining this decision to the contractor, they kept postponing the date of contract closure without giving reasons. This only made sense to the contractor-to-be by concluding that the Agency no longer wanted to award the contract. Further, there were no signs that the Agency intended to keep its informal promise to compensate for financial losses. Alongside fearing being left empty handed, there was a deadline in the financing contract between the contractor-to-be and its banks which would end in a few months. Given the credit crunch, the contactor-to-be did not want to risk having to renegotiate with the banks, in case it would not be able to fulfil the terms of its bid.

In an attempt to come closer together, the Agency asked the contractor-to-be what its financial losses were so that the informal promise of compensation could be formalised in a Version 2.00 of the contract. The contractor-to-be claimed to be out of pocket by about $10 \%$ 
of their bid price, but the Agency did not believe this. A new bargaining process started, in which both the contractor-to-be and the Agency restated their points of view. Whereas the contractor-to-be wanted to be compensated for an amount equal to $10 \%$ of the bid price, the Agency refused to accept more than $2 \%$ as realistic. The Agency made sense of what they saw as an inflated claim by explaining it as a way for the contractor-to-be to make up the difference between its bid price and that of the second best bid.

Several bargaining conversations were held about Version 2.00 of the contract but, since the Agency did not want to accept the contractor-to-be's claim for losses as realistic ("we could pick holes in their calculations and stories time after time"), the parties did not come closer to each other. Both parties tried to force an agreement. The contractor-to-be pointed out that its agreement with the banks would expire on May 25th. Further, it claimed to have counted on having three months from contract closure to financial closure, and therefore needed contract closure by the 25th of February ("otherwise the deal is off"). Given that the Agency's internal principal wanted to wait for the definitive signing of the Alignment Decision, contract closure was not foreseen until March 15th. Rather than breaking off the bargaining process about Version 2.00 of the contract as threatened, the contractor-to-be simply did not respond to this lack of action.

"Then it became February 25th and there was no decision. And what was striking, was that then nothing happened. And such things have a negative impact within the Agency. We said, "alright, seemingly this is a project which surrounds itself with mist". They are rabblerousing, applying pressure and, when the date expires, it's suddenly possible to manage in six weeks instead of three months."

The Agency then tried to force an agreement. The contractor-to-be was offered a final offer, containing a sum for financial losses and extra time to finalise the project, which he could take or leave. Given that neither the offered price nor the offered extra time was sufficient in the eyes of the contractor-to-be, the two parties did not come to an agreement. The contractor-to-be responded to the final offer by starting a legal process against the Agency, in so doing anticipating a response from the Agency's internal principal, knowing that the Agency's reputation would be harmed by being sued. And indeed, one conversation at the internal principal's offices was enough to settle the matter at a figure somewhere between the $10 \%$ and $2 \%$ positions.

Version 2.00 of the formal contract was then signed in April 2008. Both the Agency and the contractor then knew where they were standing. However, it was clear to all parties that the informal contract had been changed by the events. The contractor was satisfied by the new formal arrangement, but the Agency's employees felt cheated. This decreased the benevolence component of the informal contract: the Agency felt less sympathetic towards the contractor, and the relationship became more distant and formal.

In Figure 5.9 a schematic reflection is given of Critical Event 6b, after which Figure 5.10 reflects on Critical Event 6 as a whole. 


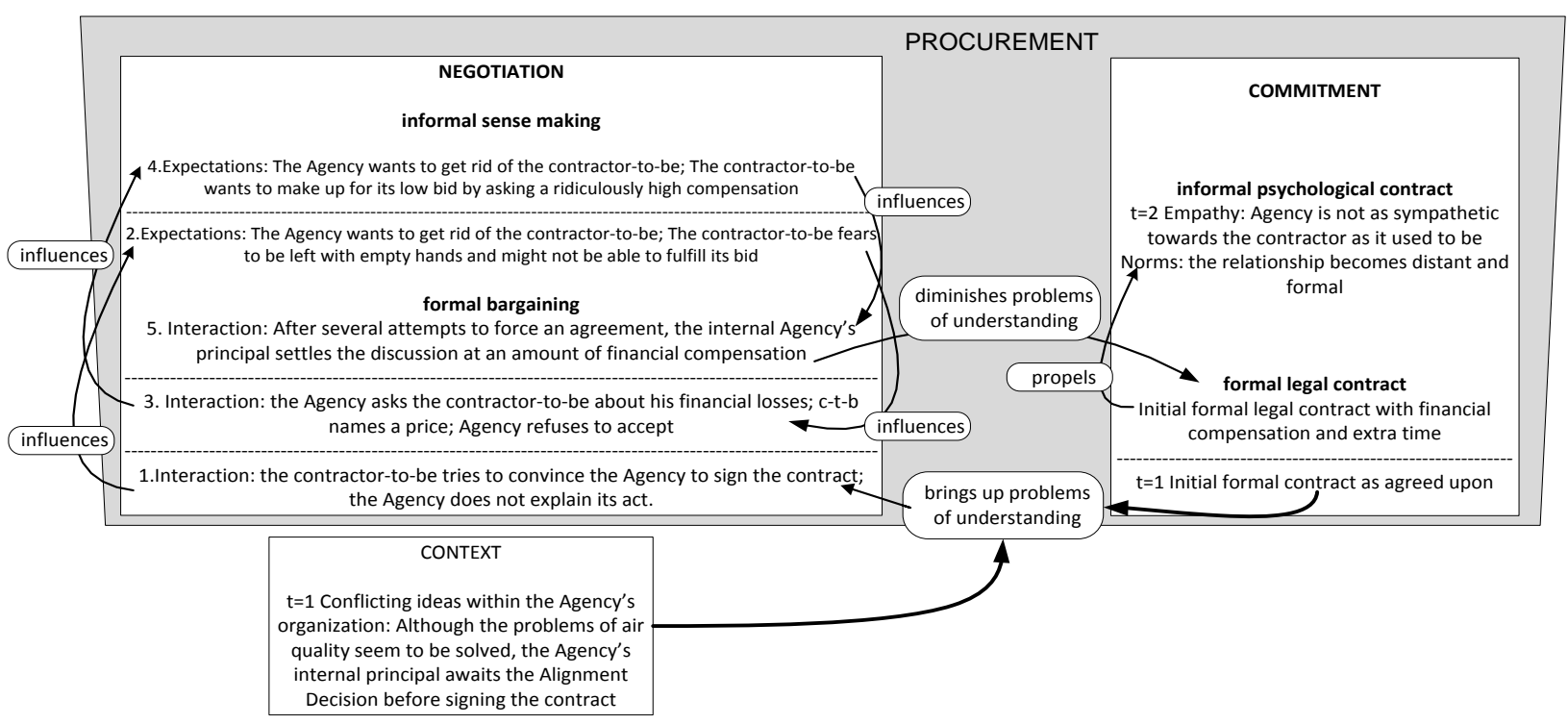

Figure 5.9. The FINCIP model for Critical Event $6 \mathrm{~b}$ (start at $\mathrm{t}=1$, end at $\mathrm{t}=2$ )

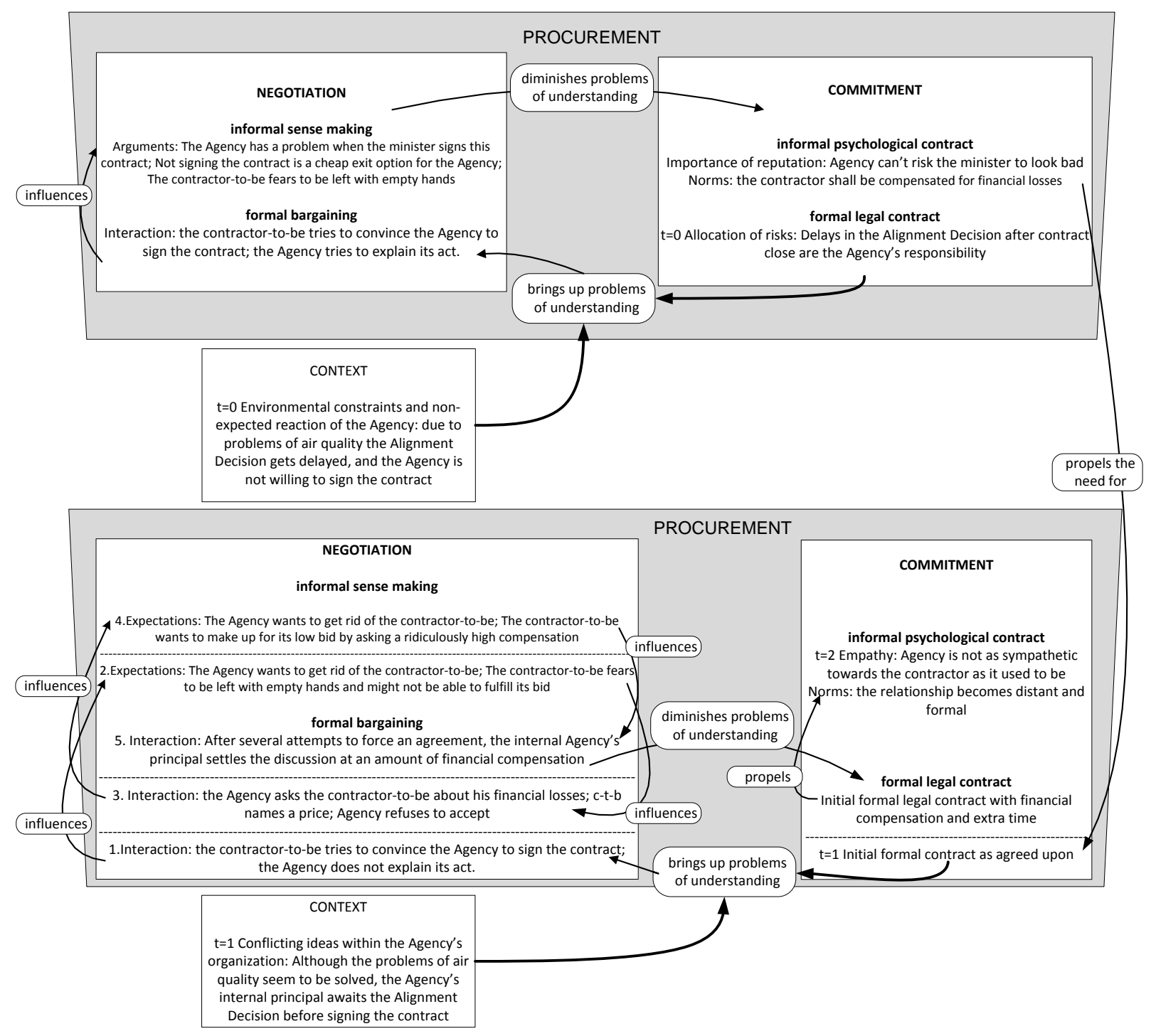

Figure 5.10. The FINCIP model for Critical Event 6 (start at $\mathrm{t}=0$, end at $\mathrm{t}=2$ ) 


\section{Problems with financial closure}

The Agency could make the bidders fulfil their bids for one year after the bids were submitted. This fulfilment term of one year had been part of the tender documents and had been agreed upon by all the candidates before they made their bids. However, the best bidder did not expect the Agency to actually need a year after the bids were submitted to reach contract closure. This bidder itself had made a financial arrangement with several banks, on which basis it had been able to make its bid. This arrangement included a tender by the banks for the surcharges they would add for administrative costs, profits and risks; alongside the base rate (the interest charged among the banks themselves).

After contract closure, the contractor was to formally be given three months by the Agency within which to reach financial closure. The best bidder had planned to use the whole three months to negotiate with the banks about its financial agreements. However, when it took eleven months to reach contract closure, the best bidder (now the contractor) came into problems. Its financial arrangement with the banks would end in only one month. This meant that the contractor had only one month to complete all the financial negotiations with the banks. This had become a problem due to the credit crunch: none of the banks were willing to stand by the agreement beyond the existing end date, and they were negotiating strongly about the terms in the financial agreement.

It was also of benefit to the Agency if the contractor could achieve financial closure within a month of contract closure. The surcharges in the financial arrangement were $0.65 \%$, against 0.90 to $1.10 \%$ which was common in the market at that time. If the financial agreements were not signed before the end date of the financial arrangement, the banks would probably start applying much higher surcharges than the contractor had anticipated when bidding. This aspect notwithstanding, the Agency did not consider itself as an interested party in the process to reach financial closure. It looked on the situation as a matter between the contractor and its banks. The Agency did not expect to have any contact with the banks, and it expected to be present at financial closure only to sign some kind of testimony to confirm that it had witnessed that the contractor and its banks had made a deal.

Problems of understanding arose when the contractor and the banks turned out to be expecting the Agency to have a more active role. In the build-up to financial closure, the contractor asked the Agency to come and talk to the banks, in order to explain some of the contract clauses in its contract with the contractor so that the banks could better calculate some risks (for example the risk that the Agency would not pay what it owed the contractor). Furthermore, the banks demanded that the Agency send a fully mandated civil servant to acknowledge financial closure. In an attempt to make sense of the fact that the contractor and its banks had a more prominent role for the Agency in mind then it had expected to have, the Agency anticipated that the contractor and its banks had plans to renegotiate the contract which had already been signed. In the formal bargaining process which followed, the Agency therefore refused to take the active role asked of it. It proposed involving the Ministry of Finance to talk to the banks, and it suggested sending a civil servant with a restricted mandate to witness financial closure. This stance was not understood by the contractor and the banks at all. These parties made sense of the situation by arguing that the Agency probably did not know what its role was. 
"The Agency did not want to talk to the banks at all. But, at the moment it needed to come across to the banks, it offered the Minister of Finance. Well, no matter what he did, bringing him in would not help the project. No, this was all very odd... the Agency thinks that it is not involved, or that it has no interest in this play. It was all very odd."

A new round of formal bargaining began, during which the contractor explained to the Agency that its role was somewhat different than it thought. Given that it was also in the Agency's interest that financial closure was reached on time, a more active role would be appropriate. As a consequence of non-involvement, failure of the whole project was mentioned as a real possibility. This argument helped the Agency in its sensemaking process. It made the Agency realise that it might have misinterpreted its role in the process. This was confirmed by its advisers who, to give one example, stated that the Agency should indeed send a fully mandated civil servant to financial closure.

"The contractor's tender manager told me that he was playing a sort of chess game. I was one of the pieces on the board which he needed right away. Well, for the progress of the project, I then answered that I would cooperate, but that I still had no idea what the banks were looking for. Also that I would still have the same message, and that I would repeat what I had said earlier: "You are more than welcome, please have a cup of coffee, but your contribution comes too late since you have committed to a financial arrangement with the contractor, and the contractor has already signed the contract. The time that you, the banks, could demand anything has passed."

Following this, the Agency did appreciate that it had a more active role. However, the informal psychological contract also contained the norm that the Agency would just stick to what had been asked for, and nothing more, so as to prevent it from entering into those feared re-negotiations. In practice, this meant that the Agency, in the conversation with the banks, did only repeat what it had already stated, and that the civil servant who was sent to financial closure did have a mandate, but only for the contractual documents which had already been sent to the Agency in concept form, and only for the day on which financial closure was planned.

A schematic reflection of Critical Event 7 is given in Figure 5.11. 


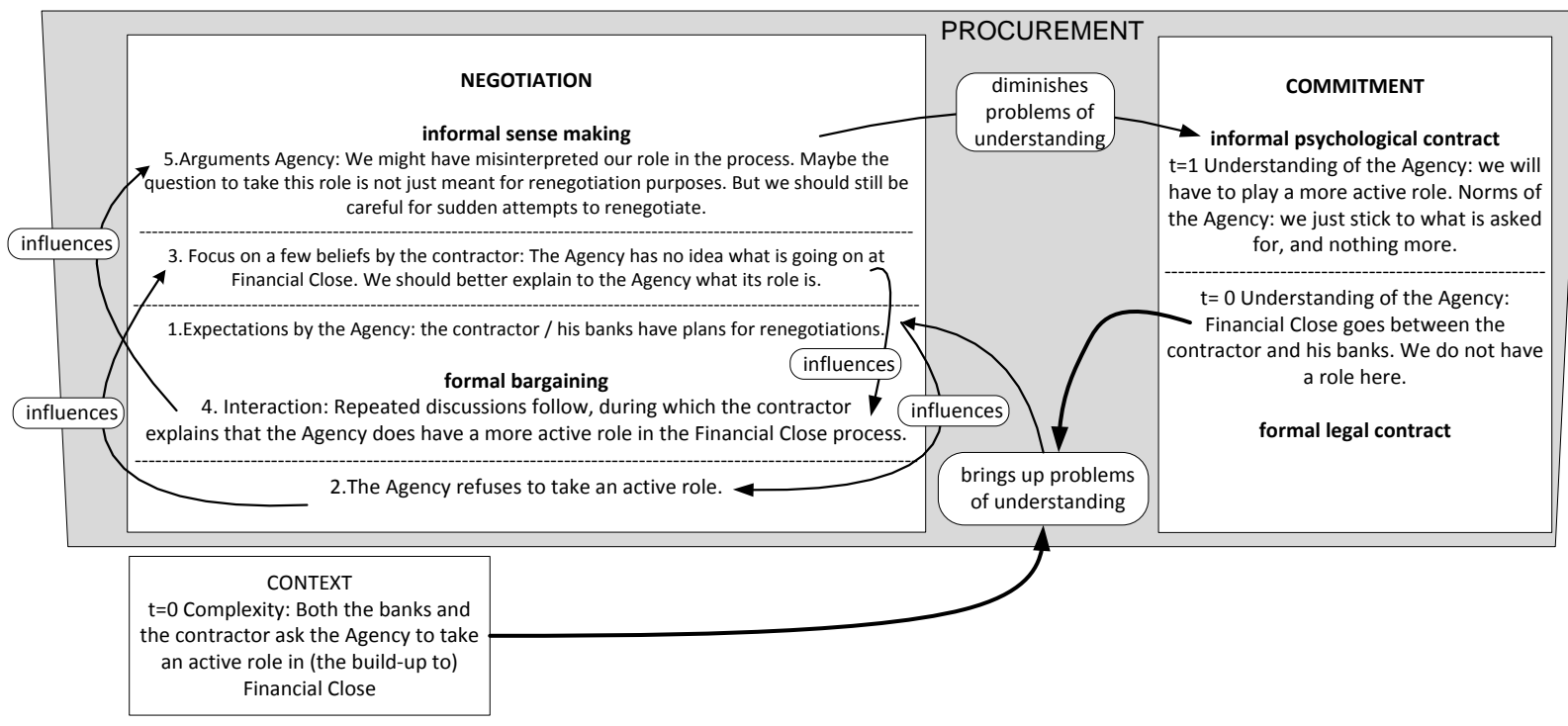

Figure 5.11. The FINCIP model for Critical Event 7 (start at $\mathrm{t}=0$, end at $\mathrm{t}=1$ )

\section{Interpretation of a penalty clause}

During the dialogue, several of the candidates had asked questions about the interpretation of a specific term in the contractual clauses of the reward system. The term was formulated as follows: "In case of a contingency or situation which falls within one of the categories mentioned in the Table below, the Principal may award penalty points (PP's) in accordance with the Table. When the Principal decides to award Penalty Points (PP's), he has to award the number given in the Table and not fewer." Candidates wanted to know what was meant by "the Principal may award penalty points": in which cases would the Principal award penalty points? However, formally, the contracting Agency had not provided an answer to such questions:

"When a contractor asks "how should I read this?', I assume that they certainly see more than one manner in which the contract COULD be read. In that case, the question might be seeking clarification, but it is more likely that it is a pretext for negotiation. It would mean to me, if I was a contractor, that I might also choose differently. [...] We, as the Agency, have tried to overcome this by not answering questions in which options are mentioned like "how would I...', "could it be possible that...', etc.". So the Agency formally answered this kind of question with the standard response "The Agency will put this question to one side".

During the dialogue conversations, however, the candidates did discuss the interpretation of this specific line with the Agency's employees. Given that the conversations were not legally binding unless confirmed in the formal answers to general and confidential questions, these dialogue conversations were never reflected in the formal legal contract. Nevertheless, the candidates were given an idea of how the formal legal contract would be interpreted. These ideas became reflected in the informal psychological contract. 
a. Penalty points first performance test

When the construction of the Coen Tunnel started, the Agency and its contractor started to work together, using the contract which was signed and agreed upon by both of them. Three months after contract closure, the contractor was put through the first performance test by the Agency. On some points, the test results were negative: the contractor was not "in control". The Agency sent the contractor its test findings, in which the negative points were mentioned along with the potential number of penalty points. Up to this point, both parties understood each other. The contractor did agree with the test result ("Indeed I am not in control"), and responded to it with many excuses and promising to do all they could do to gain control before the next performance test.

Problems of understanding arose when the Agency decided to award 12 of the 17 potential penalty points, meaning that the contractor was given a penalty of $€ 120,000$. This reading of the penalty points table in the reward system was not in line with the manner in which the contractor had interpreted it. Based on the dialogue conversations, the contractor had assumed that penalties would only be given after several warnings. Given that this was the first test of performance, the contractor had not expected any penalty at all.

A process of formal bargaining started, in which the contractor expressed much anger, stating that the Agency did not act in line with the signed agreements. The Agency responded by saying that the contractor was not in control, and that the contract, which was signed by the contractor, foresaw this situation as treated in the penalty points table. According to the reward system, the Agency was allowed to award penalty points, and the Agency was not aware of any norms about warnings before awarding penalty points.

In its sensemaking process, the contractor simply focused on its stereotypical image of civil servants: acting to the letter of the contract, not thinking about the consequences first, contract means contract. The Agency, on the other hand, did not want to be dragged into the sort of situation that existed before the introduction of DBFM contracts, where the Agency had to monitor the work, while the contractor could sit back. One of the beneficial aspects of DBFM was, for the Agency, that the contractors had to monitor the work themselves, whilst the Agency had only to conduct a few performance tests on the contractor's monitoring system. The contractor's response to the penalty points was explained by the Agency as a signal that the contractor was creating a pretext for a situation in which the Agency itself would start monitoring the work.

A new formal bargaining conversation started. The contractor tried to convince the Agency that it had misinterpreted the contract by calling in one of the Agency's tender managers who had taken part in the dialogue conversations about the reward system. When this did not convince the Agency, the contractor complained: if the contract will always be interpreted like this, we would face penalties every day until we are in control. Although the Agency had considered giving the contractor some time to gain control, it eventually decided not to give in after all.

The reason for this strict response was the Agency's expectation that the contractor would not regain control. Some of the compensation that was paid after the delay in contract closure was an amount to enable the contractor to take control. Given that the contractor 
had failed in this, the Agency's expectations of future considerate actions were not too positive. The contractor made sense of the Agency's strict attitude with the explanation that the Agency was probably still mad about the amount settled for the earlier losses:

"I sometimes have the feeling that we are being punished by the Agency's current project management for the fact that we managed to get paid for our losses, behind their backs, that day in The Hague. That is how they look at it, like "wait a minute, we will get those euros back". [...] Because the way they are acting with those penalty points is just so ineffective! We are becoming grumpy; the cooperation is under pressure, we are working inefficiently because of those penalty points, instead of becoming more effective, so it does not help. It does not help at all."

As the contractor states, its new understanding meant that its working routines changed. Instead of working hard to gain control, the contractor fights each penalty awarded. A schematic reflection of Critical Event 8a is given in Figure 5.12.

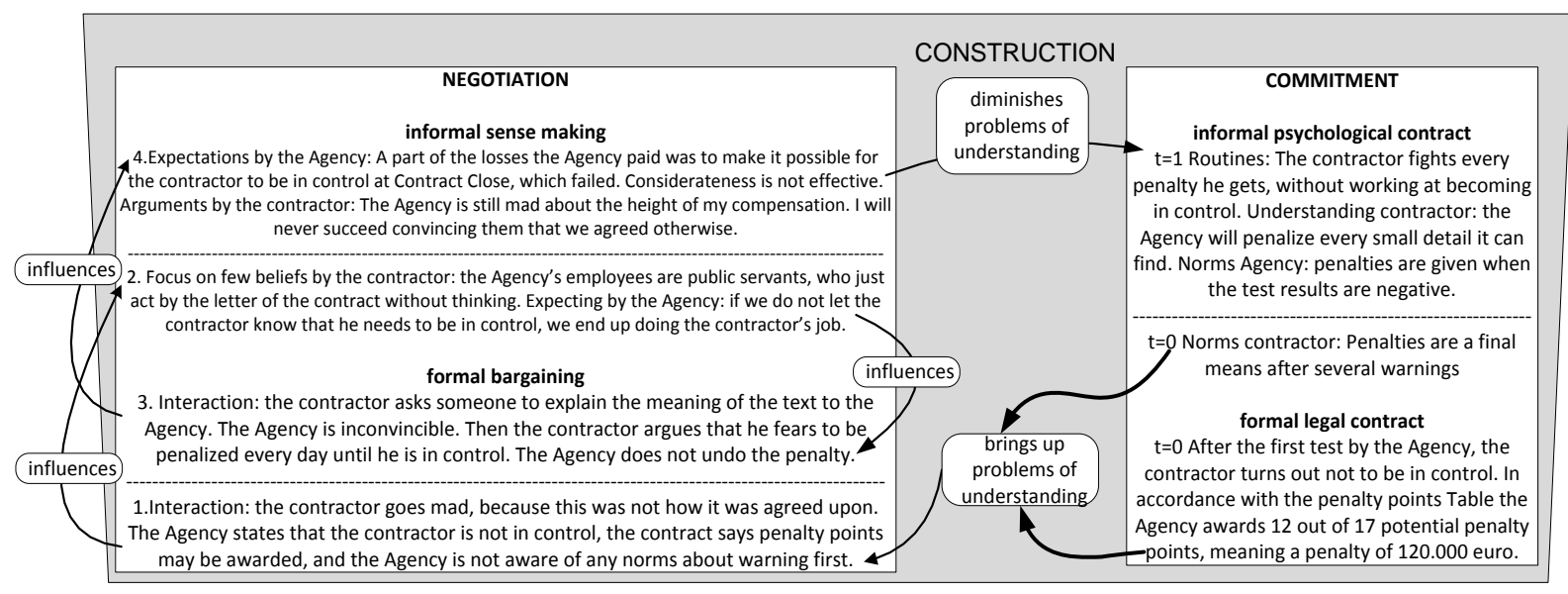

Figure 5.12. The FINCIP model for Critical Event $8 \mathrm{a}$ (start at $\mathrm{t}=0$, end at $\mathrm{t}=1$ )

\section{b. The contractor's project manager is replaced}

Through the award of the first penalty, a situation was created in which the Agency penalised the contractor's failures in order to encourage the contractor to achieve control. However, the contractor then put its effort into fighting penalties instead of gaining control. Both parties understood each other's position, and accepted them. The Agency was determined to keep penalising failures until the contractor took control, and the contractor was as determined to keep fighting the penalties until the Agency became less rigid in their interpretation of the contract.

Both parties seemed to accept their differences in interpretation of the formal legal contract until February 2009. Then, the contractor's project manager got a new job, and a new project manager took over. This manager was more direct in his communications with the Agency, and focussed on the project rather than on the contract. As a consequence, the Agency got the idea that this man would work for the benefit of the project instead of just 
for the benefit of his company. In the Agency's sensemaking process, the replacement of the former project manager was explained as a gesture from the contractor's side towards becoming closer to the Agency. In response to this, the Agency started a new formal bargaining process over the penalty points which were standing between them.

"One week ago I choose not award 20 potential penalty points. I wrote to the contractor: "I could have awarded 20 penalty points. However, these penalty points do not concern safety or the lack of maintenance; they just concern your control over the process. I see that your organisation was under construction at the time of the performance test, and the Agency understands this. With respect to the cooperation, I do not choose for rightness but for partnership, so I do not award those penalty points. Yet, I do expect you to solve the problems, because I do think these are severe". I did this because they have made a move by replacing the former project manager by this new guy. Good, and I then considered my position. Cooperation will only be established when both of us make a move. So I have to show some kind of change in my behaviour. That is fair enough. What you do, is mirror: since their former project manager was a fighter, I became a fighter as well; and if I stay a fighter, the new project manager will become a fighter too."

The attempt to reduce tensions by not awarding 20 potential penalty points did achieve the effect the Agency desired in its sensemaking process, that the contractor views the Agency's action in a positive manner. The contractor duly assumed the Agency to have acknowledged that its former rigid interpretation of the contract was doing the project no good. As a result, the contractor expected that the Agency, from then on, would become less rigid with enforcing penalties.

Problems of understanding diminished due to two sensemaking processes. The contractor developed new working routines, and the Agency adopted norms towards the formal legal penalty clauses which were more in line with the contractor's expectations. Instead of focusing on the reward system, both parties started to concentrate on the project.

Figure 5.13 provides a schematic reflection of Critical Event 8b.

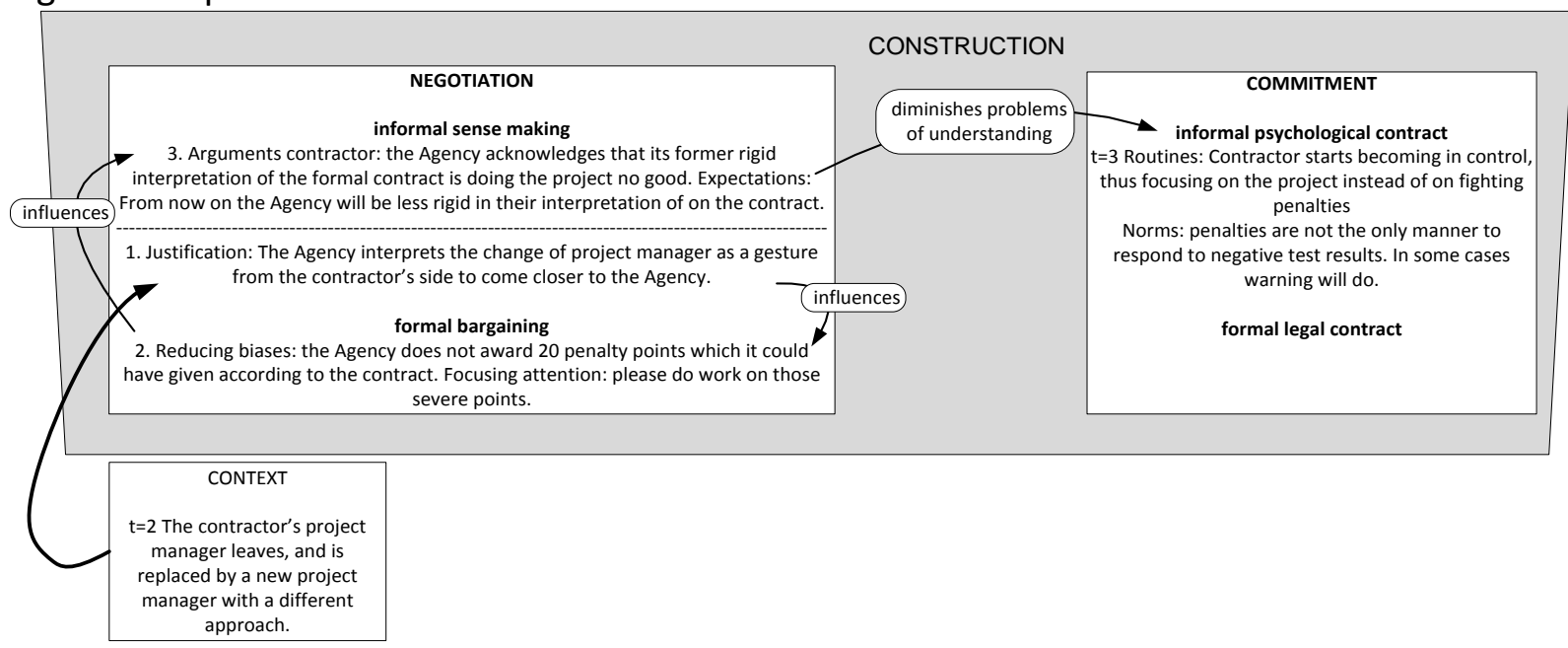

Figure 5.13. The FINCIP model for Critical Event $8 b$ (start from $t=2$, end at $t=3$ ) 


\section{Development of negotiations and commitments}

The critical events described in the previous subsections reflect how negotiations and commitments developed in the Coen Tunnel project. During the dialogue stage, all the candidates asked questions about several aspects of the contract. The answers given to questions were seen as satisfactory by the candidates except where the Agency saw a question as a pretext for possible claims or renegotiations in the construction stage of the project and declined to provide a full answer.

\section{Formal legal contract}

As a result of the dialogue conversations, the formal incentive control elements of the formal legal contract were changed on some points. The final reward system differed on some major points from the original reward system. Both parties agreed that the alterations improved the reward system. The allocation of risks was different for each of the candidates. Six of the thirteen negotiable risks were allocated identically to all three candidates. The strategy for the other seven risks differed. One candidate accepted all seven; one candidate gave six back to the Agency and took responsibility for just one; and the third candidate took four risks and left three risks with the Agency. The best bidder turned out to be the one who had left most risks with the Agency.

A few changes in the opportunity control part of the contract were also made. Where changes were made, the wording of the contract clauses became more univocal, and often less specific. These latter changes helped improve the contingency adaptability of the contract. The output specifications were subject to several discussions. Due to the fact that the contract had been rewritten from a D\&C contract to a DBFM format, the specifications were very detailed at some points. Another issue, which was caused by the fact that the Agency had only one year to rewrite the specifications, was that at some points the specifications were contradictory. Although the Agency had indicated that changes to the specifications could be made when the dialogue conversations gave good reason so to do, in practice only a few changes were made. This was mainly because the candidates were not experienced in working with functional specifications and, because of this, the Agency feared that it would not receive the product it was aiming for. In order to overcome the problems with the specifications, specialised meetings were organised during which the candidates could discuss technical issues with the Agency's technical specialists.

The monitoring system had become a major issue during the procurement stage and this carried over into the construction stage (see Critical Events 3 and 8). Being responsible for monitoring its own work was new to the contractor. The fact that the Agency feared ending up monitoring the contractor's work caused it to stick rigidly to its initial ideas about the management plan.

\section{Formal bargaining}

The formal bargaining process helped the participants to reduce complexity and focus each other's attention. For example, when a candidate asked a question about how to interpret a certain contractual clause, this made the Agency consider a change to its formulation. By discussing the reward system, both the Agency and the contractor had to articulate the expected effects of specific elements of the system. Deliberation about these effects led 
both parties to reflect on both the desired and undesired effects of the system. In some cases this ended up in changes to the system, and in others it meant that both parties better understood the effects of several elements in the system.

The interactions through which the parties bargained helped them in sharing and fusing knowledge, assumptions and mental models, and this aided the sensemaking process and thus the understanding of each other. Several such examples are described in the Critical Events. Concluding, the fact that, during the dialogue conversations, direct communication took place meant that the Agency and the candidates were able to exchange assumptions and reasoning. In so doing, they could confront each other with inconsistencies in reasoning, incomplete assumptions, judgemental errors and biases. However, besides reducing existing biases and judgemental errors, the conversations also gave reasons for new biases. For example, the winning candidate had established "a track-record of claiming, objectionable negotiating habits and putting up smokescreens" (Theunissen \& Kooiman, 2008) during the contracting stage, and this played a major role in the process leading to financial closure.

\section{Informal sensemaking}

During the project, both the Agency and the contractors were constantly confronted with actions and situations which were, in general, either congruent or contradictory with their ideas about how things should work. Cues were given in line with beliefs by arguing, expecting, committing or manipulating. The main determinants in this process were previous experiences with the other party, stereotyping, biases and judgments. The Agency's stereotypes, biases and judgments (beliefs) differed for the various candidates:

"One of the candidates was formed by old-fashioned contractors, of whom I was not too fond. Another candidate had a team of enthusiastic novices, who really wanted to build the tunnel and who we could see were learning each time we spoke to them across the dialogue table, their learning curve was steep. And then there was a third candidate, who leaned back like: we already know how this type of project should be managed; we have built [another large Dutch project]; we are [name of the candidate], this is how it works, these are our products."

In the case of the final contractor, the Agency started to talk about their track record, which was mentioned in the previous reflection on the formal bargaining following the discussions on the amount the Agency would have to pay to cover the contractor's losses. This history led the Agency to interpret practically all remarks by the contractor as pretexts for renegotiations. The contractor, on the other hand, repeatedly had reconfirmed the idea that the Agency did not quite understand what came with constructing a project as large as the Coen Tunnel. These biases largely determined the sensemaking processes of both parties. Until the contractor's original project manager left, the sensemaking processes developed around negative vicious circles: the actions of the other party were negatively interpreted, thus confirming the biases both parties had developed against each other. Breaking those circles was only possible by the Agency taking deliberate action in response to the "clue" that a new, more cooperative project manager had been appointed by the contractor. The Agency focused on the belief that non-cooperative behaviour would harm the project, and on their expectation that the other party shared this belief. 
Informal contract

Until the delay in contract closure, the level of benevolence was neutral. Differences in norms and values between the Agency and the contractor had been identified, resulting in the parties not feeling overly empathic towards each other. In the interviews, hardly any form of identification or affection was noticed. However, the working routines with each other were such that the contracting process was manageable. The spokespeople of both parties had found a way to meet with each other that resulted in discussions, with daggers drawn but without becoming negative:

"Our tender manager was very consequent in conducting the dialogue. The contractor's tender manager once said "gee, I have never met someone who could read me this well". So if he or anyone else asked a badly-timed question... well, our tender manager was not the kind of guy who would discuss the topic with the candidate. And that approach was needed and accepted at that time."

Incentive control played a much greater role during the contracting stage of the project. Dependence on the future relationship and reputation effects were taken into account when responding to each other. However, at the time that contract closure was delayed, this informal incentive control could not be used to effectively prevent the contractor from utilising this opening for opportunism. Given that benevolence was not built up between the parties, this delay caused the informal contract to develop along similarly negative vicious circle as the informal sensemaking process did. The breaking down of these vicious circles reported above similarly made room for stronger benevolence in the informal contract.

\subsection{Concluding remarks}

In this chapter, the development of the Coen Tunnel project has been described in order to find an answer to the question of how negotiations and commitments develop over time in a $C D$-procured construction project. Analysis of the critical events in the Coen Tunnel case study has led to the following conclusions:

\section{Problems of understanding}

The description of the critical events in this chapter showed that, at a certain moment, in a situation of commitment, problems of understanding arose. In most of the situations, sensemaking processes during the procurement stage of the project had led to differences in the informal psychological contract between the parties involved. These differences did not appear until a situation arose in which parties expected to have mutual understandings whilst this was not the case. Renegotiations were then necessary to resolve the problems of understanding. This finding supports proposition $B$ that extensive renegotiations during execution of the project might be prevented by purposeful sensemaking processes facilitated in the negotiations during procurement. Such sensemaking processes have not been stimulated in this case, due to a lack of openness. However, when parties participate in the $C D$ procedure with the consciousness of sensemaking processes, problems of understanding could be prevented. 
The problems of understanding that arose in this case concerned the formal legal contract as well as the informal psychological contract. Contextual situations may highlight differences between the formal legal contract and aspects of the informal psychological contract of one or both of the parties involved: the manner in which one of the parties acts upon the formal legal contract might conflict with the informal psychological contract of the other party; or new agreements might be needed due to contextual situations which are not foreseen in the formal legal contract. In such situations, a problem of understanding arises, that will have to be resolved through negotiations. This finding supports proposition $\mathrm{C}$ of Chapter 2: during all phases of a project, from initiation through to delivery, the parties involved oscillate between negotiations and commitments depending on whether there is understanding or not. Further, the parties may be involved in negotiations for some aspects, but in commitments for other aspects of the project. Negotiations and commitments do not, however, coexist within a single aspect: the two act as substitutes.

\section{Negotiations}

All the descriptions of critical events showed that parties started negotiations in response to problems of understanding. These negotiations could be in the form of formal bargaining started by one party or, alternatively, in the form of trying to make sense of the situation through actions or beliefs by one or both of the parties. Most of the critical events showed that these negotiations would start with formal bargaining, move on to informal sensemaking, and then back to formal bargaining and so to informal sensemaking again. This process would continue until problems of understanding were sufficiently diminished to enable the parties to move to the stage of commitment.

\section{Commitments}

The most common route in moving from negotiations to commitments was through adjustments in the informal psychological contract after processes of sensemaking. However, other routes were also observed, such as adjustment of the formal legal contract after processes of formal bargaining. In some situations, the pattern would end once the parties entered the stage of commitments but, in most situations, within this stage a small cycle was observed as well. For example the adjustment of formal legal contractual terms to reflect adjusted aspects of the informal psychological contract. But adjustment of aspects of the informal psychological contract as a result of changed formal legal contractual terms did also occur.

The findings on 'Negotiations' and 'Commitments' support proposition D of Chapter 2 that formal and informal components of negotiations and commitments are complementary.

\section{Context}

In most of the observed events, contextual situations led to identifying differences in understanding, or even caused the development of problems of understanding. Especially role relationships seem to be an important cause for problems of understanding. The stereotypes of contractors and of principal as known from previous projects frame the parties at the table. Their expectations of current contract partners match experiences gained with contract partners holding the same role in previous projects. However, the critical events also showed how a contextual situation can help in finding a way to resolve differences in understanding. This finding supports proposition A of Chapter 2: inter- 
organisational projects are influenced by context variables such as risk, initial trust levels, role relationships, outcome expectations and environmental constraints.

\section{Mechanisms of the CD procedure}

The results of the Coen Tunnel project study show that the interaction between negotiations and commitments changes when problems of understanding arise or are resolved. Critical events in the Coen Tunnel project developed similar during procurement and during construction of the project. The major difference between the two is that during procurement negotiations often result in changes to the formal legal contract, whereas during construction negotiations more often result in changes in the informal psychological contract. This has probably to do with the fact that before contract closure it is relatively easy to make changes to the formal contract: changing the contract after contract closure might involve a change in the project scope, which would disturb the desired level playing field. Nevertheless, in the Coen Tunnel project several requests have been submitted to change the formal legal contract.

Both during procurement and during construction, the most common route for diminishing problems of understanding was by reaching commitment through processes of sensemaking. Sensemaking arises either from internal thinking processes (expectations, focusing on a few beliefs, justifications) or from external arguments or remarks that help to focus on a few beliefs. In those events where sensemaking was the last step before resolving problems of understanding, the parties had generally made sense through an external cause: that is either arguments or remarks made by the other party. The fact that this was the case during procurement could be attributed to the mechanism of having a dialogue in the $C D$ procedure. The fact that parties meet in person enables them to hold formal bargaining conversations which directly support the sensemaking process. Formal bargaining through writing, which happens in the more traditional procurement procedures, results in sensemaking being based on indirect interpretations of what the other party is bringing to the bargaining process.

Alongside the virtues of having a dialogue within the CD procedure, there is a mechanism which delivers an opposite effect. In most of the critical events described in this chapter, problems of understanding arose due to risk aversive actions by at least one of the parties involved. Whether it was due to the fear of not gaining the contract (due to competition); of a failed tender (due to transparency demands and maintaining a level playing field); or of becoming involved in new negotiations (due to uncertainty/complexity), risk aversion largely determined the actions of the parties. Mechanisms in the CD procedure that encourage risk averse activities might lead to the dialogue developing less promising than hoped for. 


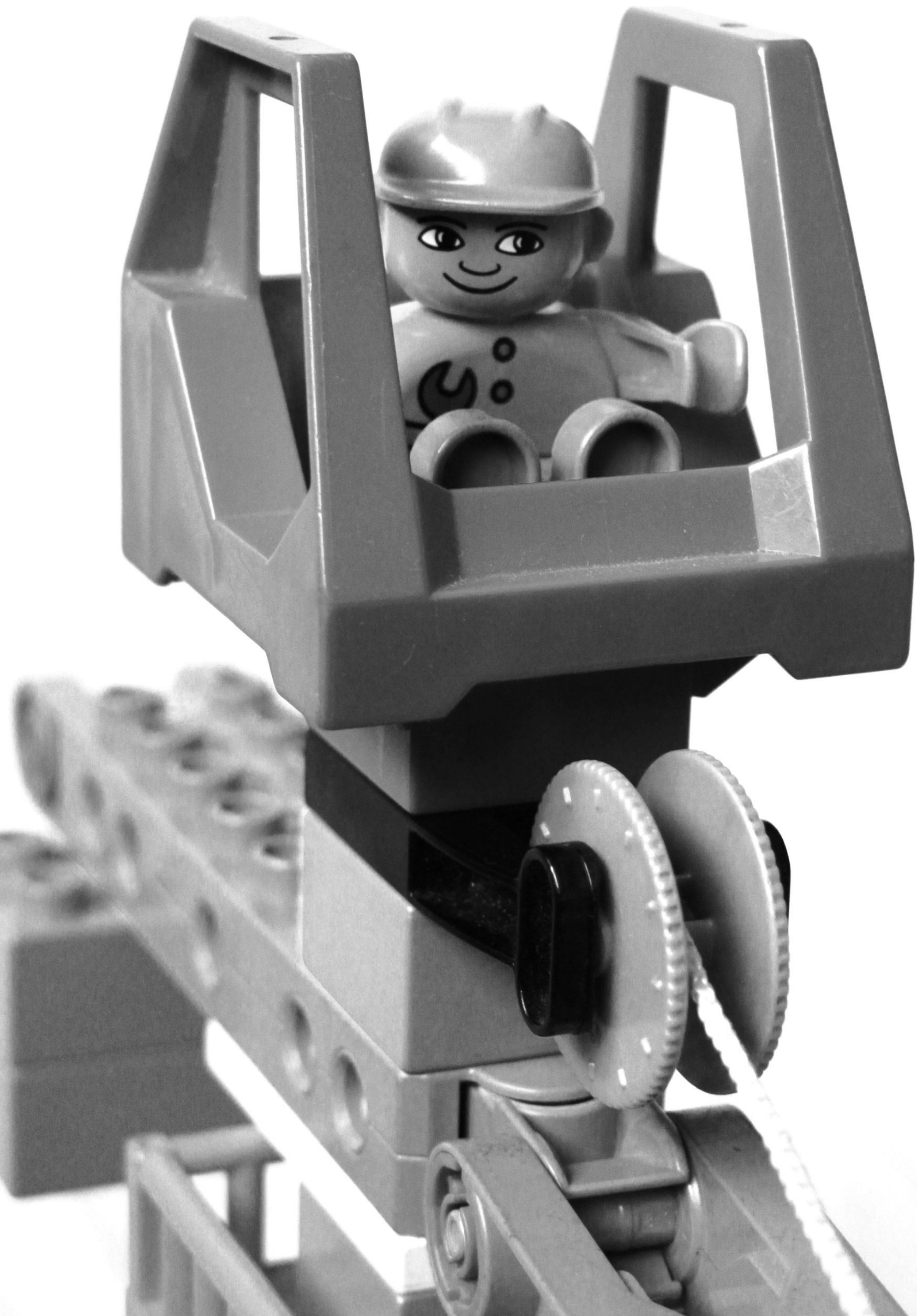




\section{Chapter 6. Conclusion: the CD procedure's impact on negotiations and commitments could be increased}

Part of this Chapter is published in:

Lenferink, S., \& Hoezen, M. (2011)

The interplay between public procuring authority and private competitors: experiences with the competitive dialogue.

In Wamelink, J.W.F, Geraerdts, R.P. \& Volker, L. (Eds) Proceedings of the CIB International Conference

Management and Innovation for a Sustainable Built Environment - MISBE2011, 20-23 June 2011, Amsterdam, The Netherlands. Amsterdam, The Netherlands: TUDelft

The combination of increased project complexity (Baccarini, 1996; Laufer et al., 1996; Alderman et al., 2005; Walker, 2007), changing government roles (Blanken, 2008) and the construction sector's poor professional functioning (Egan, 1998; National Audit Office, 2001) have changed both negotiations and commitments involved in construction projects. These developments are reflected in the design of the Competitive Dialogue procedure, which was introduced by the European Commission in 2004. The CD procedure is a procurement method that consists of several rounds of discussion between the principal and potential contractors, during which all aspects of the tender are open for discussion. The CD procedure aims at aligning the complex demands of principals with possible solutions that contractors have to offer (Hebly and Lorenzo van Rooij, 2006). It regulates the negotiation process during the procurement stage, thus expectedly affecting the commitment and possible renegotiations between principal and contractor during construction.

Academic analysis of the CD procedure's design (Arrowsmith, 2006; Raganelli \& Fidone, 2007; Ramsey, 2006) and early experiences with the CD procedure (Hoezen and Dorée, 2008; Floor and Kolkman, 2008) conclude that the actual design of the CD procedure could work against its objectives, causing ineffectiveness. The objective of the research described in this dissertation is to explain the influence of the CD procedure on the development of the inter-organisational project, based on gained insights in the interrelatedness of interorganisational negotiations and commitments during procurement and during construction. The central research question of this research is therefore how are inter-organisational negotiations and commitments interrelated in the context of procurement by the Competitive Dialogue procedure? 
The central research question contains three main questions. The first $-A)$ How are which components of negotiations and commitments playing a role in inter-organisational projects? - was answered by a literature study and resulted in a theoretical model to guide the research. The second main question $-B$ ) What is the influence of the $C D$ procedure on negotiations and commitments? - was answered by a descriptive survey identifying the $C D$ procedure's characteristics that are perceived to be of most influence to negotiations and commitments and by a comparative multiple-case study identifying how negotiations and commitments differ between CD-procured projects and projects that are traditionally procured. The third main question $-C$ ) how do negotiations and commitments develop over time in a CD-procured construction project - was answered by an in-depth single case-study analysing critical events during procurement and the first year of execution of the project. This section summarises the main conclusions in Section 6.1. The contribution of this study to both theory and practice is discussed, as well as its limitations, in Section 6.2. Section 6.3 concludes with suggestions for further research.

\subsection{Conclusion}

\section{A. Components and development of negotiations and commitments conform the FINCIP model}

Literature research (Chapter 2) indicates that negotiations and commitments are interrelated through the concept of understanding (Vlaar et al., 2006) and that mechanisms of formal and informal control are likely to be involved (Ring and Van de Ven, 1994). These models were combined with insights about the influence of context on both procurement and execution of a project from Ring and Van de Ven (2000). These three models were combined into the FINCIP model, depicting how formal and informal components of negotiations (formal bargaining and informal sensemaking) and commitments (the informal psychological contract and the formal legal contract) play a role in inter-organisational projects, both during procurement and during construction.

\section{Negotiations}

Formal bargaining is a process of interactive communication aimed at coming to an agreement in a situation where the parties involved have somewhat conflicting interests (Kamminga, 2008). By focusing attention, forcing articulation, deliberation and reflection, interacting, and reducing biases, judgement errors, incompleteness and inconsistency this process conditions the second part of negotiations: informal sensemaking.

Sensemaking is a social process during which members of an organisation interpret their environment in and through interactions with others, thus constructing observations that allow them to comprehend the world and to act collectively (Isabella, 1990; Sackmann, 1991; Sandelands \& Stablein, 1987; Starbuck \& Milliken, 1988; Weick \& Roberts, 1993). By arguments, expectations, justifications and focusing on a limited number of cues, understanding is created of the transaction, the context of the transaction and the value of it to the other party and to oneself. 
Shared understanding between the two parties are reflected in sustained structures, contexts, routines, expectations and perceptual frameworks. These form the basis for commitments.

\section{Commitments}

The informal psychological contract refers to a person's norms, values and routines (Nooteboom, 2002). As such, it is a highly flexible and undefined set of terms that are interpreted by the individuals involved. Through mutual understanding; norms; values; empathy; affection; routines; importance of the on-going relationship and of reputations, informal commitments become institutionalised, and regularly become reflected in the formal legal contract.

The formal legal contract refers to contract documents, formal procedures and monitoring policies (Nooteboom, 2002). Through determination of rights / power of decision, reward systems, monitoring and bonding, it governs the transaction. However, Vlaar et al. (2006) and Ring and Van de Ven (1994) point at the risk of making events more comprehensible and controllable than they really are. When the usage of the formal legal contract starts drifting from the intentions as expressed in the informal psychological contract, problems of understanding arise.

Problems of understanding refer to the uncertainty and ambiguity that parties in interorganisational relationships experience in (early stages of) collaboration, due to differences between the parties in terms of culture, experience, structure and industry (Vlaar et al., 2006). When discontinuities in structures, contexts, routines, expectations and perceptual frameworks like beliefs, norms, values and routines appear, problems of understanding may induce (re)negotiations.

Interrelatedness of negotiations and commitments

Inter-organisational projects encompass both negotiations and commitments, which develop within a complex context. As problems of understanding between the parties are identified or resolved, negotiations and commitments dynamically interact.

Both negotiations and commitments consist of a formal part (formal bargaining / formal legal contract) and an informal part (informal sensemaking / informal psychological contract). Within both the stages negotiations and commitments, small cycles of interaction between the formal and the informal part are observed. Formal bargaining and informal sensemaking are both meant to decrease problems linked to understanding. The formal legal contract and the informal psychological contract both reflect the understanding that has been reached. Adjustments in the formal part usually involve adjustments in the informal part as well, and vice versa.

The empirical data in the case studies (Chapters 4 and 5) confirm that negotiations and commitments in inter-organisational projects develop in line with the FINCIP model. The cases confirm the propositions that formed the starting point for empirical research into the practice of procuring inter-organisational projects by use of the CD procedure: 
Proposition A: inter-organisational projects are influenced by context variables including perceived risk, initial trust levels, role relationships, outcome expectations and environmental constraints.

Proposition B: by facilitating sensemaking processes in the negotiations during procurement, the $C D$ procedure prevents extensive renegotiations to be necessary in the execution stage of inter-organisational projects.

Proposition C: during all phases of a project, from initiation through to delivery, negotiations and commitments are substitutes for each other: the parties involved go back and forth between negotiations and commitments, depending on whether there is understanding or not.

Proposition D: formal and informal components of negotiations and commitments are complements of one another.

All cases (both the traditionally procured and the CD procured cases) developed according to what was described in the theoretical model (the FINCIP model) and formulated in the four propositions. The next two research questions further focus on the influence of the $C D$ procedure on the development of inter-organisational projects.

\section{B. The influence of the CD procedure on negotiations and commitments: mainly through sensemaking processes}

The first experiences of practitioners using the $C D$ procedure resulted in a list of 12 mechanisms that were perceived to be of influence to the effectiveness of the CD procedure (Chapter 3). Given the differences in development of negotiations and commitments between CD-procured projects and projects that were traditionally procured (Chapter 4 ), the conclusion is drawn that the CD procedure is of influence. This influence is identified as follows:

\section{Negotiations}

The formal bargaining process is influenced by CD procedural measures such as allowing dialogue conversations during the procurement process; protecting the contractors' interests; allowing flexibility in demand specifications; focusing on content rather than price; having at least three competitors making final bids; offering a design fee; and ensuring a level playing field is maintained. These measures all influence the next step in the cycle (sensemaking) by focusing the parties' attention; forcing articulation, deliberation, reflection and interaction; and reducing biases, judgement errors, incompleteness and inconsistencies. The results of the case studies indicate that these measures influence the perceived complexity to some extent, assist in task and risk formulation and allocation, and affect the degree in opportunistic behaviour and openness shown by the parties.

The informal sensemaking process is influenced not only by the results of the formal bargaining, but also by frames and cues already present in the minds of both parties involved in the procurement process. The dialogue within the CD procedure influences these frames and cues. When the construction phase starts, both contract partners could 
therefore have a clear picture of the project, of the contract and of each other such that, during renegotiations, sensemaking processes do not have to be based only on prejudices and biases, and can additionally call on cues which have developed during the procurement phase of the project. However, the results of the case studies indicate that given the strong competition, demands for transparency and maintaining a level playing field, and the risk aversion displayed by both the Agency and the candidates, the dialogue conversation which is realised in practice is not as open as that intended by the European Commission.

\section{Commitments}

When the informal sensemaking process does lead to shared understanding, this forms a basis for an informal psychological contract which contains shared norms, values and routines. Due to the dialogue, the informal contract develops alongside the formal contract during the procurement phase of a project. The likelihood that understandings about the formal legal contract are congruent between the parties increases with the introduction of the CD procedure. The case study results indicate that the possibility of having dialogue, protecting the candidates interests and keeping a level playing field all contribute to these informal contractual aspects. However, the opportunistic behaviour and limited openness, resulting from several other aspects of the procedure's design, hinder the forming of a sound informal contract.

The formal legal contract is the element most visibly influenced by the $C D$ procedure. The fact that candidates may suggest alternatives to what is proposed by the Agency could lead to more of a coproduction with which both parties agree. The case study results indicate, however, that risk aversion discourages principals from implementing suggested alternatives to those envisaged in the contract. The idea of a flexible formal contract has thus not got off the ground too successfully.

\section{Self-reinforcing cycles}

Empirical data of the multiple-case study added a notion to the theoretical FINCIP model. Sensemaking processes linked to problems of understanding served as catalysts for the development of the projects. When discontinuities between the formal legal contract and the parties' informal psychological contracts are resolved through positively assessed processes of sensemaking, future problems of understanding are more likely to be resolved smoothly as well. Thus, the formal legal contract and the parties' informal psychological contracts can be matched, preventing problems of understanding in the future. Within the CD procured KOSMOS cases in Chapter 4, however, negative cycles developed: early processes of sensemaking were negatively assessed, causing negatively assessed interaction patterns in the solving of later problems of understanding. This induced that the formal legal contract and the informal psychological contract grew apart, causing huge problems of understanding during construction, leading to even more renegotiations than in the traditionally procured KOSMOS cases.

The results of the multiple-case study (Chapter 4) indicate that the CD procedure influences negotiations and commitments both during procurement and during construction by starting processes of sensemaking during the procurement of a project. When these sensemaking 
processes develop in positive cycles, this would probably indeed diminish post contractual renegotiations, in line with proposition $B$. The results of the multiple-case study do not conflict with the propositions that inter-organisational projects are influenced by context variables (proposition A), or that negotiations and commitments substitute for one another (proposition C), whereas formal and informal components of negotiations and commitments are complementary (proposition D).

These findings are supported by the results of the single case study in Chapter 5, as well as by literature. Writers of key papers in relational governance have identified relationships as emerging, growing and dissolving over time. Relationship development is seen as an iterative and evolutionary learning process that develops over several stages (Boddy, Macbeth \& Wagner, 2000; Dwyer, Schurr \& Oh, 1987). Although differences exist in the stages identified (see Davis, 2005, pp. 47-48 for a detailed review), it is generally acknowledged that the early stages of relationships are crucial to the further development of a relationship (Boddy, Macbeth \& Wagner, 2000; Davis, 2005; Donaldson \& O'Toole, 2001; Kamminga, 2008; Vlaar, Van den Bosch \& Volberda, 2007). Relationships have been characterised as developing along self-reinforcing cycles (Ghoshal \& Moran, 1996), an aspect confirmed by research suggesting that positively assessed aspects such as mutuality, reciprocity, integrity, honesty and efforts to improve the exchange process in early stages of the relationship contribute to relationships developing positively (Larson, 1992; Tsui, Egan \& O’Reilly, 1992).

\section{Development of negotiations and commitments in a CD procured construction project: risk aversion hampers a dialogue}

With the 12 mechanisms and the perceived importance of sensemaking in mind, a closer look was taken into the development of negotiations and commitments in a CD procured project. This study (Chapter 5 ) has identified the influence of the CD procedure as follows.

The CD procedure directly affects the negotiations stage of inter-organisational projects during procurement, which is in turn affecting both the commitments and (re)negotiations during procurement and construction of the project. Thus, the CD procedure indirectly affects commitments and renegotiations as well. In theory, the CD procedure's main influence is on sensemaking processes. Proposition B was confirmed by this in-depth single case study: By facilitating sensemaking processes in the negotiations during procurement, the $C D$ procedure could prevent extensive renegotiations to be necessary in the execution stage of inter-organisational projects.

The findings of the in-depth single case study also support proposition C: during all phases of a project, from initiation through to delivery, the parties involved oscillate between negotiations and commitments depending on whether there is understanding or not. Further, the parties may be involved in negotiations for some aspects, but in commitments for other aspects of the project. Negotiations and commitments do not, however, coexist within a single aspect: the two act as substitutes.

Most of the critical events in the in-depth single case study showed that negotiations would start with formal bargaining, move on to informal sensemaking, and then back to formal bargaining and so to informal sensemaking again. This process would continue until 
problems of understanding were sufficiently diminished to enable the parties to move to the stage of commitment. The most common route in moving from negotiations to commitments was through adjustments in the informal psychological contract after processes of sensemaking. Other routes were also observed, such as adjustment of the formal legal contract after processes of formal bargaining. In some situations, the pattern would end once the parties entered the stage of commitments but, in most situations, within this stage a small cycle was observed as well. But adjustment of aspects of the informal psychological contract as a result of changed formal legal contractual terms did also occur. These findings support proposition D: formal and informal components of negotiations and commitments are complements to one another.

Yet, observations in the in-depth single case study have showed that the creation of a cooperative cycle of positively assessed sensemaking, necessary for stable, mutual informal contracts, was hindered by opportunistic behaviour and risk aversion of both parties involved in the process. This is illustrated perfectly in Critical Event 6 (Chapter 5), where the contractor-to-be (wrongly and more negative than the actual situation) fills in the blanks when the procuring agency out of risk aversion was not willing to answer questions with regard to the delay. These observations confirm proposition A: inter-organisational projects are influenced by context variables including perceived risk, initial trust levels, role relationships, outcome expectations and environmental constraints. When the parties to the dialogue refuse to open up towards each other, processes of sensemaking are mainly influenced by initial trust (stemming from similarity and/or prior transactions) and by role perceptions. These role perceptions seem to be an important cause for problems of understanding. Expectations of current contract partners match experiences gained with contract partners holding the same role in previous projects. Thus, the stereotypes of contractors and of principal as known from previous projects frame the parties at the table. Given that these perceptions are often not too positive, it is hard for dialogue partners to enter into cooperative cycles: role expectations are used to make sense of actions of the other party. Due to negative role expectations, actions that confirm these expectations are noticed and other actions are not, and sensemaking cycles rather start developing negatively than positively.

This explains why the CD procedure has led to less dialogue, stronger competition and less trust than envisaged by the European Commission. Although the level of innovation is in line with the intentions, participants in the research had the strong impression that greater innovation could be achieved. In general, the conclusion can be drawn that the $C D$ procedure is less effective than its potential. Effectiveness would probably increase when the dialogue would be used more to get the principal and the candidate to meet and openly discuss demands and possibilities, chances and risks. For this to happen, parties need to become aware of their expectations, to open up towards each other, become less averse to taking risks and behave less opportunistically than in the current situation. Besides understanding the working of the $C D$ procedure and the required actions to make it work, this asks for confidence: in the $C D$ procedure, and in each other. 


\subsection{Discussion}

Our research focus has been on explaining how inter-organisational negotiations and commitments develop in the context of procurement by the CD procedure. For this, we carried out a literature study, expert interviews, a multiple-case study and an in-depth longitudinal single case study, answering three main research questions. In this section, the contribution of this study to science and to practice is discussed, as well as its limitations.

\section{Scientific contribution}

The research conducted into the manner in which inter-organisational negotiations and commitments are interrelated in the context of procurement by the CD procedure makes several scientific contributions. The first contribution is the FINCIP model, provided in Chapter 2. This combination of insights from several studies concerning the interrelatedness of negotiations and commitments and applying these combined views on practice contributes to relational governance studies. The theoretical model provides insight in the interrelatedness of negotiations and commitments in inter-organisational projects, both during procurement and during execution of the project. The model is empirically tested and might especially help academics who intend to study bargaining processes in relation to contract structures. It points out that the key to successful contracts lies in dissolving / preventing problems of understanding.

This notion might help understanding discovered patterns in the relationship between precontractual negotiation characteristics on the final agreement (Ahola, Laitinen, Kujala \& Wikström, 2008; Cox \& Thompson, 1997; Elfving, Tommelein \& Ballard, 2005; Eriksson \& Laan, 2007; Love, Skitmore \& Earl, 1998), an how characteristics of the contract induce renegotiations during execution of the contract. Problems of understanding should therefore be given serious consideration when studying inter-organisational projects.

The second contribution concerns the interrelatedness of formal and informal components of negotiation and commitment. The FINCIP model contributes to the academic debate concerning the question whether formal and informal control are substitutes or complements to one another. Within the model the substitutes perspective (the institution of more formal aspects of control induce less reliance on informal control forms, and vice versa) (Adler, 2001; Bernheim \& Whinston, 1998; Bradach \& Eccles, 1989; Dyer \& Singh, 1998; Granovetter, 1985; Gulati, 1995; Larson, 1992; Macaulay, 1963; Uzzi, 1997) was combined with the complementary perspective (formal control and informal control co-exist alongside each other) (Baker, Gibbons \& Murphy, 1994; Blomqvist et al., 2005; Larson, 1992; Poppo \& Zenger, 2002). These two competing perspectives on the interrelatedness of formal and informal control have been aligned by broadening the scope from a focus on formal and informal commitments with the dimension of formal and informal negotiations. As Vlaar et al. (2006: p. 1619, citing Hill, 2001: p. 56) depict: "the words agreed upon" (commitments) are just as important to govern the project as "the process through which parties arrive at these words" (negotiations). The explicit distinction between negotiations and commitments in the FINCIP model qualifies the debate concerning the interrelatedness of formal and informal control by helping to align both the substitutes perspective (commitments 
substitute for negotiations until new problems of understanding arise) and the complementary perspective (formal and informal negotiations complement each other as do formal and informal commitments).

The third scientific contribution stems from Chapter 4 which provides insights into how negotiations and commitments develop under the influence of different procurement methods. This is important since academics are currently actively investigating the impact of procurement methods on all kinds of topics related to negotiations and commitments (Bresnen \& Marshall, 2000a; Cheung, Ng, Wong, \& Suen, 2003; Eriksson \& Westerberg, 2011; Kadefors, 2005; Pietroforte, 1997). It is generally acknowledged that the early stages of the relational governance process are crucial to the further development of a relationship (Boddy, Macbeth \& Wagner, 2000; Davis, 2005; Donaldson \& O'Toole, 2001; Kamminga, 2008; Vlaar, Van den Bosch \& Volberda, 2007). Relationships have been characterised as developing along self-reinforcing cycles (Ghoshal \& Moran, 1996), an aspect confirmed by research suggesting that positively assessed aspects such as mutuality, reciprocity, integrity, honesty and efforts to improve the exchange process in early stages of the relationship contribute to relationships developing positively (Larson, 1992; Tsui, Egan \& O’Reilly, 1992).

This research shows how the used procurement procedure (which is setting the rules and conditions for negotiations) influences the early stages of inter-organisational projects, thus determining to a large extent how the self-enforcing cycles start to develop. From the data it can be concluded that the existence or absence of dialogues between the principal and the contractors during procurement make that the formal legal contract and the informal psychological contract develop simultaneously or not. Shared understanding of the contract, combined with expectations about the extent to which this understanding is mutual, determines to a large extent the amount and gravity of problems of understanding during the construction stage of the project, as well as how these problems of understanding are handled by the parties involved.

\section{Practical contribution}

Besides the scientific contribution of this research, there are also two ways in which this research contributes to practice. Firstly, given that the development of negotiations and commitments was studied (in Chapters 4 and 5), greater insight has been gained into the practical implications of this development for inter-organisational relationships. The influence of certain actions on critical events has been mapped, thus giving insight into their effects on the development of the inter-organisational relationship. The research data show how negotiations develop in either positive or negative cycles, and how hard those cycles are to break. If managers of both the procuring authorities and the contractors are aware of these cycles and of the processes playing a role, especially in making sense of cues, they might be able to influence and use them to their mutual benefit. Not only do you help your dialogue partners in their sensemaking process by opening up to them (a sense giving process), you also help your own sensemaking processes since turning tacit knowledge into words decreases experienced complexity (Vlaar, Van den Bosch \& Volberda, 2006). When combined with awareness of existing prejudices and with the ability to empathise, this could help to create more mutual understanding. 
Secondly, the influence of the CD procedure to the development of the inter-organisational project is described. Given the lack of a structured, thorough evaluation of the CD procedure, this study adds to the practical knowledge on the effectiveness of the $C D$ procedure in terms of the goals set by the European Commission. The data show that the CD procedure is still less effective than anticipated by the European Commission. The large transaction costs; the lack of clarity about when the procedure may be used; the risk aversion and opportunistic behaviour of the parties involved; combined with their lack of openness resulted in less dialogue than intended, stronger competition, and less trust. It was only the level of innovation that met expectations.

Quick solutions for increasing the CD procedure's effectiveness seem unlikely: changing the $C D$ procedure itself is a lengthy process, and one could question whether changing the procedure or adding rules and guidelines would create the desired effect. Given that the procedure has been implemented literally in Dutch law, it seems inappropriate to offer implementation suggestions. In terms of the use of the CD procedure in practice, however, several suggestions can be made.

First, both parties at the dialogue table could start by looking at the opportunities and possibilities and lower their tendencies to averse risk. For example, one could start with more-functional specifications instead of prescribing every little detail, or by having "real" conversations instead of steering the dialogue on the basis of predetermined questions.

Second, opportunistic behaviour could be punished, and openness rewarded. As examples, past performance could be taken into account in the selection process, or cooperation made a selection criteria. These two measures are likely to lead to more dialogue, decrease opportunistic behaviour, enhance mutual trust and improve innovation.

Third, one could look for options to limit the dialogue to the complexity which was defined in advance. That is, if the project was defined as financially complex, one should not also discuss all the legal and technical aspects, unless these have a connection with the financial complexity. In so doing, one could decrease the transaction costs and thus open up the dialogue process to smaller contractors, creating stronger competition and enhancing innovation since candidates would be able to focus on what is to them the most interesting part of the project; and thus focus in the conversations on the more important aspects.

Furthermore, it is likely that as time goes by, the parties to competitive dialogues become familiar with the procedure, and gain confidence in how to act and what to expect from the other partner. This confidence is likely to induce more openness in the conversations, provided that experiences will be positive. The proposed Directive on public procurement (see $\operatorname{COM(2011)~} 896$ final), would probably help solving the lack of clarity over when the procedure may be used. In the concept text of the Directive, Article 24 foresees in more precise descriptions of situations in which procuring agencies are allowed to make use of the $C D$ procedure. This might help to increase the CD procedure's effect on solving complexity and dialogue. 


\section{Limitations of the study}

Although the validity and reliability of the results were kept in mind when designing the current study, each choice made imposed limitations on the study. The choices that had major impacts are discussed below.

A first limitation is that evaluation of some of the positive expectations of the CD procedure as described in Chapter 3, concerning project quality and time and costs overruns, was impossible. The projects that were included in the survey and in the single case study, were not finished within the research period; and predicted costs and schedules were not available for the projects in the multiple-case study. Expectations about the effect of the CD procedure on quality, and on time and cost overruns, could therefore not be compared with practice. Given the increased attention academics are currently paying to the effect of procurement method on a project's construction performance (see Eriksson and Westerberg, 2011 for a review), this would have been a valuable contribution.

There is another effect of including only early projects using the CD procedure. Inexperience with the procedure might cause some of the identified mechanisms to affect the development of negotiations and commitment stronger than compared to when parties would have gained confidence and routine with the procedure. For example: when procuring agencies prove to keep the level playing field in early projects, candidates in future projects might give more openness in earlier stages of the dialogue. Risk aversion might decrease, and 'real' conversations might be realised. The contextual effect of role relationships might change when parties gain experience with the procedure, since traditional expectations of role behaviour might be altered. Thus, processes of sensemaking are likely to develop differently.

A next limitation concerns the aspect of inter-contractor competition. The literature that was used to build the theoretical FINCIP model in Chapter 2 does not take account of relationships that develop under competition. The original models by Ring and Van de Ven $(1994,2000)$ and Vlaar et al. (2006) start from the assumption that there are two contracting parties, a principal and a contractor, who are willing to cooperate. The fact that the public procurement process involves at least two, and usually more, competing contractors for the public principal might have an influence. In the current model, that was derived from three earlier models, this aspect of competition is taken into account as a context variable. The research showed that this variable does influence the behaviour of contracting parties when it comes to openness and risk perception. It is not unreasonable to expect competition directly affecting the sensemaking and bargaining processes. Although the design of the FINCIP model stood up to testing with five publicly-procured cases, it would be a step too far to claim that it also holds for private procurements where competition is not a factor. Since the chosen research design neither demonstrated nor denied the influence of candidate competition on sensemaking and bargaining processes, we cannot rule out the possibility that this model might not be as generally applicable as suggested: outside public procurement circles the processes might turn out differently. 
With regard to generalising the model, all the cases included in the research are Dutch public works and water management projects, and all procured by one agency of the central government. One can therefore question if the model would hold for projects in other countries and, for example, under different cultural and legal circumstances. Further, given the limited scope within an already limited sector of building and development projects, the development of formal and informal negotiations and commitments might very well differ in other parts of this sector, not to mention in projects outside the construction industry. Moreover, the Dutch Highways and Waterways Agency is a public principal which procures large projects on a regular basis. Local governments, which are less experienced in procuring such projects, might face different issues, which could also influence the development of negotiations and commitments. Furthermore, with regard to procurement experience, the fact that all the projects involved in this study were early examples of CD-procured projects means we cannot rule out the possibility that the inexperience of the parties involved might have affected the development of formal and informal negotiations and commitments.

Another observation is that the model proposed in Chapter 2 concerns only the relationship between the principal and its contractor. The inclusion of other relevant organisations, such as subcontractors and stakeholders, might have highlighted additional issues which are important in the development of formal and informal negotiations and commitments in CDprocured construction projects.

A final concern with the model relates to the fact that we have tested the proposed model in the Coen Tunnel case and, to a lesser extent, in the KOSMOS projects through the use of interviews. We recognise that the relationships that developed are now better understood, in accordance with the propositions we formulated in Chapter 2, and the supplementary finding of their development through virtuous or viscous cycles. However, since we asked respondents to reflect on negotiations and commitments, and recall critical events, recollection and memory imperfections may have introduced a bias into this procedure (for example, sensemaking processes such as commitment and manipulation may lead respondents to retrospectively explain actions by aligning them with their beliefs). Therefore, although the use of data source triangulation should have decreased the likelihood of including incorrect recollections, the use of case study observations would have been a useful complement and added to the level of understanding reached through the interviews.

\subsection{Notes for further research}

Following on from the limitations outlined above, in this subsection we formulate suggestions for further research.

An initial research direction could be to research the relationships in the FINCIP model by use of large-scale surveys. The qualitative data in this dissertation give a solid indication of the robustness of the model, but a quantitative study would be a proper manner of confirming this. Quantitative studies are also suitable for an examination of the CD procedure's effect on criteria related to success in project performance, such as cost, time and quality, and also on environmental impact. Previous studies have shown that project performance is influenced by aspects of the procurement procedure design. Such aspects 
include the level of integration between principal and contractors in the design stage; the number of contractors that are invited to participate in the tendering process; the extent that the focus is on soft parameters in the bid evaluation; the extent to which both the principal and the contractors are jointly involved in subcontractor selection and integration; the type of payment; the usage of collaborative tools; and the evaluation of performance (Eriksson and Westerberg, 2011). Given that the original expectations in these areas were high, and that the CD procedure could influence a large number of the aspects mentioned, it seems worthwhile studying the effects of the CD procedure on project performance.

Secondly, it might be worthwhile conducting another single case-study in a more recently procured project. Using a project that is procured by a team with CD procedure experience, ideally with experienced contractor tender teams as well, could provide insight in the lasting mechanisms of the CD procedure. The mechanisms, identified in Chapter 3 of this dissertation, are derived from early projects, with inexperienced teams at both sides of the dialogue table. The occurrence and effect of these mechanisms are likely to be different in projects that are more recently procured. Combined with the changes, expected from the proposed Directive on public procurement (see COM(2011) 896 final), the effectiveness of the $C D$ procedure in recent projects expectedly will improve compared to the early projects that are included in this dissertation.

A third suggested direction is to study the effect of candidate competition on the appropriateness of the FINCIP model. In all the projects studied, the competitive element of the procedure influenced the negotiations through openness and risk aversion of the parties involved. However, a direct influence of competition on formal bargaining and informal sensemaking is likely as well. Given that we did not ask for such an effect, and given that all cases contained competing candidates, we cannot be sure whether the influence of this aspect is limited to openness and risk aversion or if it also, for example, influences the relationship between formal bargaining and informal sensemaking. This is especially important when one would like to generalise the model to include non-governmental projects. For example, principals in industrial organisations do not have to include competing candidates in their contracting processes and, because of this, negotiations and commitments may develop differently than is the case with in public projects, where procurement is involved.

A fourth option for future research would be to examine formal and informal negotiations and commitments development in projects procured by other agencies than the central government which was involved here (Rijkswaterstaat). Variation could for example be sought by investigating other countries; other areas of building or development projects, or even projects from outside construction; projects procured by principals with less experience than is typical of the procuring agency of a central government; or projects in which both the principal and the contractors are more experienced with the procurement procedure. There are indications that such factors do influence the effectiveness of the $C D$ procedure (for example, comparisons involving several European countries show differences in its use and effect (Burnett, 2009)). The CD procedure used here differed somewhat from the procedure that is used in the public utility industry from whence it was acquired, and early local governmental experiences with the $C D$ procedure suggested more promising 
effects than were found in these case studies (De Vos, 2010). Further, more recent projects procured by the Dutch Highways and Waterways Agency using this procedure show different effects than we observed (GWW-nieuwsbrief Rijkswaterstaat, 2010). If these changes in the application do influence the effectiveness of the CD procedure, this might be due to changes in the development of formal and informal negotiations and commitments, and this would have implications for the generalisation of the model.

Furthermore, further research could usefully study how third parties such as subcontractors and stakeholders influence the development of negotiations and commitments between a principal and its contractor. Such a study might result in including third parties as a contextual influence in the model, or even in additional aspects being added to the model. In projects that are procured by the Dutch Rijksgebouwendienst for example, are the specifications for a building composed by several user groups. This contributes to unique dynamics during the dialogue, when these user groups jointly have to present and explain 1 problem specification to the candidates.

Finally, an interesting option is to compare the development of negotiations and commitment between projects using several procurement methods and procedures that aim for comparable objectives as the CD procedure. For example Best Value Procurement (BVP), that was referred to in Chapter 1: an award method to contract the contractor with the best expertise to complete the project (Kashiwagi, 2004). Both the procurement procedure Competitive Dialogue and the award method Best Value Procurement aim for decreasing post-contractual renegotiations of the contract, yet the approaches differ. Whereas the CD procedure is aimed for receiving the best solution to the procuring agency's problem, the aim for BVP is to receive the contractor with most expertise. During the CD procedure, the complexity of the project is to be reduced, whereas BVP aims for gaining confidence that the contracted contractor has the skills to handle the complexity of the project. Early evaluations of projects that are awarded by use of BVP (Vulperhorst, 2012), show similar conclusions as this research, though: there is much to gain in investing in empathy and openness, and in less risk aversion (reflected in the need for more abstract specifications, and less worries about the level playing field). The transaction costs of BVP, on the other hand, seem lower. Comparison in terms of quality, time and costs, of projects using the CD procedure and projects that use BVP, might give more insight in the effect of the occurring mechanisms. 

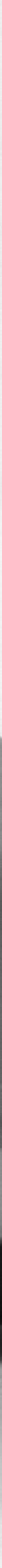


\section{References}

A5-0378/2001: ***I REPORT on the proposal for a directive of the European Parliament and of the Council on the coordination of procedures for the award of public supply contracts, public service contracts and public works contracts (By the Committee on Legal Affairs and the Internal Market of the European Parliament). Brussels, 29 October 2001.

Adler, P.S. (2001). Market, Hierarchy, and Trust: The Knowledge Economy and the Future of Capitalism. Organization Science, 12(2), 215-234.

Ahola, T., Laitinen, E., Kujala, J., \& Wikström, K. (2008). Purchasing strategies and value creation in industrial turnkey projects. International Journal of Project Management, 26(1), 87-94.

Alderman, N., Ivory, C., McLoughlin, I., \& Vaughan, R. (2005). Sense-making as a process within complex service-led projects. International Journal of Project Management, 23(5), 380-385.

Allport, G. W. (1985). The historical background of social psychology. In: Lindzey, G. \& Aronson E. (eds.), The handbook of social psychology. New York: McGraw Hill.

Argyris, C. (1960). Understanding Organizational Behaviour. London: Tavistock Publications.

Arrowsmith, S. (2006). Implementation of the new EC procurement directives and the Alcatel ruling in England and Wales and Northern Ireland: A review of the new legislation and guidance. Public Procurement Law Review, 3, 86-136.

Arrowsmith, S. (2009). The Law of Public and Utilities Procurement. London: Sweet \& Maxwell.

Arrowsmith, S., Linarelli, J., \& Wallace, D. (2000). Regulating Public Procurement: National and International Perspectives. London: Kluwer Law International.

Axelrod, R. (1984). The evolution of cooperation. New York: Basic Books.

Baccarini, D. (1996). The concept of project complexity - a review. International Journal of Project Management, 14(4), 201-204.

Bajari, P. and Tadelis, S. (2001). Incentives versus transaction costs: a theory of procurement contracts, RAND Journal of Economics, 32(3), 387-407.

Bajari, P., McMillan, R., \& Tadelis, S. (2002). Auction versus Negotiations in Procurement: An Empirical Analysis. The Journal of Law, Economics, \& Organization, 25(2), 372-399.

Baker, G., Gibbons, R. \& Murphy, K.J. (1994). Subjective Performance Measures in Optimal Incentive Contracts. Quarterly Journal of Economics, CIX: 1125-1156.

Berger, P. L. \& Luckmann, T. (1966). The Social Construction of Reality: A Treatise in the Sociology of Knowledge. Garden City, New York: Anchor Books.

Bernheim, B.D. \& Whinston, M.D. (1998). Exclusive Dealing. Journal of Political Economy, 106(1): 64-103.

Beuter, R. (2005). European Public Procurement Reform: Main Innovations in the Public Sector Directive - A Preliminary Assessment. EIPASCOPE, 2005(3), 5-11.

Bijlsma-Frankema, K., \& Costa, A.C. (2005). Understanding the Trust-Control Nexus. International Sociology, 20(3), 259-282.

Black, C., Akintoye, A. \& Fitzgerald, E. (2000). An analysis of success factors and benefits of partnering in construction. International Journal of Project Management, 18(6), 432-434.

Blanken, A. (2006). The Future of Public-Private Partnerships. In M. Bult-Spiering and G. Dewulf (Eds.), Strategic issues in PPP: an international perspective (176-202). Oxford: Blackwell Publishing Ltd.

Blanken, A. (2008). Flexibility against efficiency? - An international study on value for money in hospital concessions. (Doctoral dissertation). Retrieved from University of Twente Publications (58849).

Blumer, H. (1969). Symbolic interactionism: Perspective and method. Englewood Cliffs, NJ: Prentice Hall.

Blomqvist, K., Hurmellina, P. \& Seppänen, R. (2005). Playing the collaboration game right: Balancing trust and contracting. Technovation, 25(5), 497-504.

Boddy, D., Macbeth, D. \& Wagner, B. (2000). Implementing Collaboration between Organisations: An Empirical Study of Supply Chain Partnering. Journal of Management studies, 37(7), 1003-1017. 
Bradach, J.L. \& Eccles, R.G. (1989). Price, Authority, and Trust: From Ideal Types to Plural Forms. Annual Review of Sociology, 15: 97-118.

Bresnen, M. (2007). Deconstructing partnering in project-based organisation: Seven pillars, seven paradoxes and seven deadly sins. International Journal of Project Management, 25(4): 365-374.

Bresnen, M. and Marshall, N. (2000a). Motivation, commitment and the use of incentives in partnerships and alliances. Construction Management and Economics, 18(5), 578-598.

Bresnen, M. and Marshall, N. (2000b). Partnering in construction: a critical review of issues, problems and dilemmas. Construction Management and Economics, 18(2), 229-237.

Bruner, J. (1991). Acts of meaning. Cambridge, MA: Harvard University Press.

Buckley, P. \& Casson, M. (1988). The theory of cooperation in international businesses. In: Cooperative Strategies in International Business, Contractor, F., Lorange, P. (eds). Lexington Books: Toronto.

Bult-Spiering, M., \& Dewulf, G. (2006). Strategic issues in PPP: an international perspective. Oxford: Blackwell Publishing Ltd.

Burnett, M. (2009). Using Competitive Dialogue in EU public procurement - early trends and future developments. EIPAScope, December 2009.

Carifio, J. \& Perla, R. (2007). Ten Common Misunderstandings, Misconceptions, Persistent Myths and Urban Legends about Likert Scales and Likert Response Formats and their Antidotes. Journal of Social Sciences, 3(3), 106-116.

CC/2005/04_rev 1: Explanatory Note-Competitive Dialogue-Classic Directive (By the Directorate General Internal Market and Services: Public Procurement Policy). Brussels, 5 October 2005.

CES0515/2001: OPINION of the Economic and Social Committee on the Proposal for a Directive of the European Parliament and of the Council on the coordination of procedures for the award of public supply contracts, public service contracts and public works contracts. OJ C 193, 10.07.2011, p. 00070015.

Cheung, S., Ng, T., Wong, S.-P., \& Suen, H. (2003). Behavioral aspects in construction partnering. International Journal of Project Management, 21(5), 333-343.

Coase, R. (1937). The Nature of the Firm. Economica N.S. 4 (1937). Reprinted in Stigler, G.J. and Boulding, K.E. (eds.) (1952). Readings in Price Theory. Homewood, Ill.: Irwin.

$\operatorname{COM(2000)~275:~Proposal~for~a~Directive~of~the~European~Parliament~and~of~the~Council~on~the~Coordination~of~}$ Procedures for the Award of Public Supply Contracts, Public Service Contracts and Public Works Contracts. OJ C 29E , 30.1.2001, p. 11-111.

COM(2011)896 final: Proposal for a DIRECTIVE OF THE EUROPEAN PARLIAMENT AND OF THE COUNCIL on public procurement. Brussels, 20.12.2011.

COM(96) 583 final: Public Procurement in the European Union: Exploring the Way Forward. Green Paper. Brussels, 27.11.1996.

COM(98) 143 final: Public Procurement in the European Union - Communication from the Commission. Follow up to the Green Paper. Brussels, 11.03.1998.

Council Directive 92/50/EEC of 18 June 1992 relating to the coordination of procedures for the award of public service contracts. OJ L 209, 24.7.1992, p. 1-24.

Council Directive 93/36/EEC of 14 June 1993 coordinating procedures for the award of public supply contracts. OJ L 199, 9.8.1993, p. 1-53.

Council Directive 93/37/EEC of 14 June 1993 concerning the coordination of procedures for the award of public works contracts. OJ L 199, 9.8.1993, p. 54-83.

Cox, A., \& Thompson, I. (1997). Fit for purpose contractual relations: determining a theoretical framework for construction projects. European Journal of Purchasing \& Supply Management, 3(3), 127-135.

Das, T.K. \& Teng, S.B. (2001). Relational risk and its personal correlates in strategic alliances. Journal of business and psychology, 15(3): 449-465.

Davis, P.R. (2005). The Application of Relationship Marketing to Construction. Melbourne: MIT. 
Davis, R. (1999). Relationship marketing in the construction industry. AACE InternationalTransactions PM 11.111.6.

De Vos, A. (2010). Rondje praten voor beste deal. Binnenlands Bestuur, 27 augustus 2010: 32-35.

Dhonte, P. (1997). Conditionality as an Instrument of Borrower Credibility. IMF Paper on Policy Analysis and Assessment PPA/97/2. Washington: International Monetary Fund.

Directive 2004/18/EC of the European Parliament and of the Council of 31 March 2004 on the coordination of procedures for the award of public works contracts, public supply contracts and public service contracts. Official Journal of the European Communities L 134, 30.4.2004.

Donaldson, B. \& O'Toole, T. (2001). Strategic Market Relationships: From Strategy to Implementation. Sussex: J. Wiley.

Dorée, A.G. (2001). Dobberen tussen concurrentie en co-development: de problematiek van samenwerking in de bouw. (Inaugural lecture). Retrieved from University of Twente Publications (59648).

Douma, S. \& Schreuder, H. (2008). Economic Approaches to Organizations (4 ${ }^{\text {th }}$ edition). Harlow: Prentice Hall.

Dunahee, M.H. \& Wangler, L.A. (1974). The psychological contract: A conceptual structure for management/employee relations. Personnel Journal, 53(7), 518-526.

Dwyer, F. R., Schurr, P. H. \& Oh, S. (1987). Developing Buyer-Seller Relationships. Journal of Marketing, 51(April), 11-27.

Dyer, J.H. and Singh,H. (1998). The Relational View: Cooperative Strategy and Sources of Interorganizational Competitive Advantage. Academy of Management Review, 23(4), 660-679.

Egan, J. (1998). Rethinking Construction. HMSO, London.

Eisenhardt, K.M. (1985). Control: organizational and economic approaches. Management Science, 31(2), $134-$ 149.

Elfving, J., Tommelein, I., \& Ballard, G. (2005). Consequences of competitive bidding in project-based production. Journal of Purchasing \& Supply Management, 11(4), 173-181.

Emmerson, Sir H. (1962). Survey of Problems Before the Construction Industries: Report prepared for the Minister of Works. HMSO, London.

Eriksson, P.E., \& Laan, A. (2007). Procurement effects on trust and control in client-contractor relationships. Engineering, Construction and Architectural Management, 14(4), 387-399.

Eriksson, P.E., \& Westerberg, M. (2011). Effects of cooperative procurement procedures on construction project performance: A conceptual framework. International Journal of Project Management, 29(1), 197-208.

Essers, M.J.J.M. (2006). Aanbestedingsrecht voor overheden. 's Gravenhage: Elsevier Overheid.

European Union (1997). Consolidated Treaties - Treaty on European Union - Treaty establishing the European Community. Office for Official Publications of the European Communities, Luxembourg.

Floor, E. \& Kolkman, S. (2008). Enhancing the interaction between contracting authorities and bidders concerning the application of the competitive dialogue in the Netherlands. In IPPC, Enhancing best practices in public procurement: proceedings of the $3^{\text {rd }}$ international public procurement conference, 2830 August 2008, Amsterdam, The Netherlands (pp 167-474). Amsterdam: IPPC.

Ford, D. (1998). Managing Business Relationships. Chichester / New York: J. Wiley.

Ford, D., Hakansson, H. \& Johanson, J. (1985). How Do Companies Interact? Industrial Marketing and Purchasing, 1(1), 26-40.

Ghoshal, S., \& Moran, P. (1996). Bad for practice: A critique of the transaction cost theory. Academy of Management Review, 21(1), 13-47.

Granovetter, M. (1985). Economic Action and Social Structure: The Problem of Embeddedness, American Journal of Sociology, 91(3), 481-510.

Gulati, R. (1995). Does familiarity breed trust? The implications of repeated ties for contractual choice in alliances. Academy of Management Journal, 38(1), 85-112. 
GWW-nieuwsbrief Rijkswaterstaat (2010). MaVa-projectteam content met aanbestedingsresultaat. PPS Post 8, 28 October 2010.

Hattrup, K., \& Jackson, S. E. (1996). Learning about individual differences by taking situations seriously. In K. R. Murphy (Ed.), Individual differences and behavior in organizations (pp 507-547). San Francisco: JosseyBass.

Hebly, J.M., \& Lorenzo van Rooij, N. (2006). European Public Procurement: Legislative History of the 'Classic' Directive 2004/18/EC. Alphen aan den Rijn: Kluwer Law International.

Heijboer, G., \& Telgen, J. (2002). Choosing the open or restricted procedure: a big deal or a big deal? Journal of Public Procurement, 2(2), 187-215.

Herriot, P. \& Pemberton, C. (1995). New deals: The Revolution in Managerial Careers. Chichester: John Wiley \& Sons.

Hoezen, M.E.L. \& Dorée, A.G. (2008). First Dutch competitive dialogue projects: a procurement route caught between competition and collaboration. In A. Dainty (Ed.), Proceedings $24^{\text {th }}$ ARCOM conference, 1-3 September 2008, Cardiff, UK (pp.535-543). Reading, UK: ARCOM.

Hoezen, M. E. L., Rutten, J. van, Voordijk, J. T. \& Dewulf, G. P. M. R. (2010). Towards better customized serviceled contracts through the competitive dialogue procedure. Construction management and economics, 28(11), 1177-1186.

Hughes, W., Hillebrandt, P., Greenwood, D. \& Kwawu, W. (2006). Procurement in the Construction Industry. Oxon: Taylor and Francis.

Huque, A. (2005). Contracting Out and Trust in the Public Sector: Cases of Management from Hong Kong. Public Organization Review, 5(1), 69-84.

Isabella, L. A. (1990). Evolving interpretations as a change unfolds: How managers construe key organizational events. Academy of Management Journal, 33(1), 7-41.

Jansen, C.E.C. (2001). Totstandkoming en inhoud van design \& construct-contracten voor complexe infrastructurele projecten (Publikatie van de Vereniging voor Bouwrecht Nr. 29). Deventer: Kluwer.

Johns, G. (2006). The essential impact of context on organizational behavior. Academy of Management Review, $31(2), 386-408$.

Kadefors, A. \& Laan, A. (2010). Trust production in construction: a multilevel approach. In: Atkin, B. and Borgbrant, J. (eds.). Performance Improvement in Construction Management (pp 128-137). London: Spon.

Kadefors, A. (2005). Fairness in interorganizational project relations: norms and strategies. Construction Management and Economics, 23(8), 871-878.

Kamminga, Y.P. (2008). Towards effective Governance Structures for Contractual Relations; Recommendations from Social Psychology, Economics and Law for Improving Project Performance in Infrastructure Projects. Tilburg: Tilburg University.

Kaplan, S. \& Beinhocker, E.D. (2003). The real value of strategic planning. MIT Sloan Management Review, 44, 71-76.

Kashiwagi, D.T. (2004). Best Value Procurement. Arizona State University, College of Engineering and Applied Sciences, Performance Based Studies Research Group.

Kidder, L.H., and Judd, C.M. (1986). Research Methods in Social Relations. New York: Holt, Rinehart and Winston.

Klein Woolthuis, R., Hillebrand, B., \& Nooteboom, B. (2005). Trust, contract and relationship development. Organization studies, 26(6), 813-840.

Knill, C., \& Lenschow, A. (2005). Compliance,Competition and Communication: Different Approaches of European Governance and their Impact on National Institutions. Journal of Common Market Studies, 43(3), 583-606. 
Kooiman, A.G. (2008). Evaluatie aanbesteding Tweede Coentunnel fase concurrentiegerichte dialoog (van uitvraag tot definitieve inschrijving): Geleerde lessen voor de standaard basisovereenkomst, de Model Leidraad voor DBFM-contracten en het te voeren aanbestedingsproces. Rotterdam: Horvat en Partners.

Kotabe, M., Martin, X., \& Domoto, H. (2003). Gaining from vertical partnerships: Knowledge transfer, relationship duration, and supplier performance improvement in the US and Japanese automotive industries. Strategic Management Journal, 24(2), 293-316.

Kotter, J.P. (1973). The psychological contract: Managing the joining up process. California Management Review, 15(3), 91-99.

Laan, A.T. (2009). Building trust : the case of the construction industry (Doctoral dissertation). Retrieved from University of Twente Publications (60348).

Larson, A. (1992). Network dyads in entrepreneurial settings: A study of the governance of exchange relationships. Administrative Science Quarterly, 37(1), 76-104.

Latham, M. (1994). Constructing the Team: Final Report of the Government / Industry Review of Procurement and Contractual Arrangements in the UK Construction Industry. HMSO, London.

Laufer, A., Denker, G.R., \& Shanhar, A.J. (1996), Simultaneous management: the key to excellence in capital projects. International Journal of Project Management, 14(4): pp. 189-199.

Levine, R., Rodrigues A. \& Zelezny, L. (eds.) (2008). Journeys in Social Psychology: Looking Back to Inspire the Future. New York: Psychology Press.

Levinson, H., Price, C. R., Munden, K. J., Mandl, H. J. \& Solley, C. M. (1962). Men, Management and Mental Health. Cambridge: Harvard University Press.

Levitt, R.E., Henisz, W., Scott, W.R. \& Settel,D. (2010). Governance Challenges of Infrastructure Delivery: The Case for Socio-Economic Governance Approaches. In J. Ruwanpura, Y. Mohamed \& S. Lee. (eds.), Construction Research Congress 2010: Innovation for Reshaping Construction Practice. Proceedings of the 2010 Construction Research Congress. Reston, Virginia: American Society of Civil Engineers.

Lewicki, R.J., Barry B. \& Saunders, D.M. (2007). Essentials of Negotiation. Fourth Edition; McGraw-Hill/Irwin, New York.

Linder, S. (1999). Coming to Terms with the Public-Private Partnership. A Grammar of Multiple Meanings. The American Behavioral Scientist. 43(1), 35-51.

Love, P., Skitmore, M., \& Earl, G. (1998). Selecting a suitable procurement method for a building project. Construction Management and Economics, 16(2), 221-233.

Macaulay, S. (1963). Non-contractual relations in business: A preliminary study. American Sociological Review, 28(1), 55-67.

Macneil, I.R. (1978). Contracts: Adjustments of Long-Term Economic Relationship under Classical, Neoclassical, and Relational Contract Law. Northwestern University Law Review, 72(6), 854-906.

Maitlis, S. (2005). The social processes of organizational sensemaking. Academy of Management Journal, 48(1), 21-49.

McLean Parks, J., Kidder, D.L., \& Gallagher, D.G. (1998). Fitting square pegs into round holes: Mapping the domain of contingent work arrangements onto the psychological contract. Journal of Organizational Behavior, 19(1), 697-730.

Miles, M.B. and Huberman, A.M. (1994). Qualitative data analysis ( $2^{\text {nd }}$ edition). Thousand Oaks: Sage.

Mills, J.H. (2003). Making sense of organizational change. London: Routledge.

Morgan, G. (1986). Images of Organization. Beverly Hills, California: Sage.

Mousset, P. and Vis, C. (2008). The KOSMOS programme; stimulation of innovations with the right procurement strategy. Paper presented at the Third International Conference of the Cooperative Research Centre (CRC) for Construction Innovation - Clients Driving Innovation: Benefiting from Innovation, 12-14 March 2008, Gold Coast, Australia.

Mowday, R. T., \& Sutton, R. I. (1993). Organizational behavior: Linking individuals and groups to organizational contexts. Annual Review of Psychology, 44(1), 195-229. 
National Audit Office (2001). Modernising construction. National Audit Office, London. National Audit Office (2007). Improving the PFI process. National Audit Office, London.

Neale, M. A. \& Northcraft, G. B. (1991). Behavioral negotiation theory: A framework for conceptualizing dyadic bargaining. In L. Cummings. \& B. Straw (eds.), Research in Organizational Behavior, 13. Connecticut: JAI Press.

NEDO (1975). The public client and the construction industry (the Wood Report). London: Building and Civil Engineering Economic Development Committees, National Economic Development Office, HMSO.

Nooteboom, B. (1994). Innovation and Diffusion in Small Business: Theory and Empirical Evidence. Small Business Economics, 6(5), 327-347.

Nooteboom, B. (1996). Trust, opportunism and governance: a process and control model. Organization Studies, 17(6), 985-1010.

Nooteboom, B., (2002). Trust: forms, foundations, functions, failures and figures. Cheltenham UK: Edward Elgar.

Nooteboom, B. (2006), Forms, sources and processes of trust, In: Bachmann, R. and A. Zaheer (eds.), Handbook of Trust Research, Cheltenham: Edward Elgar, pp247-264.

Pascale, S. \& Sanders, S. (1997). Supplier Selection and Partnering Alignment: A Prerequisite for Project Management Success for the Year 2000. In Project Management Institute (Ed.), The 28th Annual Project Management Institute 1997 Seminars and Symposium (pp. 19-26). Project Management Institute.

PEC (2002). De bouw uit de schaduw: Eindrapport Parlementaire Enquêtecommissie Bouwnijverheid, Kamerstukken II, 2002-2003, 28 244, 5-6. 's-Gravenhage: Sdu Uitgevers.

Perloff, R. M. (2008). The dynamics of persuasion. New York: Lawrence Erlbaum Associates.

Pietroforte, R. (1997). Communication and governance in the building process. Construction Management and Economics, 15(1), 71-82.

Pijnacker Hordijk E.H., Van der Bend, G.W., \& Van Nouhuys, J.F. (2009). Aanbestedingsrecht: Handboek van het Europese en het Nederlandse aanbestedingsrecht. 's-Gravenhage: SDU Juridisch.

Poole, M.S., Van de Ven, A.H., Dooley, K. \& Holmes, M. (2000). Organizational Change and Innovation Processes: Theory and Methods for Research. New York: Oxford University Press.

Poppo, L., \& Zenger, T. (2002). Do formal contracts and relational governance function as substitutes or complements? Strategic Management Journal, 23(8), 707-725.

Portwood, J.D. \& Miller, E.L. (1976). Evaluating the psychological contract: its implications for employee satisfaction and work behavior. Proceedings of the Annual Academy of Management, 109-113.

PSIBouw \& Regieraad Bouw (2007). Bouwen is teamwork!:Praktijkgids voor succesvol samenwerken in de bouw. PSIBouw and Regieraad Bouw: Gouda. (E.C. Boudewijn \& R.P.V. Broekhuizen).

Raganelli B., \& Fidone G. (2007). Public Private Partnerships and Public Works: Reducing Moral Hazard in a Competitive Market. In: G. Sobbrio (ed.), Searching for New Models in the Economic Analysis of Law, International Workshop, 25-27 March 2007, University of Messina, CUSEP (Centro Universitario Studi di Economia Pubblica).

Rahman, M., and Kumaraswamy, M. (2002). Joint risk management through transactionally efficient relational contracting. Construction Management and Economics, 20(1), 45-54.

Ramsey, L. (2006). The new public procurement directives: A partial solution to the problems of procurement compliance. European Public Law, 12(2), 275-94.

Reniers, M. (2007). Ontevredenheid in de Nederlandse bouw: Een onderzoek naar het sociale interactieproces tussen partijen (Doctoral dissertation). Retrieved from TU Delft Institutional Repository.

Ring, P.S., \& Rands, G.P. (1989). Sensemaking, understanding, and committing in Research on the management of innovation: The Minnesota Studies. A.H. Van de Ven, H. Angle, and M.S. Poole (eds), 337-366. New York: Ballinger/Harper Row.

Ring, P.S. \& Van de Ven, A.H. (1994). Developmental processes of cooperative interorganizational relationships. Academy of Management Review, 19(1), 90-118. 
Ring, P.S. \& Van de Ven, A.H. (2000). Formal and informal dimensions of transactions. In: Van de Ven, A.H. (ed.), Research on the management of innovation: the Minnesota studies. New York: Oxford University Press.

Rousseau, D.M. \& Tijoriwala, S.A. (1998). Assessing psychological contracts: Issues, alternatives and measures. Journal of Organizational Behavior, 19(S1), 731-744.

Rousseau, D.M. (1989). Psychological and Implied Contracts in Organizations. Employee Responsibilities and Rights Journal, 2(2), 121-139.

Rousseau, D.M. (1990). New hire perceptios of their own and employer's obligations: A study of psychological contracts. Journal of Organizational Behavior, 11(5), 389-400.

Rousseau, D.M. (1998). The "problem" of the psychological contract considered. Journal of Organizational Behavior, 19(S1), 665-671.

Sackmann, S. A. (1991). Cultural knowledge in organizations: Exploring the collective mind. Newbury Park, CA: Sage.

Sandelands, L. E., \& Stablein, R. E. (1987). The concept of organizational mind. In Bacharach, S. \& DiTimaso, N. (eds.). Research in the sociology of organizations, vol. 5 (pp 135-161). Greenwich, CT: JAI Press.

Schein, E. H. (1965). Organizational Psychology. Englewood Cliffs, NJ: Prentice-Hall.

Schrijvers, E., Buijs, D., Robben, M., Vis, C., Volwerk, J., van Es, L., and van Amstel, N. (2007). KOSMOS, de verandering in gezet. Amersfoort: ECS/ANH.

Scott, R.W., (2001). Institutions and Organizations ( $2^{\text {nd }}$ ed). Sage Publications, Thousand Oaks, CA.

Sitkin, S.B. \& Roth, N.L. (1993). Explaining the Limited Effectiveness of Legalistic "Remedies" for Trust/Distrust. Organization Science, 4(3): 367-392.

Starbuck, W. H., \& Milliken, F. J. (1988). Executives' perceptual filters: What they notice and how they make sense. In Hambrick, D.C. (ed.), The executive effect: Concepts and methods for studying top managers (pp. 35-56). Greenwich, CT: JAI Press.

Sutcliffe, K.M. \& Huber, G.P. (1998). Firm and industry as determinants of executive perceptions of the environment. Strategic Management Journal, 19(8), 793-807.

Swanborn, P.G. (1987). Methoden van sociaal-wetenschappelijk onderzoek. Amsterdam: Uitgeverij Boom.

Swanson, R.A. and Holton, E.F. (2005). Research in organizations: foundations and methods of inquiry. San Francisco: Berret-Koehler Publishers.

Ter Bogt, H.J. (1999). Financial and Economic Management in Autonomized Dutch Public Organizations. Financial Accountability \& Management, 15(3-4), 329-351.

Theunissen, R.P.G.J. \& Kooiman, A.G. (2008). Quick scan voorbereidingsproces Financial Close $2 e$ Coentunnel. Rotterdam: Horvat en Partners.

Thompson, P. J. \& Sanders, S. R. (1998). Partnering Continuum. Journal of Management in Engineering, 14(5), 73-78.

Trepte P.(2007). Public Procurement in the EU. A Practitioner's Guide (2nd ed.). Oxford: Oxford University Press.

Tsui, A. S., Egan, T.D. \& O'Reilly, C.A. (1992). Being Different: Relational Demography and Organizational Attachment. Administrative Science Quarterly, 37(4), 549-579.

Turner, J.R. (2004). Farsighted project contract management: incomplete in its entirety. Construction Management and Economics, 22(1), 75-83.

Uzzi, B. (1997). Social structure and competition in interfirm networks: the paradox of embeddedness. Administrative Science Quarterly, 42(1), 35-67.

Van Den Brande, I., Sels, L., Janssens, M. \& Overlaet, B. (2002). Assessing the nature of psychological contracts: conceptualization and measurement. Leuven: K.U.Leuven - Departement toegepaste economische wetenschappen.

Vedung, E. (2000). Public Policy and Program Evaluation. New Brunswick, NJ: Transaction Publishers.

Vlaar, P.W.L., Van den Bosch, F.A.J. \& Volberda, H.W. (2006). Coping with Problems of Understanding in Interorganizational Relationships: Using Formalization as a Means to Make Sense. Organization Studies, 27(11), 1617-1638. 
Vlaar, P.W. L., Van den Bosch, F.A.J. \& Volberda, H.W. (2007). On the Evolution of Trust, Distrust, and Formal Coordination and Control in Interorganizational Relationships: Toward an Integrative Framework. Group Organization Management, 32(4), 407-429.

Vulperhorst, L. (2012). Innovatieve marktbenadering. Rijkswaterstaat Nieuwsbrief Opdrachtnemers. Essay, to be published.

Walker, A. (2007). Project Management in Construction (5th ed.). Oxford: Blackwell Science.

Walker, D.H.T., and Hampson, K. (2003). Procurement strategies. A relationship based approach. Oxford: Blackwell.

Weick, K.E. \& Roberts, K.H. (1993). Collective mind in organizations: Heedful interrelating on flight decks. Administrative Science Quarterly, 38(3), 357-381.

Weick, K.E. (1993). The collapse of sensemaking in organizations: The Mann Gulch disaster. Administrative Science Quarterly, 38(4), 628-652.

Weick, K.E. (1995). Sensemaking in organizations. California: Thousand Oaks.

Weick, K.E., Sutcliffe, K.M. \& Obstfeld, D. (2005). Organizing and the process of sensemaking. Organization Science, 16(4), 409-421.

Welling, D.T. (2006). Bouwen op een gemeenschappelijk verleden, aan een succesvolle toekomst: Een onderzoek naar samenwerkingsproblemen in interorganisationele relaties vanuit bouwnijverheid. (Doctoral dissertation). Retrieved from Dissertaties - Rijksuniversiteit Groningen. (302529764).

Williamson, O.E. (1975). Markets and hierarchies: analysis and antitrust implications. New York: Free Press.

Williamson, O.E. (1979). Transaction-Cost Economics: The Governance of Contractual Relations. Journal of Law and Economics, 22(2), 233-261.

Williamson, T.M. (1999). The need for new paradigms for complex projects. International Journal of Project Management, 17(5), 269-273.

Wilson, D. (1995). An Integrated Model of Buyer-Seller Relationships. Journal of the Academy of Marketing Science, 23(4), 335-345.

Yin, R.K. (2009). Case Study Research Design and Methods ( $4^{\text {th }}$ ed.). California: Sage Publications, Inc.

Zaghoul, R. and Hartman, F. (2003). Construction contracts: the cost of mistrust. International Journal of Project Management, 21(6), 419-424. 


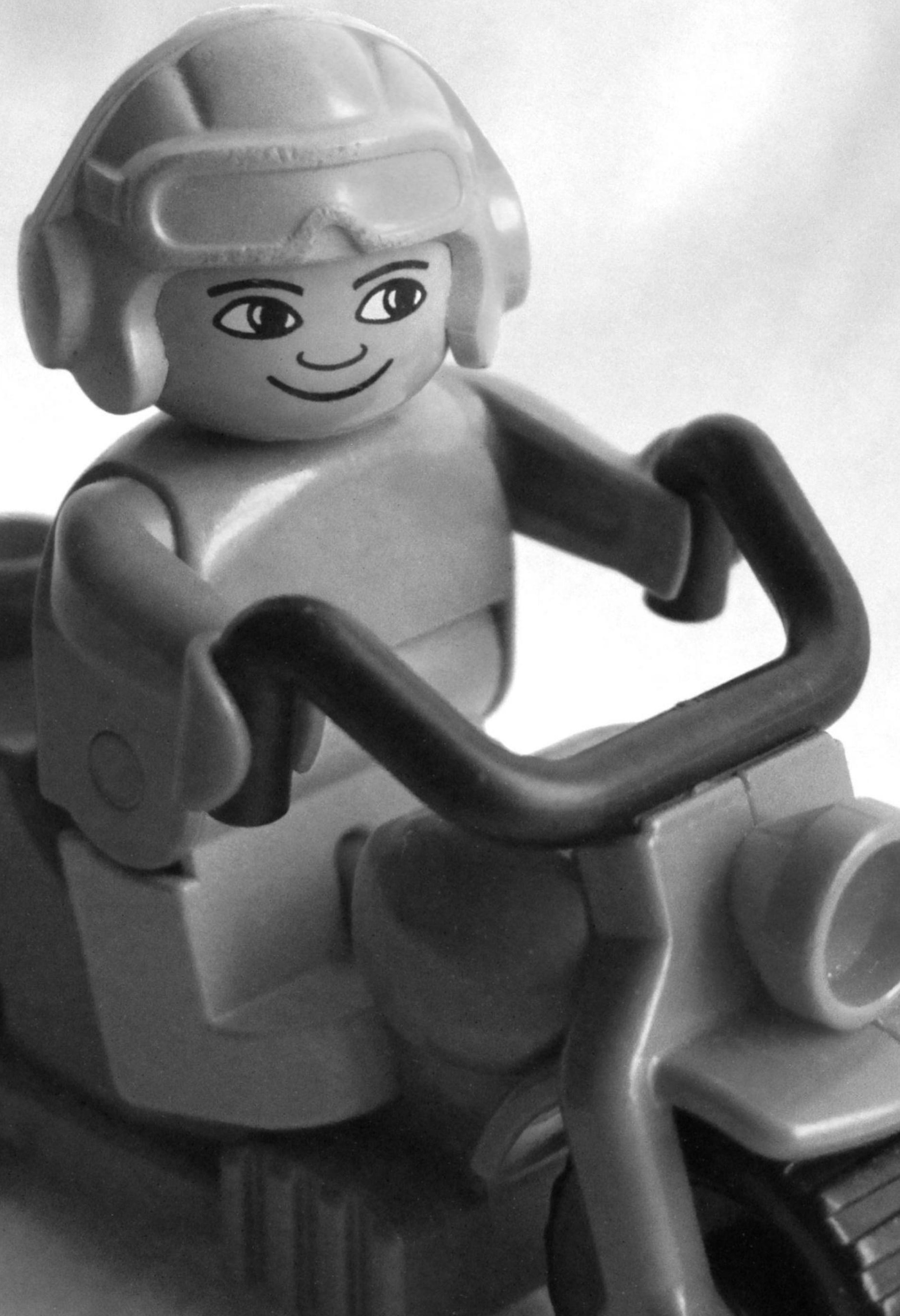




\title{
Publications related to this research
}

\author{
Journal articles
}

Hoezen, M. E. L., Rutten, J. van, Voordijk, J. T. \& Dewulf, G. P. M. R. (2010). Towards better customized service-led contracts through the competitive dialogue procedure. Construction management and economics, 28(11), 1177-1186.

Hoezen, M.E.L., Voordijk, J.T. \& Dewulf, G.P.M.R. (2012). Contracting dynamics in the Competitive Dialogue procedure. Built Environment Project and Asset Management, 2(2).

Hoezen, M.E.L., Voorijk, J.T \& Dewulf, G.P.M.R. (in press). Formal and informal contracting processes in the competitive dialogue procedure: a multiple-case study. Engineering Project Organization Journal.

Hoezen, M., Voordijk, H. \& Dewulf, G. (in press). Procuring complex projects using the competitive dialogue procedure. International Journal of Project Organisation and Management.

\section{Conference proceedings}

Blanken, A., Dewulf, G. P. M. R., Voordijk, J. T. \& Hoezen, M. E. L. (2008). Contingency adaptability of hospital concession contracts. In A. Wheelock (Ed.), International symposium "redefining healthcare infrastructure: integrating services, technologies and the built environment", 3-4 april 2008, London, UK (pp. 1-14). London, UK: Tanaka Business School, Imperial College.

Blanken, A., Dewulf, G. P. M. R., Voordijk, J. T. \& Hoezen, M. E. L. (2008). Demand risks and integrated contracts in the health care: the case of hospital concessions. In T. van der Vaart, D.P. van der Donk, W. van Wezel, G. Welker \& J. Wijngaard (Eds.), Proceedings 15th International Annual EurOMA Conference, Tradition and Innovation in Operations Management: Connecting Paste and Future, Groningen, the Netherlands: University of Groningen.

Hoezen, M. \& Hillig, J. B. (2008). The competitive dialogue procedure: advantages, disadvantages, and its implementation into english and dutch law. In J. Adriaanse, P. Kennedy, J. Adshead \& M. Brand (Eds.), Proceedings of COBRA 2008, 4-5 September 2008, Dublin, Ireland (pp. 1-16). London, United Kingdom: RICS.

Hoezen, M. \& Voordijk, H. (2011). "Procuring complex projects using the competitive dialogue: Expected effects ", COST Symposium Public Private Partnerships in Transport: Trends \& Theory - Research Roadmap, Lisbon, Jan. 12, 2011.

Hoezen, M. E. L. \& Dorée, A. G. (2008). First Dutch competitive dialogue projects: a procurement route caught between competition and collaboration. In A. Dainty (Ed.), Proceedings 24th ARCOM conference, 1-3 September 2008, Cardiff, UK (pp. 535-543). Reading, UK: Arcom.

Hoezen, M. E. L., Blanken, A., Voordijk, J. T. \& Benschop, T. (2007). Organization models and performance in housing construction: An evaluation framework. In M Garvin, F. Edum Fotwe \& P. Chinowsky (Eds.), ACSE CIB Construction Research Congress, 6-8 mei 2007, Grand Bahamas. 
Hoezen, M. E. L., Reymen, I. M. M. J. \& Dewulf, G. P. M. R. (2006). The problem of communication in construction. In F. Scheublin, A. Pronk, M. Prins, S. Emmitt \& A. den Otter (Eds.), Proceedings of the joint CIB, Tensinet, IASS International Conference on Adaptability in Design and ConstructionAdaptables 2006, International Conference on Adaptable Building Structures, July 3-5, Eindhoven, the Netherlands, Vol 3 (pp. 12-1412-19). Eindhoven: University of Technology Eindhoven.

Hoezen, M. E. L., Voordijk, J. T., Dewulf, G. P. M. R. \& Benschop, T. (2007). Integrated organization models in construction: why are they not used more often? In M. Garvin, F. Edum-Fotwe \& P. Chinowski (Eds.), Proceedings of the 2007 ASCE/CIB Construction Research Congress. LLC, Louisville, Colorado, United States of America.

Hoezen, M., Voordijk, H. \& Dewulf, G. (2011). Formal and informal contracting with the competitive dialogue procedure. In Wamelink, J.W.F, Geraerdts, R.P. \& Volker, L. (Eds) (Eds.) Proceedings of the CIB International Conference Management and Innovation for a Sustainable Built Environment - MISBE2011, 20-23 June 2011, Amsterdam, The Netherlands. Amsterdam, The Netherlands: TUDelft.

Hoezen, M., Voordijk, J.T. \& Dewulf, G.P.M.R. (2011). Sense making and bargaining in the Competitive Dialogue procedure. In F. Rozemeijer, M. Wetzels \& L. Quintens (Eds) Conference proceedings $20^{\text {th }}$ IPSERA conference, Vision 20/20 - Preparing today for tomorrow's challenges. 10-13 April, Maastricht, The Netherlands: IPSERA.

Kuhlmann, M., Hoezen, M. \& Laan, A. (2011). Stimulation of project cooperation by procurement procedures and procurement climate. In Wamelink, J.W.F, Geraerdts, R.P. \& Volker, L. (Eds)Proceedings of the CIB International Conference Management and Innovation for a Sustainable Built Environment - MISBE2011, 20-23 June 2011, Amsterdam, The Netherlands. Amsterdam, The Netherlands: TUDelft.

Lenferink, S., \& Hoezen, M. (2011). The interplay between public procuring authority and private competitors: experiences with the competitive dialogue. In Wamelink, J.W.F, Geraerdts, R.P. \& Volker, L. (Eds) Proceedings of the CIB International Conference Management and Innovation for a Sustainable Built Environment - MISBE2011, 20-23 June 2011, Amsterdam, The Netherlands. Amsterdam, The Netherlands: TUDelft.

\section{Oral contributions}

Hoezen, M., Voordijk, H. and Dewulf, G. (2012). Intended and realized public objectives in transport infrastructure projects through the competitive dialogue. Weimar, Germany, P3T3 Open Day 22 March 2012.

Hoezen, M. E. L. (2009). Efficiëntie en effectiviteit van de Europese Commissie: ontwerp en invoering van de concurrentiegerichte dialoog als voorbeeld. Berg en Dal, the Netherlands, 8ste Nederlands-Belgisch PoliticologenEtmaal 29 May 2009. 


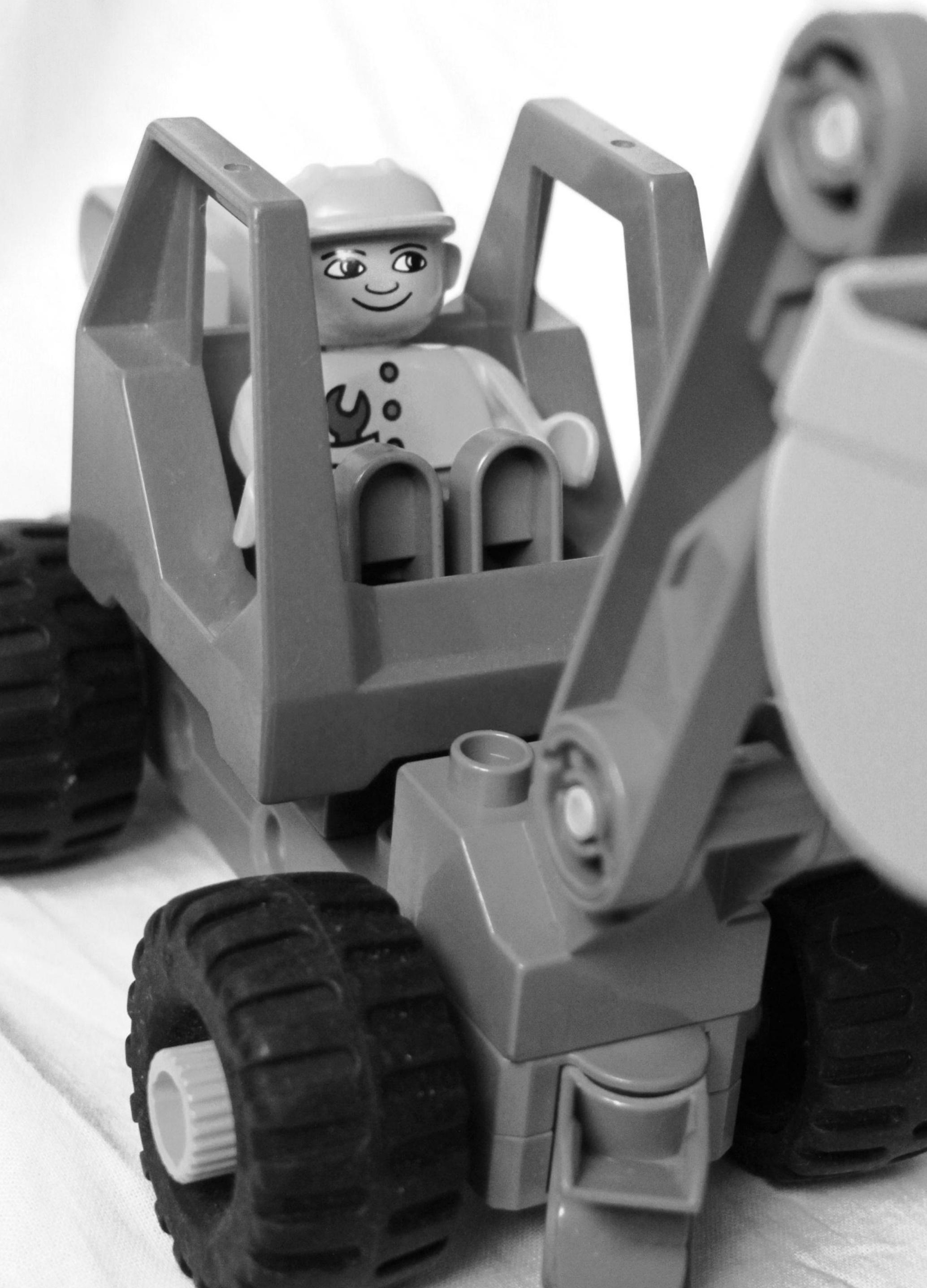




\section{Summary}

The combination of increased project complexity (Baccarini, 1996; Laufer et al., 1996; Alderman et al., 2005; Walker, 2007), changing government roles (Blanken, 2008) and the construction sector's poor professional functioning (Egan, 1998; National Audit Office, 2001) have changed both negotiations and commitments involved in construction projects. Public principals remain more distant to construction projects, sourcing out more and more of the work. Contractors became involved in projects more early, and as a consequence, the contracts to govern construction projects had to be signed earlier in the process, when the chances to unforeseeable contingencies were great. Renegotiations during the execution stage of projects therefore occurred on a regular basis (Dorée, 2001). To come to a better understanding about project details, the allocation of responsibilities and risks and the terms for cooperation, both procuring authorities and contractors felt the need to have conversations before a contract was signed (Dorée, 2001; PEC, 2002; PSIBouw \& Regieraad Bouw, 2007; Reniers, 2007).

Therefore, it is not surprising that the negotiated procedure gained popularity towards the end of the 1990s. None of the existing other procedures provided the opportunity of direct communication during the procurement. Only in the negotiated procedure procuring authorities were able to consult contractors of their choice and negotiate contractual terms with one of them. The European Commission (EC), well aware of the desire for a procurement method that left room for extensive dialogue during the negotiations, noticed that the negotiated procedure was often used improperly (COM(96) 583 final). The EC did not want this procedure to be used too often, because it left no room for other competitors during the negotiations stage. To overcome this problem without denying procuring agencies a procurement procedure with room for dialogue, the EC introduced a new procedure in 2004: the Competitive Dialogue (CD) procedure.

The CD procedure is a procurement method that consists of several rounds of discussion between the principal and potential contractors, during which all aspects of the tender are open for discussion. The CD procedure aims at aligning the complex demands of principals with possible solutions that contractors have to offer (Hebly and Lorenzo van Rooij, 2006). It regulates the negotiation process during the procurement stage, thus expectedly affecting the commitment and possible renegotiations between principal and contractor during construction. Academic analysis of the CD procedure's design (Arrowsmith, 2006; Raganelli \& Fidone, 2007; Ramsey, 2006) and early experiences with the CD procedure (Hoezen and Dorée, 2008; Floor and Kolkman, 2008) conclude that the actual design of the CD procedure could work against its objectives, causing ineffectiveness. The objective of the research described in this dissertation is to explain the perceived ineffectiveness of the CD procedure, based on gained insights in the interrelatedness of inter-organisational negotiations and commitments during procurement and during construction. The central research question of this research is therefore how are inter-organisational negotiations and commitments interrelated in the context of procurement by the Competitive Dialogue procedure?

In the academic literature, many descriptions of the development of inter-organisational relationships can be found. A model that does not just focus on the stage of procurement 
(like Walker and Hampson (2003); Pascale and Sanders (1997)) or on just the stage of execution of the contract (like Boddy, Macbeth and Wagner (2000); Dwyer, Schurr and Oh (1987); Thompson and Sanders (1998)), is the process model of Ring and Van de Ven (1994). They include mechanisms of formal and informal control, concepts that are currently frequently discussed. Ring and Van de Ven (1994) do not, however, go into detail about the manner in which negotiations and commitments are interrelated. Furthermore, the influence of contextual aspects such as the procedure by which the project is procured, are not incorporated. Therefore, several scientific insights are combined (Ring \& Van de Ven, 1994; Ring \& Van de Ven, 2000; Vlaar et al., 2006). This led to the development of the FINCIP model, depicting how formal and informal components of negotiations and commitments play a role in inter-organisational projects, both during procurement and during construction. In this model, the CD procedure was incorporated as a context variable, setting the rules and conditions for processes of negotiation.

Notwithstanding the limited knowledge about how procurement procedures affect negotiations and commitments, the European Commission (EC) had assumptions about the working of the $C D$ procedure. A reconstruction of the policy rhetoric shows how the $E C$ intended the $C D$ procedure to directly affect the procurement stage and to indirectly affect the construction stage of projects. Intended objectives with concern to the procurement stage were: stronger contractor competition than possible with the negotiated procedure, improved dialogue between procuring agency and potential contractors than possible with traditional procedures, innovation was expected to be stimulated, and the procurement was expected to become a basis for a trust-based relationship. Thus, the construction of the projects were expected to face less complexity, more proper allocation of tasks and risks, and renegotiations concerning quality, time and costs were expected to decrease.

However, the results of a survey amongst practitioners working in the first sixteen Dutch construction projects that were procured with use of the CD procedure, indicate that use of the procedure worked out different than expected. In the sixteen projects in the survey, practitioners experienced unexpected negatively influencing side-effects of CD procedure's elements. These (mostly unintended) mechanisms likely determine to what extent the intended objectives are reached. The CD procedure in its early use is experienced to lead to less dialogue than intended, to more competition, to less trust and hardly any improvement on complexity or task/risk allocation. Only the actual experienced level of innovation and the price-quality ratio meet the expectations. The identified mechanisms are conversation; focus on content; risk aversion; opportunistic behaviour; lack of openness; protection of contractors' interests; flexibility in demand specifications; a minimum of three candidates to the dialogue; design fee; level playing field; transaction costs; and a lack of clarity over when to use the procedure. These mechanisms seemingly affect negotiations and commitments, both during procurement and construction of the projects.

A multiple-case study in which negotiations and commitments in CD procured projects are compared to negotiations and commitments in traditionally procured projects confirms this experienced low effectiveness of the CD procedure. Analysis of the development of negotiations and commitments in both types of cases in the reconstruction programme KOSMOS further shows how the CD procedure influences negotiations and commitments 
both during procurement and during construction by facilitating processes of sensemaking during the procurement of a project. Whether or not extensive renegotiations are necessary during construction of the project, depends on how these sensemaking processes induced parallel development of the formal legal contract and the informal psychological contract. When these two contracts have been grown apart during procurement, huge problems of understanding will be caused during construction, leading to even more renegotiations than in traditionally procured projects.

However, still, the dynamic interrelationship of negotiations and commitments within projects procured with the $C D$ procedure is not explained by just untangling the influence of the $C D$ procedure on negotiations and commitments. Therefore, a single case study was performed in the second Coen Tunnel project, to answer the question how negotiations and commitments develop over time in a CD-procured construction project. Analysis of critical events during the procurement stage and first year of construction of the project are in line with the expectations in the FINCIP model. The parties involved in a project, go back and forth between negotiations and commitments from initiation through to delivery, depending on whether there is understanding or not. In most of the observed events, contextual situations caused the development of problems of understanding, or led to identifying differences in understanding. The two-way route between negotiations to commitments to overcome problems of understanding differ per critical event. Problems of understanding arise from formal and informal negotiations and commitments, and are resolved by formal and informal negotiations and commitments as well. There have not been discovered any strong patterns between the components. Observations do indicate that during procurement, negotiations more often result in adjustments to the formal legal contract than during construction. This has probably to do with the fact that before contract closure it is relatively easy to make changes to the formal legal contract.

From this research, two main conclusions were drawn. The first conclusion is that interorganisational negotiations and commitments are interrelated conform the FINCIP model. During all phases of a project, from initiation through to delivery, negotiations and commitments are substitutes for each other: the parties involved go back and forth between negotiations and commitments, depending on whether there is understanding or not. Formal and informal components of negotiations and commitments are complements of one another. Empirical data add to this that positively developed sensemaking processes decrease chances to renegotiations during construction, since sensemaking processes develop along self-reinforcing cycles.

The second conclusion is that using the $C D$ procedure influences the development of negotiations and commitments, both during procurement and during construction. By facilitating sensemaking processes in the negotiations during procurement, the $C D$ procedure could prevent extensive renegotiations to be necessary in the execution stage of inter-organisational projects. Yet, inter-organisational projects are influenced by context variables including perceived risk, initial trust levels, role relationships, outcome expectations and environmental constraints. This explains why the CD procedure is currently less effective than its potential. Effectiveness would probably increase when the dialogue would be used more to get the principal and the candidate to meet and openly discuss demands and possibilities, chances and risks. 


\section{Samenvatting}

Door toegenomen projectcomplexiteit (Baccarini, 1996; Laufer et al., 1996; Alderman et al., 2005; Walker, 2007), de veranderende rol van overheden (Blanken, 2008) en het slechte functioneren van de bouwsector (Egan, 1998; National Audit Office, 2001), zijn bouwprojecten veranderd, zowel op het gebied van onderhandelen als bij het aangaan van verbintenissen tussen partijen. Publieke opdrachtgevers zijn zichzelf meer op afstand van het werk gaan plaatsen, en besteden steeds meer uit. Marktpartijen worden eerder in projecten betrokken, met als gevolg dat de contracten die de projecten beheersen steeds vroeger in het proces moeten worden gesloten. Dit vergroot de kans op onvoorziene omstandigheden tijdens de looptijd van het contract. Deze veranderingen leidden er eind jaren ' 90 toe dat er steeds vaker tijdens de uitvoering van projecten heronderhandelingen plaatsvonden over het project (Dorée, 2001). Zowel aanbestedende overheidsdiensten als marktpartijen voelden de behoefte om met elkaar in gesprek te gaan voor sluiting van een contract, om beter begrip te krijgen van de projectdetails, de verdeling van taken en risico's, en de inhoud van de samenwerkingsovereenkomst (Dorée, 2001; PEC, 2002; PSIBouw en Regieraad Bouw, 2007; Reniers, 2007).

Dit verklaart de toegenomen populariteit van de onderhandelingsprocedure, eind jaren ' 90 . Geen van de andere beschikbare procedures verschafte de publiek opdrachtgever en marktpartijen de mogelijkheid om al tijdens de aanbesteding direct met elkaar in gesprek te gaan. Slechts binnen de onderhandelingsprocedure konden aanbestedende diensten geselecteerde marktpartijen consulteren en met één van hen onderhandelen over de contractuele bepalingen. De Europese Commissie (EC) was zich bewust was van de behoefte aan een aanbestedingsmethode die ruimte bood voor uitgebreide dialoog tijdens de aanbesteding. Toch constateerde de EC dat de onderhandelingsprocedure regelmatig oneigenlijk werd gebruikt (COM(96)583 final). Het orgaan wilde niet dat de procedure te vaak zou worden toegepast, aangezien deze geen ruimte liet voor andere gegadigden tijdens het onderhandelingsproces. Om dit probleem te omzeilen zonder aanbestedende diensten de mogelijkheid te ontzeggen om tijdens een aanbesteding in dialoog te kunnen treden met gegadigden, introduceerde de EC in 2004 een nieuwe aanbestedingsprocedure: de Concurrentiegerichte Dialoog (CD).

De $C D$ is een aanbestedingsprocedure die bestaat uit verschillende discussieronden tussen de opdrachtgever en potentiele aannemers. Tijdens deze ronden kunnen alle aspecten van de opdracht besproken worden. De CD is ervoor bedoeld om de complexe vraag van opdrachtgever in lijn te brengen met mogelijke oplossingen die marktpartijen te bieden hebben (Hebly en Lorenzo van Rooij, 2006). De procedure reguleert het onderhandelingsproces tijdens de aanbestedingsfase, aldus naar verwachting ook de verbintenis tussen de partijen beïnvloedend, alsmede mogelijke heronderhandelingen tussen opdrachtgever en opdrachtnemer gedurende de uitvoering.

Wetenschappelijke analyses van het ontwerp van de CD (Arrowsmith, 2006; Raganelli en Fidone, 2007; Ramsey, 2006) en vroege ervaringen met de procedure (Hoezen en Dorée, 2008; Floor en Kolkman, 2008) leiden tot de conclusie dat het ontwerp van de CD weleens anders zou kunnen werken dan bedoeld, aldus leidend tot ineffectiviteit. Doel van het 
onderzoek, beschreven in dit proefschrift, is het verklaren van de verwachte ineffectiviteit van de $C D$, gebaseerd op inzichten in de relatie tussen onderhandelingen en verbintenissen tussen organisaties tijdens zowel de aanbesteding als de uitvoering van bouwprojecten. De centrale onderzoeksvraag is dan ook: hoe verhouden onderhandelingen en verbintenissen zich tot elkaar in de context van aanbesteden met de Concurrentiegerichte Dialoog? In de wetenschappelijke literatuur is een groot aantal beschrijvingen te vinden van hoe relaties tussen organisaties zich ontwikkelen. Een model dat zich niet alleen op de aanbestedingsfase richt (zoals Walker en Hampson (2003); Pascale en Sanders (1997)) of juist alleen op de uitvoeringsfase (zoals Boddy, Macbeth en Wagner (2000); Dwyer, Schurr and Oh (1987); Thompson and Sanders (1998)), is het procesmodel van Ring en Van de Ven (1994). In hun model worden mechanismen van formele en informele controle bij elkaar gebracht, concepten die momenteel frequent worden besproken. Ring en Van de Ven (1994) treden echter niet in detail over de manier waarop onderhandelen en het aangaan van verbintenissen zich tot elkaar verhouden. Verder worden contextuele aspecten zoals de procedure waarmee het project wordt aanbesteed, niet in het model meegenomen. Om die reden is er in dit onderzoek voor gekozen om verschillende wetenschappelijke inzichten met elkaar te combineren (Ring en Van de Ven, 1994; Ring en Van de Ven, 2000; Vlaar et al., 2006). Dit heeft geleid tot de ontwikkeling van het FINCIP model, dat beschrijft hoe formele en informele componenten van onderhandelen en verbintenissen aangaan een rol spelen in projecten tussen organisaties, zowel tijdens aanbesteding als gedurende de uitvoering. In dit model is de CD opgenomen als contextvariabele die de regels en voorwaarden schept voor het onderhandelingsproces.

Ondanks de beperkte kennis over hoe aanbestedingsprocedures van invloed zijn op onderhandelingen en het aangaan van verbintenissen, had de EC verwachtingen ten aanzien van de werking van de $C D$. Een reconstructie van de beleidsretoriek laat zien hoe de EC beoogde dat de $C D$ direct van invloed zou zijn op de aanbestedingsfase en indirect ook de uitvoeringsfase van projecten moest beïnvloeden. Beoogde doelen met betrekking tot de aanbestedingsfase waren: steviger marktconcurrentie dan mogelijk was binnen de onderhandelingsprocedure; verbeterde dialoog tussen aanbesteder en potentiele aannemers dan mogelijk was binnen traditionele procedures; men verwachtte innovatie te stimuleren; en aanbestedingen met de CD moesten een basis vormen voor een op vertrouwen gebaseerde samenwerkingsrelatie tussen opdrachtgever en opdrachtnemer. Op deze manier verwachtte men indirect in de uitvoeringsfase van projecten te maken te krijgen met verminderde complexiteit; een betere allocatie van taken en risico's; en minder heronderhandelingen ten aanzien van kwaliteit, tijd en kosten.

De uitkomst van een survey onder praktijkbeoefenaars in de eerste zestien Nederlandse bouwprojecten die werden aanbesteed met de $C D$, duidde erop dat toepassing van de procedure anders uitwerkte dan verwacht. De praktijkbeoefenaars in deze zestien projecten ervoeren onverwachte negatieve neveneffecten van elementen van de CD. Deze (veelal onbedoelde) mechanismen bepalen vermoedelijk de mate waarin de beoogde doelen worden bereikt. Vroege ervaringen met de CD duiden erop dat deze leidt tot minder dialoog dan beoogd, tot meer concurrentie, tot minder vertrouwen en bijna geen verbetering ten aanzien van complexiteit of taak/risico allocatie. Slechts het daadwerkelijk ervaren niveau van innovatie en de prijs-kwaliteit verhouding bleken conform verwachtingen. De 
geïdentificeerde mechanismen daartoe zijn gesprek; focus op inhoud; risico aversie; opportunisme; gebrek aan openheid; bescherming van de belangen van de aannemer; flexibiliteit van de vraagspecificaties; minimaal drie gegadigden in de dialoog; ontwerpkostenvergoeding; level playing field; transactiekosten; en onduidelijkheid over wanneer de CD mag worden toegepast. Deze mechanismen lijken onderhandelingen en het aangaan van verbintenissen te beïnvloeden, zowel tijdens de aanbesteding als de uitvoering van projecten.

De ervaren beperkte effectiviteit van de $C D$, zoals die uit het survey bleek, wordt bevestigd door een vergelijkende multiple-case studie waarbij onderhandelingen en het aangaan van verbintenissen in projecten met de $C D$ procedure zijn vergeleken met onderhandelingen en het aangaan van verbintenissen in projecten die op traditionele wijze zijn aanbesteed. Analyse van de ontwikkeling van onderhandelingen en het aangaan van verbintenissen in beide soorten cases binnen het renovatieprogramma KOSMOS laat verder zien dat de CD zowel tijdens de aanbesteding als gedurende de uitvoering van invloed is op onderhandelingen en het aangaan van verbintenissen, doordat de procedure zingevingsprocessen tijdens de aanbesteding faciliteert. Of extensieve heronderhandelingen tijdens de uitvoering van het project noodzakelijk zijn, hangt af van hoe deze zingevingsprocessen hebben bijgedragen aan parallelle ontwikkeling van het formele juridische contract en het informele psychologische contract tussen partijen. Wanneer deze twee contracten tijdens de aanbesteding uit elkaar zijn gegroeid, zal dit leiden tot grote begripsproblemen tijdens de uitvoering, met zelfs nog meer heronderhandelingen tot gevolg dan in op traditionele wijze aanbestede projecten.

Met het ontrafelen van de invloed die de CD heeft op onderhandelingen en het aangaan van verbintenissen, is de dynamische relatie hiertussen in projecten die met de CD zijn aanbesteed nog niet geheel verklaard. Daarom werd een single case studie uitgevoerd in het Tweede Coentunnel project met als onderzoeksvraag hoe onderhandelingen en het aangaan van verbintenissen zich in de tijd ontwikkelen binnen een bouwproject dat met de CD is aanbesteed. Analyse van kritieke momenten tijdens de aanbestedingsfase en het eerste jaar van uitvoering van het project zijn in lijn met de verwachtingen vanuit het ontwikkelde FINCIP model. De partijen die bij een project zijn betrokken, gaan van initiatie tot aan oplevering heen er weer tussen onderhandelen en het aangaan van verbintenissen, afhankelijk van de vraag of er wederzijds begrip is of niet. In het grootste deel van de kritieke momenten veroorzaakten contextuele situaties de ontwikkeling van begripsproblemen, of leidden deze tot identificatie van begripsverschillen.

De route die tussen onderhandeling en het aangaan van verbintenissen wordt gevolgd om begripsproblemen het hoofd te bieden verschilt per kritiek moment. Begripsproblemen ontstaan vanuit formele en informele onderhandelingen en verbintenissen, en worden ook door formele en informele onderhandelingen en verbintenissen weer opgelost. Er zijn geen sterke patronen ontdekt. Observaties impliceren dat onderhandelingen tijdens de aanbestedingsfase eerder leiden tot wijzigingen in het formele juridische contract dan tijdens de uitvoeringsfase. Dit komt waarschijnlijk doordat het voor sluiting van het contract relatief gemakkelijker is om wijzigingen in het formele juridische contract aan te brengen. 
Uit dit onderzoek zijn twee hoofdconclusies getrokken. De eerste is dat onderhandelingen en het aangaan van verbintenissen tussen organisaties zich tot elkaar verhouden conform het FINCIP model. Gedurende alle fasen van een project, van initiatie tot aan oplevering, vormen onderhandelingen en het aangaan van verbintenissen substituten voor elkaar: de betrokken partijen gaan heen en weer tussen onderhandelingen en verbintenissen, afhankelijk van de vraag of zij elkaar begrijpen of niet. Formele en informele componenten van onderhandelingen en verbintenissen complementeren elkaar. Empirische data voegden daaraan toe dat positief verlopen initiële zingevingsprocessen de kans op heronderhandelingen in de uitvoeringsfase doen verminderen, doordat zingevingsprocessen zich langs zelfversterkende cycli ontwikkelen.

De tweede conclusie is dat toepassing van de $C D$ de ontwikkeling van onderhandelingen en het aangaan van verbintenissen beïnvloedt, zowel tijdens de aanbesteding als de uitvoering. Door zingevingsprocessen in de aanbesteding te faciliteren, kan de CD extensieve heronderhandelingen tijdens de uitvoeringsfase van projecten tussen organisaties voorkomen. Dit type projecten wordt echter ook beïnvloed door contextvariabelen zoals risico-inschattingen; initiële vertrouwensniveaus; rolrelaties; verwachtingen van de uitkomst; en omgevingsfactoren. Dit verklaart waarom de CD momenteel minder effectief is dan mogelijk is. Wanneer de CD meer wordt ingericht zodat opdrachtgever en gegadigden in openheid de vraag, mogelijke oplossingen, kansen en risico's kunnen bespreken, zou de effectiviteit van de aanbestedingsprocedure waarschijnlijk toenemen. 

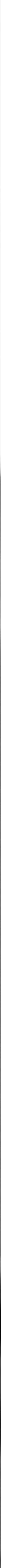


\section{Dankwoord}

"Sports do not build character. They reveal it." John Wooden

Wie mij een beetje kent, weet dat ik erg sportief ben, maar niet zo van inspanning houd. Ik wil nog weleens meedoen aan een voetbal- of volleybaltoernooi of aan de Batavierenrace, en ik heb zelfs een tijd wekelijks gesquasht. De sportprestatie is daarbij echter ondergeschikt aan de gezelligheid. Tot ik het gevoel heb, er goed in te zijn. Dan word ik opeens bloedfanatiek. Voor mijn promotietraject geldt het omgekeerde. Ik begon eraan vol ambitie: vastberaden gedegen onderzoek te doen. Gaandeweg is het halen van de eindstreep belangrijker geworden dan de winst. Een promotietraject kent geen vaste spelregels. Soms maak je meters, soms lijkt het of je stil staat. Soms vraagt het veel inspanning, soms gaat het vanzelf. Het sportelement in het promoveren dreigde me soms op te breken, maar nu is de finish in zicht. Daarom een paar woorden van dank aan trainers, scheidsrechters, technische staf, teamgenoten en fans.

Geert en Hans, coach en trainer. Bedankt voor alle begeleidingsuren die jullie in mij en dit traject hebben gestoken. Ik heb er veel van geleerd, zeker ook mentaal. Deze promotie wordt succesvol afgesloten dankzij jullie commentaar aan de zijlijn en de vrijheid die ik kreeg om er een vrije oefening van te maken. Misschien vind ik zwemmen toch leuker dan gedacht. Jos Arts, André Dorée, Chris Jansen, Anna Kadefors en Maarten van Riemsdijk, deskundig arbitrair kwintet. Hartelijk dank voor jullie kritisch-constructieve commentaar. Teruggefloten worden is nooit leuk, maar met een gele kaart op zak ben ik wel zorgvuldiger gaan spelen. Het heeft me het vertrouwen in mijn onderzoekskwaliteiten teruggegeven, en ik zie erg uit naar de finale!

Dank ook aan het verzorgende team, op alle punten in de race. Binnen de UT wil ik Yolanda en Jacqueline bedanken, voor ondersteuning, luisterend oor en goede raad. De ICT'ers die mijn materieel onderhielden zijn goud waard. Ze konden me altijd helpen, zelfs als iets kromgebogen was of als ik er thee over gegoten had. Bij RWS veel dank aan Peter en Christelle die de weg overal weten, en me geholpen hebben het hoofd koel te houden.

Aan alle Rijkswaterstaters in het veld: bedankt voor het inzicht dat jullie gaven in het parcours. Speciale dank aan Hans, dat je me toestemming gaf om op jullie terrein te komen trainen, en aan Ferdinand, voor je tijd en heerlijke bespiegelingen op het academische wereldje. 'Mijn' junioren René, Martijn, Everhard, Tim en Kamiel hebben me geweldig geholpen door het testen van methoden in de voorrondes; en John, zonder jouw kennis en hulp had dit alles me veel meer tijd en moeite gekost. Huub en Frans, bedankt voor jullie belangstelling en flexibiliteit: het had iets meer voeten in aarde dan 'alleen nog maar opschrijven'...

Promoveren blijkt een individuele sport te zijn: er is geen team met wie je het samen doet. Toch zijn er meer spelers in het veld, bij wie je de kunst kunt afkijken en waar je af en toe op kunt leunen. Albertus, bedankt voor de wandelingen en bespiegelingen; Inge voor de opvang, vooral toen ik net van start ging; Anneloes, voor je kracht om overal een feestje van 
te maken; Robin en Arjen, voor een nadere duiding van de spelregels binnen Bouw/Infra; Tijs, voor je praktische tips; Maartje, voor de gedeelde Wageningen-ervaring; Maarten, voor het Eindhoven-gevoel; Jeroen en Ariën, voor al jullie inspanning om de vrieskou te verslaan; Sanne, voor je hulp en de koffie in Nijmegen; Amber en Suzanne, voor de herkenbaarheid... promotietrajecten lijken uiteindelijk toch op elkaar, al zullen we allemaal onze eigen hordes moeten nemen.

Er is een moment geweest dat ik bijna de handdoek in de ring had gegooid, maar ik ben blij dat ik dat niet heb gedaan. Harm, zonder jou was ik, denk ik, niet meer overeind gekomen. Super bedankt voor je stimulerende woorden vanaf de tribune. Franka, eigenlijk altijd in het publiek aanwezig, dankjewel voor je tips, plezierige afleiding en zelfs concrete hulp! Ik ben ook erg blij met de hulp van Renee en Monique, die de laatste meters danig hebben verlicht. En dan zijn er nog Bauke en Leentje, mijn hazen in het veld. Ik ben erg blij met jullie hulp in de voorbereiding en dat jullie me bijstaan in de finale.

Overig publiek: Japke, Niels, Bauke, Evert, Babs, Bianca, Liza, Odette, Jos, Rik, Afke, Harrie, Loes, Marianne, en al mijn andere (Facebook)vrienden en familie... bedankt ook voor jullie aanmoediging, met of zonder vuvuzela en spandoek. Het is fijn te weten dat mensen achter je staan. Bijzondere steun heb ik daarbij gehad aan Eric en Annie. Bedankt voor alle dingen die jullie me uit handen hebben genomen die me anders het sporten onmogelijk zouden hebben gemaakt. Ik denk dan aan twee verhuizingen, aan ettelijke oppasuren, aan diverse vakanties waarin ik ongestoord kon werken, maar zeker ook aan de broodnodige gezellige ontspanning tussen de trainingsuren door.

Geschiktheid voor een sport wordt bepaald door genetische aanleg, motivatie en stimulans. Pa en ma, daarvoor staan jullie aan de basis. Dank voor het vertrouwen en de zelfstandigheid waarmee jullie me hebben opgevoed. Inmiddels ben ik ook erg goed in hulp accepteren, en dat hebben jullie geweten. Bedankt voor de uren dat ik bij jullie in totale afzondering mocht trainen, met ondertussen optimale verzorging. Eveneens bedankt voor alle kinderopvang, diverse wassen en andere facilitaire ondersteuning. Hoewel jullie de afgelopen tijd druk geweest zijn met jullie eigen toernooi, weet ik me gesteund door jullie allebei. Zet hem op: dat doorzettingsvermogen heb ik niet alleen van mezelf!

Jip en Tes, mensen mogen dan zeggen dat promoveren met twee kinderen wel zwaar zal zijn, ik denk dat het veel moeilijker was geweest zonder jullie. Niet alleen omdat de beste ideeën me invielen wanneer ik jullie in bad deed, maar vooral doordat jullie blije koppies me bij thuiskomst alle sores doen vergeten. Jullie laten me zien dat er meer in het leven is dan promoveren. En mochten jullie me dat niet duidelijk genoeg maken, dan is daar jullie vader wel. Arjen, dankjewel voor je altijd luisterend oor, en heerlijk nuchter, mannelijk commentaar. En hoewel het 'natuurlijk' nooit goed is wat je doet, vooral ook dank voor het feit dat jij de afgelopen jaren het huishouden draaiend hebt gehouden. Weet dat ik het altijd fijn vind om thuis te komen, hoe weinig ik er dan ook (fysiek en mentaal) ben geweest. Mocht je vinden dat ik teveel thuis ben de komende tijd, laat me dat dan weten: dan ga ik op zoek naar een leuke sport! 


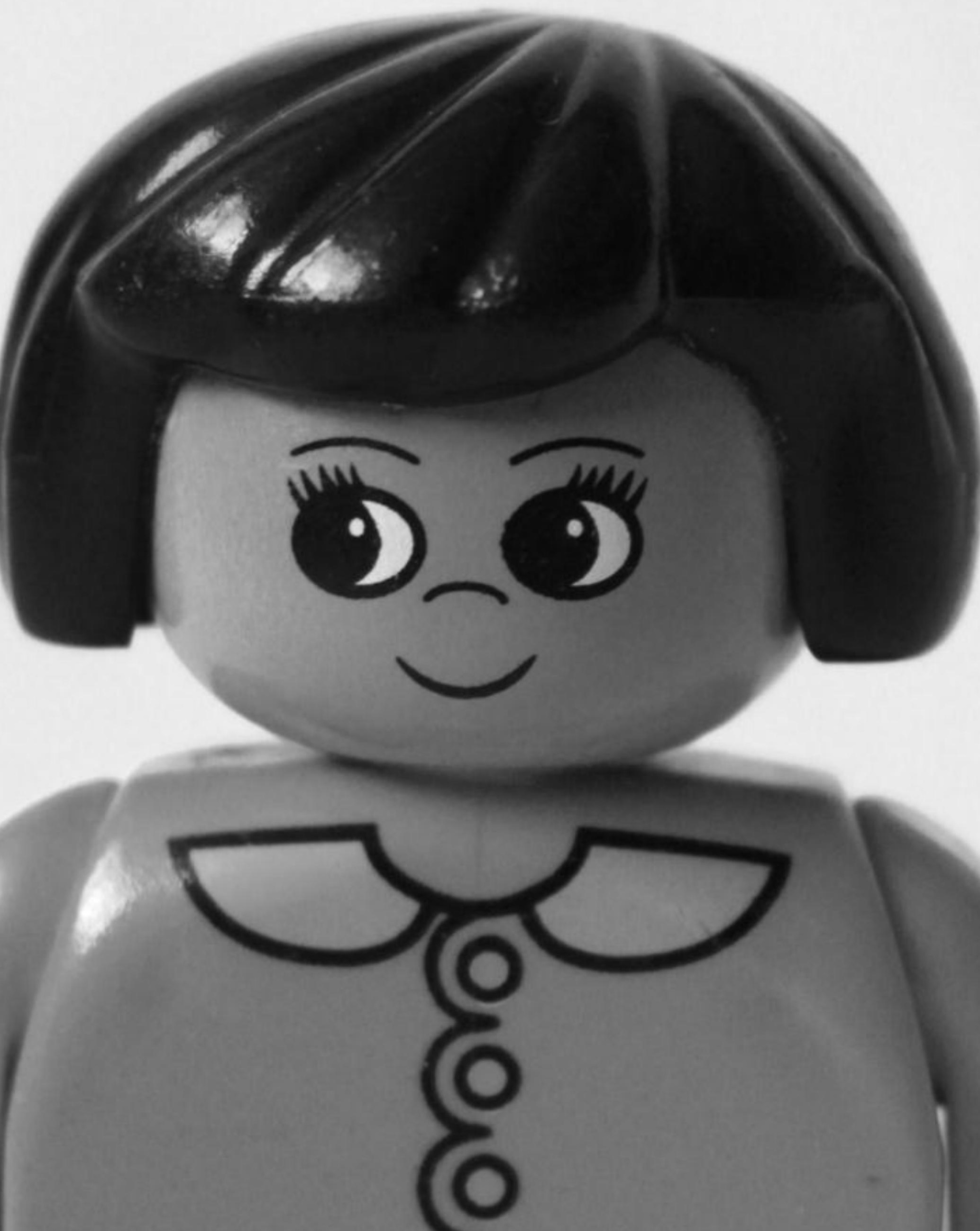




\section{About the author}

Mieke Hoezen was born in Eindhoven, the Netherlands. She graduated from high school (Van Maerlantlyceum) in 1999. After that, she obtained five certificates in policy sciences (Katholieke Universiteit Nijmegen), and then moved to Wageningen to study Home Economics (later Management, Economics and Consumer Studies) at the Educational Institute Society at Wageningen University. Here, she specialised in Technology and graduated cum laude in 2005 . Her master thesis dealt with consumer utilisation of floor plan flexibility in homes, commissioned by a steering committee of the Dutch Ministry of Housing, Spatial Planning and Environment. When the thesis was completed, Mieke worked at the steering committee for half a year. As a project assistant she contributed to the book "België als gidsland: particulier opdrachtgeverschap bij een beperkt budget" about low-budget privately commissioned housing in Belgium.

During her study, Mieke was an active member in several local and national participative bodies and boards dealing with the quality of her study in particular and higher education in general. Furthermore, she wrote a participation handbook and organized two national conferences. One dealt with the privatization of higher education and the other with knowledge and innovation in the Netherlands. Her internship at the Dutch Ministry of Housing, Spatial Planning and Environment concerned the design, conceive and procurement of residents committees in 56 deprived areas.

In September 2005 Mieke started as a researcher at the department of Construction Engineering and Management at the University of Twente. Feed by an innovation voucher she started with a practical research about possibilities to include soft qualification measures in MEAT criteria for the construction and installation sector. She defined the PhD proposal for communication in the construction industry as a study into interaction patterns between public principal and private contractors in the context of the Competitive Dialogue procedure. During the $\mathrm{PhD}$ research Mieke participated in teaching and supervising graduate students. Furthermore, she has written various articles for scientific journals and conference proceedings, and has been speaker at several (inter)national conferences and workshops.

In 2010 Mieke jointly organised the professional seminar "De Concurrentiegerichte Dialoog en de weg er naartoe" for local governments. In November 2010 she started working for Rijkswaterstaat, the Dutch Highways and Waterways Agency, as adviser / specialist Market and Procurement. For the department Purchasing Management of Works and Waterworks Mieke performs research as an input to procurement strategies, market communication and contracting. Thus, she advises policy makers at a strategic level and purchasers at the operational level. 


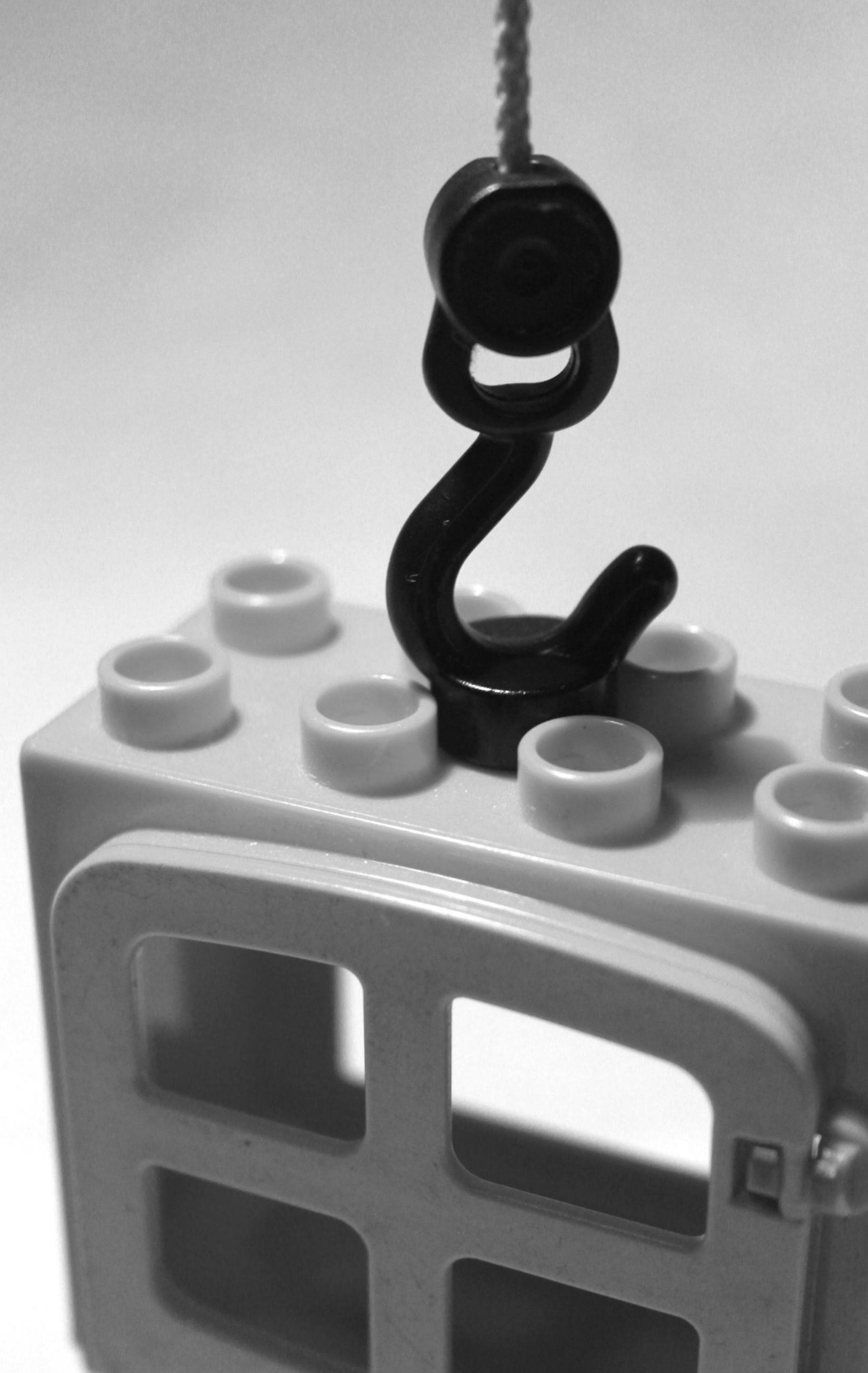




\section{Tables and Figures}

\section{Tables}

1.1. Characteristics of three contract types (Hoezen et al., 2010)

1.2. Usage of procurement procedures and award methods before 2004 (based on Heijboer \& Telgen, 2002) ...14

2.1. Weick's (1995) four sensemaking principles ...........................................................................................38

2.2. The relationships between formal / informal contracts and three control-ordering principles ......................39

2.3. Conceptualisation of the main sensitising concepts..............................................................................43

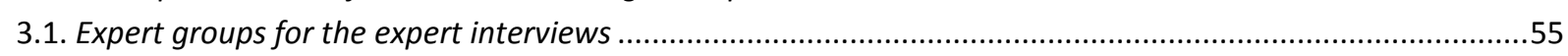

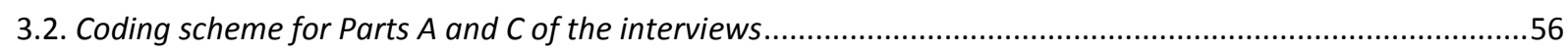

3.3. Early CD-procured construction projects in the Netherlands ...................................................................56

3.4. Expectations from expert interviews and corresponding survey statements..............................................58

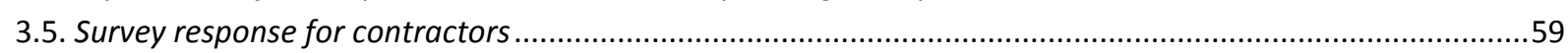

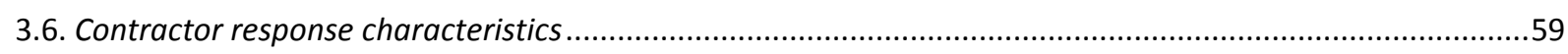

3.7. Effects of the mechanisms within the CD procedure on the $E C^{\prime}$ 's objectives ................................................60

4.1. The case study's testing constructs and aspects, and their sources in the multiple-case study.....................73

4.2. The case study's explanative constructs and aspects, and their sources in the multiple-case study ..............74

4.3. Number of interviews, differentiated by participation level and role ..........................................................75

4.4. Timeline of the procurement decisions for the KOSMOS work packages....................................................79

4.5. Procurement developments within traditionally procured KOSMOS projects.................................................80

4.6. Problems of understanding during construction of traditionally procured KOSMOS projects ........................82

4.7. Construction developments within traditionally procured KOSMOS projects ................................................84

4.8. Procurement developments within the CD-procured KOSMOS projects ....................................................87

4.9. Problems of understanding in the CD-procured KOSMOS projects ..............................................................89

4.10. Construction developments within the CD-procured KOSMOS projects...................................................90

4.11 Timeline for development of the KOSMOS projects ..............................................................................94

5.1. The case study variables, dimensions and aspects, and their source in the single revelatory case study.....105

5.2 Number of interviews, differentiated by type of interview and informants' role ............................................106

5.3. Timeline of stages by year and month for the Coen Tunnel project..............................................................110

5.4. Type and number of questions asked during the various dialogue stages................................................112

5.5. Timeline of critical events in the Coen Tunnel project ....................................................................................114 Figures

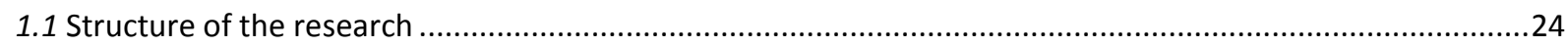

2.1 Process Framework of the Development of Cooperative IORs (Ring \& Van de Ven, 1994) ............................30

2.2. The FINCIP model: Formal and Informal Negotiations and Commitments, in Inter-organisational Projects. 35

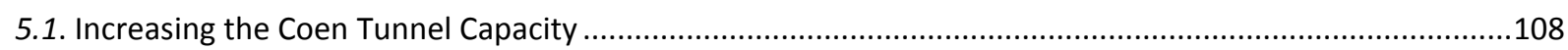

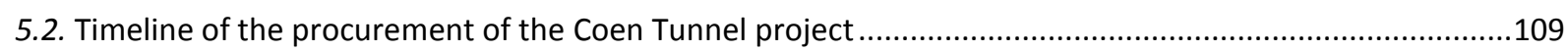

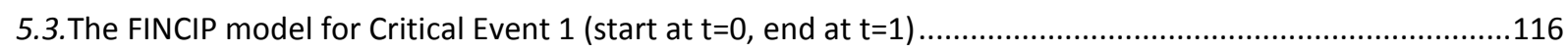

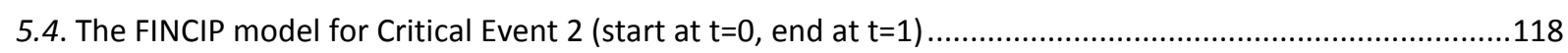

5.5. The FINCIP model for Critical Event 3 (start at $\mathrm{t}=0$, end $\mathrm{t} \mathrm{t}=1$ ) .........................................................119

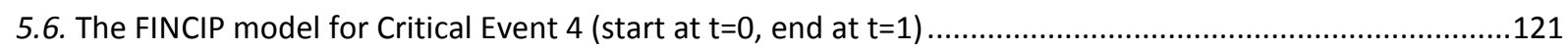

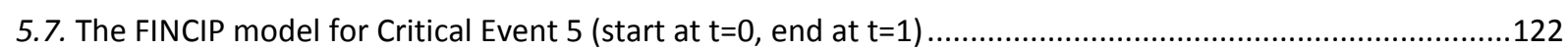

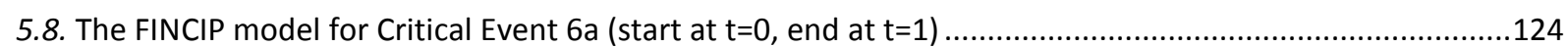

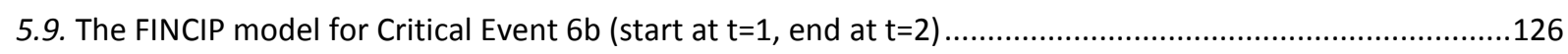

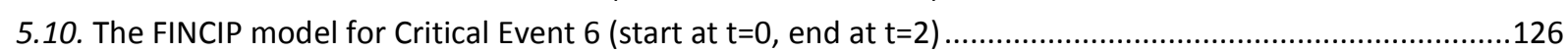

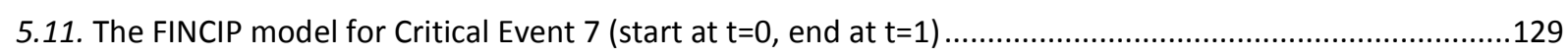

5.12. The FINCIP model for Critical Event 8a (start at $\mathrm{t}=0$, end at $\mathrm{t}=1$ ) ........................................................131

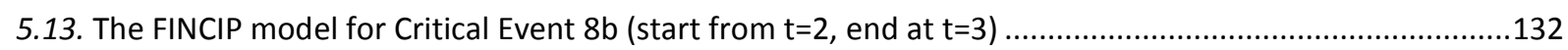





\section{Appendices}

\section{Appendix 1. Expert interview protocol}

A: Added value of the CD procedure

Open question:

- What added value do you expect from the CD procedure, compared to the negotiated and the restricted procedures?

Statements:

- All features of the CD procedure are already incorporated in the existing negotiated and restricted procedures.

- The way we used the negotiated procedure in the past does not differ from the current CD procedure.

\section{B: Expected impact of the CD procedure's design}

Open questions:

- In your opinion, which elements will have the most positive impact in terms of the ECobjectives with the CD procedure?

- In your opinion, which elements will have the most negative impact in terms of the ECobjectives with the CD procedure?

- Do you think there is a solution that would overcome the effects of the elements with negative impact in terms of the EC-objectives with the $\mathrm{CD}$ procedure?

\section{C: Other expectations}

Open questions:

- What are your general expectations in terms of the effect of the CD procedure?

Statements:

Explicit EC-objectives

- I expect the CD procedure to facilitate a conversation between the contracting agency and contractors.

- I expect that there will be greater competition in CD-procured tenders than was possible with the negotiated procedure.

- I expect the CD procedure to stimulate innovation.

- I expect the CD procedure to contribute to a trust-based relationship between the procuring authority and the contractor.

Implicit EC-objectives

- I expect the CD procedure to contribute to solving project complexity

- I expect the CD procedure to contribute to reaching a proper risk and task allocation Project control

- I expect the quality of projects to increase when procured by the CD procedure.

- I expect projects to face fewer time overruns when procured by the CD procedure.

- I expect projects to face fewer cost overruns when procured by the CD procedure. 


\section{Appendix 2. Survey questionnaire - contractors}

\section{A: Respondent and project characteristics}

Prior to the survey proper, you are first asked for some characteristics of you and the project you were involved in. These data will be used to check which people who were asked to take part in the survey have responded and who have not.

\section{Respondent}

This survey is completed by (name and organisation):

\section{My position}

[ ] project director

In the project

[ ] A2 Hooggelegen

[ ] A2 Maastricht

[ ] A4 Burgerveen - Leiden

[ ] Belastingkantoor Doetinchem

[ ] 2e Coentunnel

[ ] Combiplan Nijverdal

[ ] Detentiecentrum Zestienhoven

[ ] Kromhoutkazerne
[ ] tender manager

[ ] Nieuwbouw IB-Groep / Belastingdienst Groningen

[ ] Renovatie Haringvliet

[ ] KOSMOS (Kunstwerken Noord-Holland)

[ ] KOSMOS (Kunstwerken Utrecht - Z.-Holland - N.-Holland)

[ ] KOSMOS (Kunstwerken Z.-Holland Zuid en Zeeland)

[ ] KOSMOS (Noordelijk Nederland)

[ ] KOSMOS (Limburg onderhoud droge projecten)

[ ] KOSMOS (Limburg en Noord-Brabant nat)

\section{For this project}

[ ] the contract has been awarded to us.

[ ] the contract has been awarded, but not to us. We were a potential contractor until the final bid.

[ ] the contract has been awarded, but not to us. We were not selected to make a final bid.

[ ] the contract has not yet been awarded, we are still a potential contractor.

[ ] the contract has not been awarded yet, but we are no longer a potential contractor.

The design of the dialogue was as follows (number of dialogue rounds and conversations per round)

Duration of the tender

The (estimated) duration of the tender is ....... Months 


\section{B: The CD procedure}

In general

1.1 Use of the CD procedure leads to more innovative solutions.

1.2 Use of the CD procedure leads to a better price-quality ratio.

1.6 The CD procedure has potential.

Project-specific

1.8 In the project considered, emphasis was more on bid price than on quality.

1.9 In the project considered, qualitative aspects should have received greater emphasis.

1.12 Use of the CD procedure stimulated us to propose innovative solutions.

\section{Remarks:}

\section{C: Dialogue experiences}

2.1 Use of the CD procedure leads to bids that better match the wishes and needs of procuring authorities.

2.8 Fear that certain information will become public is a reason for us to be restrained in contributing to the dialogue.

2.11 In the project considered, the demand was specified in functional terms (open solution).

2.12 Use of the CD procedure has led to better demand specifications. $2.13 \mathrm{We}$, as contractors, were given the opportunity to influence the demands.

2.14 The demand specifications gave sufficient opportunities for us to distinguish ourselves from other potential contractors.

2.18 The procuring authority provided answers that were useful to us.

2.19 There was sufficient time during the dialogue to discuss issues.

2.20 The issues that came up during the dialogue were well discussed.

2.21 The interactions improved as the process developed.
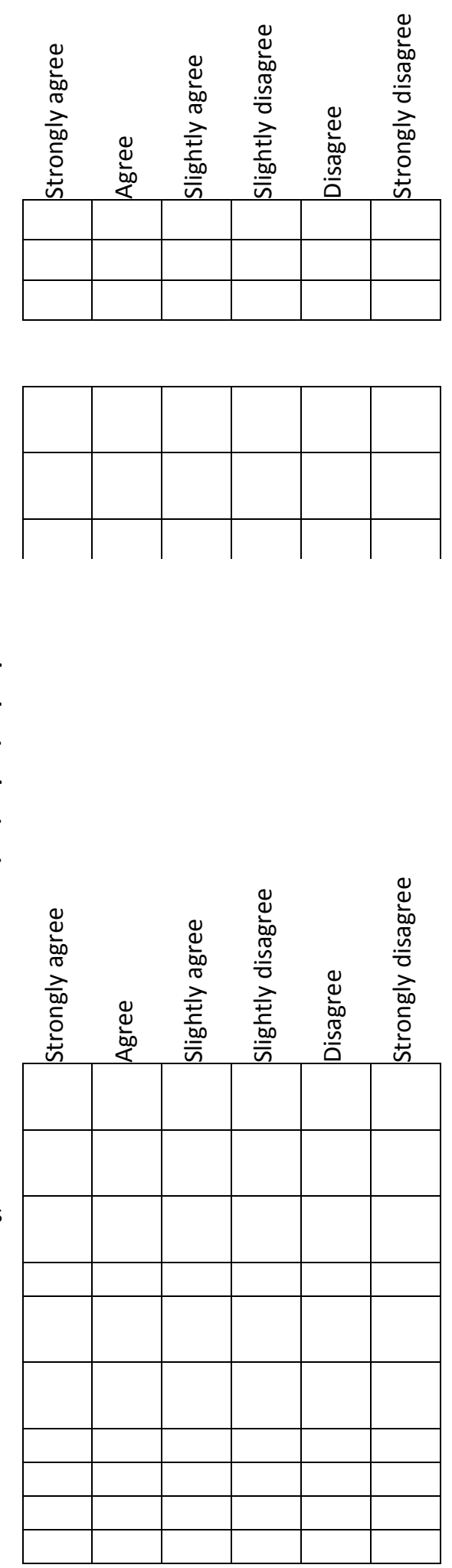
2.28 During the design stage, we detailed our design more than was asked for.

2.29 The number of dialogue products which had to be delivered was excessive.

2.30 There were too many dialogue conversations.

2.32 The procuring authority carefully handled the information we provided during the dialogue.

2.36 The time spent on the dialogue compares well with its result.

2.37 The same result could have been accomplished with fewer conversations.

2.38 There was mutual trust between the procuring authority and us.

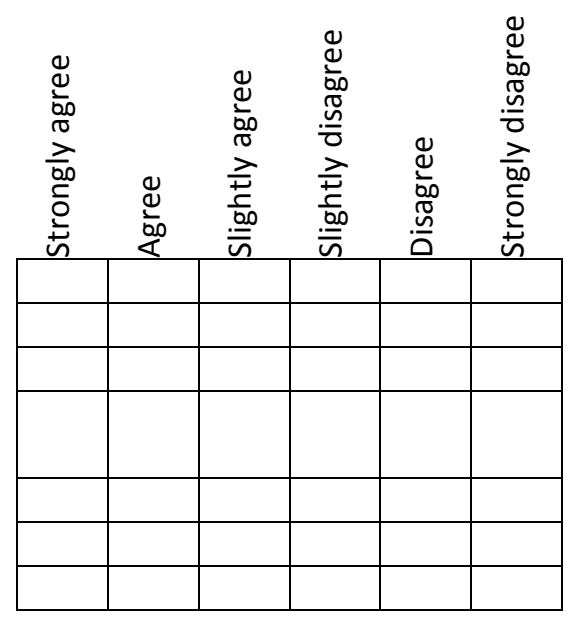

\section{Remarks:}

\section{$D$ : The $C D$ procedure in the future}

What are, in your opinion, the main bottlenecks concerning use of the CD procedure?

What should be changed to enable the CD procedure to be used in a proper manner in the future?

How would you like to cooperate with the procuring authority when using the CD procedure? 


\section{Concluding questions:}

If necessary, can I call you in the future to ask some further questions?

[ ] I would prefer not to be further disturbed.

[ ] I have no objections, my telephone number is

If you would like to receive a report on the outcome of this survey, please enter your e-mail address:

My e-mail address:

\section{THANK YOU VERY MUCH FOR YOUR HELP}

\section{Other remarks:}




\section{Appendix 3. Survey questionnaire - procuring authorities}

\section{A: Respondent and project characteristics}

Prior to the survey proper, you are first asked for some characteristics of you and the project you were involved in. These data will be used to check which people who were asked to take part in the survey have responded and who have not.

\section{Respondent}

This survey is completed by (name and organisation):

\section{My position}

[ ] project director

In the project

[ ] A2 Hooggelegen

[ ] A2 Maastricht

[ ] A4 Burgerveen - Leiden

[ ] Belastingkantoor Doetinchem

[ ] 2e Coentunnel

[ ] Combiplan Nijverdal

[ ] Detentiecentrum Zestienhoven

[ ] Kromhoutkazerne

For this project

[ ] the contract has been rewarded

[ ] the contract has not yet been rewarded

The design of the dialogue was as follows (number of dialogue rounds and conversations per round)
[ ] Nieuwbouw IB-Groep / Belastingdienst Groningen

[ ] Renovatie Haringvliet

[ ] KOSMOS (Kunstwerken Noord-Holland)

[ ] KOSMOS (Kunstwerken Utrecht - Z.-Holland - N.-Holland)

[ ] KOSMOS (Kunstwerken Z.-Holland Zuid en Zeeland)

[ ] KOSMOS (Noordelijk Nederland)

[ ] KOSMOS (Limburg onderhoud droge projecten)
[ ] KOSMOS (Limburg en Noord-Brabant nat)

Duration of the tender

The (estimated) duration of the tender is ....... months 


\section{$B:$ The $C D$ procedure}

In general

$1.1 \mathrm{It}$ is clear when it is allowed to use the CD procedure.

1.3 Use of the CD procedure leads to a better price-quality ratio.

1.7 The CD procedure has potential.

Project-specific

1.9 In the project considered, emphasis was more on bid price than on quality.

1.10 In the project considered, qualitative aspects should have received greater emphasis.

1.12 Use of the CD procedure stimulated contractors to propose innovative solutions.

Remarks:
1.2 Use of the $C D$ procedure leads to more innovative solutions.
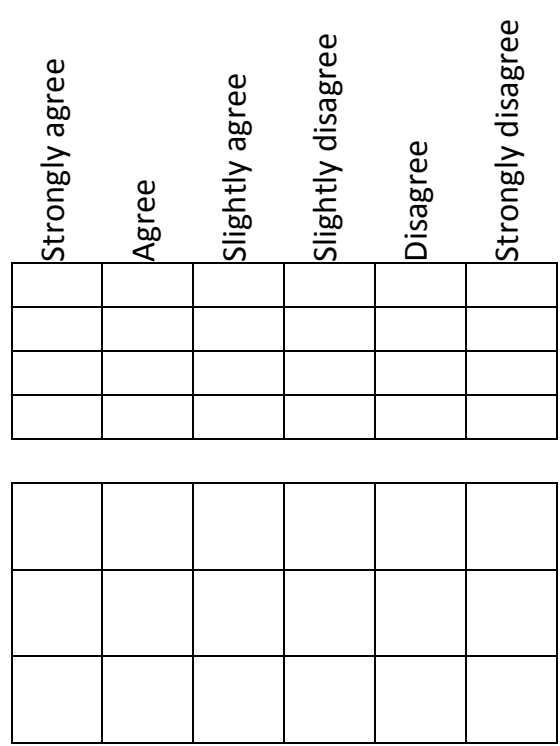

\section{C: Dialogue experiences}

2.1 Use of the CD procedure leads to bids that better match the wishes and needs of procuring authorities.

2.7 Fear that certain information will become public is a reason for contractors to be restrained in contributing to the dialogue.

2.9 In the project considered, the demand was specified in functional terms (open solution).

2.10 Use of the CD procedure has led to better demand specifications.

2.11 Contractors were given the opportunity to influence the demands.

2.12 The demand specifications gave contractors sufficient opportunities to distinguish themselves from other potential contractors.

2.15 Contractors asked appropriate questions.

2.16 There was sufficient time during the dialogue to discuss issues.

2.17 The issues that came up during the dialogue were well discussed.

2.18 The interactions improved as the process developed.

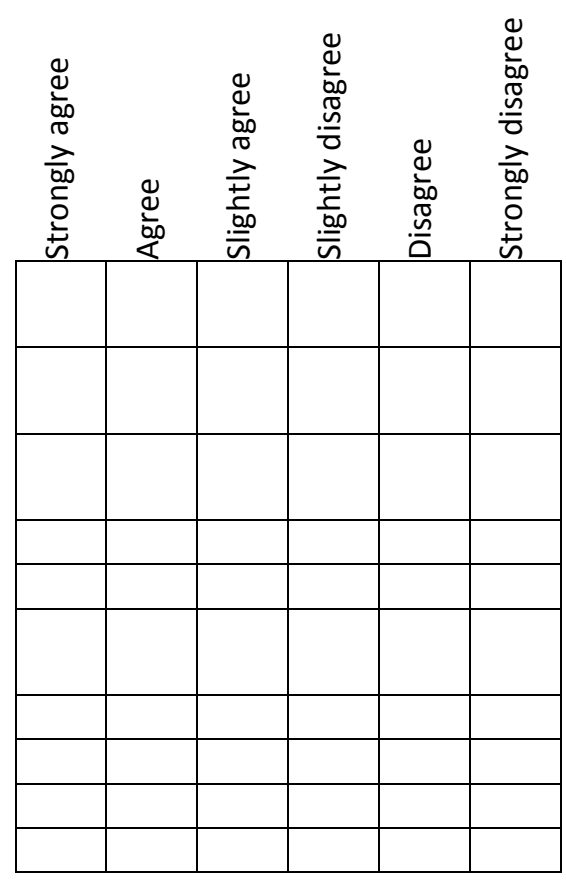


2.23 During the design stage, the contractors detailed their designs more than we asked for.

2.24 The number of dialogue products which had to be delivered was excessive.

2.25 There were too many dialogue conversations.

2.30 The time spent on the dialogue compares well with its result.

2.31 The same result could have been accomplished with fewer conversations.

2.32 There was mutual trust between the contractors and us.

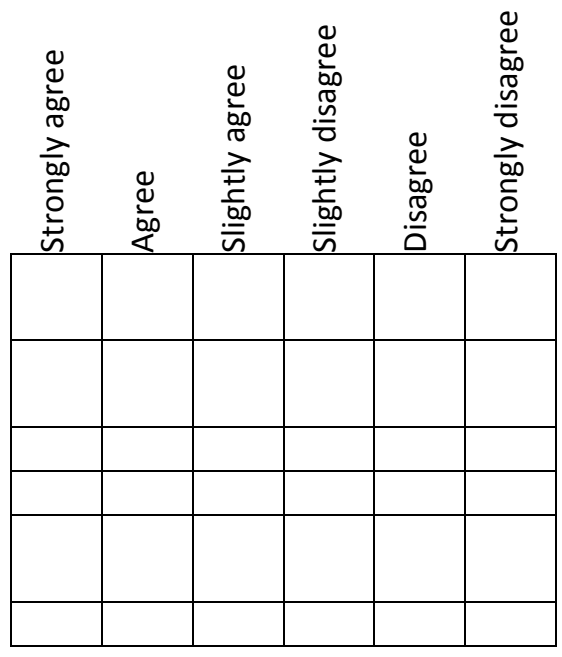

Remarks:

$D$ : The $C D$ procedure in the future

What are, in your opinion, the main bottlenecks concerning use of the CD procedure?

What should be changed to enable the CD procedure to be used in a proper manner in the future?

How would you like to cooperate with contractors when using the CD procedure? 


\section{Concluding questions:}

If necessary, can I call you in the future to ask some further questions?

[ ] I would prefer not to be further disturbed.

[ ] I have no objections, my telephone number is

If you would like to receive a report on the outcome of this survey, please enter your e-mail address:

My e-mail address:

\section{THANK YOU VERY MUCH FOR YOUR HELP}

\section{Other remarks:}




\section{Appendix 4. Case study protocol KOSMOS projects with CD procedure}

\section{Question 1: Background information and context}

In what period of time were you involved in this project? What was your role during this project? Could you give me a short description of what your tasks were during PROCUREMENT and CONSTRUCTION? How did you assess the risk of this project? Why? How are you experienced with projects of this size and contract form? Why is the CD procedure used for the procurement of this project? What did you think of this at forehand? What were your expectations of the CD procedure? Did you know the contractor from earlier projects? How did you trust this contractor? Why?

\section{Question 2: Commitment during procurement}

To what extent did you experience the $C D$ procedure to facilitate a conversation between the two parties? Do you feel like the other organization was committed to the project in this stage? Why? Could you give examples of situations / actions that might illustrate this? To what extent did the procurement stage facilitate reducing the project's complexity? Which part of the agreement needed explanation or discussion? Which were the hot potatoes during the procurement and how did both organisations handle them? Do you think that the fact that the project was procured by the CD procedure influenced the contract? Which were the hot potatoes in the contract and how were these solved?

Asking further on topics related to:

\author{
Reward system \\ Allocation of risks \\ Contract clauses \\ Output specifications \\ Monitoring system
}

\author{
Importance of the future relationship \\ Importance of reputation \\ Understanding \\ Norms / values \\ Empathy / affect \\ Routines
}

\section{Question 3: Negotiation during procurement}

How do you look back at the dialogue (positively / negatively, and why)? How would you describe the competitiveness between the participants of the dialogue? Which innovative suggestions did the participants come with during the procurement stage? How were these treated? How did the tender contribute to the building of trust between you and the other party? How did the negotiations develop during procurement? How would you describe the atmosphere and contact between the parties during procurement? Do you think that the fact that the project was procured by the CD procedure influenced the development of the negotiations? 
Asking further on topics related to:

Focal points in protocols and agenda's Arguments

Individual and mutual goals, knowledge Expectations

and assumptions

Justifications

Exchange of ideas, conversations,

Focus on few beliefs

dialogue

Revision / nuancing points of views,

uncovering and elimination of

inconsistencies

Question 4: Negotiation and Commitment during construction

To what extent do you think that the allocation of risks turned out to be balanced (both in positive and negative sense)? How do you think the other party assesses the contract? Why? Which were the hot potatoes during execution of the project and how were these solved? To what extent was the contract helpful in solving issues during execution of the project? Do you feel like the other organization was committed to the project in this stage? Why? Could you give examples of situations / actions that might illustrate this? How do you assess the delivered quality of the project? What causes any overruns in time and / or costs? How were these overruns treated by both parties involved?

Asking further on topics related to:

\begin{tabular}{|c|c|}
\hline Reward system & Importance of the fu \\
\hline Allocation of risks & Importance of reput \\
\hline Contract clauses & Understanding \\
\hline Output specifications & Norms / values \\
\hline Monitoring system & $\begin{array}{l}\text { Empathy / affect } \\
\text { Routines }\end{array}$ \\
\hline $\begin{array}{l}\text { Focal points in protocols and agenda's } \\
\text { Individual and mutual goals, } \\
\text { knowledge and assumptions } \\
\text { Exchange of ideas, conversations, } \\
\text { dialogue } \\
\text { Revision / nuancing points of views, } \\
\text { uncovering and elimination of } \\
\text { inconsistencies }\end{array}$ & $\begin{array}{l}\text { Arguments } \\
\text { Expectations } \\
\text { Justifications } \\
\text { Focus on few beliefs }\end{array}$ \\
\hline
\end{tabular}

Question 5: Remaining questions

(If relevant:) You have been involved in more than one KOSMOS project. When comparing the two projects you were involved in, what are the most remarkable differences then? Do you think that the fact that in one of the two projects the $C D$ procedure was used played a role in these differences? Are there other things which I forgot to ask and which you would like to add? 


\section{Appendix 5. Case study protocol traditionally procured KOSMOS projects}

\section{Question 1: Background information and context}

In what period of time were you involved in this project? What was your role during this project? Could you give me a short description of what your tasks were during PROCUREMENT and CONSTRUCTION? How did you assess the risk of this project? Why? How are you experienced with projects of this size and contract form? Did you know the contractor from earlier projects? How did you trust this contractor? Why?

Question 2: Commitment during procurement

To what extent did you experience the procurement procedure to facilitate a conversation between the two parties? Do you feel like the other organization was committed to the project in this stage? Why? Could you give examples of situations / actions that might illustrate this? To what extent did the procurement stage facilitate reducing the project's complexity? Which part of the agreement needed explanation or discussion? Which were the hot potatoes during the procurement and how did both organisations handle them? Which were the hot potatoes in the contract and how were these solved?

Asking further on topics related to:

$\begin{array}{ll}\text { Reward system } & \text { Importance of the } \\ \text { Allocation of risks } & \text { Importance of reput } \\ \text { Contract clauses } & \text { Understanding } \\ \text { Output specifications } & \text { Norms / values } \\ \text { Monitoring system } & \text { Empathy / affect } \\ & \text { Routines }\end{array}$

Question 3: Negotiation during procurement

How do you look back at the procurement stage (positively / negatively, and why)? How would you describe the competitiveness between the participants of the tender? Which innovative suggestions did the participants come with during the procurement stage? How were these treated? How did the tender contribute to the building of trust between you and the other party? How did the negotiations develop during procurement? How would you describe the atmosphere and contact between the parties during procurement? 
Asking further on topics related to:

Focal points in protocols and agenda's Arguments

Individual and mutual goals, knowledge Expectations

and assumptions

Justifications

Exchange of ideas, conversations,

Focus on few beliefs

dialogue

Revision / nuancing points of views,

uncovering and elimination of

inconsistencies

Question 4: Negotiation and Commitment during construction

To what extent do you think that the allocation of risks turned out to be balanced (both in positive and negative sense)? How do you think the other party assesses the contract? Why? Which were the hot potatoes during execution of the project and how were these solved? To what extent was the contract helpful in solving issues during execution of the project? Do you feel like the other organization was committed to the project in this stage? Why? Could you give examples of situations / actions that might illustrate this? How do you assess the delivered quality of the project? What causes any overruns in time and / or costs? How were these overruns treated by both parties involved?

Asking further on topics related to:

\begin{tabular}{|c|c|}
\hline Reward system & Importance of the fu \\
\hline Allocation of risks & Importance of reput \\
\hline Contract clauses & Understanding \\
\hline Output specifications & Norms / values \\
\hline Monitoring system & $\begin{array}{l}\text { Empathy / affect } \\
\text { Routines }\end{array}$ \\
\hline $\begin{array}{l}\text { Focal points in protocols and agenda's } \\
\text { Individual and mutual goals, } \\
\text { knowledge and assumptions } \\
\text { Exchange of ideas, conversations, } \\
\text { dialogue } \\
\text { Revision / nuancing points of views, } \\
\text { uncovering and elimination of } \\
\text { inconsistencies }\end{array}$ & $\begin{array}{l}\text { Arguments } \\
\text { Expectations } \\
\text { Justifications } \\
\text { Focus on few beliefs }\end{array}$ \\
\hline
\end{tabular}

Question 5: Remaining questions

(If relevant:) You have been involved in more than one KOSMOS project. When comparing the two projects you were involved in, what are the most remarkable differences then? Do you think that the fact that in one of the two projects the CD procedure was used played a role in these differences? Are there other things which I forgot to ask and which you would like to add? 


\section{Appendix 6. Case study protocol Dutch Highways and Waterways Agency}

\section{INTRODUCTION}

- Period of time in which involved in the project

- Position during PROCUREMENT and EXECUTION

- Experience with projects of this size and contract form

- First opinion about procurement by the CD procedure

\section{THE DIALOGUE}

I would like to speak with you about the development of the dialogue, from the moment that you became involved in the project until ... (you left / the end of the dialogue). When doing so, I ask you to go into moments which you think of important for the procurement process. Think about documents and questions as well as about events during the dialogue. I would like to focus on the development in the dialogue, and the manner in which you experienced the process.

\begin{tabular}{|c|c|}
\hline $\begin{array}{l}\text { Important documents / general or confidential } \\
\text { question }\end{array}$ & Important events \\
\hline $\begin{array}{l}\text { Describe the document / the question: what } \\
\text { kind of document / question was it, and what } \\
\text { was its purpose? }\end{array}$ & $\begin{array}{l}\text { Describe the event: what happened, and } \\
\text { why? }\end{array}$ \\
\hline $\begin{array}{l}\text { Process: tactics } \\
\text { Where was the focus in this document / } \\
\text { question? } \\
\text { How were your interests reflected in this } \\
\text { document / question? } \\
\text { Do you think that enough attention was paid to } \\
\text { your interests? Why? }\end{array}$ & $\begin{array}{l}\text { Beliefs \& Actions (matching or not) } \\
\text { What did you think of the event? } \\
\text { How do you think the other party / parties } \\
\text { have experienced this event? Why do you } \\
\text { think so? }\end{array}$ \\
\hline $\begin{array}{l}\text { Substance } \\
\text { What were the considerations before the } \\
\text { document / question was sent in this form to } \\
\text { the other party / parties? (demands and } \\
\text { judgement) } \\
\text { How did the other party / parties think of that? } \\
\text { What makes you think that? } \\
\text { What were the consequences of this document } \\
\text { / this clarification for the development of the } \\
\text { procurement? }\end{array}$ & $\begin{array}{l}\text { Expecting \& Arguing, Commitment \& } \\
\text { Manipulation } \\
\text { Which considerations determined how } \\
\text { you acted in this event? } \\
\text { How did this event affect the relationship } \\
\text { between you and the other party / } \\
\text { parties? } \\
\text { How did the development of this event } \\
\text { determine your attitude in the build-up to } \\
\text { the bid? }\end{array}$ \\
\hline
\end{tabular}


- Furthermore, I am curious to know how you look back at the dialogue.

- And how do you think that the participants look back at the dialogue?

- To what extent do you think that the fact this contract was drawn by the CD procedure contributed to a balanced allocation of risks and interests (both in positive and negative sense)?

- How do you think the winning construction firm perceives the contract?

- Does it matter for the contract with the winning construction firm that the project was procured by the $\mathrm{CD}$ procedure?

\section{THE RELATIONSHIP DEVELOPMENT}

- How would you describe the team spirit in your own project organisation? Which are the differences between the procurement and now?

- Do you feel that the winning construction firm committed itself to the project, both the people and the organisation?

- How would you describe the attitudes of both organisations? Which are the differences between the procurement and now?

- How is the contact between the botch organisations (formally/informally)? Which are the differences between the procurement and now?

- Were there changes in personnel in either of the organisations? How were such changes affecting the project?

- What is the project planning for coming year?

- Which are potential bottlenecks and how do you expect both organisations to cope with that?

CONCLUDING

Did I forget about other things which you would like to mention? 


\section{Appendix 7. Case study protocol market organisations}

\section{INTRODUCTION}

- Period of time in which involved in the project

- Position during PROCUREMENT and EXECUTION

- Experience with projects of this size and contract form

- First opinion about procurement by the CD procedure

\section{THE DIALOGUE}

I would like to speak with you about the development of the dialogue, from the moment that you became involved in the project until ... (you left / the end of the dialogue). When doing so, I ask you to go into moments which you think of important for the procurement process. Think about documents and questions as well as about events during the dialogue. I would like to focus on the development in the dialogue, and the manner in which you experienced the process.

\begin{tabular}{|c|c|}
\hline $\begin{array}{l}\text { Important documents / general or confidential } \\
\text { question }\end{array}$ & Important events \\
\hline $\begin{array}{l}\text { Describe the document / the question: what } \\
\text { kind of document / question was it, and what } \\
\text { was its purpose? }\end{array}$ & $\begin{array}{l}\text { Describe the event: what happened, and } \\
\text { why? }\end{array}$ \\
\hline $\begin{array}{l}\text { Process: tactics } \\
\text { Where was the focus in this document / } \\
\text { question? } \\
\text { How were your interests reflected in this } \\
\text { document / question? } \\
\text { Do you think that enough attention was paid to } \\
\text { your interests? Why? }\end{array}$ & $\begin{array}{l}\text { Beliefs \& Actions (matching or not) } \\
\text { What did you think of the event? } \\
\text { How do you think the other party / parties } \\
\text { have experienced this event? Why do you } \\
\text { think so? }\end{array}$ \\
\hline $\begin{array}{l}\text { Substance } \\
\text { What were the considerations before the } \\
\text { document / question was sent in this form to } \\
\text { the other party / parties? (demands and } \\
\text { judgement) } \\
\text { How did the other party / parties think of that? } \\
\text { What makes you think that? } \\
\text { What were the consequences of this document } \\
\text { / this clarification for the development of the } \\
\text { procurement? }\end{array}$ & $\begin{array}{l}\text { Expecting \& Arguing, Commitment \& } \\
\text { Manipulation } \\
\text { Which considerations determined how you } \\
\text { acted in this event? } \\
\text { How did this event affect the relationship } \\
\text { between you and the other party / parties? } \\
\text { How did the development of this event } \\
\text { determine your attitude in the build-up to } \\
\text { the bid? }\end{array}$ \\
\hline
\end{tabular}


- Furthermore, I am curious to know how you look back at the dialogue.

- And how do you think that the participants look back at the dialogue?

- To what extent do you think that the fact this contract was drawn by the CD procedure contributed to a balanced allocation of risks and interests (both in positive and negative sense)?

- How do you think the winning construction firm perceives the contract?

- Does it matter for the contract with the winning construction firm that the project was procured by the $\mathrm{CD}$ procedure?

\section{THE RELATIONSHIP DEVELOPMENT}

- How would you describe the team spirit in your own project organisation? Which are the differences between the procurement and now?

- Do you feel that the winning construction firm committed itself to the project, both the people and the organisation?

- How would you describe the attitudes of both organisations? Which are the differences between the procurement and now?

- How is the contact between the botch organisations (formally/informally)? Which are the differences between the procurement and now?

- Were there changes in personnel in either of the organisations? How were such changes affecting the project?

- What is the project planning for coming year?

- Which are potential bottlenecks and how do you expect both organisations to cope with that?

CONCLUDING

Did I forget about other things which you would like to mention? 


\section{Appendix 8: Timeline for the Coen Tunnel case}

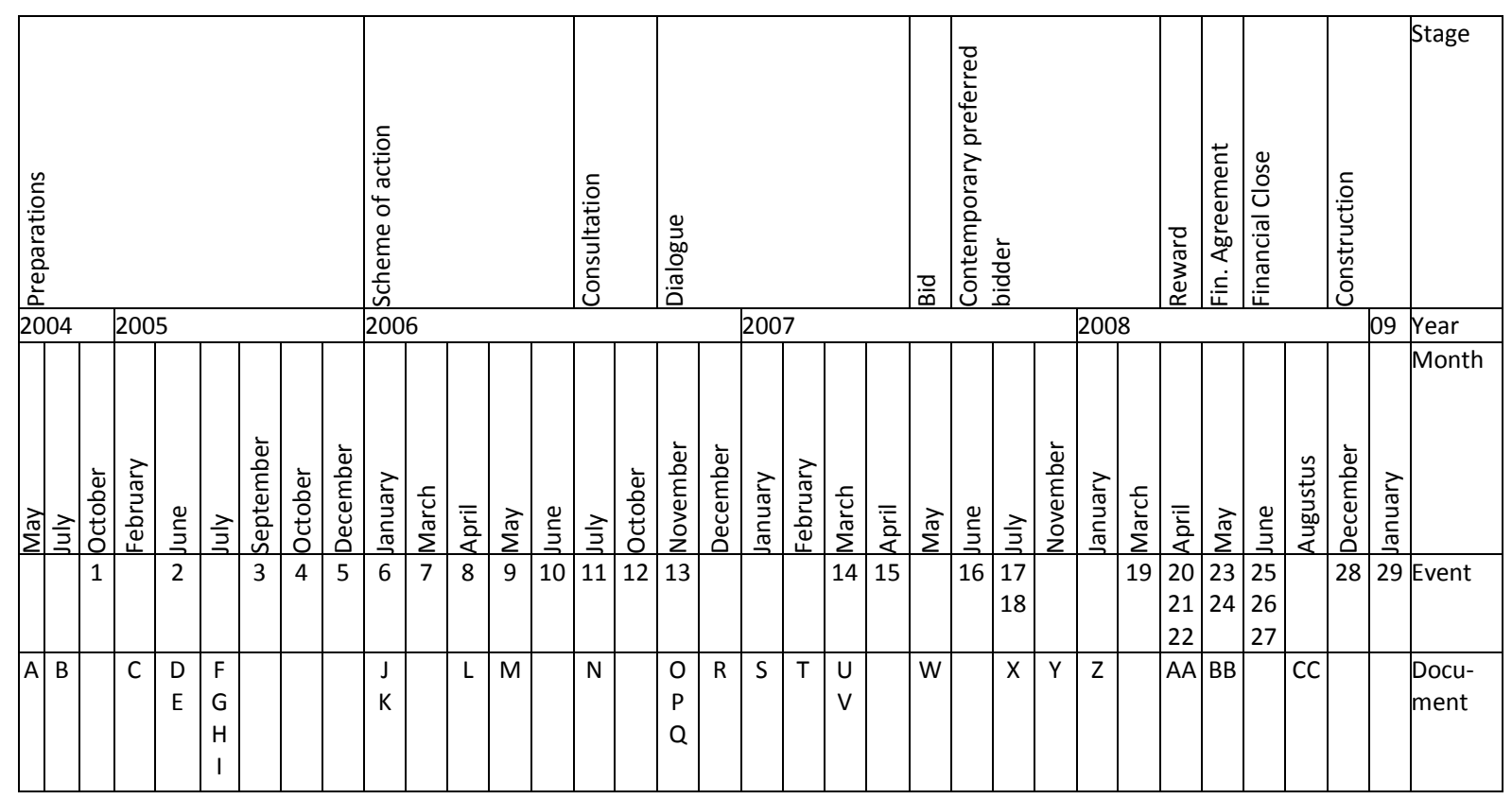

In this scheme the figures are for documents, and the characters for events.

A. Draft Alignment Decision Coen Tunnel Trace, most environment-friendly alternative: 14 May 2004

B. Governance agreement PPP (Minister and the district of Amsterdam): analogy in Alignment law procedure and procurement, including maintenance and renovation existing Coen Tunnel. Focus on the users' demands: reward based on availability of the road: 6 July 2004

1. Rewriting from Design and Construct contract to another contract form: October 2004 - February 2005

C. Internal scheme of action Agency, from D\&C contract $\rightarrow$ DBFM: February 2005

D. Purchasing plan: 14 June 2005

E. Publication pre-announcement: sixteen June 2005

2. Meeting at Schiphol with market parties to explain about the project and the procurement method: 30 June 2005

F. DBFM Basic Agreement: July 2005

G. Modular Model Procurement Guide for Projects by the DBFM Basic Agreement: July 2005

H. Protocol Pre-qualifications stage: 20 July 2005

I. Announcement Project: 22 July 2005

3. Submitting requests to participate in the tender: 15 September 2005

4. End of pre-qualifications stage: Selected participants noticed at 17 October 2005

5. Invitation to the Scheme of Action stage: 23 December 2005

J. Contract version A: 20 January 2006

K. Protocol Scheme of Action stage: 23 January 2006

6. Submitting and Answering General and Confidential Questions: January 2006 - April 2007 
7. Moving of one of the Agency's lawyers to one of the Participants' legal offices; departure of this legal office from the participant: March 2006

L. Submitting Schemes of Action, based on the Critical Aspects (CA): 20 April 2006, 14:00 uur

- CA1, Management plan (Assessment not of influence in the future, although included in the Management Plan which became a part of the contract)

- CA2, Air quality (good assessment $=$ higher score at the (future) Optional Requirement Air quality)

- CA3, Integrity and stability existing Coen Tunnel (link with Risk 0403 and Optional Requirement Stability existing Coen Tunnel; better score for the rest risk = smaller penalty in the final bids)

- CA4, Integration of the Traffic and Tunnel Safety Technical System with the Traffic and Tunnel Safety Technical System in the surrounding area (link with Optional Requirement Integration TTSTS's)

- CA 5, Availability and traffic flow (link with Optional Requirements on these subjects)

8. Assessment of the Schemes of Action: 21 April 2006 until 19 May 2006

9. Participant 4 and 5 put in the waiting room: compensation for the design costs: 19 May 2006

M. Contract version B: 19 May 2006

10. Invitation to the Consultation stage: 14 June 2006 (Objectives of this stage: discussing the Participants" Schemes of Action, fixing the final scope of Risks and Optional Requirements)

11. Alternative solutions by Participants: June / July 2006

N. Protocol Consultation stage: 9 July 2006

12. End of Consultation stage: fixing the text of the concept DBFM Agreement, final list of Risks, final list of Optional Requirements and the rating of the Optional Requirements by the Agency: October 2006

13. Invitation to the Dialogue stage: 1 November 2006

O. Protocol Dialogue stage: 3 November 2006

P. Contract version C: 27 November 2006

Q. Submitting Dialogue products 1. Management plan, 2. Inventory of Risks, 3. Plans, resulting from the Management plan, 5. Sub-plan Performance Measurement System (PMS), 17. Procedure Recording Critical Delay: 30 November 2006

R. Submitting Dialogue product 16. Prices per Risk: 21 December 2006 at the notary in The Hague, where also the Agency's prices are announced.

S. Changes to the Draft Alignment Decision Coen Tunnel Trace announced: January 2007

T. Submitting Dialogue products 4. Specifications Contractor, 6. Sub-plan Document Management System (DMS), 8. Maintenance Transition System, 11. Project plan, 15. Consultative Structure: 1 February 2007.

U. Submitting of Dialogue products 7. Quality plan in between Contract Close and ISO certification, 9. Safety \& Health Transition System, 10 Five sub-plans for the Optional 
Requirements $A$ to $E, 12$. Indexation formula, 13. Formula Original Financial Model, 14. Original Subcontractors, 18. Insurances, 19. Cables and Ducts: 8 March 2007

V. Contract version D: 21 March 2007

14. Data incident: contract parts of party $\mathrm{X}$ are put in the data room of party Y: March 2007

15. Draft Alignment Decision Coen Tunnel Trace available for perusal: 20 April 2007

W. Final bid: 25 May 2007

16. Losing bidders known, design fee paid to the drop-outs: 22 June 2007

X. Contract version 1.00: 20 July 2007

Y. Council of the State reverses the Alignment Deciscion for a project close to the Coen Tunnel, due to poor research to the air quality and to lacking long-term ideas for the possible situation when the project would not be executed: 25 July 2007

17. Plenary meeting with the three participants to the consultation and the dialogue stage, to further interpret / analyse some of the findings from the evaluation: July 2008.

18. Evaluation procurement process Second Coen Tunnel, the participants' perspectives: 28 November 2007

Z. Contract version 2.00: 29 January 2008

19. Establishment of the changed Alignment Decision Coen Tunnel Trace: 13 March 2008

20. Evaluation procurement Second Coen Tunnel (stage: competitive dialogue): 3 April 2008

21. Best bidder starts proceedings against the Agency, planned for 18 April 2008, to claim costs for delay.

22. Agreement Agency and best bidder about costs for delay: 8 April 2008

AA. Contract award to winning consortium (Contract Close): 22 April 2008

BB. Announcement of contract reward: 8 May 2008

23. Planned Financial Close, however, the consortium did not meet one of the demands of the banks: 22 May 2008

24. Signing Financial Agreements (agreement consortium and banks remained, base rate remained low - within the due date (which ended 25 May 2008): 23 May 2008

25. Financial Close: 10 June 2008

26. Away day consortium and Agency: After strong negotiations, it was time to get to know each other and en de neuzen dezelfde richting op te krijgen: Juni 2008

27. Project start-ups, consortium and Agency around the table: how do we work, how are you working, how do the two of us work together? From June 2008

CC. Quick scan preparation process Financial Close Second Coen Tunnel: 25 August 2008

28. Alignment Decision becomes irrevocable: appeal towards the Alignment Decisions of, amongst others, Milieu Defense and Milieu Centre Amsterdam are rejected: 3 December 2008

29. Calling in organisation Reflecting on Construction: January 2009 